Portland State University

PDXScholar

Summer 8-1-2016

\title{
Torsional Strengthening of Reinforced Concrete Beams Using CFRP Composites
}

Ranj Rafeeq

Portland State University

Follow this and additional works at: https://pdxscholar.library.pdx.edu/open_access_etds

Part of the Structural Engineering Commons

Let us know how access to this document benefits you.

\section{Recommended Citation}

Rafeeq, Ranj, "Torsional Strengthening of Reinforced Concrete Beams Using CFRP Composites" (2016). Dissertations and Theses. Paper 3125.

https://doi.org/10.15760/etd.3121

This Thesis is brought to you for free and open access. It has been accepted for inclusion in Dissertations and Theses by an authorized administrator of PDXScholar. Please contact us if we can make this document more accessible: pdxscholar@pdx.edu. 
Torsional Strengthening of Reinforced Concrete Beams Using CFRP Composites

\author{
by \\ Ranj Rafeeq
}

A thesis submitted in partial fulfillment of the

requirements for the degree of

\author{
Masters of Science \\ in \\ Civil and Environmental Engineering
}

Thesis Committee:

Franz Rad, Chair

Peter Dusicka

Evan Kristof

Portland State University

2016 


\begin{abstract}
Few decades ago, there were no guidelines for torsion design of reinforced concrete (RC) beams. Hence, many existing beams in older buildings have a lack of adequate torsional strength since they were not properly designed for torsion. One way to regain/rehabilitate adequate torsional strength is through application of externally bonded carbon fiber reinforced polymers (CFRP). To date, American Concrete Institute (ACI) code, as well as other building codes, do not have recommendations or provisions for strengthening $\mathrm{RC}$ beams for torsion using fiber-reinforced polymer (FRP) composites due to the inexistence of conclusive experimental and analytical data. Of the very limited works on this behavior, the majority of the focus has been devoted to experimental works. Realistic spandrel beams in a building that lack torsional strength were modelled in this research, and strengthened to examine various behaviors such as load capacity, deflection, torque, twist, crack propagation, ductility, and failure modes. For this purpose, six RC beams were tested: four reference beams and two strengthened beams were used to observe additional capacity through the use of carbon fiber-reinforced polymer (CFRP) sheets. To strengthen the beams, one layer of sheets was completely wrapped around them. Results show an additional torsional capacity of $63 \%$ and $178 \%$ relative to their respective reference beams. Through strengthening, modes of failure of the beams changed from brittle torsion-dominated failure to shear-flexure failure in both beams. The study also included crack pattern and ductility of test beams. Cracks became smaller in width and more evenly distributed across the torsion-loaded area, and torsional ductility was enhanced by $266 \%$ and $165 \%$ respectively. Flexural ductility was also greatly enhanced
\end{abstract}


by more than five folds. Finally, using ACI 318-14, ACI 440.2R-02, and available formulae in the literature, the beams were analyzed and the respective values were compared. 


\section{Acknowledgement}

Special thanks goes to the KRG Ministry of Higher Education for its sponsorship of this MS program. I want to show my deepest gratitude to my mother, Kalshan, for her endless support throughout the duration of the program. Special expressions of gratitude given to my thesis committee members, professors Franz Rad, Chair, Peter Dusicka, and Evan Kristof, for their support during the program of study.

Additionally, a special tribute goes to Dr. Mike Gorji and Dr. Franz Rad for their great contribution through their outstanding ways of teaching and the advanced courses they offered. Many thanks to Karen Hanson, Karen Pop, Tom Bennet, Hussein Albustany, Kamal Ahmed, Anas Yosefani, Yasir Hamad Saeed, Hayder Al Khafaji, Karar Al-Lami, Salam Al-Obaidi, Sam Rediske, and Ali Zerkane for their assistance, help with experimental works, and their encouragement. 


\section{Table of Contents}

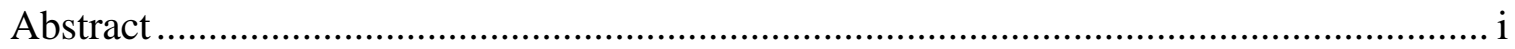

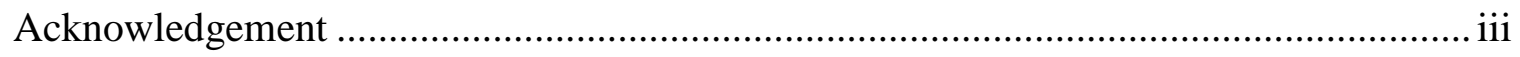

Table of Contents .............................................................................................. iv

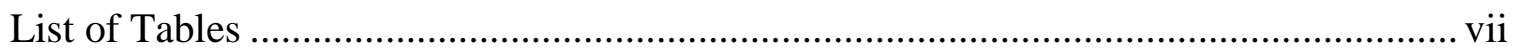

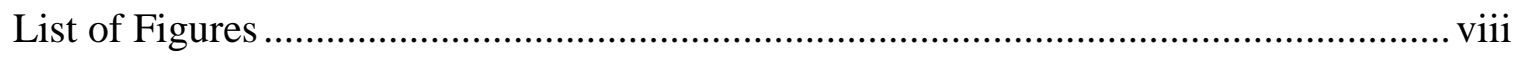

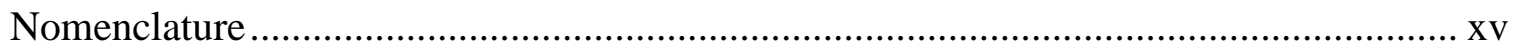

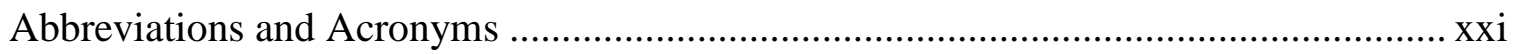

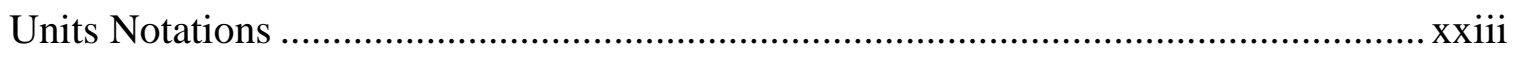

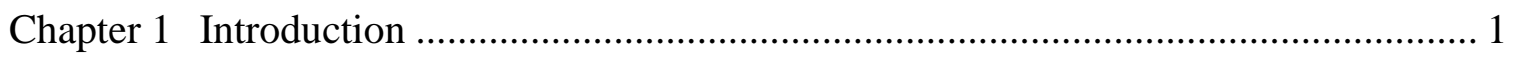

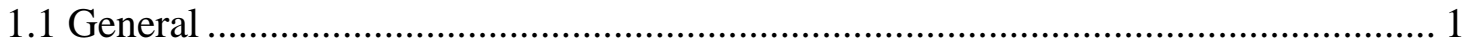

$1.2 \quad$ Fiber Reinforced Polymer Composites, FRP …............................................. 3

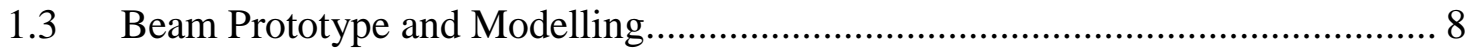

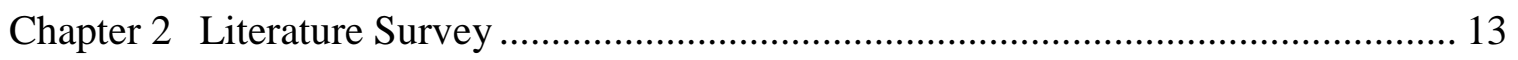

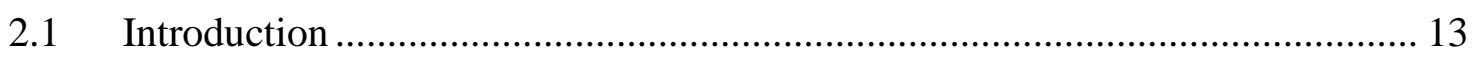

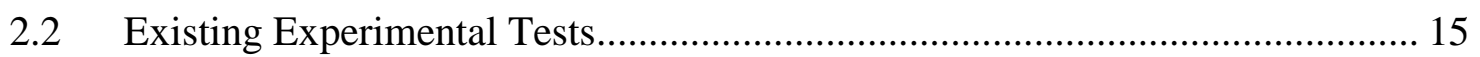

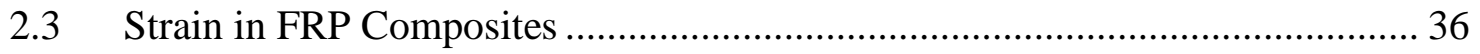

$2.4 \quad$ Numerical and Computer Modeling ............................................................... 37

2.5 Analytical Modeling and Design Expressions ............................................ 44

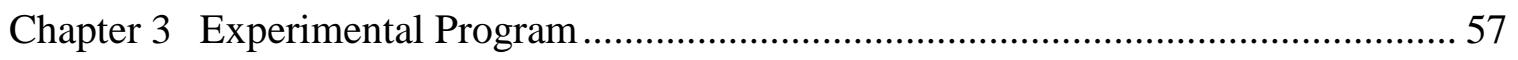

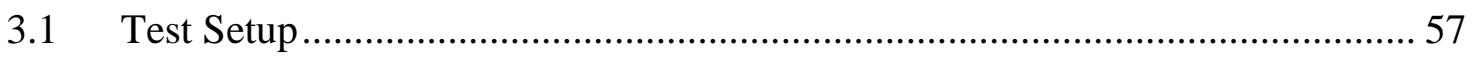

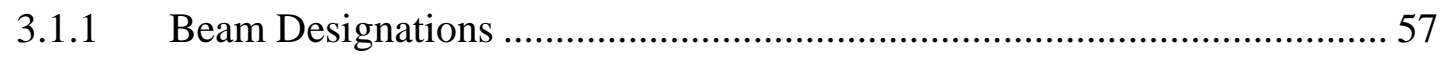

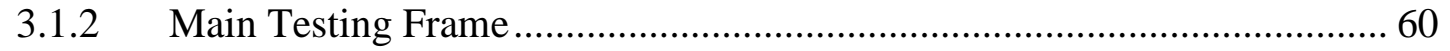

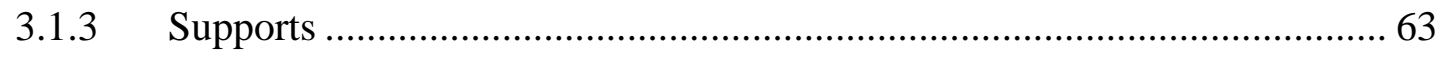

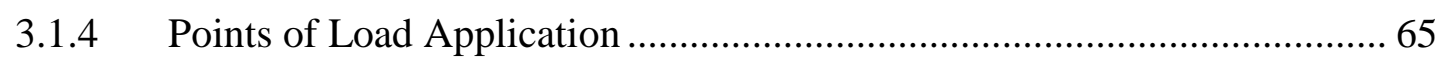

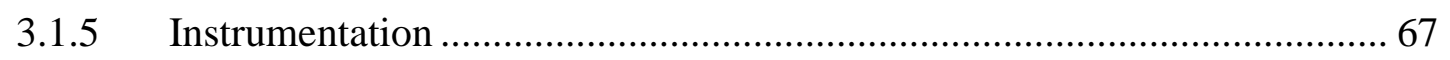

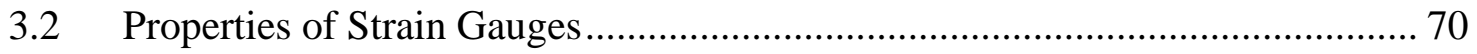

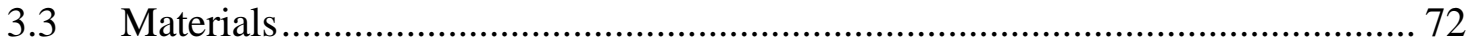

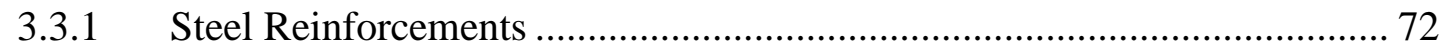

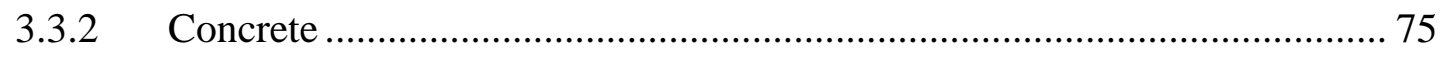

3.3.3 Carbon Fiber Reinforced Polymer ....................................................... 76 


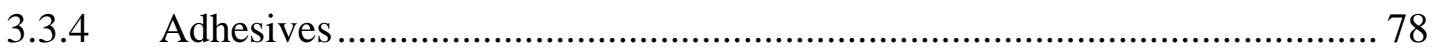

3.4 CFRP Coupons for Tensile Strength .......................................................... 82

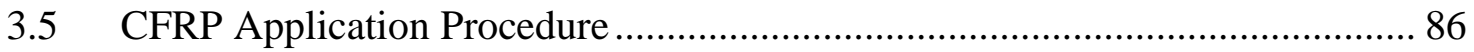

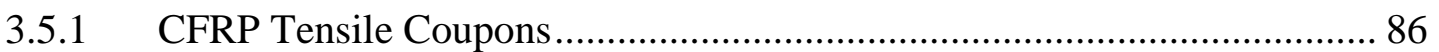

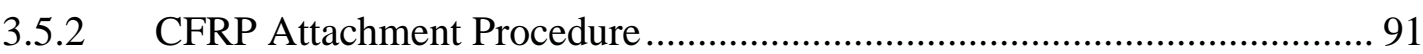

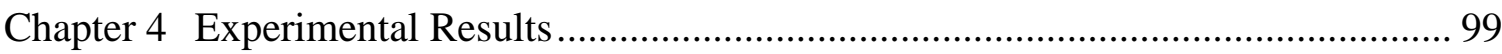

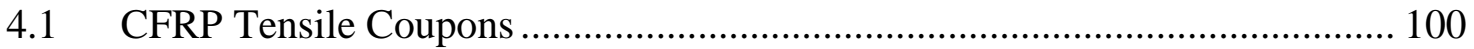

4.2 Standard Test for Concrete Compression and Modulus of Elasticity ............... 102

4.3 Concrete Tensile Splitting Test .................................................................. 104

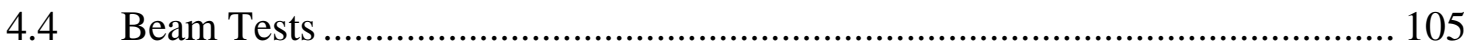

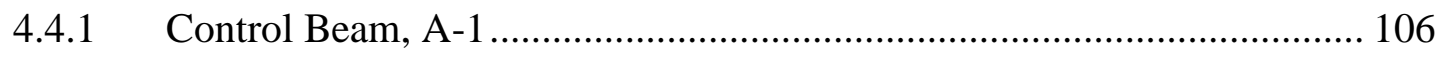

4.4.2 Control Beam, A-2 ............................................................................. 111

4.4.3 Strengthened Beam, A-3 ……………………….................................. 117

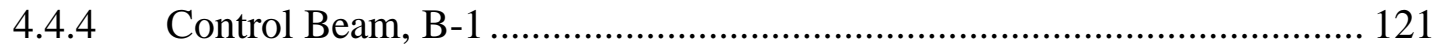

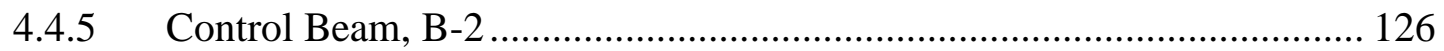

4.4.6 Strengthened Beam, B-3 ………………………………………...... 130

4.5 Crack Patterns of Tested Specimens ………............................................... 137

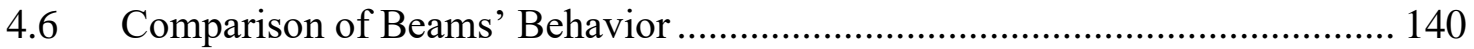

Chapter 5 Theoretical Analysis and Comparison with Experimental Results .............. 145

5.1 Specimen A-1, medium live load, subjected to V and M ................................ 145

5.2 Specimen A-2, medium live load, subjected to $\mathrm{V}$, M, and T ........................... 146

5.3 Specimen A-3. Strengthened subjected to V, T, M........................................... 147

5.4 Specimen B-1, high live load, subjected to V, and M..................................... 153

5.5 Specimen B-2, high live load, subjected to V, M, and T ................................ 155

5.6 Specimen B-3. Strengthened subjected to V, T, M ......................................... 155

Chapter 6 Summary, Conclusions, and Recommendations .......................................... 157

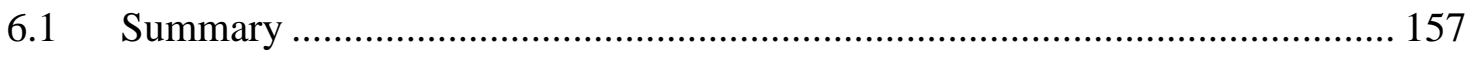

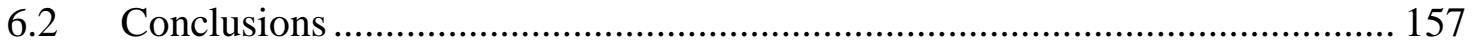

6.3 Recommendations for Future Studies ...................................................... 158

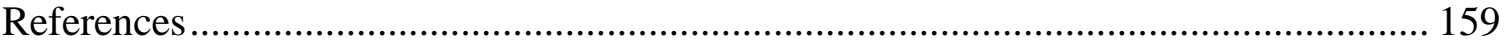

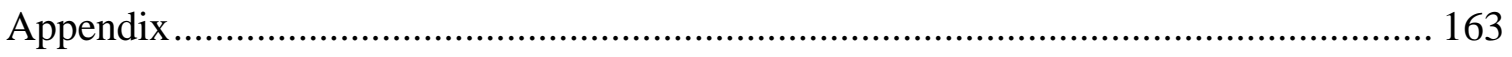




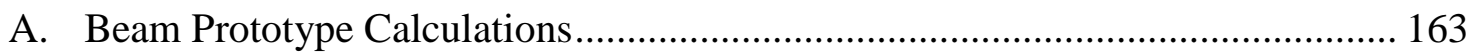

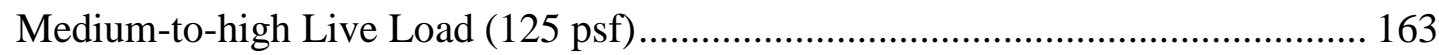

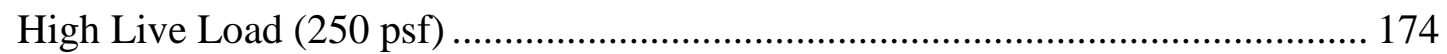

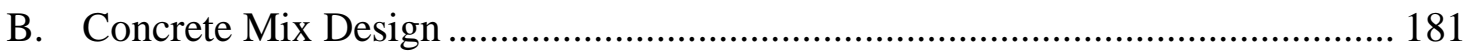

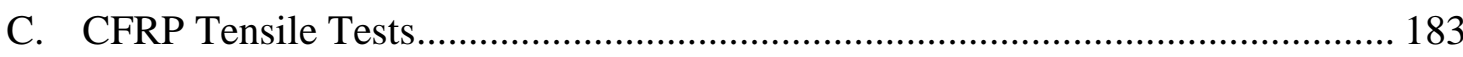

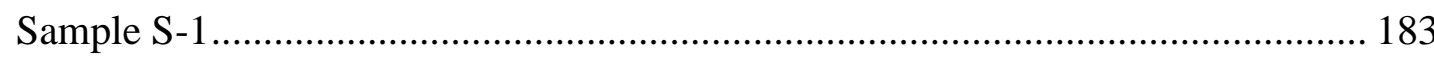

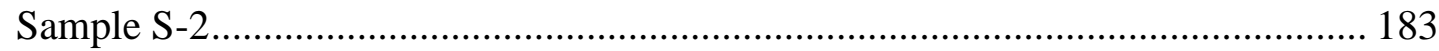

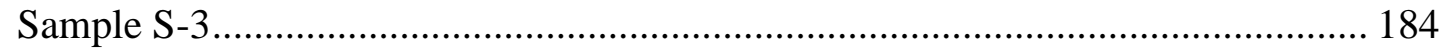

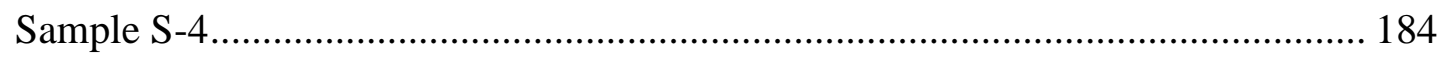

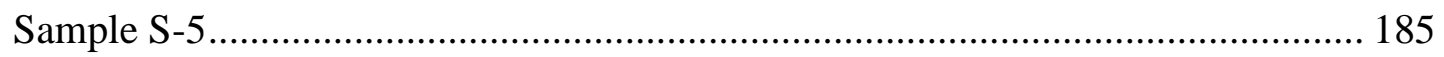

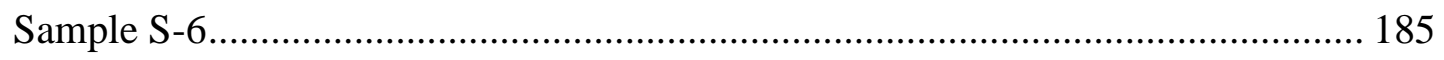

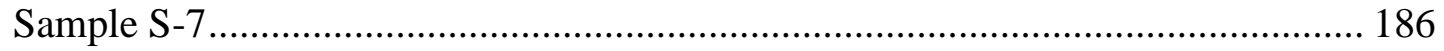

D. Concrete Compressive Strength Tests ………................................................ 187

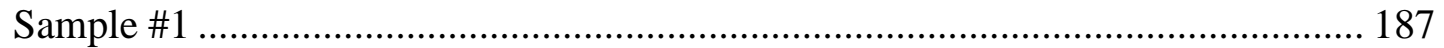

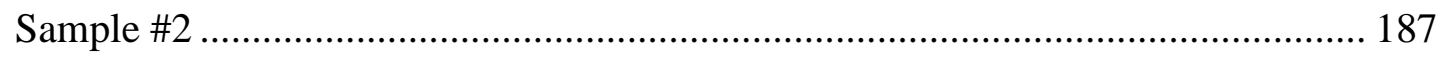

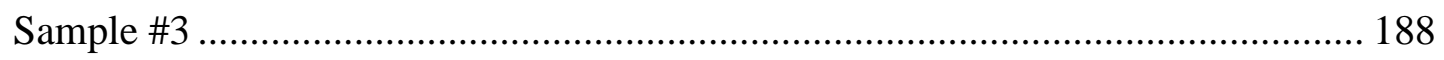

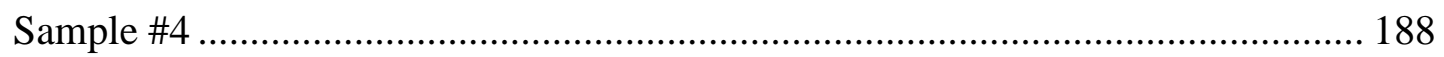

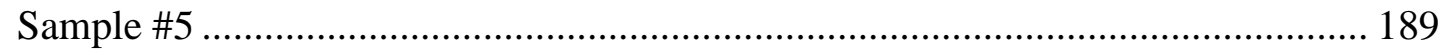

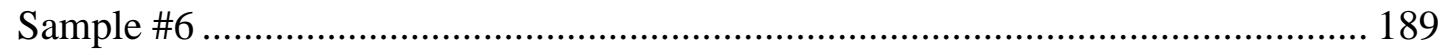

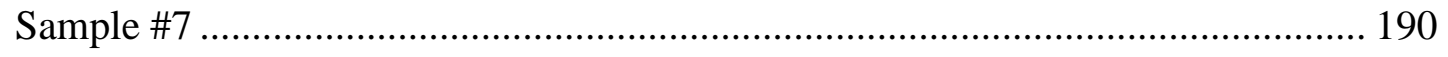

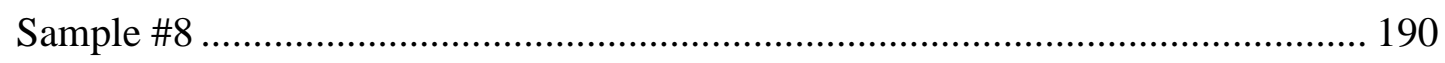

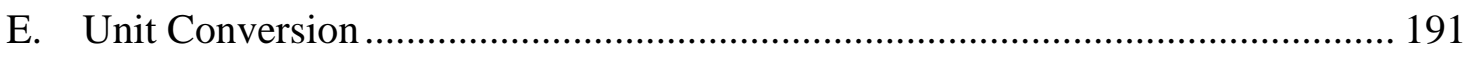

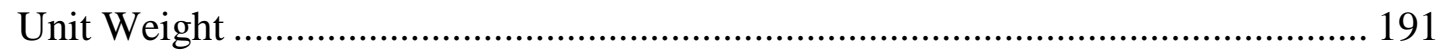

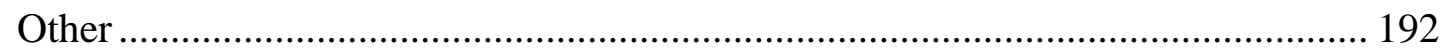

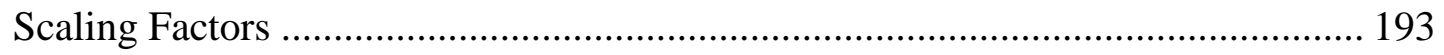

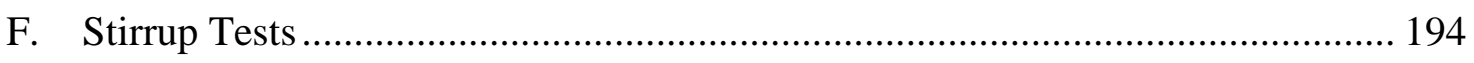

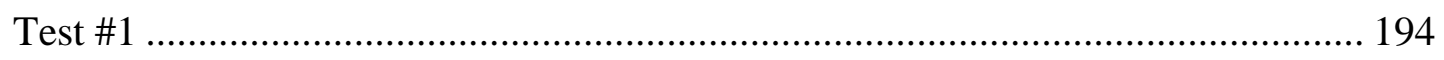

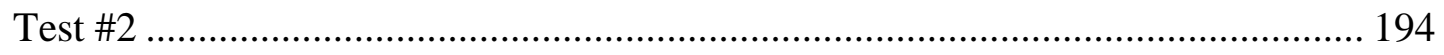




\section{List of Tables}

Table 2-1 FEA Element Descriptions used by Mustafa Dawood (2013) -----------------41

Table 2-2 Comparison Between Experimental and Various Analytical Methods' Results

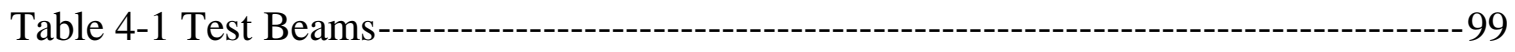

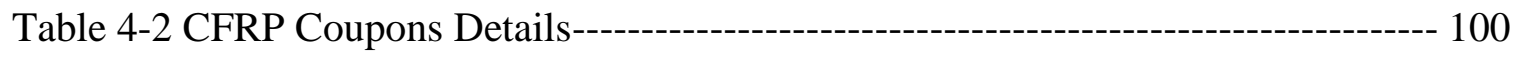

Table 4-3 Summary of CFRP Tensile Coupon Results --------------------------------- 102

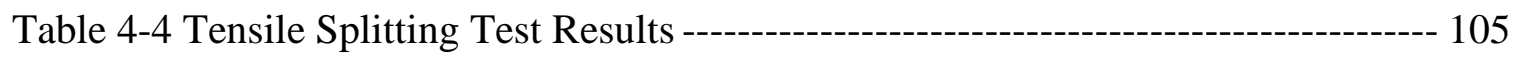

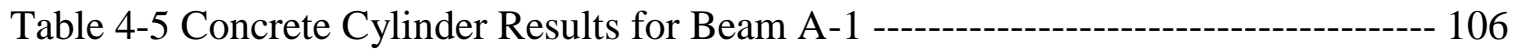

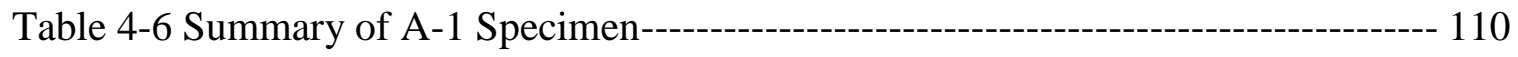

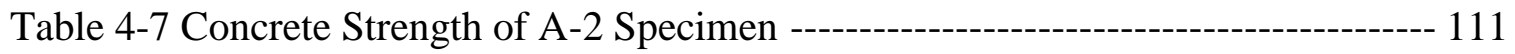

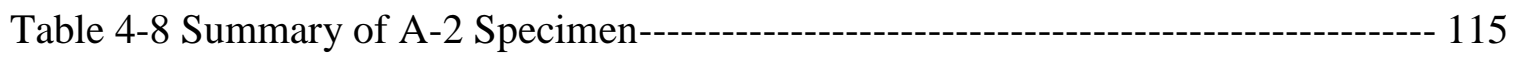

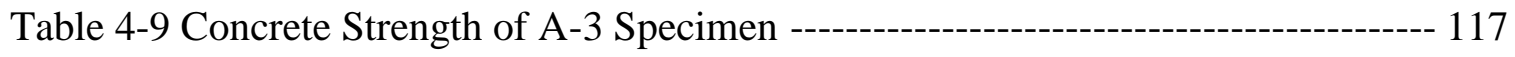

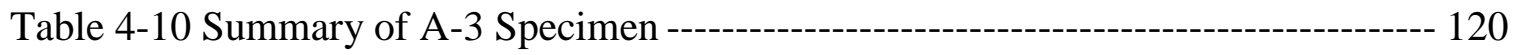

Table 4-11 Concrete Cylinder Results for B-1 Specimen ------------------------------- 122

Table 4-12 Summary of B-1 Specimen ------------------------------------------------- 124

Table 4-13 Concrete Strength of B-2 Specimen ---------------------------------- 126

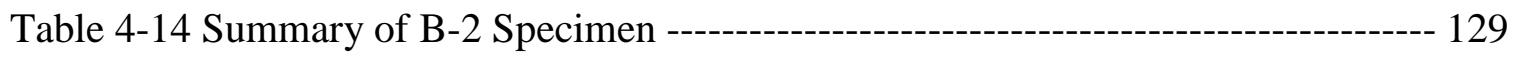

Table 4-15 Concrete Strength of B-3 Specimen ------------------------------------------ 131

Table 4-16 Summary of B-3 Specimen --------------------------------------------------- 134

Table 5-1 Summary of Theoretical and Experimental Capacities and Modes of Failure156 


\section{List of Figures}

Figure 1-1 a Typical Shear Strengthening Using CFRP Composites (Source: Google) --- 5

Figure 1-2 a Typical Slab Strengthening Using CFRP Composites (Source: Google)----- 5

Figure 1-3 a Typical CFRP Sheet Roll (MBrace cf 130) ------------------------------------ 6

Figure 1-4 ACI 440.2R-08 Suggestions for Shear Strengthening (Courtesy of ACI

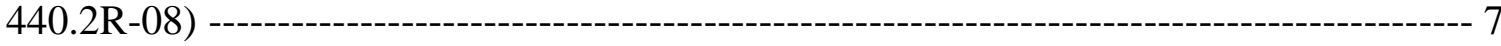

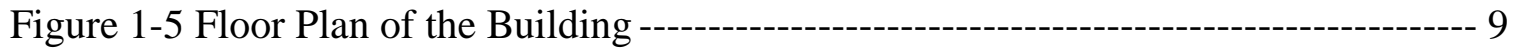

Figure 1-7 Cross-section Details of Set A Prototype-------------------------------------------- 10

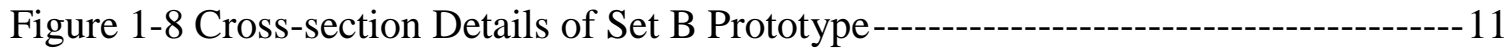

Figure 1-9 Testing Structure of the Model ------------------------------------------------------ 11

Figure 1-9 Testing Structure of the Model ------------------------------------------------------ 11

Figure 1-10 Shear and Moment Diagrams for the Model -------------------------------------12

Figure 1-10 Shear and Moment Diagrams for the Model -----------------------------------12

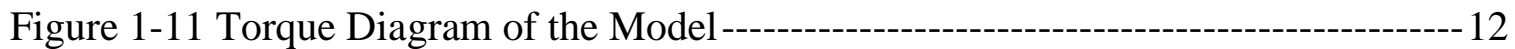

Figure 2-1 Test Set-up by Pedro Salom et al. (2004) ------------------------------------------ 16

Figure 2-2 Torque-Twist Hysteresis provided by Pedro Salom et al. (2004)--------------- 18

Figure 2-3 Some Wrapping Configurations used by Khalaf and Bayer (2013) ------------ 19

Figure 2-4 Torque-Twist Behavior of All Samples Tested by Khalaf and Bayer (2013)-21

Figure 2-5 Test Set-up by Mohammadizadeh and Fadaee (2009) ----------------------------22

Figure 2-6 Torque-Twist Behavior of All Samples Tested by Mohammadizadeh and

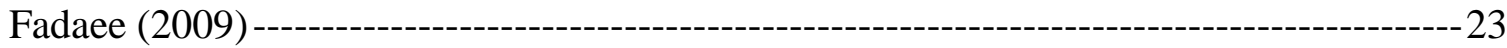

Figure 2-7 Torsional Test Layout for Saravanan et al. (2002)--------------------------------25 
Figure 2-8 Fiber Orientation Effects on Torque-Twist Curve from Saravanan et al. (2002)

Figure 2-9 Effect of Wrapping Schemes on Torque-Twist Curve from Saravanan et al. (2002)

Figure 2-10 Effect of Numbers of Faces Strengthened on Torque-Twist Curve from

Saravanan et al. (2002) ---------------------------------------------------------------------------------28

Figure 2-11 Effect of Full Wrapping vs Strip Wrapping on Torque-Twist Curve from

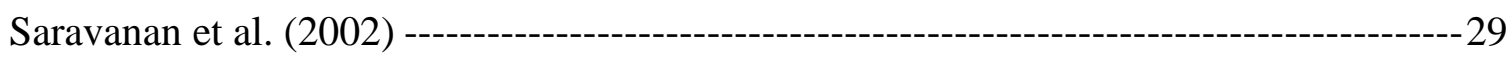

Figure 2-12 Torsional Test Layout by Mustafa Higazy and Mahmoud El-Kateb (2011) 30 Figure 2-13 Strip Wrapping Configurations by Mustafa Higazy and Mahmoud El-Kateb (2011) $-31$

Figure 2-14 Torque-Twist Behavior for All Tests Carried out by Mustafa Higazy and Mahmoud El-Kateb (2001) -------------------------------------------------------------------------31

Figure 2-15 Combined Shear and Torsion Testing Tet-up by Mostofinejad et al. (2014) 33

Figure 2-16 Elevation View of the Beam by Mostofinejad et al. (2014)--------------------34

Figure 2-17 Experimental Behavior of Strengthened Beams, Tests by Mostofinejad et al. (2014) $-35$

Figure 2-18 Strain Variation against Torsional Moment from Ghobarah et al. (2002) ---36 Figure 2-19 Strain Attainment in the Fibers of Test Beams Carried out by Khalaf and

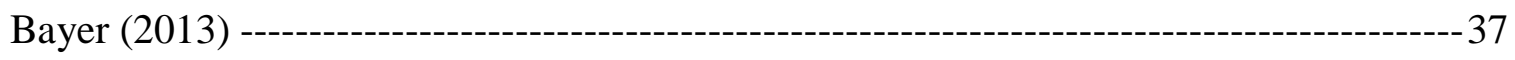

Figure 2-20 Load-Deflection Curves for Various Beams by Santhakumar et al. (2007) -39 Figure 2-21 Variation of Flexural Strength with Torsion by Santhakumar et al. (2007) -40 
Figure 2-22 Steel Material Modeling used in Mustafa Dawood (2013) Modeling

Figure 2-23 Diagrammatic Behavior of FRP Composites in Mustafa Dawood (2013)

Modeling 42

Figure 2-24 A Typical Torque vs Twist Curve for a Strengthened Beam from Mustafa

Dawood (2013) $-43$

Figure 2-25 Spacing Effects on Strength in the Modeling from Mustafa Dawood (2013)

Figure 2-26 Steel Anchor Bolts from Pedro Salom et al. (2004) Testing --------------------45

Figure 2-27 Force Mechanism in FRP Sheets from Saravanan et al. (2002) ---------------49

Figure 2-28 Effect of Fiber Orientation on the Modules of Elasticity, E from Stijn

Matthys et al (2001)----------------------------------------------------------------------------------50

Figure 2-29 Variation of Effective Fiber Strain Model by Triantafillou (1997, 1998)----52

Figure 2-30 Effective FRP Strain by Triantafillou and Antonopolous (2000) -------------52

Figure 2-31 FRP strain Model by Matthys (2000) ---------------------------------------------53

Figure 2-32 Element Discretization for Ghobrah et al. (2010) Modeling--------------------54

Figure 2-33 Concrete Models Proposed by Belarbi \& Hsu (1995) used in Ghobarah et al.

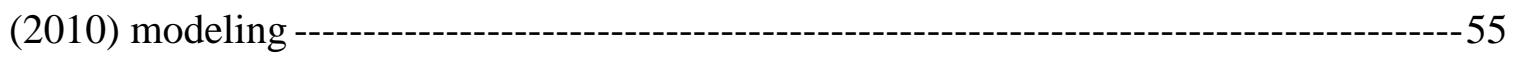

Figure 2-34 A Typical Program Torque-Twist Curve from Ghobarah et al. (2010)

Compared to Experimental Data --------------------------------------------------------------------56

Figure 3-1 Beam Model Details for Test Set A --------------------------------------------------58

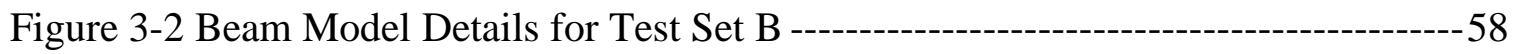

Figure 3-3 Formwork for the Beams --------------------------------------------------------------59 
Figure 3-4 Longitudinal and Transverse Reinforcement Layouts------------------------------60

Figure 3-5 Front View of the Main Loading Frame--------------------------------------------61

Figure 3-6 Side View of the Main Loading Frame ----------------------------------------------61

Figure 3-7 Plan View of the Test Set-up-------------------------------------------------------62

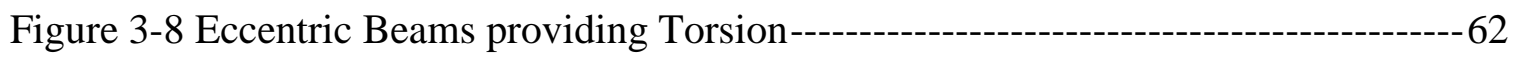

Figure 3-9 Top View of the Beam Supports ----------------------------------------------------64

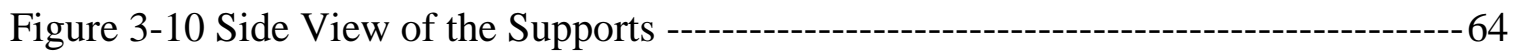

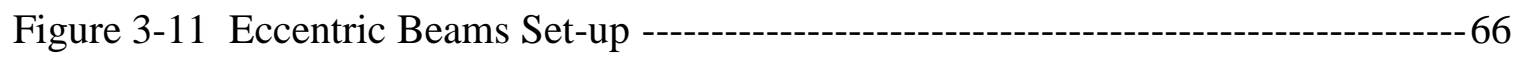

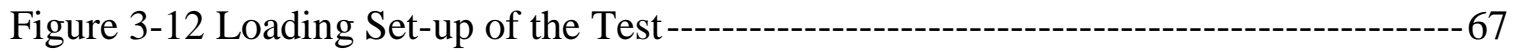

Figure 3-13 Plan View of Specimens A-1 and B-1 Instrumentations -----------------------68

Figure 3-14 Plan View of Specimens A-2 and B-2 Instrumentations------------------------68

Figure 3-15 Plan View of Specimens A-3 and B-3 Instrumentations------------------------68

Figure 3-16 Side View of Specimens A-3 and B-3 Instrumentations-------------------------69

Figure 3-17 Strain Gauge Installed on 0.15', Steel Wire Gauges -----------------------------71

Figure 3-18 Surface Grinding of a Longitudinal Rebar for Strain Gauge Attachment----71

Figure 3-19 Locations of Strain Gauge Set-up on CFRP Sheets -----------------------------72

Figure 3-20 Stress-Strain Diagram for \#3 Steel Rebar -------------------------------------------73

Figure 3-21 Stress-Strain Diagram for \#4 Steel Rebar ------------------------------------------73

Figure 3-22 A Sample of \#7 Steel Wire Gauge Used as Transverse Reinforcement------74

Figure 3-23 Stress-Strain Diagram for \#7 Wire Gauge (Test 1)------------------------------75

Figure 3-24 Stress-Strain Diagram for CFRP (Courtesy of BASF, the Chemical

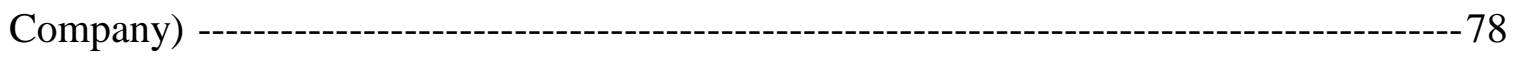


Figure 3-25 A CFRP Tensile Coupon Tab (Dimensions in mm)-----------------------------85

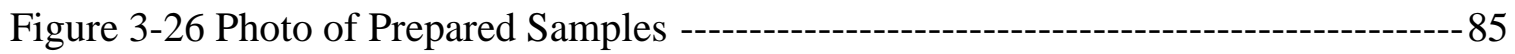

Figure 3-27 Tensile Testing Materials and Tools ------------------------------------------------87

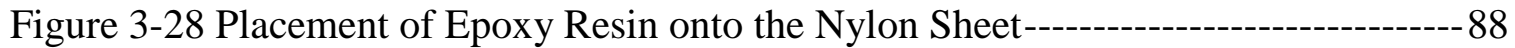

Figure 3-29 Placement of the CFRP Sample Sheet onto the Base Layer of Epoxy -------89

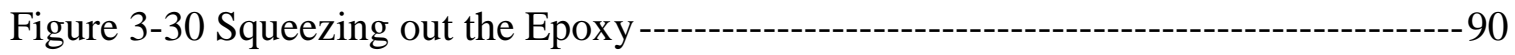

Figure 3-31 the End of the Sample Preparation (with Some Weights on) ------------------91

Figure 3-32 A Schematic Representation of CFRP Sheet Installations in Order ----------92

Figure 3-33 Rounding the Edges of Concrete Beams------------------------------------------93

Figure 3-34 Cement Mortar around the Holes on the Surface ------------------------------94

Figure 3-35 the Beam Surface Coated by MBrace F2000 (Putty) ---------------------------96

Figure 3-36 Application of CFRP Sheets and MBrace SAT 4500 ---------------------------98

Figure 3-37 the Beam Fully Wrapped with CFRP Sheets ------------------------------------98

Figure 4-1 S-1 CFRP Tensile Coupon Test --------------------------------------------------- 101

Figure 4-2 Stress-Strain Diagram of Coupon S-1 --------------------------------------------- 102

Figure 4-3 Compression Test of Concrete Cylinders ----------------------------------------- 103

Figure 4-4 Stress-Strain Diagram of a Sample of A-3 Beam Specimen ------------------- 104

Figure 4-5 Tensile Splitting Failure of a B-1 Test Cylinder (a Typical Sample) -------- 105

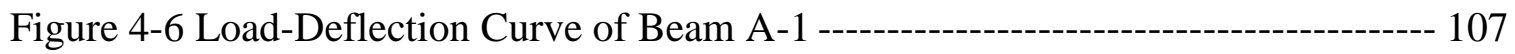

Figure 4-7 Concrete Spalling at Mid-Span ----------------------------------------------------- 108

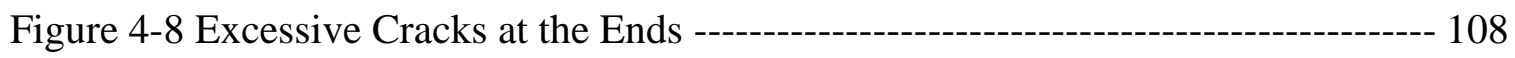

Figure 4-9 Concrete Crush in the Support Sleeve Zone ------------------------------------- 109 


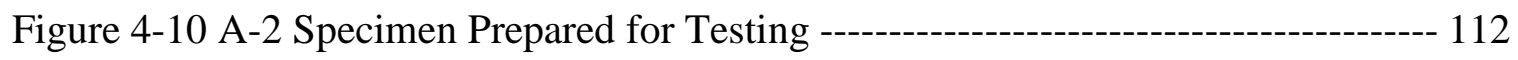

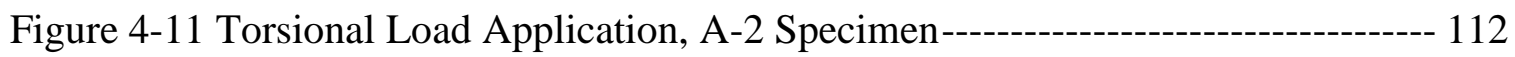

Figure 4-12 Load-Deflection Curve of A-2 Specimen------------------------------ 113

Figure 4-13 Torque-Twist Curve of A-2 Specimen -------------------------------- 114

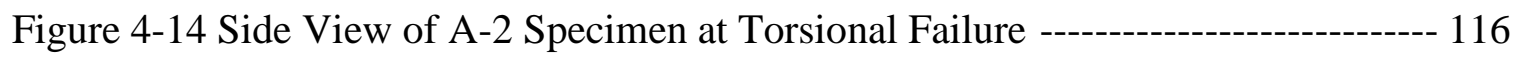

Figure 4-15 Top View of A-2 Specimen at Failure ------------------------------------- 116

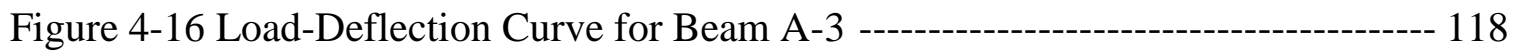

Figure 4-17 Torque-Twist Curve for Beam A-3

Figure 4-18 A-3 Specimen under Excessive Deformation at Failure---------------------- 121

Figure 4-19 Load-Deflection Curve for Beam B-1--------------------------------- 123

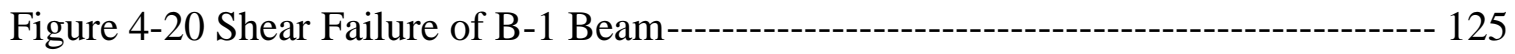

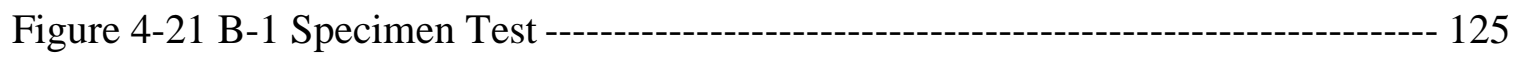

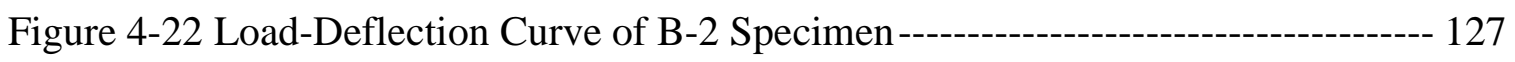

Figure 4-23 Torque-Twist Curve of B-2 Specimen --------------------------------------- 128

Figure 4-24 Top View of B-2 Specimen at Failure under Torsional Load -------------- 129

Figure 4-25 Side View of B-2 Specimen at Failure under Torsional Load --------------- 130

Figure 4-26 Load-Deflection Curve for B-3 Specimen-------------------------------------- 131

Figure 4-27 Torque-Twist Curve for B-3 Specimen -------------------------------- 132

Figure 4-28 CFRP Strain Development in B-3 Specimen--------------------------------- 133

Figure 4-29 B-3 Specimen under Excessive Deformation --------------------------- 135

Figure 4-300 Flexural Cracks at Failure of B-3 Specimen ---------------------------- 135

Figure 4-31 Side View of Flexural Cracks at Failure of Specimen B-3----------------- 137 


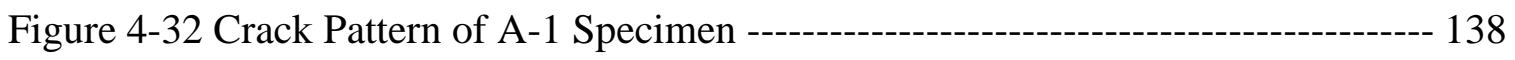

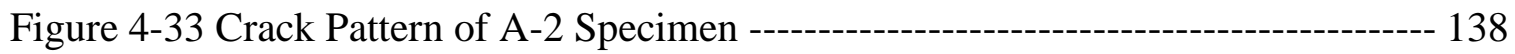

Figure 4-34 Crack Pattern of A-3 Specimen ----------------------------------------------- 139

Figure 4-35 Crack Pattern of B-1 Specimen ------------------------------------------- 139

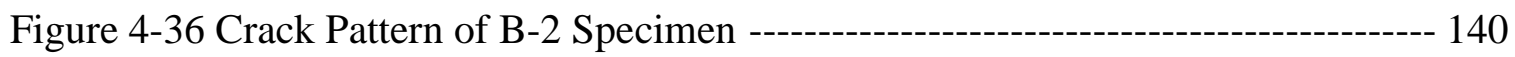

Figure 4-37 Crack Pattern of B-3 Specimen ---------------------------------------------- 140

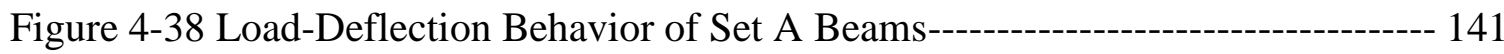

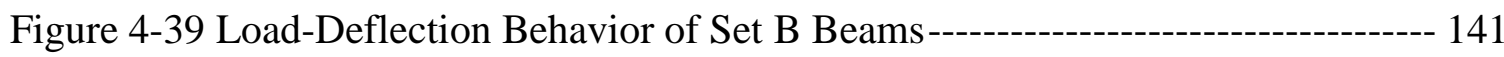

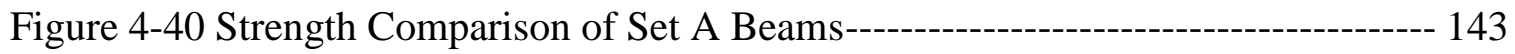

Figure 4-41 Strength Comparison of Set B Beams----------------------------------------- 143

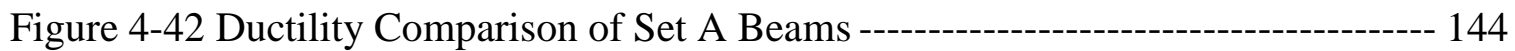

Figure 4-43 Ductility Comparison of Set B Beams --------------------------------------- 144

Figure 5-1 ACI Recommendations for Concrete Strength through Different Confinement

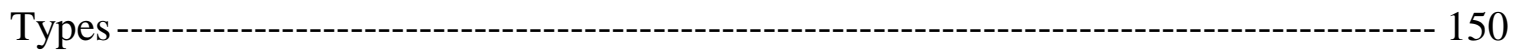

Figure 5-2 Confinement Effects on Concrete Strength Suggested by ACI 440.2R-35 - 152

Figure 5-3 Strain Hardening in A-3 Specimen---------------------------------------- 153 


\section{Nomenclature}

$\emptyset_{p}$

$\emptyset_{y}$

$\epsilon_{c c u}$

$\mathrm{d}_{\mathrm{e}}$

$A s_{\min }$

$P_{\max }$

$W_{D}$

$W_{L}$

$b_{w}$

$f_{l}$

$S_{C}$

$\mu_{\varnothing}$

$\emptyset$

$\varnothing 0.85 p$

$\Delta p$

points

$\Delta \epsilon$
Twisting Angle at Ultimate Loading

Twisting Angle at Yield Loading

Maximum strain of confined concrete

Effective depth of FRP composites

Minimum Flexural Steel Reinforcement Area

Maximum tensile force before failure (\#)

Uniform dead load

Uniform live load

Concrete beam width

Maximum confinement pressure

Side cover

Strength reduction factor

Twisting Angle at $85 \%$ of Ultimate Loading

Difference in applied tensile force between two strain

Difference between two strain points, nominally 0.002 
a

$\mathrm{A}_{b}$

$\mathrm{A}_{\mathrm{cp}}$

$\mathrm{A}_{\mathrm{f}}$

$\mathrm{A}_{l}$

$\mathrm{A}_{\mathrm{o}}$

strengthening

$\mathrm{A}_{\mathrm{oh}}$

$\mathrm{A}_{\mathrm{s}}$

$\mathrm{a}_{\mathrm{s}}$

$\mathrm{A}_{\mathrm{t}}$

$\mathrm{A}_{\mathrm{v}}$

b

C

c

CA

$\mathrm{cc}$

D
Depth of equivalent compression block

Area of a steel reinforcement bar

Area of gross concrete resisting torsion

Area of FRP composites

Longitudinal steel reinforcement resisting torsion

Area enclosed inside the critical shear flow path due to

Flexural steel reinforcement area

Shear span

Torsion steel reinforcement area

Shear steel reinforcement area

With of concrete beams

Cement

Depth of compression block

Coarse aggregate

clear cover of beams

Diameter of concrete cylinder 
DL

$\mathrm{e}$

$E_{c}$

$E_{f}$

$\mathrm{E}_{\mathrm{s}}$

$\mathrm{F}^{*}$

$f^{\prime} \mathrm{c}$

$f^{\prime} c c$

FA

$f_{f}$

$f_{\text {fe }}$

$f_{i}$

fy

fyt

h

$\mathrm{h}$
Effective depth of concrete beams

Depth of compression reinforcements

Dead Load

Torsion eccentricity

Modulus of elasticity of concrete

Modulus of elasticity of FRP composites

Modulus of elasticity of steel

Maximum tensile force per unit width (\#/in)

Concrete compressive strength

Compressive strength of confined concrete

Fine aggregate

Ultimate strength of FRP composites

Effective stress in FRP composites

Force per unit width at the ith data point (\#/in)

Longitudinal steel yield strength

Transverse steel yield strength

Concrete beam height

Depth of concrete beams 
strain

$\mathrm{k}^{*}$

$\mathrm{k}_{\mathrm{b}}$

1

$\mathrm{L}_{\mathrm{e}}$

LL

$l_{n}$

$\mathrm{M}_{\mathrm{u}}$

n

$\mathrm{P}$

$\mathrm{p}_{\mathrm{cp}}$

$\mathrm{p}_{\mathrm{i}}$

$\mathrm{P}_{\mathrm{ul}}$

$\mathrm{Qb}_{\mathrm{b}}$

$\mathrm{Q}_{\mathrm{t}}$

Q v

$\mathrm{R}$
Reduction ratio for defining characteristic effective FRP

Chord tensile stiffness per unit width

Shape factor

Center-to-center span

Effective bond length

Live Load

Clear span

Factored ultimate moment

Number of CFRP Layers/Steel Reinforcement

Point load applied to the beam

Perimeter of concrete area resisting torsion

Force at ith data point (\#)

Ultimate failure load

Beam load bearing capacity based on flexure

Beam load bearing capacity based on torsion

Beam load bearing capacity based on shear

Reaction force 
SD

$\mathrm{Sf}_{\mathrm{f}}$

$\mathrm{sg}$

$\mathrm{T}_{\mathrm{cr}}$

$\mathrm{t}_{\mathrm{f}}$

$\mathrm{T}_{\mathrm{f}}$

$t_{s}$

$\mathrm{T}_{\mathrm{u}}$

tu

$\mathrm{V}_{\mathrm{c}}$

$V_{f}$

$\mathrm{V}_{\mathrm{s}}$

$\mathrm{V}_{\mathrm{u}}$

W

$w$

W

Wc
Sustained dead load

Spacing of FRP strips

Strain gauge

Cracking torque strength

Thickness of FRP composites

Torsional strength of FRP composites

Slab thickness

Factored ultimate torque

Twisting factored torque per unit length

Shear Strength of Concrete

Shear strength of CFRP

Shear strength of Steel

Factored ultimate shear

Water

Width of CFRP tensile specimens (in)

Width of FRP coupons for tensile test

Crack width 


\begin{tabular}{|c|c|}
\hline $\mathrm{W}_{\mathrm{f}}$ & Width of FRP strips \\
\hline $\mathrm{Wu}$ & Factored uniform load \\
\hline $\mathrm{X}_{1}$ & Horizontal distance between transverse reinforcements \\
\hline $\mathrm{y}_{1}$ & Vertical distance between transverse reinforcements \\
\hline $\mathrm{Z}$ & Flexural moment lever arm \\
\hline$\varepsilon c^{\prime}$ & Strain at ultimate strength of unconfined concrete \\
\hline$\varepsilon t^{\prime}$ & Strain at ultimate strength of confined concrete \\
\hline$\kappa_{\mathrm{a}}$ & Shape factor \\
\hline$\kappa \varepsilon$ & Factor accounts for the premature failure of the FRP system \\
\hline$\Psi f$ & Shear reduction factor based on CFRP composites \\
\hline$\alpha$ & Angle of fiber fabrics with respect to the beam axis \\
\hline$\varepsilon_{\mathrm{fe}}$ & Effective strain in FRP composites \\
\hline$\varepsilon_{\mathrm{fu}}$ & Ultimate strain in FRP composites \\
\hline$\theta$ & Angle of crack in concrete with respect to the beam axis \\
\hline$\rho$ & Longitudinal steel reinforcement ratio \\
\hline $\boldsymbol{\sigma}$ & Stress \\
\hline$\varepsilon$ & Strain \\
\hline
\end{tabular}




\section{Abbreviations and Acronyms}

$3 \mathrm{D}$

AASHTO

Officials

ACI

aka

ANSYS

ASCE

ASTM

$\mathrm{c} / \mathrm{c}$

CFRP

CL

EBR

FEA

FIB

FRP

GFRP

HSC
Three Dimensional

American Association of State Highway and Transpiration

American Concrete Institute

Also Known As

A Finite Element Computer Aided Program

American Society of Civil Engineers

American Society of Testing and Materials

Center-to-Center distance

Carbon Fiber Reinforcements

Centerline

Externally Bonded Reinforcement

Finite Elements Analysis

Fédération internationale du béton

Fiber Reinforced Polymers

Glass Fiber Reinforced Polymers

High Strength Concrete 


$\begin{array}{ll}\text { LVDT } & \text { Linear Variable Differential Transformer } \\ \text { MCFT } & \text { Modified Compression Field Theory } \\ \text { N/A } & \text { Not Available } \\ \text { NSC } & \text { Normal Strength Concrete } \\ \text { PCA } & \text { Portland Cement Association } \\ \text { POLA } & \text { Point of Load Application } \\ \text { PSU } & \text { Portland State University } \\ \text { RB } & \text { Rehabilitated Beams } \\ \text { RC } & \text { Reinforced Concrete } \\ \text { RF } & \text { Reference Beams } \\ \text { SB } & \text { Strengthened Beams } \\ \text { SG } & \text { Strain Gauge } \\ \text { TBD } & \text { to Be Determined }\end{array}$




\begin{tabular}{|c|c|}
\hline Units $N$ & \\
\hline${ }^{\circ}, \operatorname{deg}$ & Degree \\
\hline $\mathrm{cm}$ & Centimeter \\
\hline $\mathrm{ft}\left({ }^{\circ}\right)$ & Feet \\
\hline gal & Gallon (volume) \\
\hline gm & Gram \\
\hline $\mathrm{hr}$ & Hour \\
\hline in (") & Inch \\
\hline k, kips & Kilo pound \\
\hline $\mathrm{kg}$ & Kilogram \\
\hline klf & Kilo pound per feet \\
\hline ksf & Kilo pound per square feet \\
\hline ksi & Kilo pound per square inch \\
\hline $\mathrm{L}$ & Liter (volume) \\
\hline $\mathrm{lb}$ & Pound \\
\hline $\mathrm{m}$ & Meter \\
\hline $\min$ & Minute \\
\hline $\mathrm{mn}$ & Millimeter \\
\hline
\end{tabular}




$\begin{array}{ll}\text { pcf } & \text { Pound per cubic feet } \\ \text { plf } & \text { Pound per feet } \\ \text { psf } & \text { Pound per square feet } \\ \text { psi } & \text { Pound per square inches } \\ \text { rad } & \text { Radian } \\ \text { sec } & \text { Second }\end{array}$




\section{Chapter 1 Introduction}

\subsection{General}

Torsion is an undesirable brittle mode of failure in reinforced concrete (RC) beams, if the beams have not been properly designed for torsion. Even today, not all torsional problems are well understood. A tremendous amount of work has been carried out on other behaviors such as shear and flexure, yet little focus has been apportioned to torsion. Older buildings were designed without any consideration for torsion. Now that a better understanding has been achieved, existing older structures ought to be checked for performance, efficiency, and structural soundness in torsional performance. Torsion in beams is generally categorized into two types - primary and secondary torsion. Primary torsion, also known as equilibrium torsion, is basically a strength problem by which the members fail when torsional loads exceed torsional strength of the member. This can be mainly seen in statically determinate structures. On the other hand, secondary torsion, which is the result of continuity requirements in statically indeterminate structures, is the latter category which in some instances can cause colossal damage when continuity requirements are neglected. When torsion acts on an $\mathrm{RC}$ member, it forms two orthogonal diagonal loops in which one of them is in compression, which is generally resisted by concrete, and the other in tension, which is generally resisted by steel or other reinforcements. Torsion, especially in concrete structures, is of a great importance in the following scenarios:

Spandrel (edge) beams.

Change in occupancy of existing structures. 
Curved beams, boxes, and girders in plan.

$>$ Member in space frame.

Eccentrically loaded components.

Spiral stair cases.

Significance difference between two adjacent spans (panels) or difference in load magnitude between successive spans.

As techniques in reinforced concrete advance, many methods for design and construction of concrete have become feasible. Existing structures often need rehabilitation or retrofitting due to:

Load-related conditions.

- Increased live loads in warehouses, buildings, and such.

- Increased traffic flow on bridges.

- Use of heavy machinery in industrial structures.

- Vibrations in structures.

- Change of occupancy in structures.

- Codes that become more stringent.

Earthquake-related problems.

- Weak columns.

- Weak beam-column joints.

Weak masonry wall Damage in structural elements.

- Deterioration of building materials.

- Vehicle impact and fatigue. 
- Fire.

$>$ Changes in structural system.

- Elimination of walls or columns.

- Removal of slab sections for openings.

Design or construction errors.

- Inadequate reinforcement.

- Inadequate structural depth.

\subsection{Fiber Reinforced Polymer Composites, FRP}

When damage happens in members of concrete, one way to repair it is by installment of externally applied Fiber-Reinforced Polymer (FRP) composites. FRP composites, mostly in the form of sheet or laminates, are desirable for such a purpose. In the industry, a lot of types and brands for FRP are available with different manufacturer specifications such as carbon fiber, glass fiber, aramid, and such. Quality control testing may be performed to determine strength parameters of FRP sheets such as yield strength, ultimate rupture strength, and modulus of elasticity. Each FRP application with concrete needs attachments by means of epoxy. The type of epoxy and the way it is applied is a sensitive part of such works because it might introduce premature failure, such as, cover delamination prior to reaching the targeted strength. FRP composites have been identified as having brittle failure contrary to steel reinforcements without significant advanced warning prior to failure. However, research has shown that FRP application can tremendously improve behavior of RC beams under torsion. FRP composites must be used and allowed to have adequate development length (if strips are to be adopted), in 
addition to making sure that premature failures are avoided. In the beginning of 1980s, FRP composites emerged in the construction industry as a promising option for strengthening existing structures, mostly for damages caused by earthquake-induced loads. FRP is a good alternative for upgrading deficient structures because replacing the whole damaged component might not be viable or economically feasible. FRP composites are becoming more popular for:

High strength and stiffness.

Resistance to corrosion, and electric and heat insulation.

Light weight compared to steel.

Excellent creep and fatigue resistance.

$>$ Ease of installation (concealed color, wrap around complex edges, and such).

> Not magnetic, good weathering, alkali and chemical resistance.

$>$ Excellent durability.

The drawbacks about FRP composites are:

$>$ Its highly brittle nature.

$>$ Its cost and affordability. 


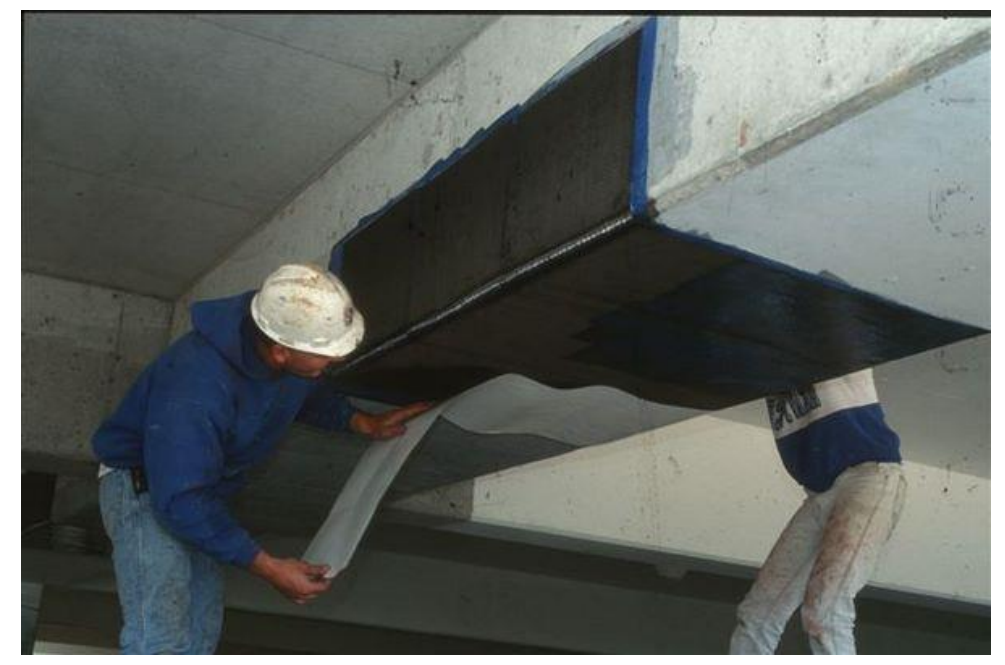

Figure 1-1 a Typical Shear Strengthening Using CFRP Composites (Source: Google)

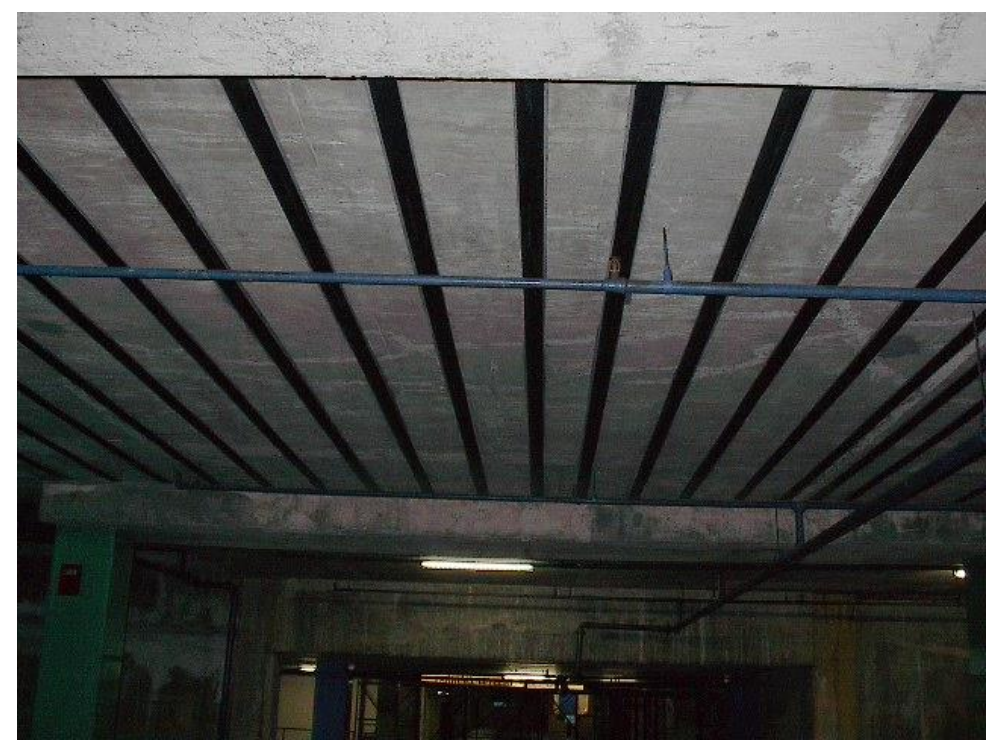

Figure 1-2 a Typical Slab Strengthening Using CFRP Composites (Source: Google)

FRP composites emerged in Switzerland in early 1990s for the rehabilitation of bridges, whereas today it is mostly used in building sector. This technique then moved to the U.S., and a lot of empirical and models have been tested on it ever since. Many factors influence torsional strengthening of RC beams, including, but not limited to: 
Fiber orientation.

Number of FRP plies.

Number of faces strengthened.

Type of anchorage or attachment scheme.

Shear span-to-depth ratio.

Type of epoxy used in attachment.
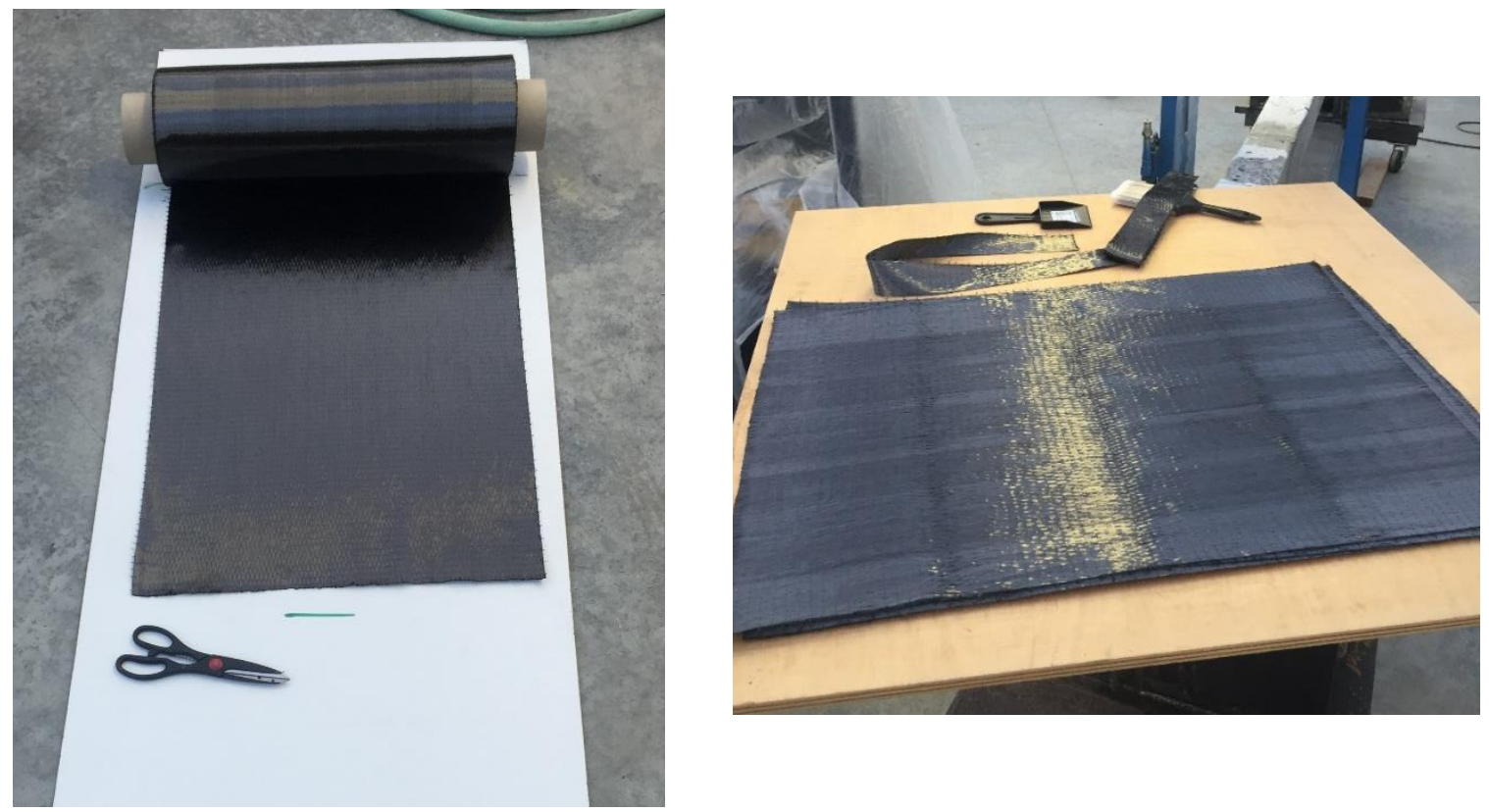

Figure 1-3 a Typical CFRP Sheet Roll (MBrace cf 130)

Numerous experiments and analytical models have been done/proposed to examine the behavior of FRP composites when used in different types of structures, however, not all behaviors have been well categorized for each case, nor has there been a specific standard for the use of FRP unlike vast number of standards for concrete, steel, and wood constructions. The vast majority of experiments and models dealing with FRP composites 
are concerned with flexural and shear behavior, while very limited focus is given to torsion. Torsion in structures can sometimes be considered secondary by engineers, and this oversight might cause detrimental damages in structures.

Structural members have various shapes such as: rectangular, hollow, T, and L-shapes. The behavior of each section is different, which makes it more complex to examine the amount of strength improvement under torsion. For the sake of ease, research is more often based on rectangular cross-sections. In normal RC slab-beam construction, full wrapping of beams is not practical. Special types of anchors must be used to allow continuous torsional shear flow across the beam.

ACI 440.2R-08 does not provide explicit guidance or formulas for strengthening under torsion, but it does provide provisions for shear strengthening that can be extended to torsion. ACI 440.2R-08 suggests the following wrapping schemes for shear strengthening.

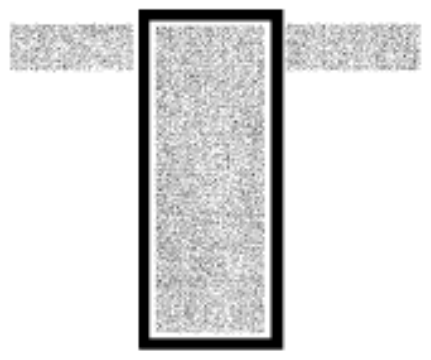

Completely wrapped

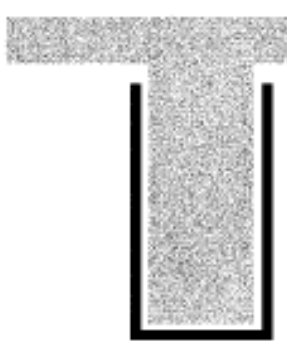

3 -sided

"U-wrap"

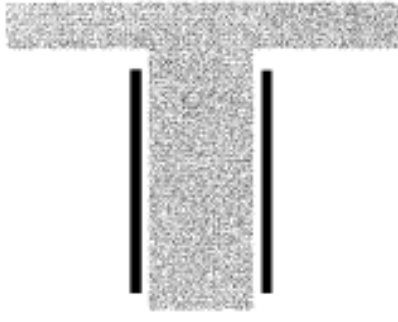

2 sides

Figure 1-4 ACI 440.2R-08 Suggestions for Shear Strengthening (Courtesy of ACI 440.2R-08) 
Efficiency of externally bonded FRP composites greatly depends on the interface bond between concrete and FRP laminates. In the majority of cases, failure is due to delamination rather than the rupture of FRP itself. Moreover, the surface preparation and the quality of workmanship play a vital role in the effectiveness of the application.

\subsection{Beam Prototype and Modelling}

The motive behind this research is the lack of accurate data and knowledge on this topic. This research aims to provide realistic tests of a RC spandrel beam subjected to M, V, and T loads strengthened with CFRP to add additional torsional strength.

This research focuses on the behavior of a spandrel beam in the frame shown in Figure 1-

5. The assumed prototype beam in the frame is subject to two different live loads:

Set A (125 psf) 
Set B (250 psf)

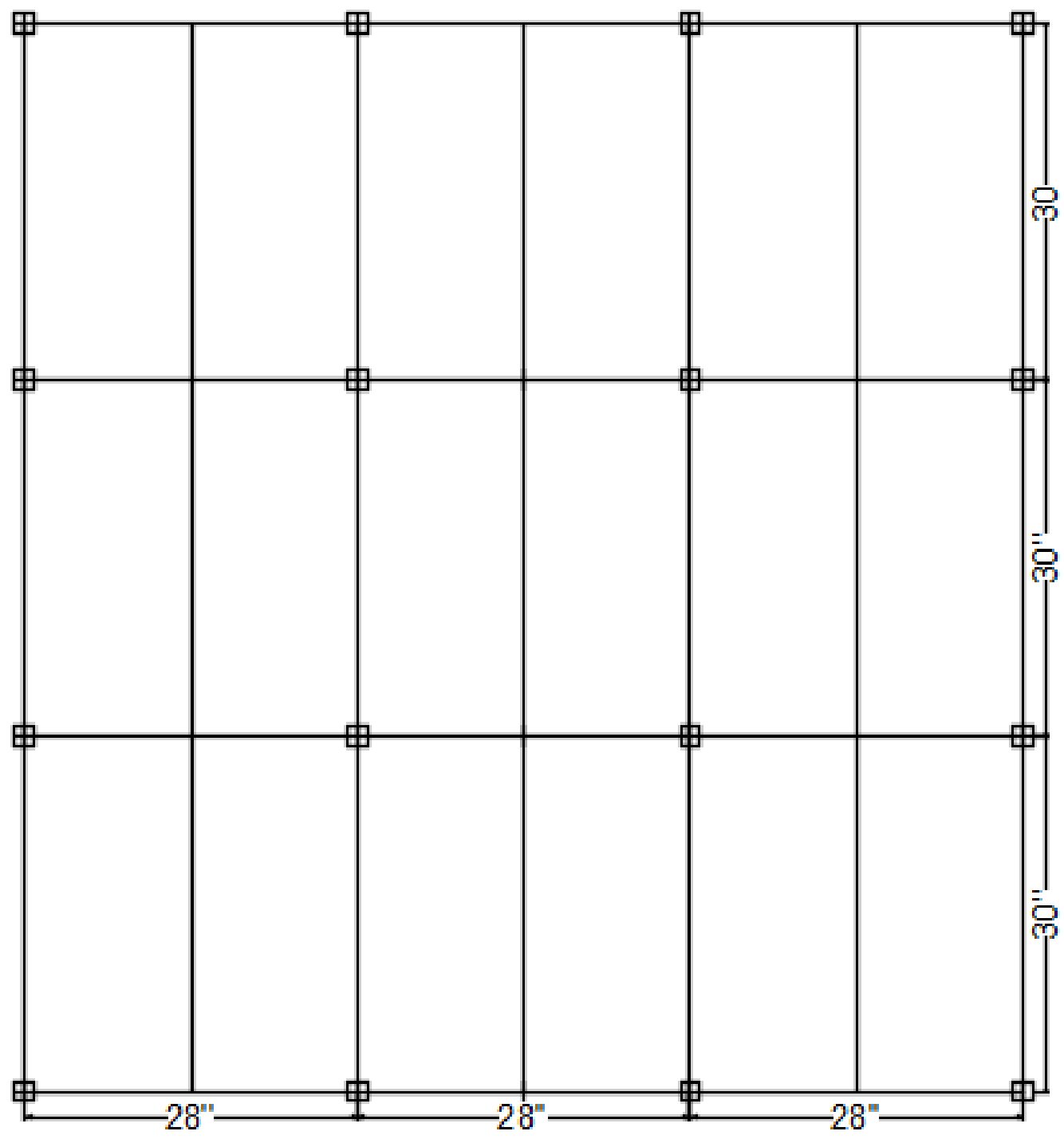

Figure 1-5 Floor Plan of the Building 


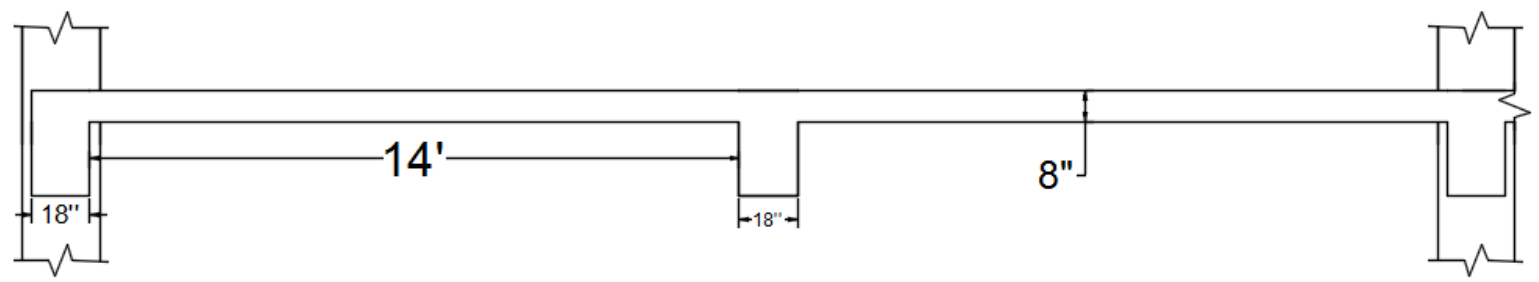

Figure 1-6 Framing System of the Assumed Existing Structure

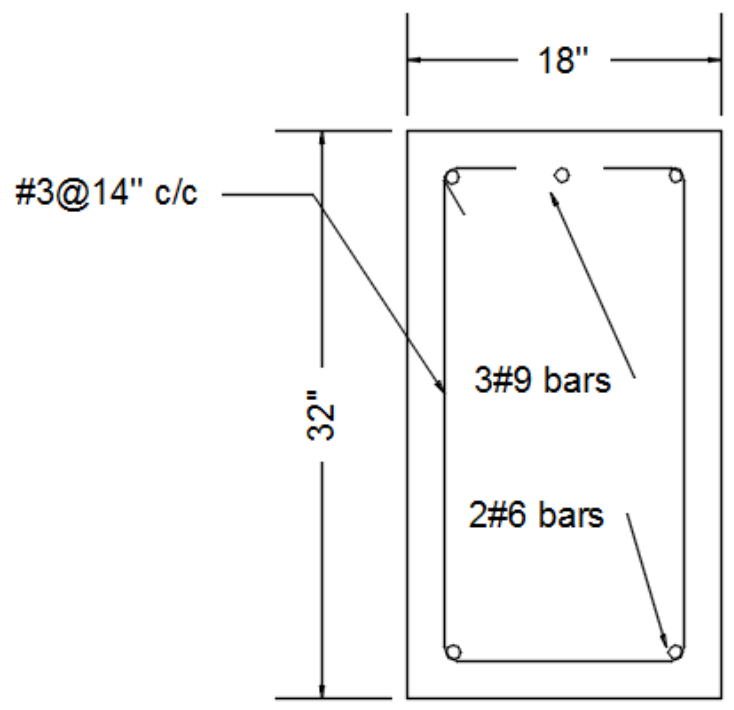

Figure 1-6 Cross-section Details of Set A Prototype 


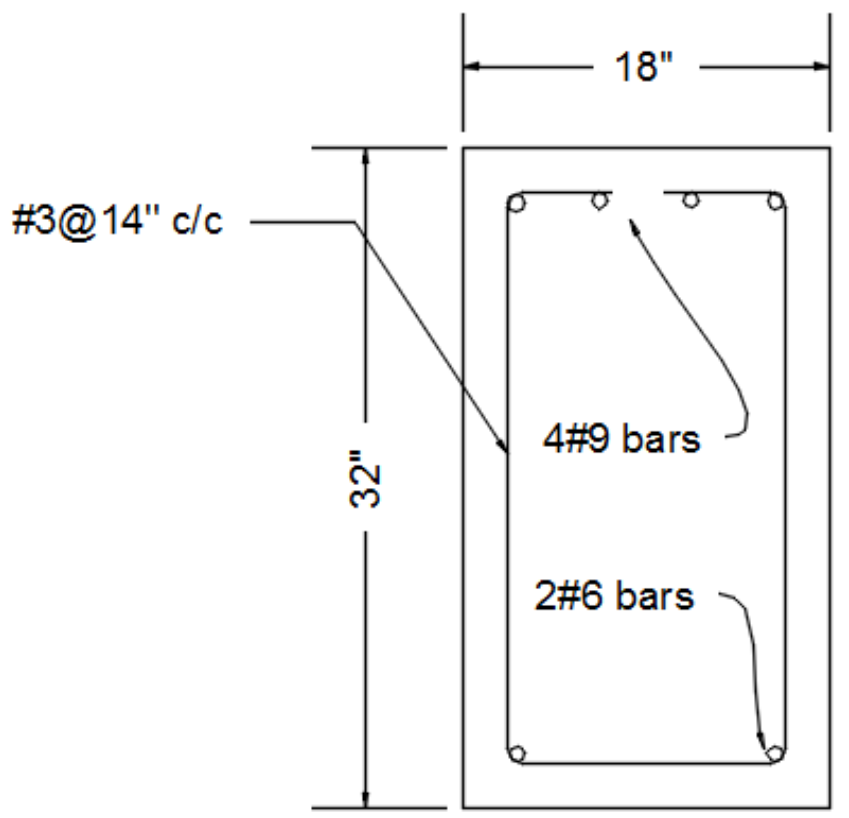

Figure 1-7 Cross-section Details of Set B Prototype

The prototype spandrel beams were designed using ACI 318-14 provisions considering shear and bending loads only. It is assumes that the designer did not include torsional moment in the design similar to what practitioners did using older codes. The detailed frame analyses for each set of loading are in the appendix.

For the testing purposes, the designed beam prototype is modeled as clamped-clamped ends to simulate negative moments at the ends, and also provide adequate torsional stability at the ends. The prototype aspects are then scaled down to a fourth. A two-pointload pattern was used to emulate the beam model in the lab, as shown in Figure 1-9.

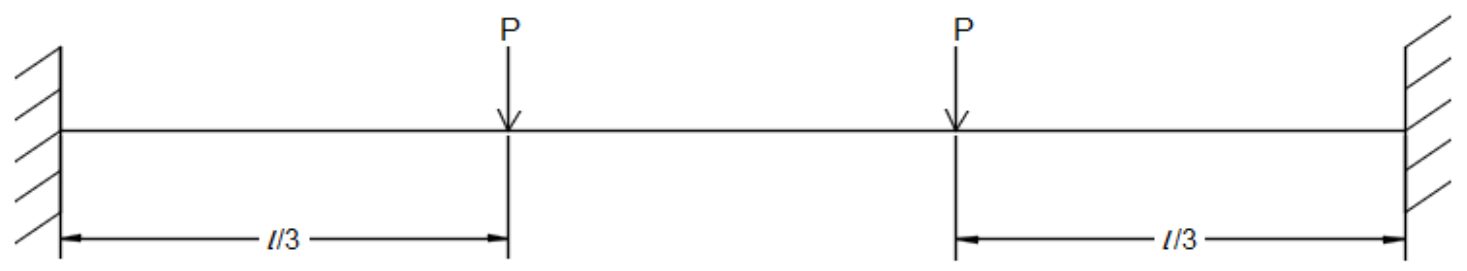

Figure 1-8 Testing Structure of the Model 
The shear and moment diagrams for the model would be:
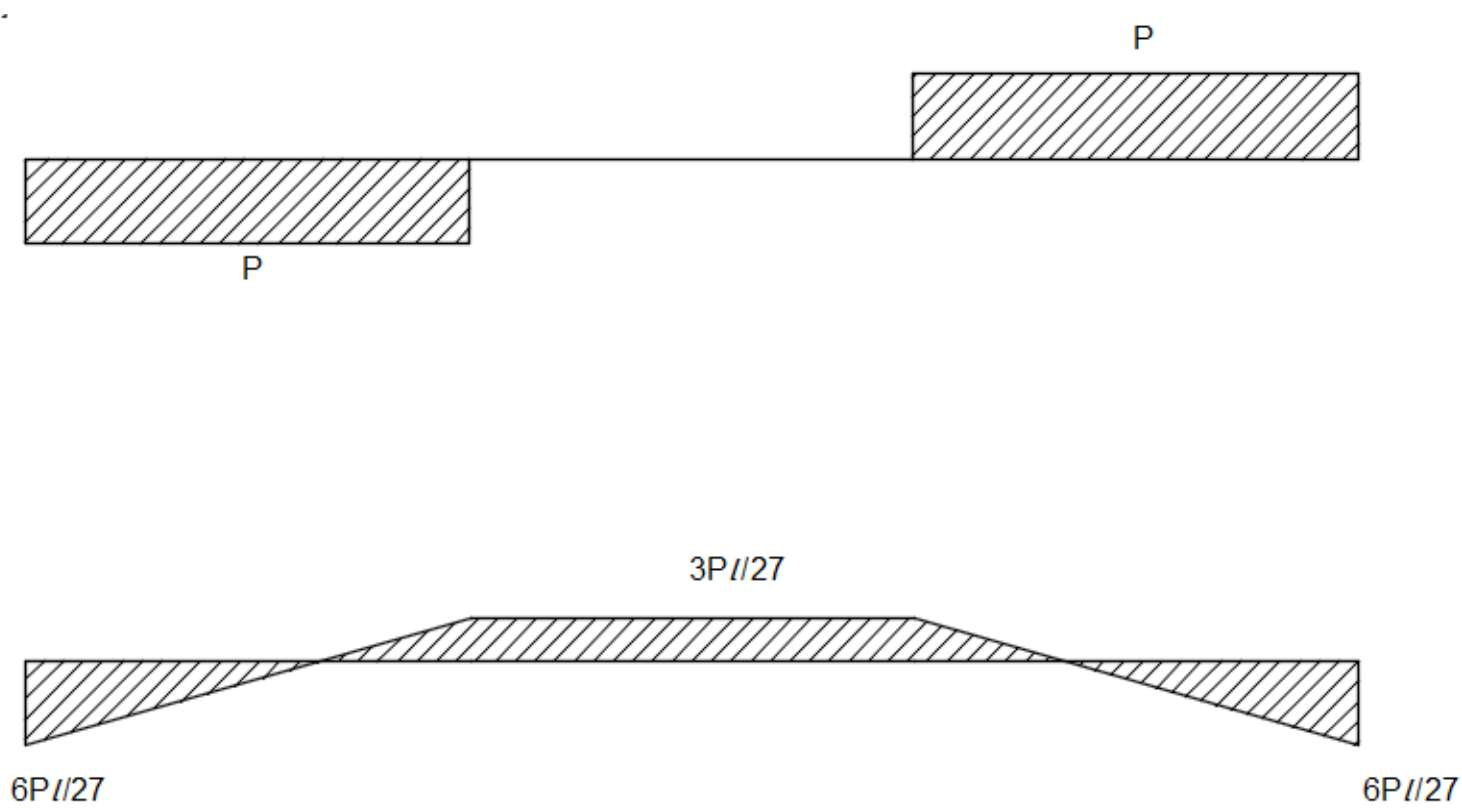

Figure 1-10 Shear and Moment Diagrams for the Model

When the load is eccentrically applied, and knowing that the shear and moment diagrams remain unchanged, the resulting torsion diagram would be as follows:

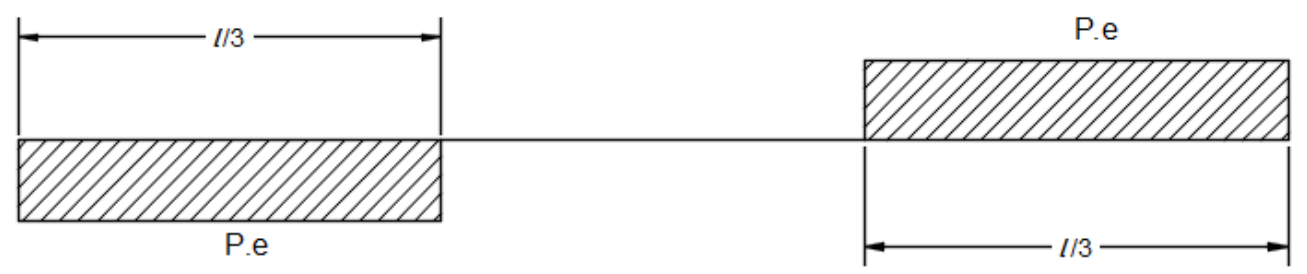

Figure 1-12 Torque Diagram of the Model

Details of the structural analysis for the model are attached in the appendix. 


\section{Chapter 2 Literature Survey}

\subsection{Introduction}

The current science and literature on torsional strengthening of reinforced concrete (RC) beams is neither intensive nor adequate. Torsional failure is unpredictable and often catastrophic, so there needs to be more rigorous studies done in order to provide safe and accurate guidelines. Alexander and Cheng (1996) stated that not only flexural, but also shear and possibly torsional strengthening, are required in actual structures. Many existing buildings have been reported to have shear deficiency. Since the nature of flexural shear and torsion shear are similar. The strengthening schemes for shear can also be used for torsion with slight differences. Popular methods of torsional strengthening used at the current time are:

- Enlarging concrete cross sectional area followed by addition of transverse reinforcements.

- Using surface bonded steel plates with concrete.

- Applying axial force to the deficient member through post-tensioning. Koutchoukali and Belarbi (2001) performed a study on torsional capacity of high strength $\mathrm{RC}$ beams, and they came up with an expression for minimum torsional reinforcement based on $20 \%$ post cracking reserve strength to provide reasonable ductility.

Previously, Hii and Al-Mahaidi (2007) carried out experimental tests on torsional strengthening and reported a $40 \%$ cracking torque increase and angle of twist for ultimate torque strength. Ameli et al. (2007) showed that whereas carbon fiber reinforced polymer (CFRP) sheets fail soon after peak torque capacity, glass fiber reinforced polymer 
(GFRP) can go for a longer period of time thus providing more energy absorption capacity. This enhanced post-peak behavior is more suitable for earthquake-related applications. Research on fiber reinforced polymer (FRP) strengthening shows that a substantial increase in post cracking stiffness and ultimate load bearing capacity can be attained under flexural and shear loads. Cross sections subjected to torsion are usually non-rectangular sections, which makes it complicated to analyze the nature of torsion in such sections. At the same time, these sections aren't only subjected to torsion in the real world, they are also carrying shear and bending loads. To simplify the study, most researchers use rectangular sections subjected only to pure torque.

In many cases, the behavior of RC elements should be evaluated after the elements have been loaded and subjected to some damage, and where subsequently they will need repair or rehabilitation. There are many techniques for strengthening, and much research has been carried out on such methods. Hrick et al. (2003) strengthened three bridge girders for flexure by amending shear-induced cracks near the supports, and shrinkage cracks by using epoxy resin injection into cracks. Each beam showed adequate capacity gain after rehabilitation. Obaidat (2010) tested two reinforced concrete beams until their cracking loads, and then they were unloaded. Later, the beams were strengthened using CFRP strips and subsequently loaded until failure. The tests achieved an average of a $23 \%$ load bearing capacity.

Until very recently, research on the behavior of FRP composites has been experimental, but modeling and numerical studies have been scarce Arduini (1997). With a lack of knowledge in defining crack patterns in the work, Arduini (1997) performed a finite 
element analysis on RC beams strengthened by FRP plates to simulate the behavior and mechanisms of failure. Kachlakev et al. (2001) used ANSYS, a finite element program, to study bending and shear behavior of crack-free reinforced concrete beams strengthening with FRP composites. In his study he used Solid46 (a finite element parameter) element to model FRP composites, and found the program results and their corresponding experimental results agreed with each other. Gesund et al. (1964) first carried out numerical studies using finite element analysis on un-retrofitted beams to validate analyses accuracy compared to experimental data. The same study was later expanded to deal with retrofitted beams' behavior strengthened by CFRP sheets. The study was carried out for various aspects of bending moment-to-twisting moment ratios.

\subsection{Existing Experimental Tests}

Pedro Salom et al. (2004) carried out an experimental and analytical program to address torsional behavior of strengthened spandrel beams by CFRP composites. In this study, six normal strength concrete (NSC) beams were tested under pure torsion to eliminate complexities in the behavior making it very hard to analyze the contribution of torsion to the whole behavior. Due to the fact that a full wrapping scheme for strengthening is hardly achieved in reality, the CFRP sheets were attached only to three faces in the study. Special anchors were used to allow continuous shear flow across the perimeter of the beams, which is necessary for resisting torsion. These researchers attempted to answer the following questions:

- Amount of CFRP used.

- Combination of different fiber orientations. 
- Effect of fiber orientation on strengthening.

- Effect of composite anchors.

Six of the four beams were strengthened by various configurations. The cross section they used was L shaped with $102 \times 203 \mathrm{~mm}$ flange and $2438 \mathrm{~mm}$ span, and pure torsion test set-up is used as shown below:

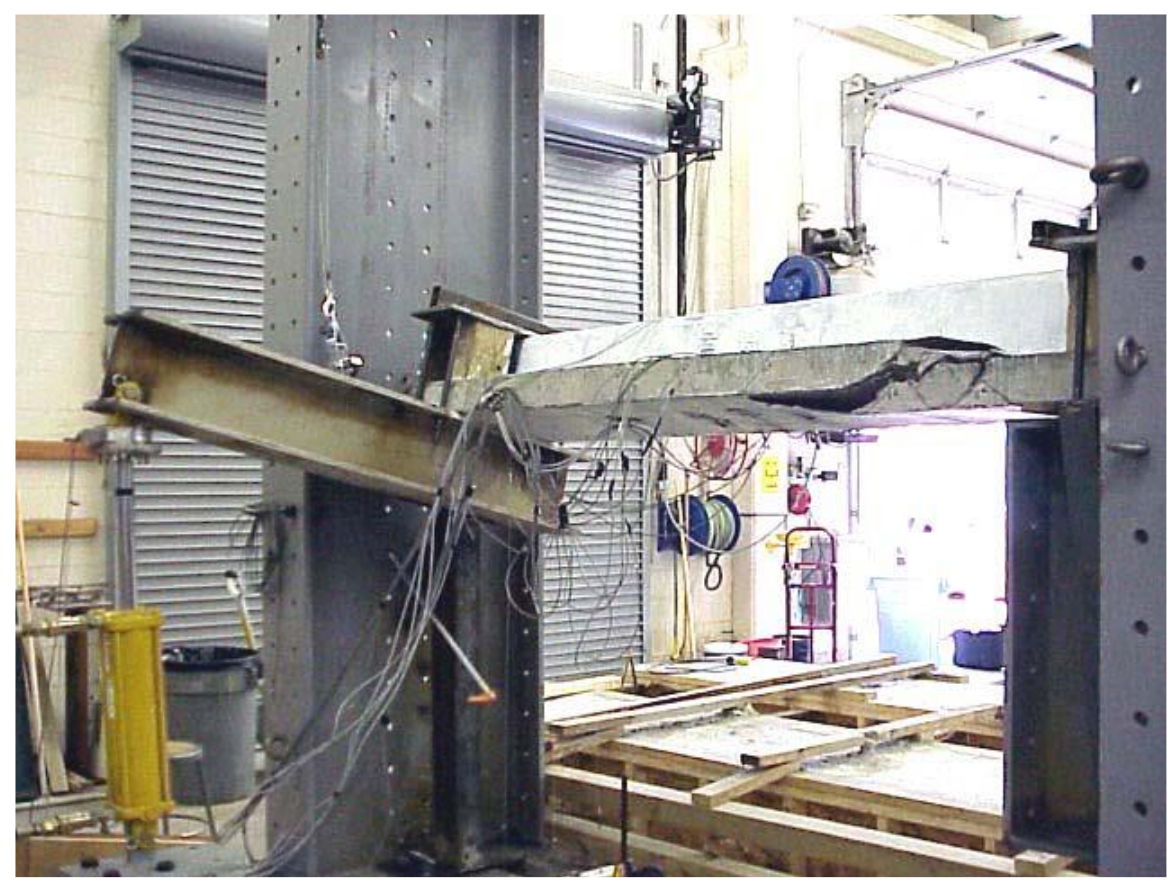

Figure 2-1 Test Set-up by Pedro Salom et al. (2004)

The structure of their testing was:

- Two control beams.

- Third beam was strengthened by two unidirectional $0 / 90^{\circ}$ layers without anchors.

- The fourth beam was strengthened by two unidirectional $\pm 45^{\circ}$ layers with special anchors. 
- The fifth beam was similar to the third, but with special anchors.

- The sixth beam was strengthened by one layer of $90^{\circ}$ sheet with special anchors. The first two control beams carried an average torque of $22.3 \mathrm{kN}-\mathrm{m}$ and 5.3 degrees of rotation. The third beam sustained a torque of $32.5 \mathrm{kN}-\mathrm{m}$ and 9.3 degrees of rotation. Failure happened near the supports due to excessive concrete crush and fiber delamination. The effective CFRP strain was only $11 \%$ of laboratory rupture strain. Strain in CFRP started after the formation of the first cracking. This was a good indication that FRP composites are only suitable for post cracking stages. The fourth beam with $\pm 45^{\circ}$ lamina sustained a torque of $43.4 \mathrm{kN}-\mathrm{m}$ and rotation of 6.4 degrees. Effective strain was about $24 \%$ of rupture. This increase in capacity was due to the effectiveness of fiber directions as they were aligned in the principal stress directions. This strengthening was the most effective scheme, but least feasible practically. The fifth beam behaved a little stronger than the third beam, and the subsequent beam was more or less similar. In all specimens, general delamination occurred and excessive concrete crush occurred shortly after that. The anchors provided more resistance to the beams and less damage at failure. A zero degree lamina was deemed to have a significant role in crack width reduction and an increase in stiffness of the beams, while a $90^{\circ}$ lamina was responsible for additional torsional capacity behaving similarly to transverse stirrups. Figure 2-2 shows is a typical torque-twist hysteresis for the fourth beam which was strengthened by $\pm 45^{\circ}$ lamina. 


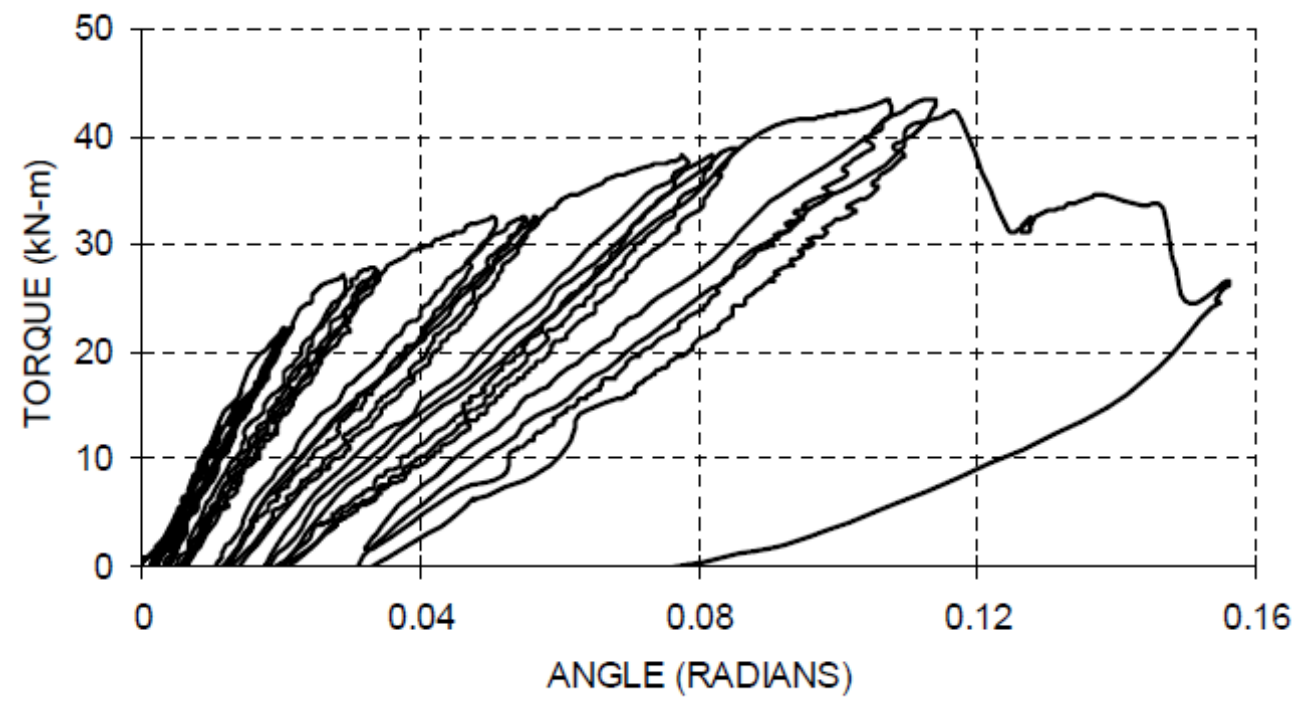

Figure 2-2 Torque-Twist Hysteresis provided by Pedro Salom et al. (2004)

More studies were recommended by the researchers to validate effectiveness of CFRP materials in torsional strengthening. Khalaf and Bayer (2013) conducted a series of experimental tests to measure effectiveness of externally bonded carbon fiber sheets. Four beams wrapped by a different configuration were tested. Figure 2-3 shows the wrapping configurations used in their study. 

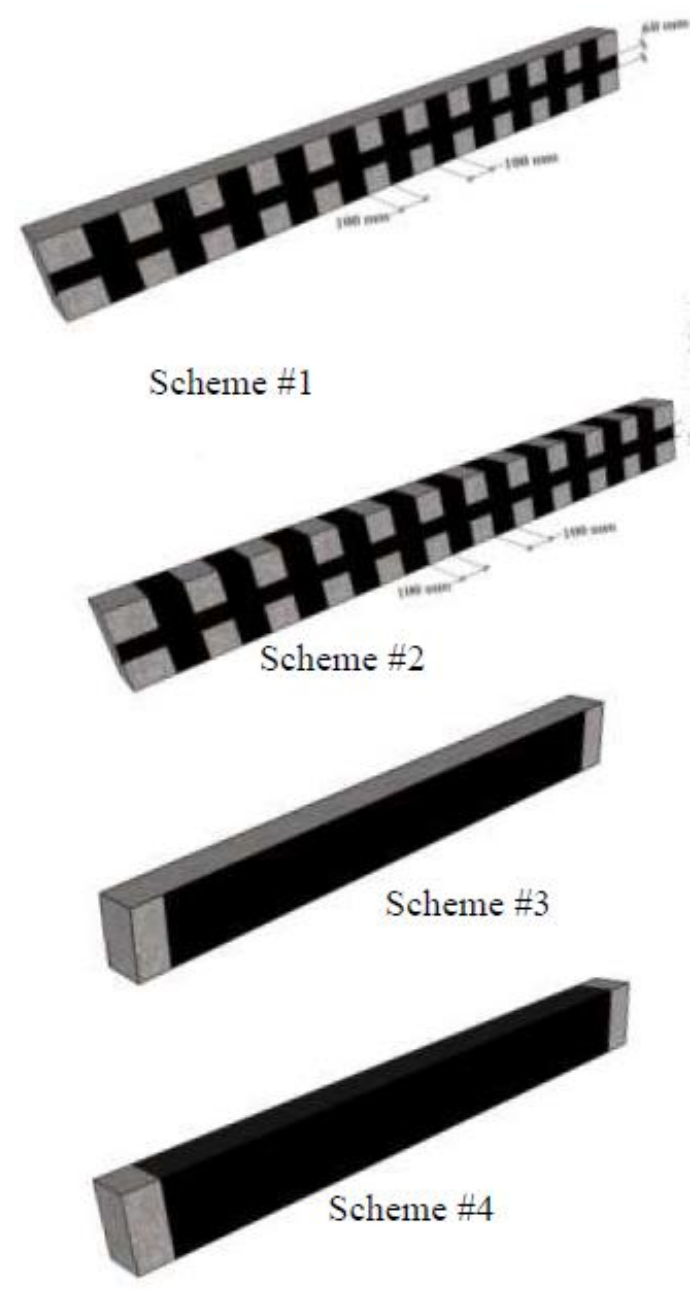

Figure 2-3 Some Wrapping Configurations used by Khalaf and Bayer (2013)

Five $150 \times 250 \mathrm{~mm}$ rectangular beams with $2.1 \mathrm{~m}$ effective test span, and four beams wrapped by unidirectional woven CFRP of brand SikaWrap 30c/45 sheets were tested by Khalaf and Bayer (2013). All fiber orientations were $90^{\circ}$, perpendicular to the beam axis. The tests, similar to most torsional tests, consisted of pure torque application, with a lever arm of $81 \mathrm{~cm}$. The first two strip wrapped beams proved that the presence of CFRP sheets prevented cracks from opening and kept their widths small. Failure, however, 
occurred in un-strengthened regions. In the partially strip wrapped beam, concrete crushing occurred on the top region where there was no CFRP sheets applied. Full wrapping the same sheets for the later strengthened beam accommodated more than twice ultimate torque with respect to the reference beam. Both beams showed that cracking torques remain unchanged, which means that the sheets work only after cracks propagate due to torque loads. The beams failed right after reaching the ultimate torque. The other two beam specimens were wrapped in CFRP sheets; one with U-jacket and the other with full wrap. The U-jacket fairly behaved much like the first strengthened beam with strips, as shown in the accompanying figure. This was due to the absence of anchorages, which makes it very easy to peel the sheets off. The full wrapped beams, however, provided a better confinement, which improved concrete strength, prevented crack widening, and gave about a $75 \%$ increase in ultimate torque. Cracking torque almost did not change compared to other tests. Its failure was excessive concrete crush followed by CFRP rupture at mid-span. That said, this scheme was the most promising scheme for in torsion strengthening. Sufficient anchorage in the U-jacket sheets improved the overall response significantly. 


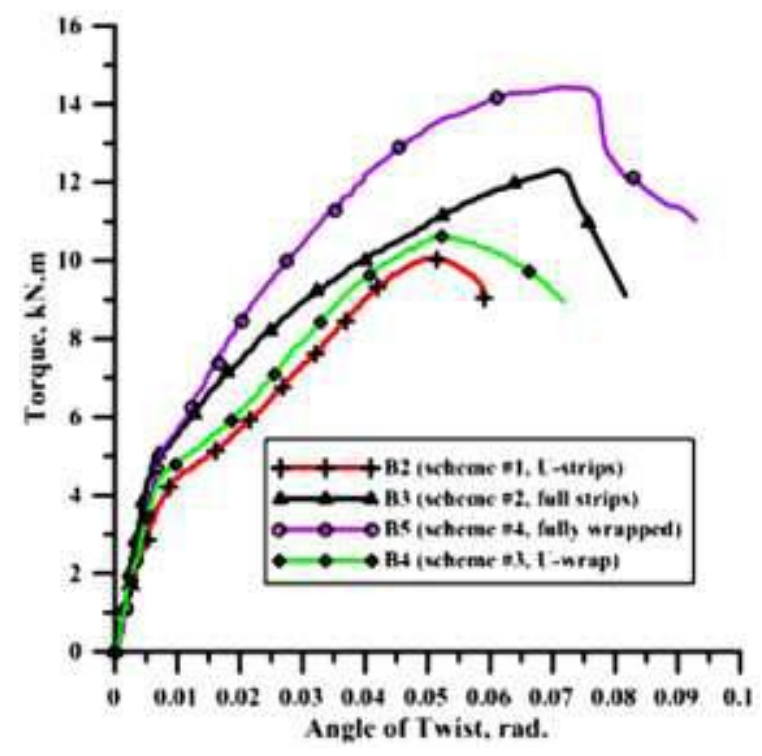

Figure 2-4 Torque-Twist Behavior of All Samples Tested by Khalaf and Bayer (2013)

Due to the fact that very limited tests have been carried out on torsional strengthening of $\mathrm{RC}$ beams, and that even these meager tests are devoted to normal strength concrete (NSC), Mohammadizadeh and Fadaee (2009) also conducted an experimental study on strengthening of RC beams with high strength concrete (HSC). In the study, seven beams were used, and CFRP sheets were used for strengthening them. Four beams were wrapped by various techniques for these parametric studies:

- Different wrapping configurations (full, strip, U-jacket).

- Numbers of plies.

- Effect of anchors in U-wrapped beams.

Similar to previous tests by researchers, pure torsion was used in the test. The CFRP brand used was MBrace cf 240, the test span was $1.6 \mathrm{~m}$, and the load eccentricity was 40 $\mathrm{cm}$ from the beam centerline. 


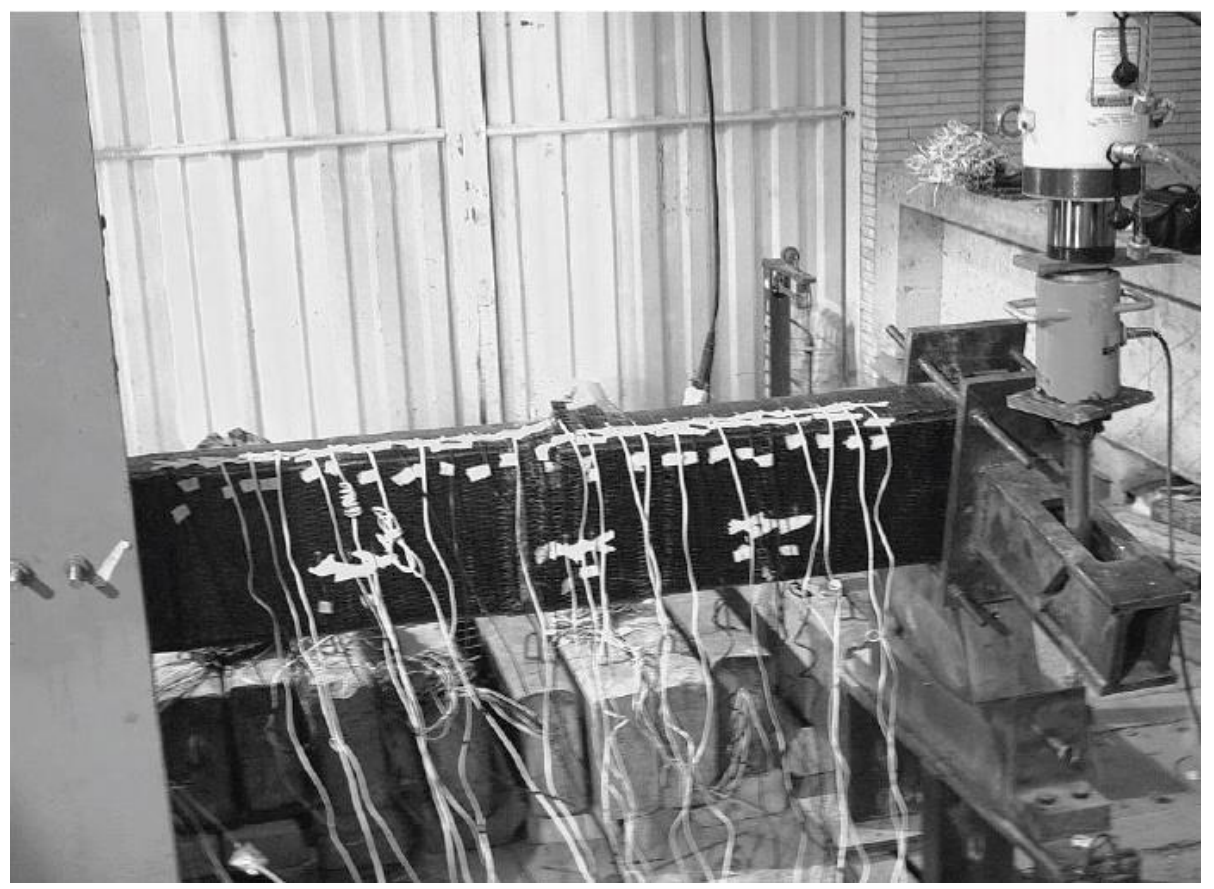

Figure 2-5 Test Set-up by Mohammadizadeh and Fadaee (2009)

From the test results, all strengthened beams exhibited an increase in both cracking and yield torque strengths. The increase depended on the CFRP ratio and strengthening configuration. Using anchors in U-wrapped beams improved the beam behavior so well that it gave identical cracking, yield, and ultimate torque capacities compared to a full wrapped beam with one layer CFRP sheet even though the primary purpose of anchors around the edges of FRP sheets was to avoid de-bonding or delamination. The bolts in the anchoring system continued the shear loop mechanism caused by torsional forces. The torque-twist curves of all the seven beams with three reference beams are shown in Figure 2-6. 


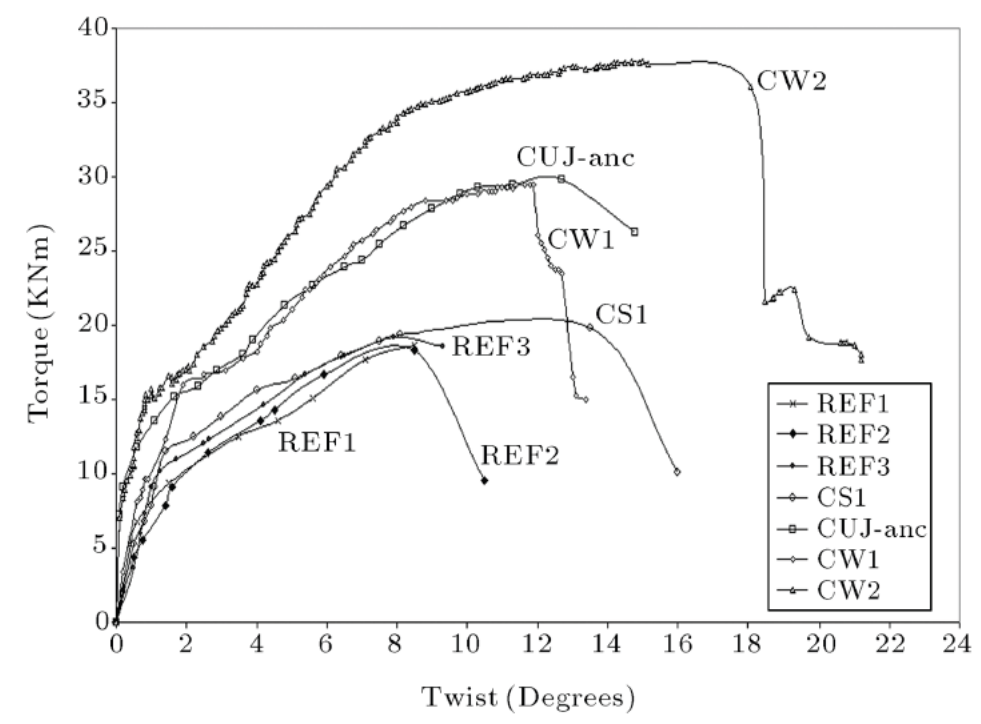

Figure 2-6 Torque-Twist Behavior of All Samples Tested by Mohammadizadeh and Fadaee (2009)

The torque-twist response, according to Mohammadizadeh and Fadaee (2009), was qualitatively defined by three zones:

- Zone one- stiffness of un-cracked beam.

- Zone two- stiffness of cracked beam strengthened by CFRP sheets.

- Zone three- damaged beam with excessive cracks, yielding stirrups, and rupturing CFRP sheets.

Full wrapping was the most efficient configuration because in the strip-wrapped concrete the cracking and crushing happened in un-strengthened regions--- i.e. between the strips. CFRP rupture was the common failure in all of the beams except the beam strengthened with strips. The beam fully wrapped with two layers gave the maximum increase of about $90 \%$ in ultimate torque, and eventually failed by CFRP rupture at the passive end support, whereas the beam fully wrapped with one layer gave about $55 \%$ respectively. It was also 
noted that in the U-wrapped beam the top surface where it was not strengthened had big cracks as compared to other regions that were strengthened.

\section{Ductility measurements}

Ductility is the amount of energy a member can store during plastic deformation, which also is the energy absorption capacity. The most common way to quantify it is:

$$
\mu_{\varnothing}=\frac{\emptyset_{p}}{\emptyset_{y}}
$$

Where: $\emptyset_{\mathrm{p}}$ is the twist angle at the ultimate torque and $\emptyset_{\mathrm{y}}$ is the yield twist angle.

Other researchers also use:

$$
\mu_{\emptyset 0.85 p}=\frac{\emptyset_{0.85 p}}{\emptyset_{y}}
$$

Where:

$\emptyset_{0.85 p}=$ twist angle at $85 \%$ of the peak torque.

The beam strengthened by two layers of full wrap was the most ductile with about $150 \%$ increase, while the strip wrap beam was the least ductile with about $30 \%$ increase with respect to the reference beams. Both U-wrapped and strip wrapped beams embraced a smaller number of cracks, but a larger width in their un-strengthened portions

Saravanan et al. (2002) tested eight square RC beams strengthened by GFRP composite sheets. The ends of the RC beams were more strongly reinforced than the rest of the span transversely in order to shift the failure from the ends. 
The span used was about $4 \mathrm{~m}$ and the study parameters were:

- Fiber orientation $\left(0 / 90^{\circ}\right)$.

- Access to three or four faces of the beam.

- Number of plies orthogonally applied.

- Full wrap vs strip wraps.

- Effect of anchors in U-jacket wraps.

The commercial brand of FRP used was MBrace EG 900 E-Glass Fibers. The test set up was able to provide $508 \mathrm{~mm}$ eccentricity for pure torsion, and the test layout is:

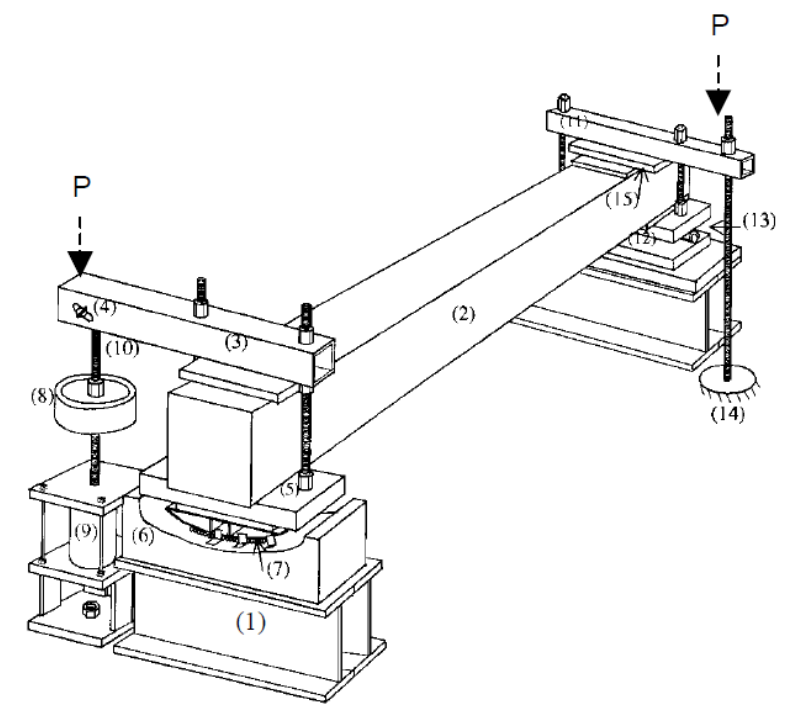

Figure 2-7 Torsional Test Layout for Saravanan et al. (2002)

The end reactions in the layout were set free to slide in a longitudinal direction to release axial loads, which can form and complicate understanding the behavior. Experimental results showed that both cracking and ultimate torques can be improved. 
For the beam strengthened on all sides with $0^{\circ}$ fibers, a $53 \%$ of cracking strength was reported, whereas in the same beam strengthened with $90^{\circ}$ fibers, a $150 \%$ of ultimate torque strength was reported.

\section{Effect of fiber orientation}

Saravanan et al. (2002) shows fiber orientation can enhance certain zones in the torquetwist curve. Zero degree oriented fibers enhanced cracking strength, whereas $90^{\circ}$ fibers enhanced the ultimate strength effectively as shown in Figure 2-8.

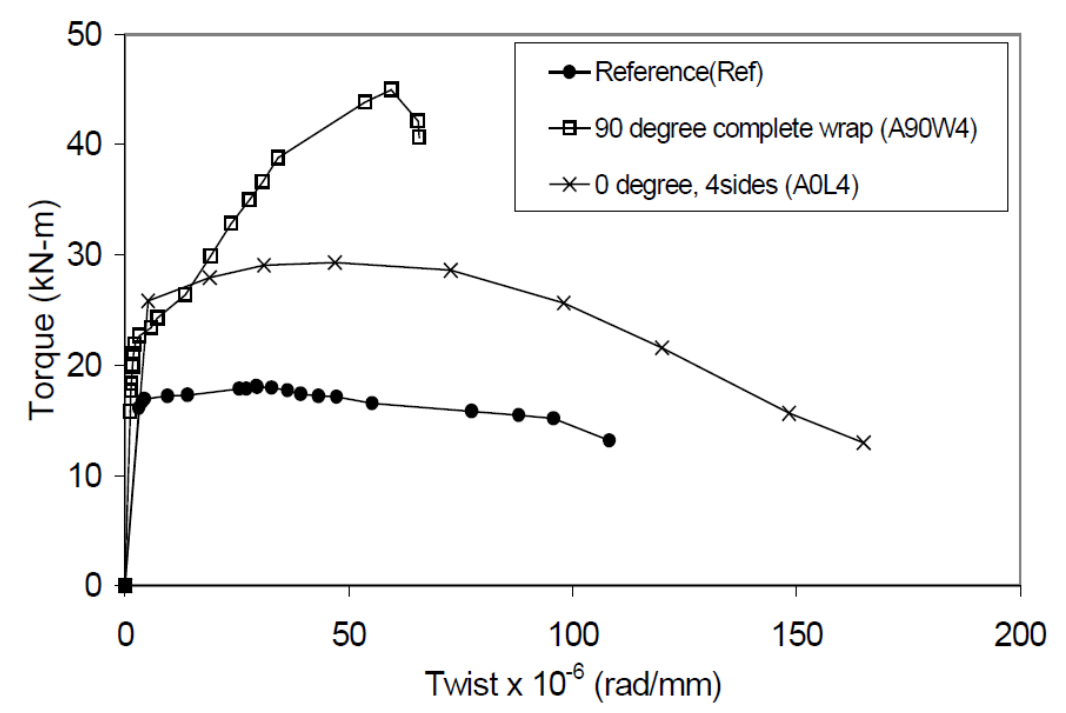

Figure 2-8 Fiber Orientation Effects on Torque-Twist Curve from Saravanan et al. (2002)

Zero degree fibers provided higher energy absorption capacity, higher ductility, larger post-cracking twist, and deformation softening. The mode of failure was the tearing off of the fibers. On the other hand, the $90^{\circ}$ fibers provided stronger post-cracking stiffness and better confinement, which increased ultimate torque. The mode of failure was the rupture of fibers. 


\section{Effect of continuous vs strip wraps}

Continuously wrapped beams had a higher post-cracking stiffness due to the existence of a better confinement. Spacing of the strips also played a vital role in strengthening---the larger spacing gave less post-cracking stiffness due to loss in confinement. That said, both the width and the spacing of the FRP strips were affected by post-cracking behavior sensitivity in the $90^{\circ}$ fibers. Post-cracking energy deformation and energy absorption capacity of the FRP strips, however, was more than in the fully wrapped beams. Cracking strength, on the other hand, was essentially the same for both $90^{\circ}$ wrapped beams as shown in the following figure:

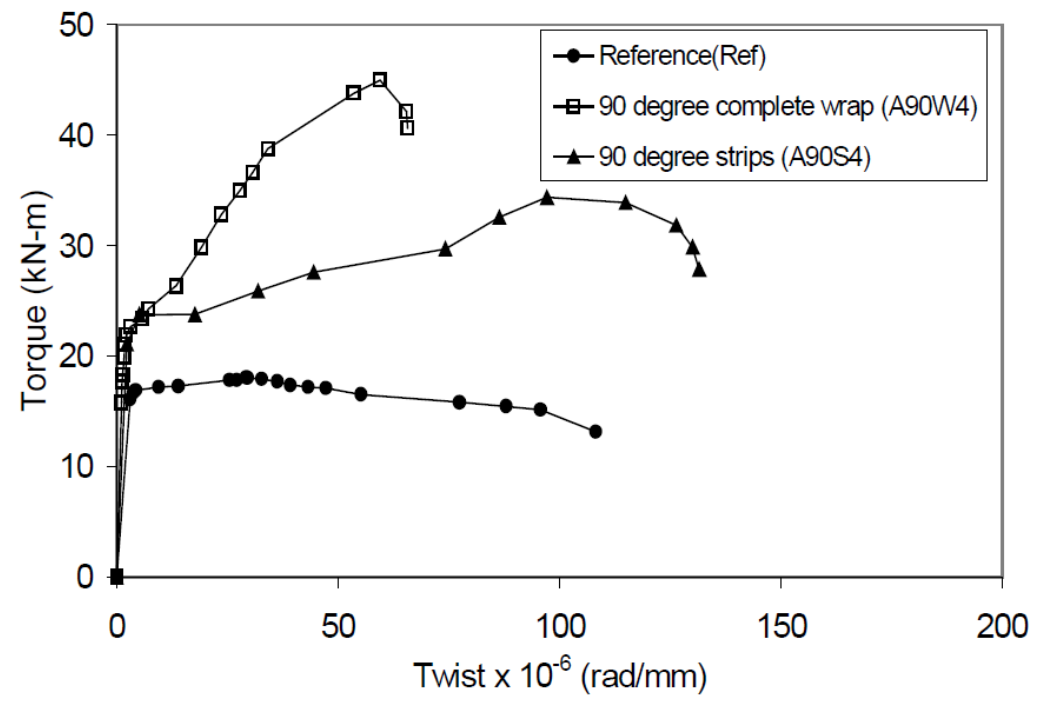

Figure 2-9 Effect of Wrapping Schemes on Torque-Twist Curve from Saravanan et al. (2002)

Effect of three faces vs four faces

Fibers oriented in the direction of beam axis didn't show any difference between the three faces and the four faces of the strengthened wraps. They both had almost the same 
cracking torque strength. The ultimate torque, however, was dependent on the ratio of the FRP used. The beams with three faces also had less torsional ductility compared to the four faces strengthened. This was due to the fact that the three faces strengthened had one face un-strengthened. Consequently the concrete crush happened on the un-strengthened face of beam, which halted excessive twisting as the load was increased. Figure 2-10 shows this trend:

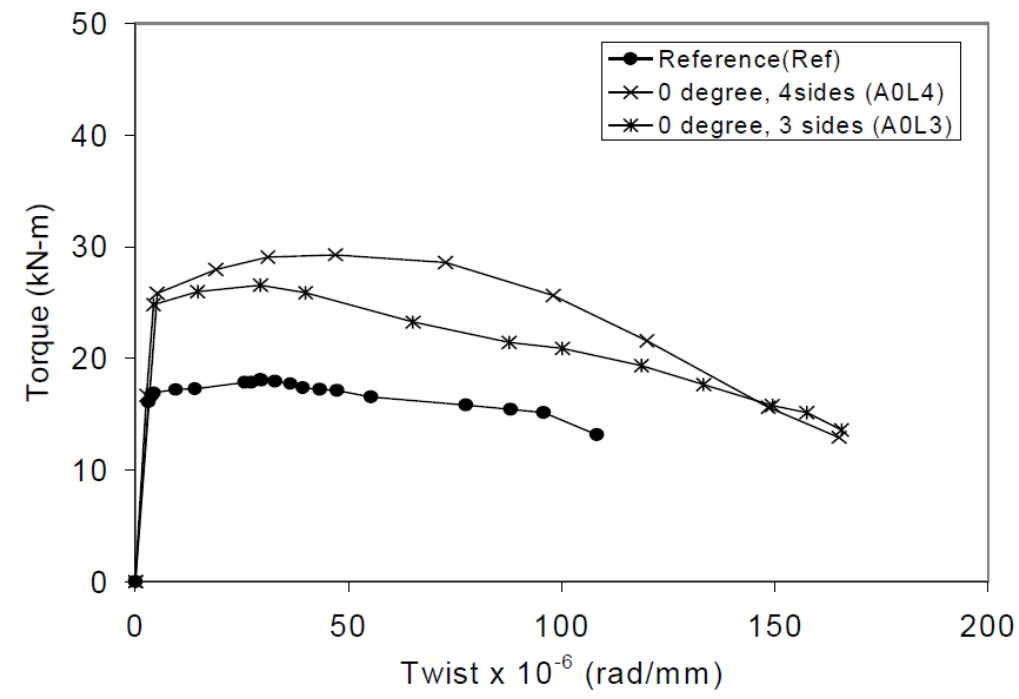

Figure 2-10 Effect of Numbers of Faces Strengthened on Torque-Twist Curve from Saravanan et al. (2002)

\section{$>$ Effect of complete wrap vs U-wrap}

Full wrapping was the most powerful configuration for torsion strengthening due to circulatory nature of shear flow, which needs a closed loop of stress distribution. The Ujacket was not effective since the shear flow cannot form a continuous loop. Concrete spalling and crushing easily occurred right after GFRP sheets peeled off, which is considered as premature failure. This gave U-jacket wraps a much lower ultimate torque 
strength. By anchoring the ends of GFRP sheets, this premature failure was substantially avoided giving the beam a much better post cracking behavior. Concrete crush and pulling out the anchoring bars were noted instead of GFRP delamination at failure. However, the anchors did not provide an increase in the ultimate strength. The anchors could give more energy absorption capacity in the test beams. Complete wraps had substantial ultimate strength increase. Cracking torque for all, full wrap and U-jacket (with and without anchor bars), was almost the same. Figure 2-11 shows the effect of full wrapping vs. strip wrapping.

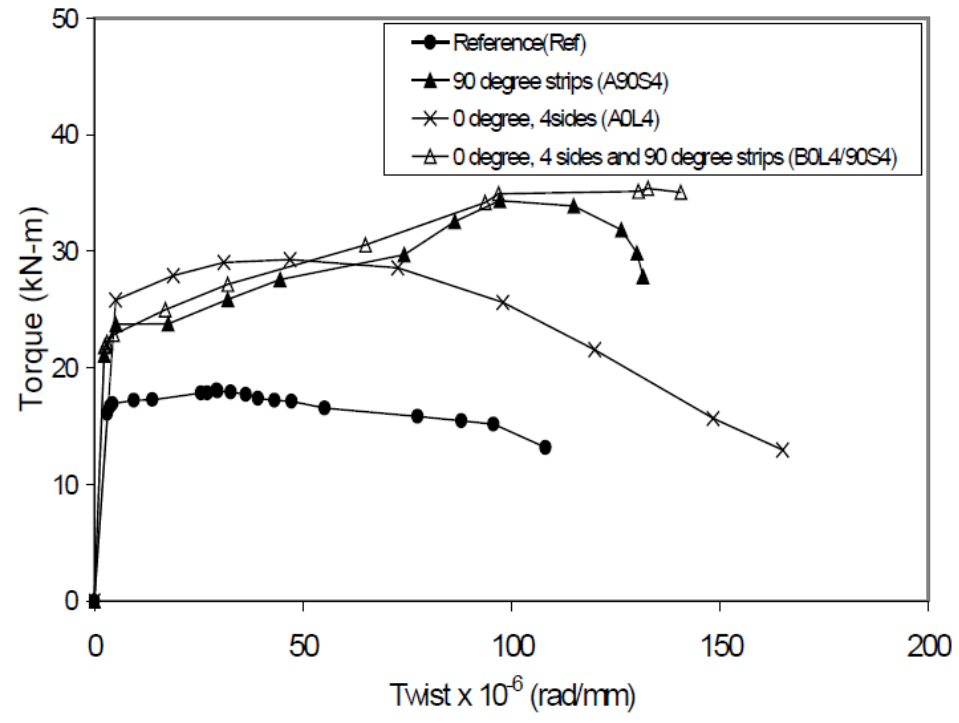

Figure 2-11 Effect of Full Wrapping vs Strip Wrapping on Torque-Twist Curve from Saravanan et al. (2002)

El Mustafa Higazy and Mahmoud El-Kateb (2011) carried out five tests on RC beams strengthened by EBR CFRP sheets. The tests were subjected to combined shear, flexure, and torsion. The focus of their investigation was on the spacing of the wrap strips. The amounts of concrete and steel reinforcements was kept unchanged for all of the five 
specimens. The main point of interest was the influence of the aforementioned parameters on torsion response in particular, as well as the feasibility of CFRP strengthening for torsion. Of the five rectangular beams, one beam was un-strengthened and the rest were strengthened with different wrapping configurations. The cross section dimensions used were $120 \times 300 \mathrm{~mm}$ with $310 \mathrm{~cm}$ span. The beam edges were rounded in the tests to avoid reduction in fibers strength. A two-point load test setup was used with eccentric loads as shown below:

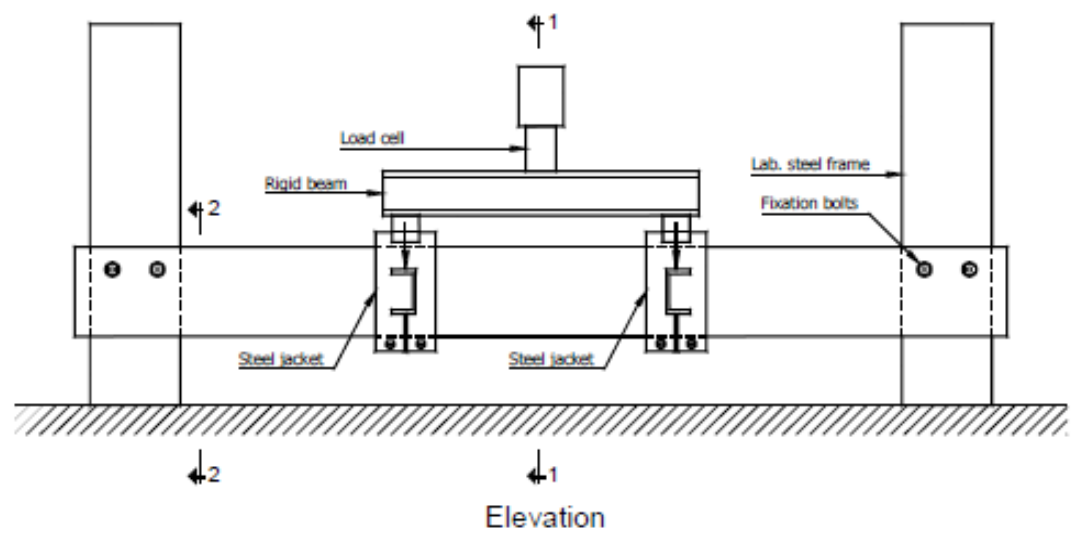

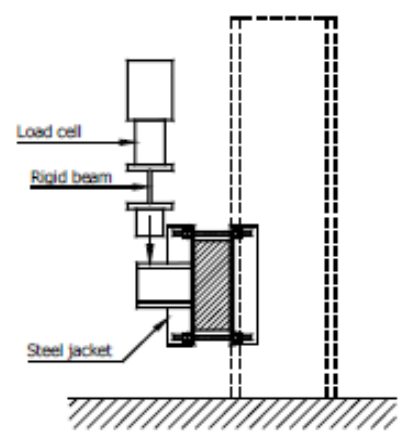

Sec. $(1-1)$

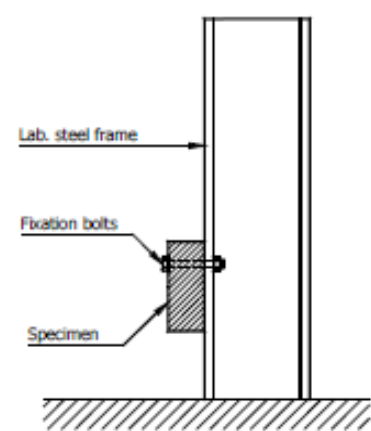

Sec. $(2-2)$

Figure 2-12 Torsional Test Layout by Mustafa Higazy and Mahmoud El-Kateb (2011) 
Details of strengthening configurations and their results are diagrammatically shown in Figures 2-13 and 2-14.
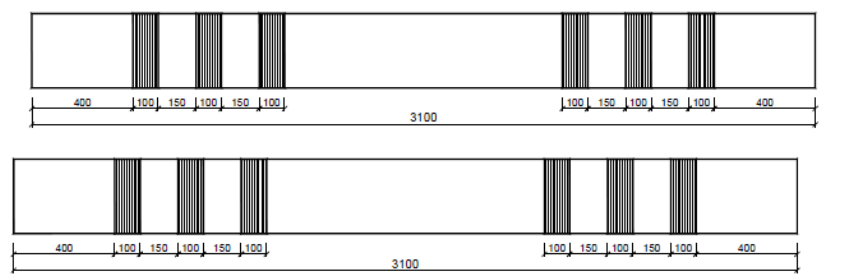

BR4

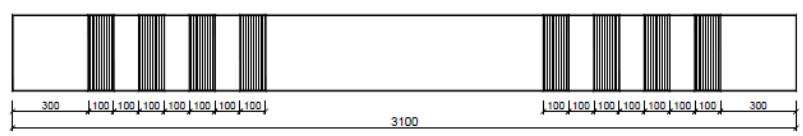

BR5

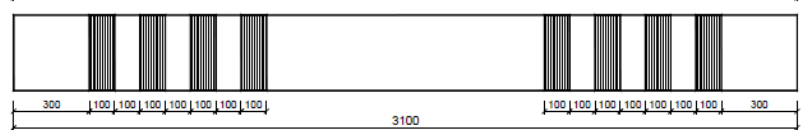

2 plies

Figure 2-13 Strip Wrapping Configurations by Mustafa Higazy and Mahmoud El-Kateb (2011)

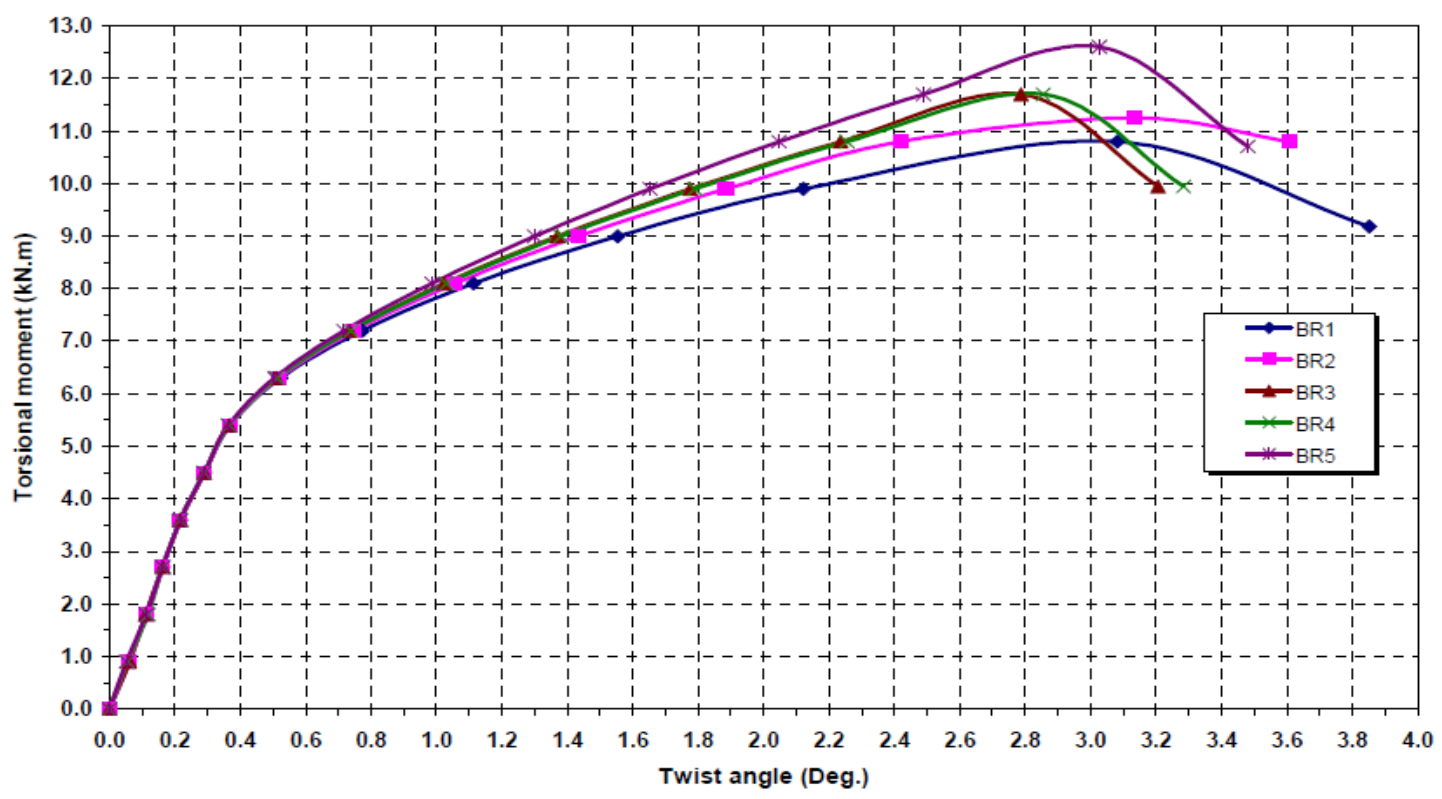

Figure 2-14 Torque-Twist Behavior for All Tests Carried out by Mustafa Higazy and Mahmoud El-Kateb (2001) 
According to the above torque-twist diagram, all tests show that CFRP sheets were inactive at early loading stages and had no contribution to the individual beam behaviors. The responses are linear at the beginning, and then follow a parabolic form until failure. Yield torque occurred at about $7 \%$ of the ultimate twist angle. The additional

Ultimate strengths of the first two beams were about $5 \%$ and $8 \%$ respectively, whereas ductility was reduced by a range of $20-30 \%$, as it can be observed from the previous curve. The more capacity increased, the less the ductility was observed in all specimens. As to the crack progression, the control beam sustained wider cracks than the other beams, but the strengthened beams also followed similar cracking pattern as the control beam. This was due to inexistence of a large amount of CFRP across the surface of the beams. Diagonal cracks initiated at the points of load application and gradually moved toward the end supports. At about $75 \%$ of the ultimate twist, all cracks were completely formed; failure mode in all the specimens was dominated by delamination of the CFRP sheets. The experimental results were compared to analytical expressions proposed by Fédération internationale du béton (FIB) Bulletin 14 (as described previously), and the results followed each other closely with maximum deviation of approximately $10 \%$ and minimum of $1 \%$. The total moment strength was the summation of the concrete torsion strength and the CFRP sheets, where concrete strength was obtained from ACI 318-08 equation 11-18.

$$
\sqrt{\left(\frac{V_{u}}{b_{w} d}\right)^{2}+\left(\frac{T_{u} p h}{1.7 A_{0 h}{ }^{2}}\right)^{2}} \leq \varnothing\left(\frac{V_{c}}{b_{w} d}+0.66 \sqrt{f^{\prime} c}\right)
$$


Mostofinejad (2014) tested nine RC beams under combined shear and torsion with different loading aspects to determine the behavior. To do this, five RC beams were used as control beams, four of which were rehabilitated after initial cracking stage by rubbing cement mortar on the cracking surface the loading system varied from shear (no torsion) to pure torsion (infinite eccentricity). The testing system is shown in Figure 2-15 with fixed-fixed supports at the ends.

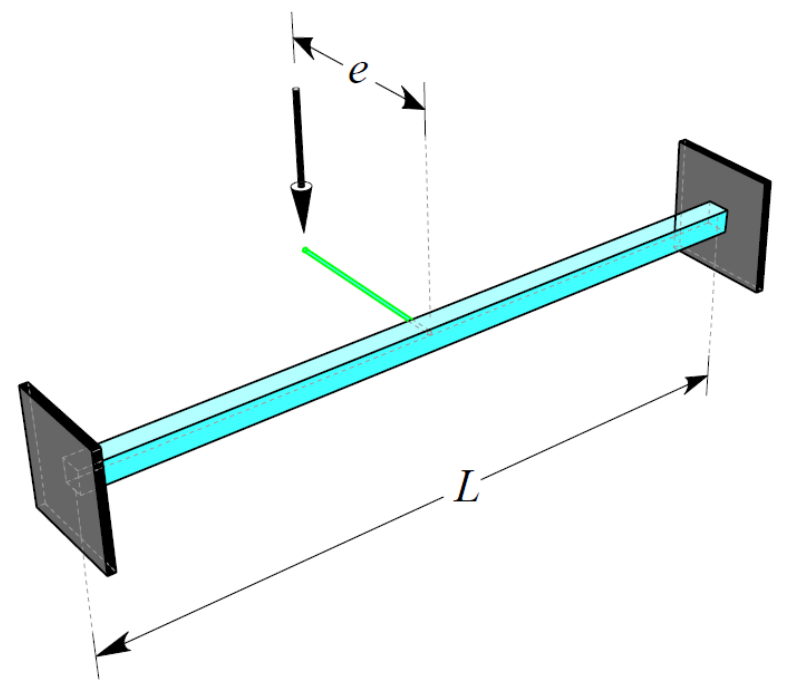

Figure 2-15 Combined Shear and Torsion Testing Set-up by Mostofinejad et al. (2014)

Multiple bay beams and non-prismatic beams (as shown below), were used to shift the failure to the reduced-height zone at the contra-flexure zone (zero flexure) at the two end quarters of the span. 


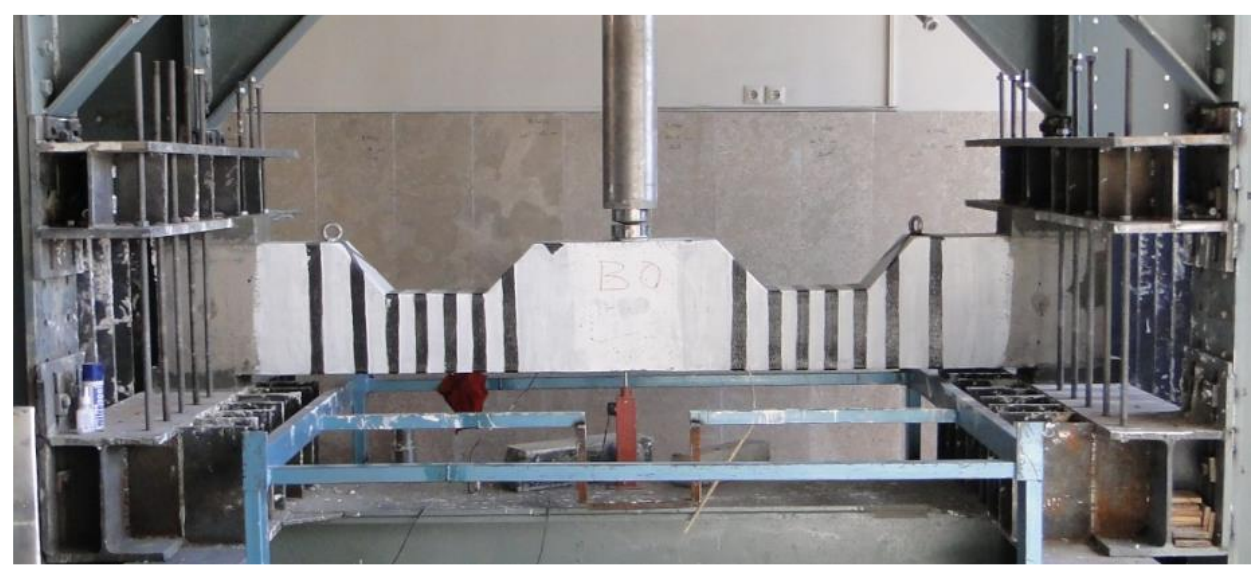

\section{Figure 2-16 Elevation View of the Beam by Mostofinejad et al. (2014)}

The CFRP strengthening scheme was in the form of strips with $40 \mathrm{~mm}$ width placed on $85 \mathrm{~mm}$ on centers. After testing the specimens, all cracks were seen to be inclined due to shear and torsional loads. In the rehabilitated specimens, the cracks were dispersed more uniformly compared to the control beams. The inclination of cracks ranged between 3440 degrees for the control beams, while for the strengthened/rehabilitated beams the inclination was more like 45 degrees. An eighty percent reduction in crack width was also seen compared to the control beams. On average, the ultimate-to-cracking loads were 1.7, 2.4, and 4 for control, strengthened, and rehabilitated beams respectively. In the reduced zone, where the longitudinal reinforcement ratio was higher than other regions across the span, the longitudinal reinforcements did increase torsional cracking and ultimate load bearing capacity by $68 \%$.

By definition, CFRP "strengthened specimens" are those without inherent cracks/damages, whereas the "rehabilitated specimens" do have initial damage prior to 
application of CFRP. De-bonding happened after increasing loads, but in all cases CFRP rupture occurred once de-bonding started. From the torque-twisting diagrams, the initial stiffness of the strengthened beams increased, but for the rehabilitated beams decreased, due to the fact that cracks were already inherent when FRP strips had been applied. The energy absorption, the area under the torque-twist curve, in strengthened beams was much more than that of the rehabilitated beams. The increase in cracking and ultimate loads was observed to be adversely affected by eccentricity. In pure torsion, the maximum increase in cracking loads was noted.

The rehabilitated beams obtained a $60 \%$ increase in load bearing capacity. Their initial crack patterns were different from other specimens by that they occurred on the opposite faces compared to other beams. The torque-twisting curves consistently showed gain in shear-torsion capacity, and reduction in ductility in all specimens. Figure 2-17 shows the experimental torque behavior of strengthened beams, tests by Mostofinejad, et al (2014).
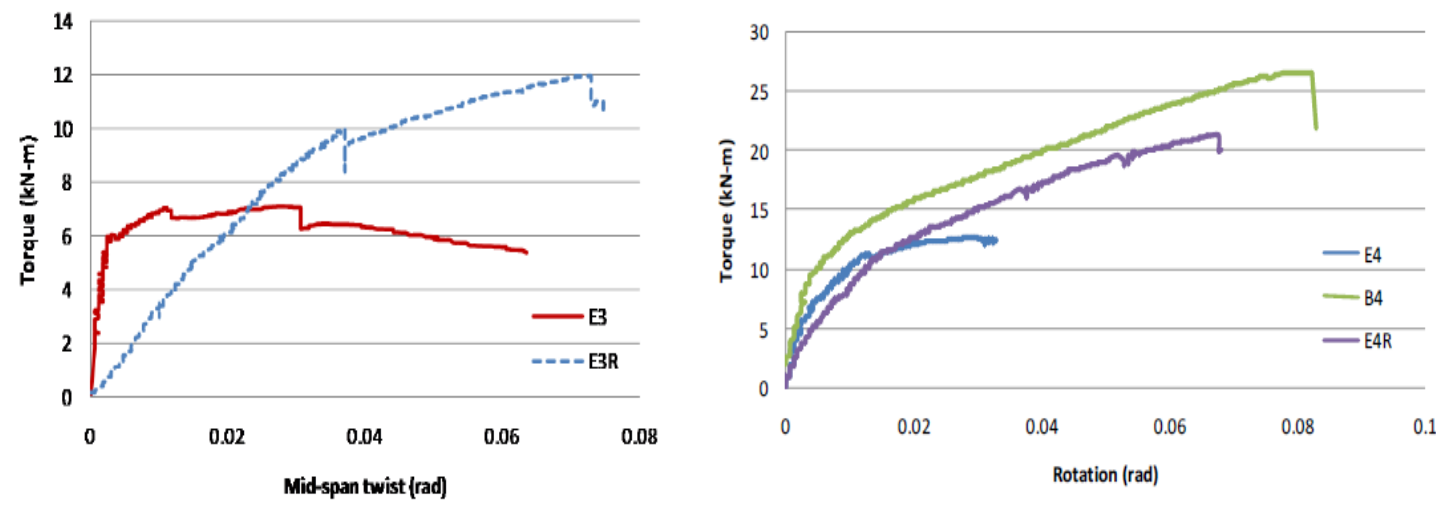

Figure 2-17 Experimental Behavior of Strengthened Beams, Tests by Mostofinejad et al. (2014) 


\subsection{Strain in FRP Composites}

Torsional failure using FRP composites either fails by de-bonding or by FRP rupture

(Ghobarah et al., 2002), in which in either cases ultimate strain was much lower than the laboratory tensile strain (Deifalla, 2007). FRP strain depends on:

- Dominating failure mode.

- FRP properties.

- Beam dimensions.

- Concrete properties.

- Strengthening scheme.

FRP strain was observed to be a negligible amount at the beginning of loading process, and then linearly changing up to the cracking point, by a small amount (Ghobarah, 2002). The sudden increase in the FRP strain was assumed to occur once the stresses exceeded concrete tensile strength as shown in the below figure:

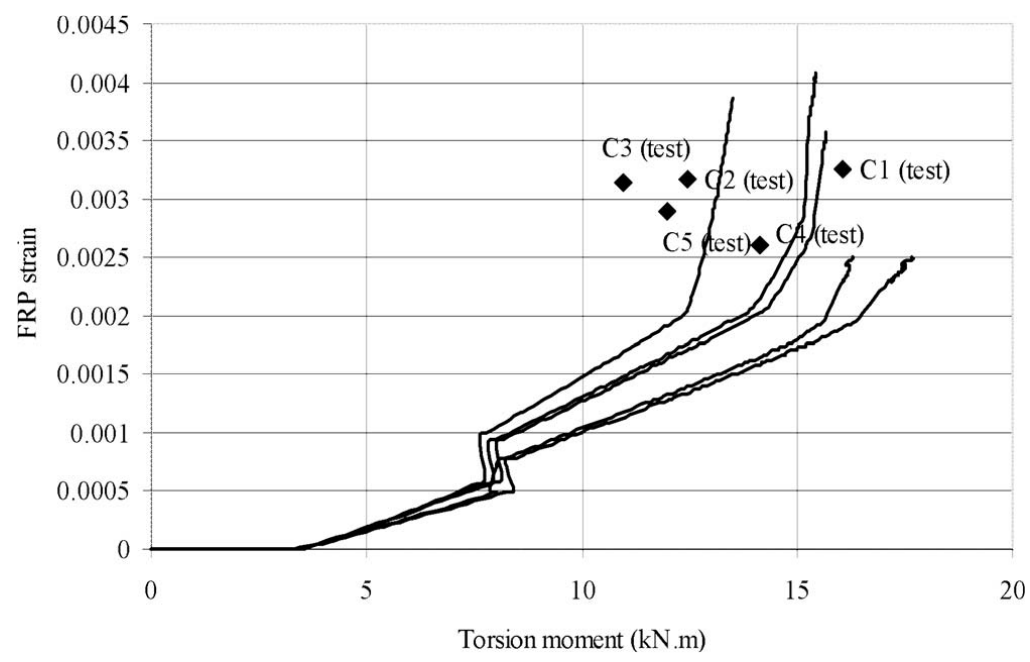

Figure 2-18 Strain Variation against Torsional Moment from Ghobarah et al. (2002) 
All tested beams by Khalaf et al. (2013) showed that strain did not vary until cracks occurred and widened. Strain in the continuous looped sheets was much higher compared to the U-jacket wraps because de-bonding occurred in the U-jacket wrapped beams, while other beams attained more strain until rupture. Strain in the fibers is a very important index in assessing effectiveness of CFRP sheets because it shows utilization of CFRP strength directly. Torque vs. strain of all beams are shown in Figure 2-19.
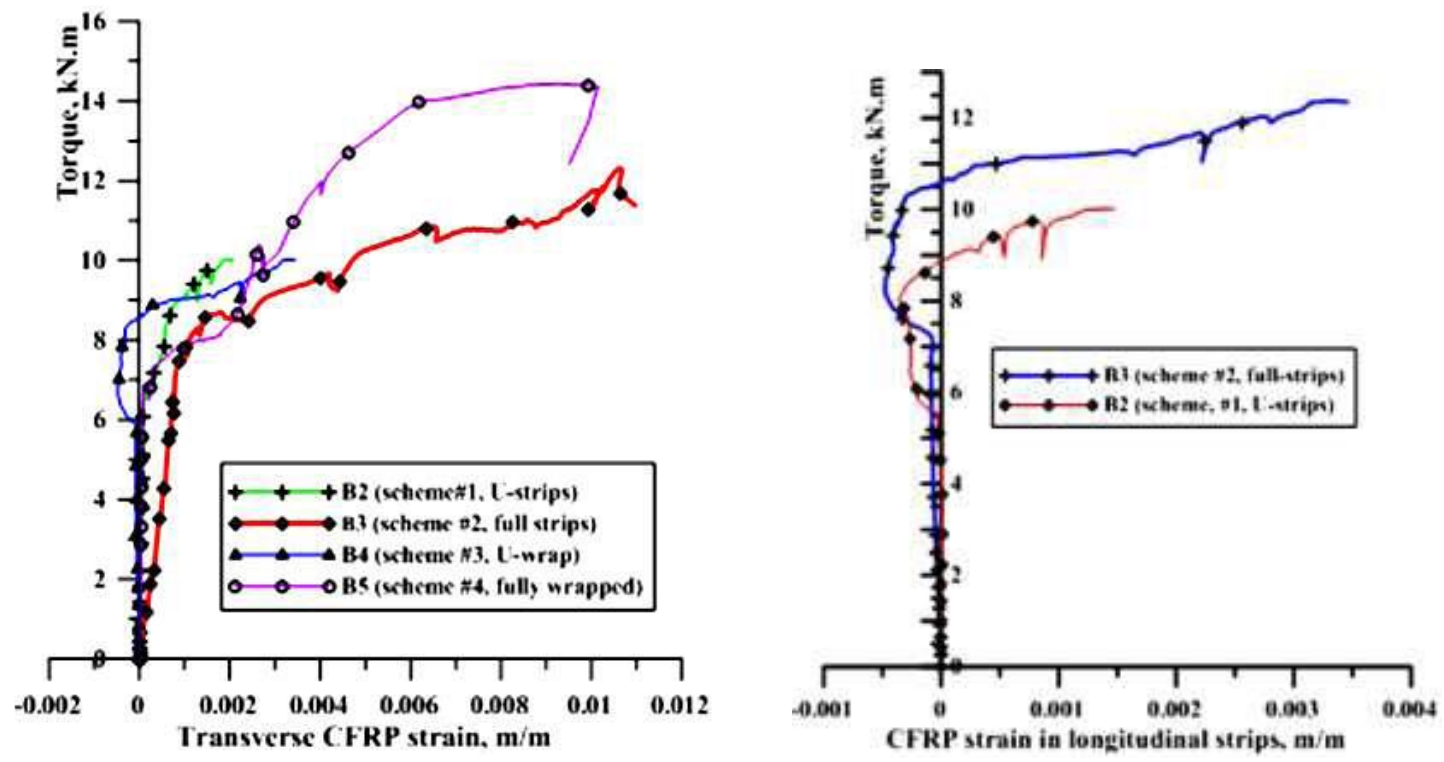

Figure 2-19 Strain Attainment in the Fibers of Test Beams

Carried out by Khalaf and Bayer (2013)

\subsection{Numerical and Computer Modeling}

Santhakumar et al. (2007) adopted Gesund (1964) geometric numbers to expand the same study, the dimensions were 8 '’ $\times 8$ "' square cross-section with 64 inches clear span. 
In this study, the twisting moment was applied through reversed point loads bending moment developed in the test span. Fiber orientations \pm 45 and 0/90 degrees were used. The CFRP material properties were the same as what was previously used by Norris et al. (1997). The thickness, 1mm/layer, was obtained from the Theoretical Moment Resistance by Andre (1995). In this study, concrete was modelled by a three dimensional (3D) structural RC Solid element, Solid65 (a finite element parameter). This element has eight nodes with three translational degrees of freedom at each node which made it capable of cracking in tension zones and crushing in compression zones. This element treated nonlinearity in material properties very well. The reinforcements, on the other hand, were modelled by Link8 (a type of element used in FEA for modelling reinforcing bars), a 3D Spar element with eight nodes for which each node has three translational degrees of freedom. And for the FRP sheets, the Solid46 (a type of element used in FEA) was used to model them. The bond between steel reinforcements and concrete was assumed to be perfect with no bond loss (Kachlakev 2001; Fanning 2001) by connecting the Link8 and the Solid 65 elements at their nodes. Same concept was used for the bonding of CFRP with concrete. The program results closely follow the experimental results reported by Gesund (1964). The results show excellent conformance between the experimental and the analytical works as soon as the cracking stage in concrete started, as shown in the accompanying curve. For retrofitted RC beams, this was very interesting because the FRP effectively contributed to the strength after cracks began to form. Load-deflection curves of different twisting-to-bending moment ratios show that CFRP wrapping did not enhance initial stiffness. Twisting curves proved that in the post-cracking stage there 
existed a progressive gain in stiffness. This is an interesting observation since strengthening is only required after concrete has cracked.

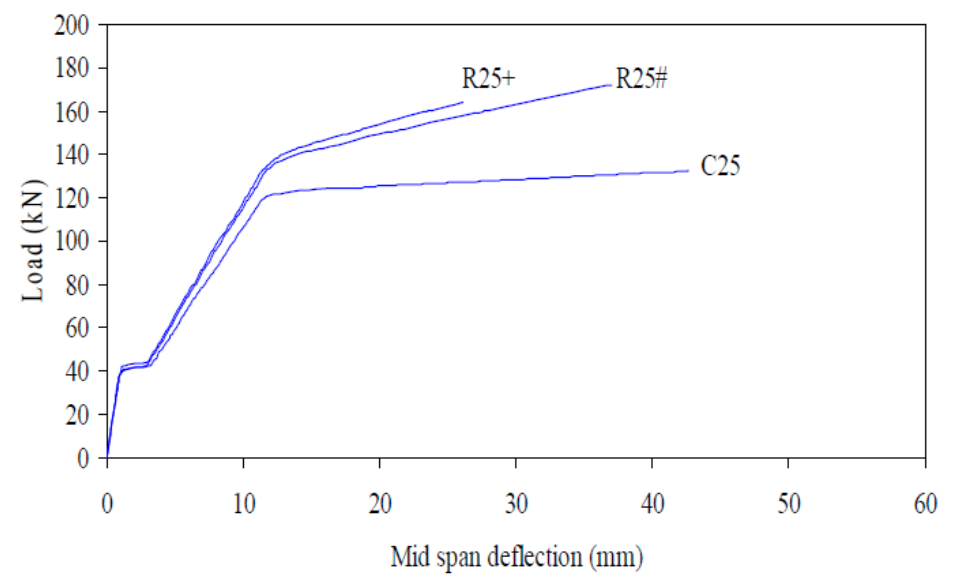

\section{Figure 2-20 Load-Deflection Curves for Various Beams by Santhakumar et al. (2007)}

After running a series of analysis with different twisting angle $(\varnothing)$, CFRP wrapping was seen to be more effective in enhancing the load carrying capacity as $\emptyset$ values get higher. The $0 / 90$ degree configuration of fibers were more effective when $\emptyset$ values were less than 0.43 degrees in the analyses, while \pm 45 dgree configuration was more effective for $\emptyset$ values more than 0.43 degrees approximately. At high $\emptyset$ values, the \pm 45 degree configuration effectively resisted the shear. It was also noted that the flexural strength of the beams became less as $\emptyset$ values tended to increase. A schematic explanation of this trend is shown in figure 2-21. 


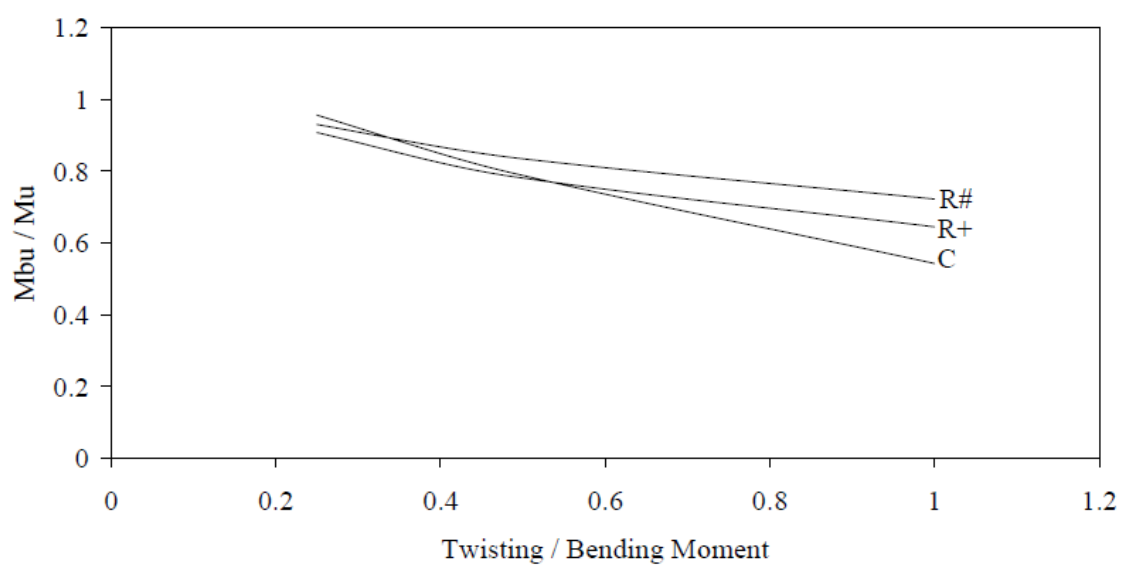

Figure 2-21 Variation of Flexural Strength with Torsion by Santhakumar et al. (2007)

From the data obtained during the analyses, it was observed that fiber orientations a \pm 45 degree orientation of fibers was more effective than 90 degree fibers in combined bending and torsion. This configuration was also more effective for higher values of $\varnothing$ aspects.

In a finite element analysis of RC beams strengthened with CFRP materials, Mostafa Dawood (2013) examined the behavior and performance of solid and box section RC beams. An increase in torsional strength was reported with various ways to enhance torsional strength by using CFRP composites. For this purpose, the researcher used the ANSYS (a finite element program) program to model the beam. In the model, the Solid65 element was used to model the concrete. It had eight nodes each with three translational degrees of freedom. This element was capable of plastic deformation and cracking in three orthogonal directions. The details of elements for each material are tabulated below: 
Table 2-1 FEA Element Descriptions used by Mustafa Dawood (2013)

\begin{tabular}{|c|c|}
\hline Material type & ANSYS element type \\
\hline Concrete & SOLID54 \\
\hline Flexural rebar (steel, CFRP) & LINK8 \\
\hline CFRP strips & SHELL41 \\
\hline Plate loading and supporting & SOLID45 \\
\hline Interface element & CONTACT 52 point to point \\
\hline
\end{tabular}

In the modeling, Dawood modeled steel materials as bilinear elasto-plastic as shown in

Figure 2-22.

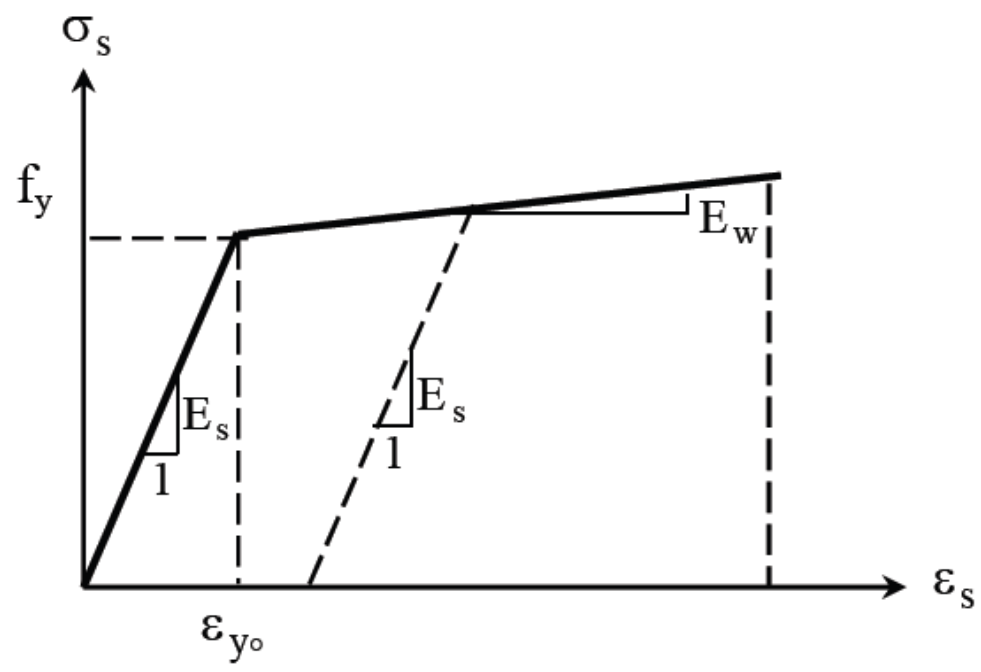

Figure 2-22 Steel Material Modeling used in Mustafa Dawood (2013) Modeling

On the other hand, CFRP materials were modelled as linear-elastic up to failure. Dawood also noted that the CFRP yield strain was approximately ten times higher than that of 
steel. A schematic behavioral curve of steel and the different types of FRP composites in the model is shown below:

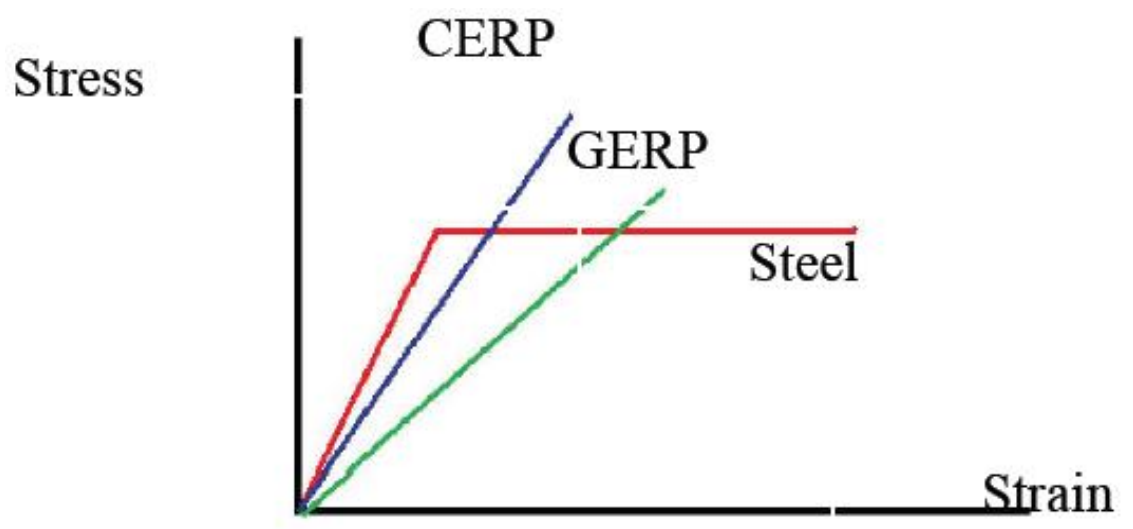

Figure 2-23 Diagrammatic Behavior of FRP Composites in Mustafa Dawood (2013) Modeling

After performing the analysis, the researcher found very good agreement between the analytical and the experimental results. A typical torque vs twist curve is shown in Figure 2-24. 


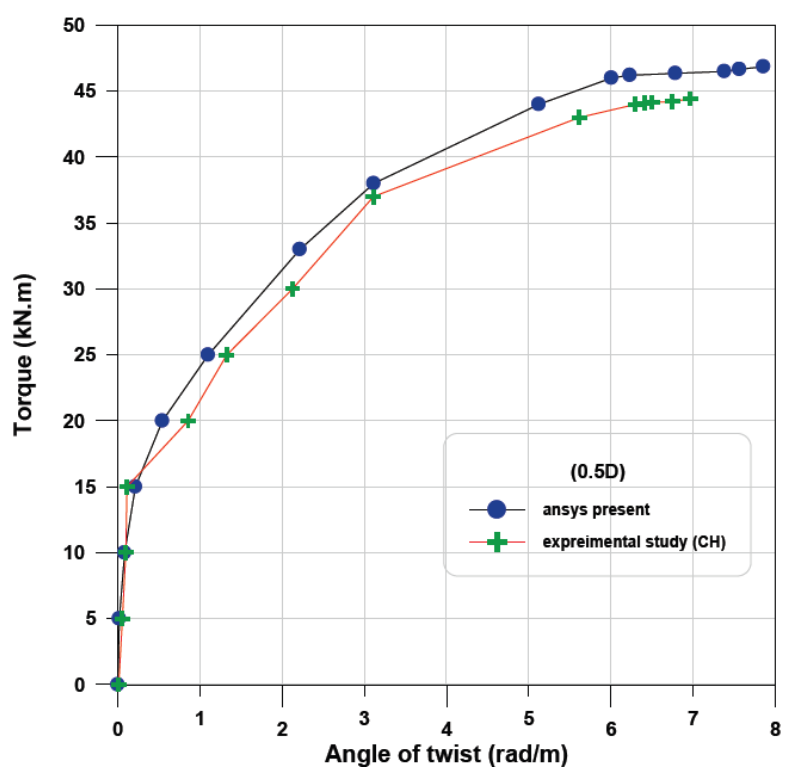

Figure 2-24 A Typical Torque vs Twist Curve for a Strengthened Beam from Mustafa Dawood (2013)

In the study, spacing between CFRP strips played a vital role. Changing the spacing in the parametric study from $0.75 \mathrm{D}$ to $0.25 \mathrm{D}$ gave $19 \%$, as an average, additional torsional strength for the same amount of CFRP ratio. A schematic curve showing this trend from the program is as follows: 


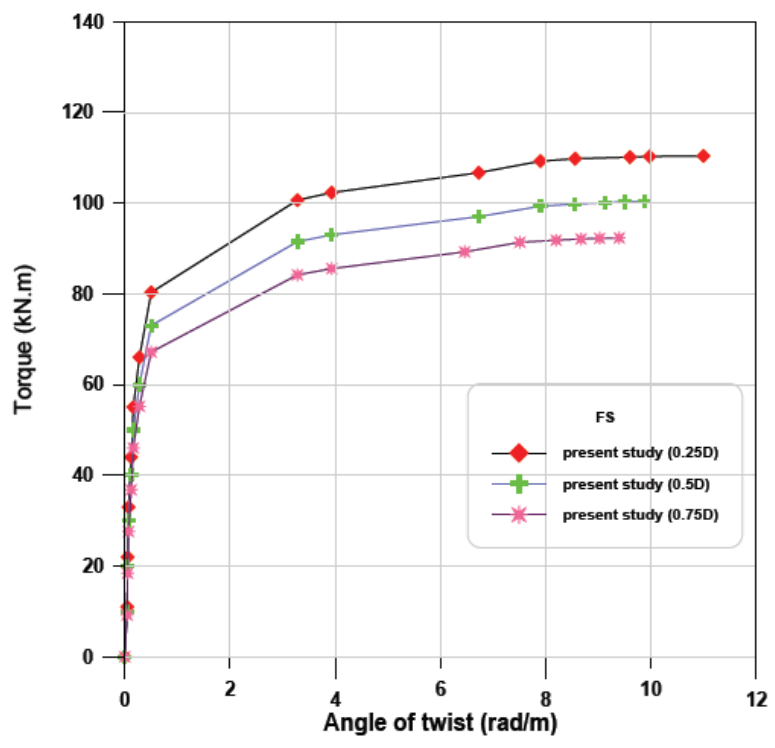

Figure 2-25 Spacing Effects on Strength in the Modeling from Mustafa Dawood (2013)

The results showed that CFRP strengthening did increase torsional capacity of solid and box beam cross-sections effectively by $49.12 \%$ and $77.6 \%$ respectively, and the program followed the experimental results closely.

\subsection{Analytical Modeling and Design Expressions}

Pedro Salom et al. (2004) assumed that the CFRP sheets behaved similarly to the transverse steel reinforcements. Having said that, they modified the ACI torsion equation for CFRP as follows:

$$
T_{f}=\frac{2 A_{\circ} A_{f} f_{f e}}{s}(\cos \propto+\sin \propto)
$$

The above formula can then be combined with the ACI 440.2R-08 formula for shear strength. After analyzing the beams using the aforementioned formulas, the experimental and analytical results closely followed each other. Over all, the CFRP composites could 
increase torsional capacity even at very low CFRP strain levels, and the addition of steel anchors (shown in figure 2-26) caused about a $25 \%$ increase in capacity.

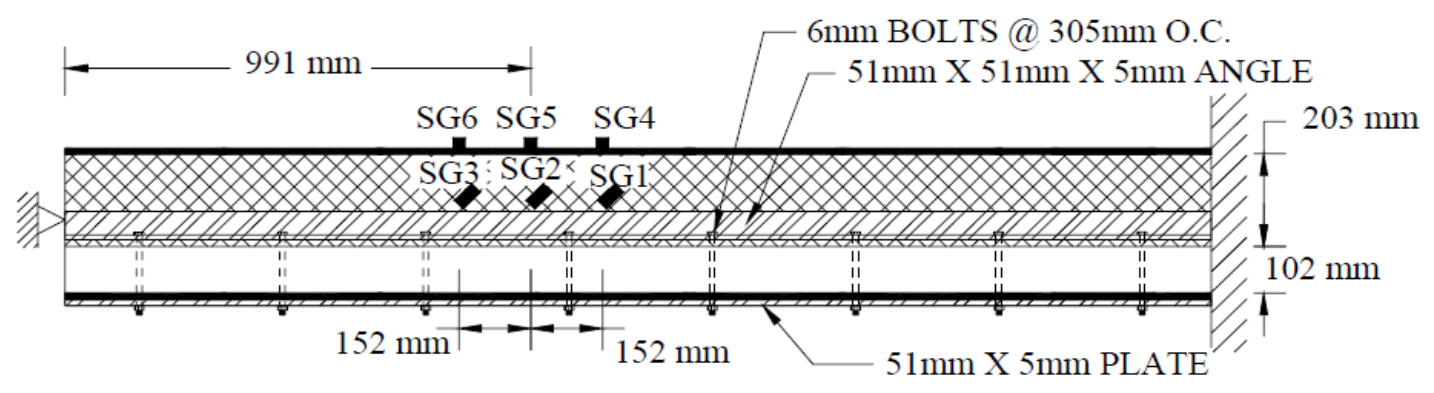

Figure 2-26 Steel Anchor Bolts from Pedro Salom et al. (2004) Testing

There are a very limited number of analytical methods. The main methods are:

\section{- FIB 14 Bulletin}

Ultimate torque capacity is based on fiber orientation and mode of failure. If FRP ruptures and fibers are at $90^{\circ}$ with respect to the beam longitudinal axis, CFRP contribution to ultimate strength is based on effective strain in fibers. Effective strain is proposed by an empirical formula.

Is rupture does not occur, calculations are based on effective bond length for ultimate strength.

For complete wraps:

$$
T_{n(f r p)}=2 \epsilon_{k e, f} E_{f u} \frac{t_{f} b_{f}}{s_{f}} A_{c}[\cot \alpha+\cot \beta] \sin \beta
$$

For U-wraps with anchors: 


$$
\begin{aligned}
& T_{n(f r p)}=\epsilon_{k e, f} E_{f u} \frac{t_{f} b_{f}}{s_{f}} A_{c}[\cot \alpha+\cot \beta] \sin \beta \\
& \epsilon_{k e}=k . \epsilon_{f e}<\epsilon_{\max }=5000 \mu
\end{aligned}
$$

- Hii's Method

Hii et al. (2007) proposed on expression based on an equivalent hollow tube for the solid section.

$$
T_{n(f r p)}=2 \in_{k e, f} E_{f u} \frac{t_{f} b_{f}}{s_{f}}\left[0.85 A_{0 h}\right][\cot \alpha+\cot \beta] \sin \beta
$$

- Combination of FIB-14 method and experimental FRP strain

This method used experimental FRP strain along with FIB'S approach.

$$
\epsilon_{f(c a l c)}=\frac{T_{f(\exp }}{2 E_{f u} \frac{t_{f} b_{f}}{s_{f}} A_{c}[\cot \alpha+\cot \beta] \sin \beta}
$$

Where $T_{f(\exp )}=T_{(\exp )-} T_{(\text {ref })}$

The current test results are verified with all the above three approaches. All analyses are based on $45^{\circ}$ concrete crack angle. FIB-14 generally seems unconservative. Hii's method looks more conservative than the third method. The analyzed results performed by 
Mohammadizadeh are tabulated in this survey in table 2-2. The testing description was shown in section 2.2.

Table 2-2 Comparison Between Experimental and Various Analytical Methods' Results

\begin{tabular}{|c|c|c|c|c|c|c|}
\cline { 2 - 7 } \multicolumn{1}{c|}{} & $T_{f, \exp } / T_{n, f r p}$ & $T_{f, \exp } / T_{n, f r p}$ & $T_{f, \exp } / T_{n, f r p}$ & $T_{\exp } / T_{n}$ & $T_{\exp } / T_{n}$ & $T_{\exp } / T_{n}$ \\
\hline Specimen & FIB-14 & $\begin{array}{c}\text { Hii's } \\
\text { Method }\end{array}$ & $\begin{array}{c}\text { FIB-14 } \\
\varepsilon_{f, \text { ave } \exp }(\mu \varepsilon)\end{array}$ & FIB-14 & $\begin{array}{c}\text { Hii's } \\
\text { Method }\end{array}$ & $\begin{array}{c}\text { FIB-14 } \\
\varepsilon_{f, \text { ave,exp }}(\mu \varepsilon)\end{array}$ \\
\hline CS1 & 0.20 & 0.47 & 0.38 & 0.95 & 1.12 & 1.00 \\
\hline CUJ-anc. & 0.50 & 1.16 & 1.00 & 0.80 & 1.19 & 1.13 \\
\hline CW1 & 0.49 & 1.12 & 0.91 & 0.79 & 1.18 & 1.08 \\
\hline CW2 & 0.39 & 0.90 & 1.04 & 0.60 & 1.04 & 1.13 \\
\hline
\end{tabular}

Concrete torsional strength was obtained using the ACI code equations and superposition is used to combine the CFRP and concrete strengths for the total strength. Experimental results, as seen in the table above, match fairly well the analytical models for full and strip wrapped beams, but not necessarily for the U-wrapped beam. FIB used an experimental shear strengthening strain in this method. More statistical data for torsional strengthening are needed to refine his method.

Saravan et al. (2002) idealized the increase in cracking torque as a concrete beam subjected to a prestress force. The strain in GFRP was proportioned to tensile stresses at the surfaces of the beam. Mohr's circle of strain was used to find the FRP strain

$$
\begin{gathered}
\text { Effective prestress }=\frac{\epsilon_{f} E_{f}}{2} \\
T_{c r}=c_{1} b^{2} h f_{t} \sqrt{1+\frac{\text { Effective prestress }}{f_{f}}}
\end{gathered}
$$


Where:

$\mathrm{c}_{1}=$ St. Venant's constant

Ultimate torque strength was dependent on mode of failure and fiber orientation. When failure was dominated by a FRP rupture and fibers are $90^{\circ}$, an effective FRP strain was used to determine the FRP contribution to ultimate strength. This effective strain was proposed by FIB with an empirical equation. If rupture didn't govern the test failure, the ultimate strength was based on an effective bond length. Where fibers were oriented in $0^{\circ}$, no increase in ultimate strength was expected, thus, the cracking torque could be counted as the ultimate torque.

$\checkmark$ FIB equations for full and U wraps are provided in earlier sections!

Torsional strength of a RC section based on ACI is:

$$
T_{n(R C)}=\frac{2 A_{0} A_{t} f_{y t}}{s} \cot \propto
$$

Superposing both equations give the total strength

$$
\mathrm{T}_{\mathrm{n}}=\mathrm{T}_{\mathrm{n}(\mathrm{RC})}+\mathrm{T}_{\mathrm{n}(\mathrm{FRP})}
$$

The following figure shows FRP contributions of different wrapping schemes 


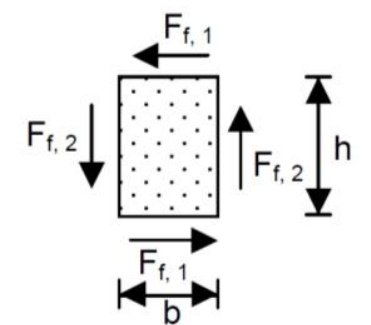

a) Complete wrap and strips

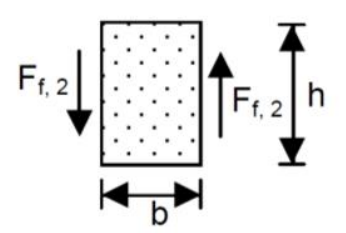

b) U-wrap with anchors

\section{Figure 2-27 Force Mechanism in FRP Sheets}

from Saravanan et al. (2002)

One test that had GFRP fibers aligned both in 0 and $90^{\circ}$ orientations showed substantial increase in both cracking and ultimate strength. The foregoing expressions estimate theoretical strength of the beams very closely.

Stijn Matthys et al (2001) noted that in a practical sense $90^{\circ}$ fibers in strip configuration was the most practical and economical case because it provided moisture exchange in concrete. Fibers of $45^{\circ}$ orientation were more efficient as the fibers were more or less aligned along the direction of the principal stresses, which gave more anchorage length. Modules of elasticity of fibers was dependent on the fiber directions. This was indicative of how shear strengthening, and also torsion, was influenced by fiber directions. The following figure shows this fact. 


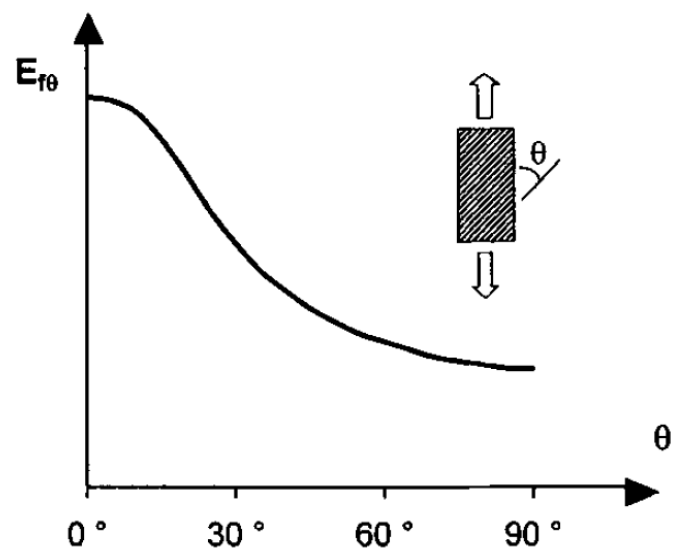

Figure 2-28 Effect of Fiber Orientation on the Modules of Elasticity, E from Stijn Matthys et al (2001)

FRP sheets were either fully wrapped or anchored to avoid bond failure in compression zone. More complex cross sections needed a harder amount of anchorage works to be done properly to prevent bond and anchorage failure. The effectiveness of FRP strengthening depended on effective strain in fibers, and it had been reported that this was always lower than the ultimate FRP strain (Taljisten 1997; Triantafillou 1998; Matthys 2000). All principles of shear strengthening could be applied to torsion strengthening with slight modifications. Shear and torsion cracks were diagonal and inclined; therefore, fibers placed with angle $\propto$ with respect to the beam axis could be very effective in resisting diagonal stresses on one side and ineffective on the other side. Only full wrapping FRP externally bonded reinforcements were efficient in torsional strengthening because tensile forces at each side of the beam formed a continuous loop (Matthys, 2001). Taljsten (1998) proved that FRP can be very effective in torsional strengthening through experimental works. Torsional strengthening investigations are somewhat 
controversial. Researchers have mostly assumed FRP contribution is more like internal shear reinforcements and subsequently they use the principle of superposition to sum up individual strengths (Matthys 2000; FIB 2001). Based on truss analogy:

$$
\begin{array}{ll}
V_{w s}=\frac{A_{w s}}{S_{s}} 0.9 d f_{w y}\left(\cot \theta+\cot \alpha_{s}\right) \sin \alpha_{s} & \text { For steel } \\
V_{w f}=\frac{A_{w f}}{S_{f}} 0.9 E_{f} \in_{f . e f f}\left(\cot \theta+\cot \alpha_{f}\right) \sin \alpha_{f} & \text { For FRP }
\end{array}
$$

Where $\propto_{s}$ and $\propto_{f}$ were the angles of stirrups and fibers with respect to the beam axis respectively. The controversy comes from some researchers arguing that superposition is not applicable since contribution of concrete to shear capacity can change when FRP sheets are used, while others argued that FRP effective strain must be limited so as to prevent reduction of concrete contribution to the ultimate shear strength. A deterministic approach proposed by Triantafillou $(1997 ; 1998)$ predicts $\epsilon_{e f f}$ based on curve fitting analysis of a large experimental database. Triantafillou $(1997,1998)$ argues that $\in_{e f f}$ depends on both available FRP development length and axial rigidity of fibers. Assuming that FRP contribution is the difference between strengthened and un-strengthened beams, cracks are inclined at $45^{\circ}$, the preveous equation is used to find $\epsilon_{e f f}$ in the approach. This model, figure 2-29, was later upgraded by Triantafillou and Antonopoulos (2000) as shown in figure 2-30. These results are based on 70 tests. Based on the same database, Matthys (2000) suggested a relationship based on

$$
\Gamma_{f}=\frac{\epsilon_{f} \rho_{w f}}{f_{c m}{ }^{\frac{2}{3}}\left(\frac{a}{d}\right)}
$$


Where $\mathrm{a} / \mathrm{d}$ is the shear span-to-depth ratio. His approach is shown in Figure 2-31.

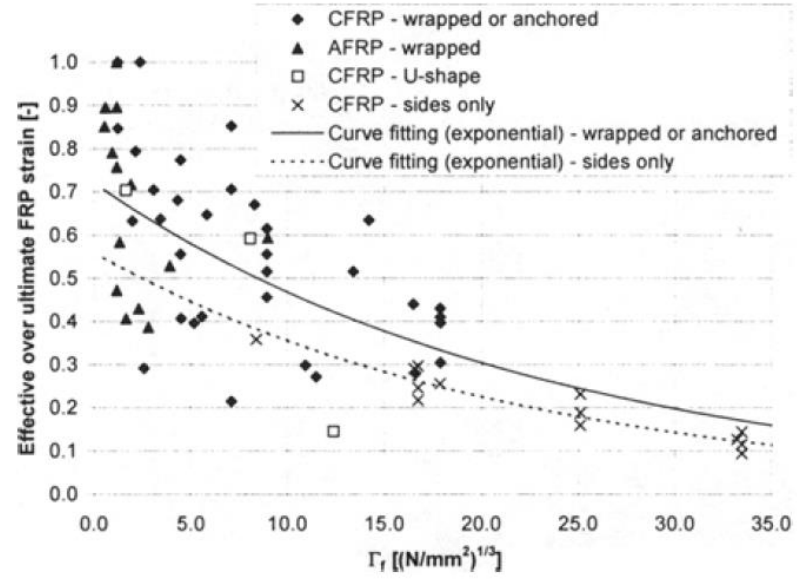

Figure 2-29 Variation of Effective Fiber Strain Model by Triantafillou $(1997,1998)$

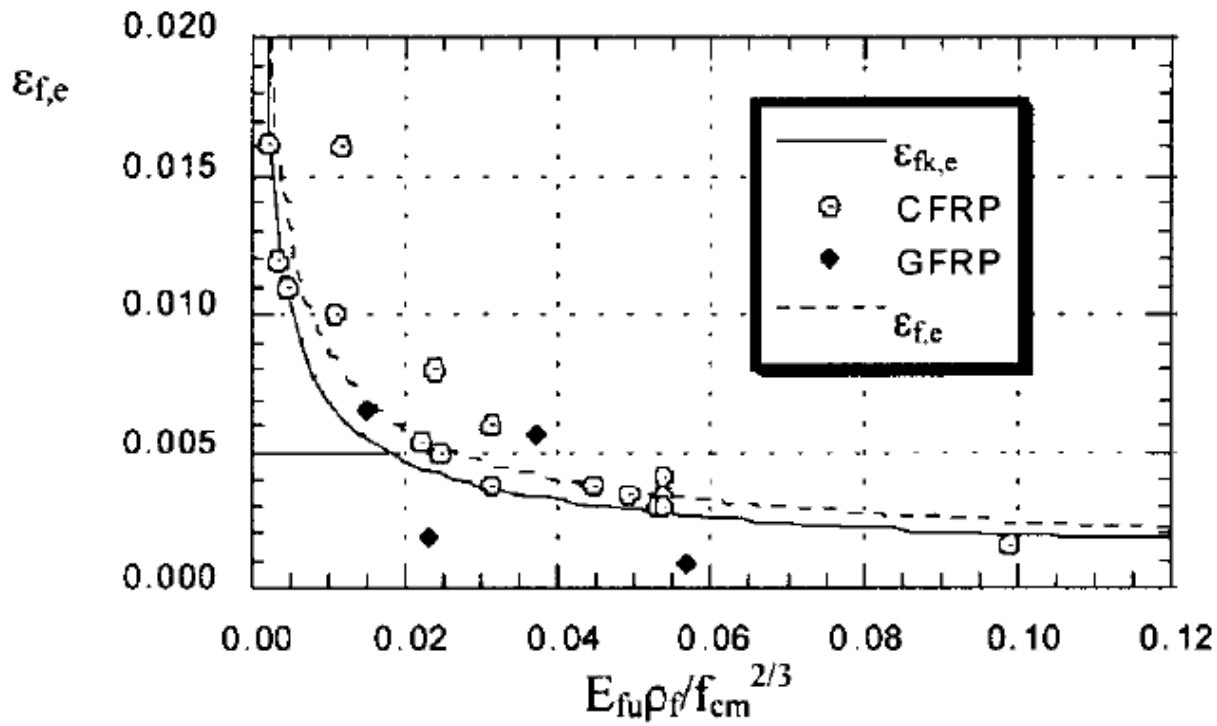

Figure 2-30 Effective FRP Strain by Triantafillou and Antonopolous (2000) 


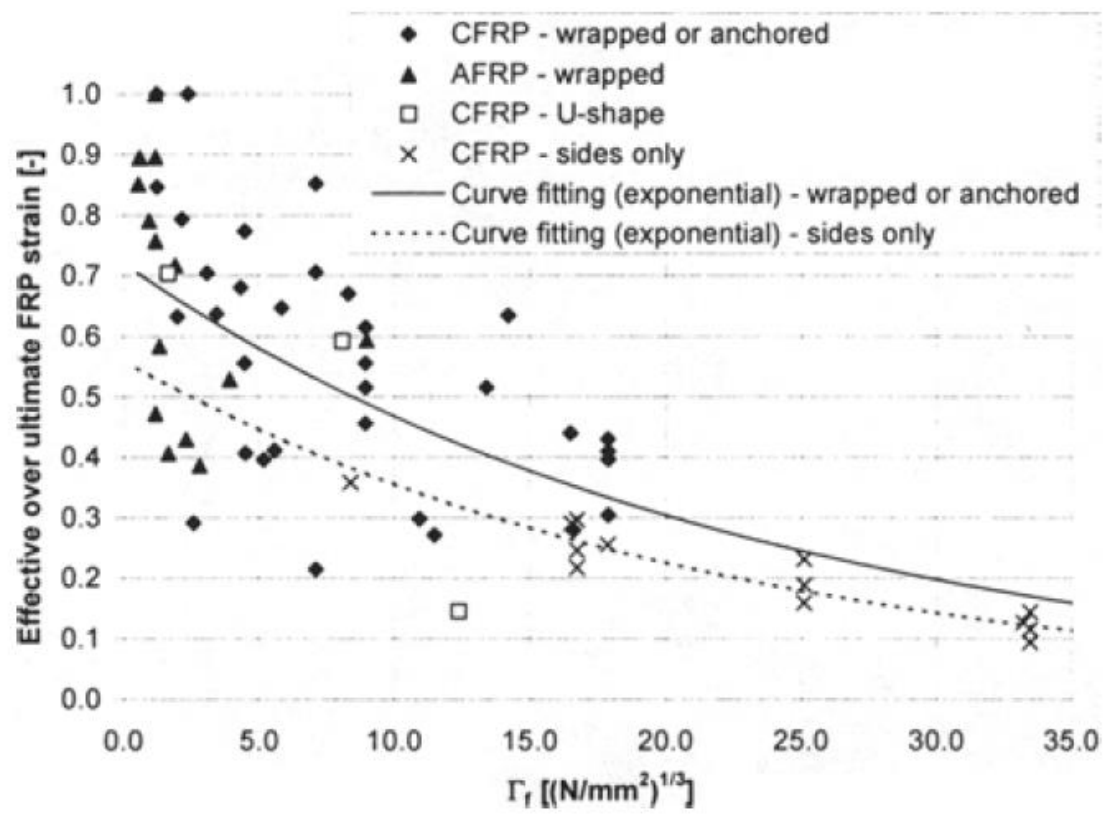

Figure 2-31 FRP Strain Model by Matthys (2000)

The large scatter of data points in all of the curves indicates that more experimental data are required for a solid understanding of $\epsilon_{e f f}$. with all of these uncertainties in mind, the big factors of safety are used for shear and torsion strengthening (FIB, 2001). A more comprehensive model is proposed by FIB task Group 9.3 (2001) for design, and it provides fairly accurate strain predictions.

Space truss analogy has been used and refined to include rotation calculations, angle of diagonal cracks, and maximum diagonal strain in concrete (Collins and Mitchell, 1997). Very limited works have been devoted to CFRP contribution to torsional strength of a RC section (Ameli and Ronagh 2007; Hii and Al-Mahaidi 2007; Rahal and Collins 1995). In torsional calculations, unconfined concrete is negligible in strength, thus, a concrete cover doesn't have any contribution since it is not confined by stirrups. This face was reported by tests by Arbesman (1975), Ghoabrah et al. (2002), and Deifalla (2007). 
Of the few previous analytical models for predicting torsional strength of a $\mathrm{RC}$ section, none of them fully addressed the strength of a section strengthened with FRP composites, or considered the fact that the FRP was not bonded to all beam faces, nor considered the ultimate strain that developed. Ghobarah and Deifalla (2010) proposed a full behavior model based on the basics of modified compression field theory (MCFT), hollow tube analogy, and compatibility at section corners. Parameters such as strengthening schemes, FRP contribution, and modes of failure were taken into account. A series of tests made by Ghobarah et al. (2002), included eleven RC beams that used both CFRP and GFRP, to validate the model. The basics of this theory was from MCFT by Vecchio and Collins (1982), hollow tube analogy by Mitchell and Collins (1974), and compatibility at corners of cross section by Osongo (1978). The hollow tube was divided into elements each with the same shear flow, but had different thicknesses and maybe different FRP properties. In the model, Mohr's circle of strain and stress were used. Constative models of concrete, steel, and FRP were also made to more accurately model the whole behavior. There were a lot of assumptions on which the model is based: see references. The model idealization is as follows:

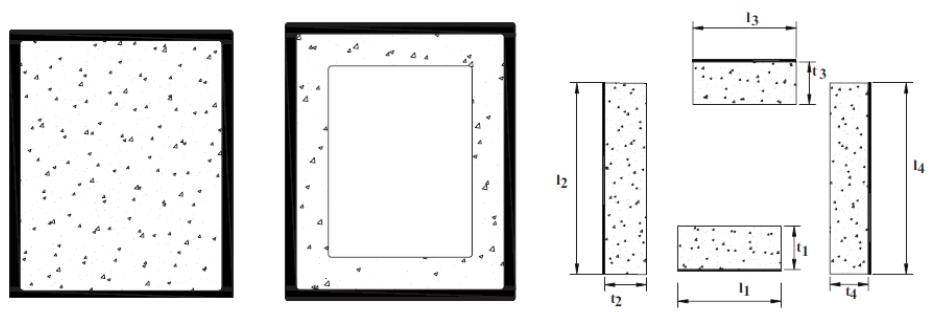

Figure 2-32 Element Discretization for Ghobrah et al. (2010) Modeling 
Ghobrah et al. (2002) showed that concrete spalling was prevented by FRP composites where it happened between strips. FRP composites bonded to surfaces of concrete and captured tension cracks. That decreased the concrete softening and increased confinement, which enhanced the ultimate load bearing capacity. These composites also provided additional torsion reinforcement to the concrete, which increased the ability to resist diagonal tensile stresses. After a rigorous mathematical modeling considering various parameters, material modeling started, which was considered a very important part in the modeling. Since standard compression test of concrete did not capture the concrete softening or confinement, a concrete model from Belarbi and Hsu (1995) was adopted in the modeling to consider FRP confinement, as shown below:

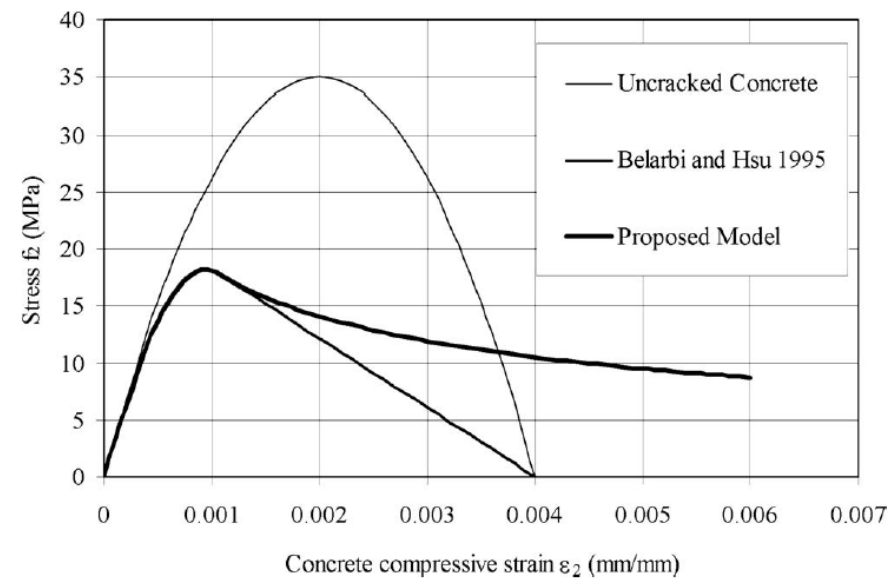

Figure 2-33 Concrete Models Proposed by Belarbi \& Hsu (1995) used in Ghobarah et al. (2010) modeling

Experimental studies have demonstrated that FRP substantially enhances concrete strain without increasing strength (Ilki et al., 2004; Sauce et al., 2004). In the modeling, steel was assumed to be elastic-perfectly plastic, and FRP was assumed to be elastic until 
failure, as reported by Deifalla (2007). A set of equations was codified using a programming language, and the results were compared with a series of tests by conducted by Zheng et al. (2001), Ghobarah et al. (2002), and Panchacharam and Belarbi (2002). For full wrapping, the model had a very good agreement with a 5\% error at the ultimate strength, as shown below.

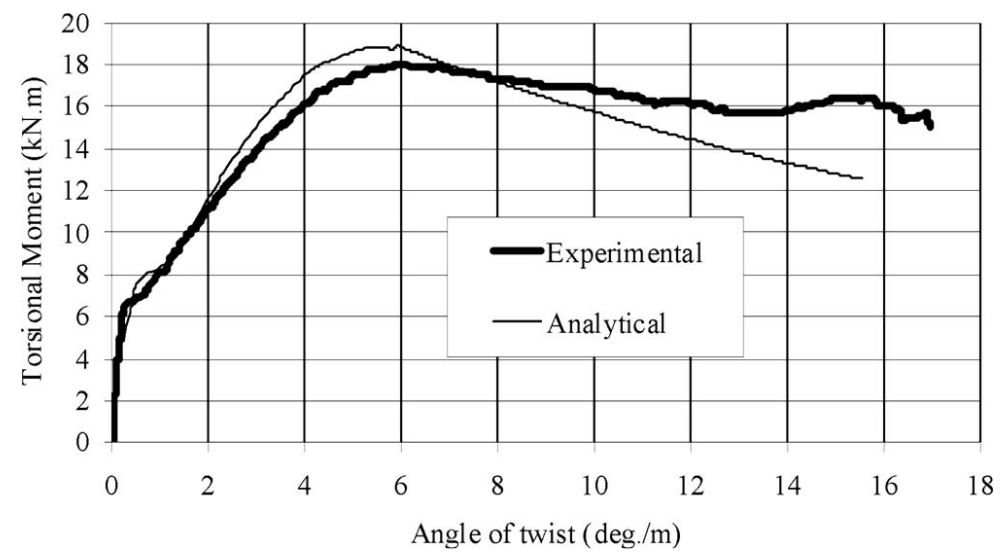

Figure 2-34 A Typical Program Torque-Twist Curve from Ghobarah et al. (2010) Compared to Experimental Data

As CFRP spacing of strips became wider, the modeling results encountered larger errors of up to $25 \%$. The reason was because the model assumed full wrapping by reducing FRP cross sectional area to account for spacing, whereas it ignored the fact the concrete spalling happened between strips. Experimental investigation by Ghobarah et al. (2002) proved this fact. This model predicted the full behavior until failure in torsion. The model was displacement based, and was more accurate than FIB's model. Minimum and maximum errors ranged from $1 \%$ to $25 \%$. The model also predicted mode of failure and FRP strain fairly accurately. However, there was no closed-form solution. 


\section{Chapter 3 Experimental Program}

\subsection{Test Setup}

\subsubsection{Beam Designations}

The tests comprise of two main sets:

I. Set A (series of three beams, prototype designed for $\mathrm{LL}=125 \mathrm{psf}$ )

II. Set B (series of three beams, prototype designed for $\mathrm{LL}=250 \mathrm{psf}$ )

Each prototype was analyzed and designed and details are included in the Appendix. The prototype beams were assumed as rectangular beams to facilitate testing, and then scaled down to a fourth according to the conversion table (see appendix).

Each set of tests (series A and B) consists of three tests for:

I. Shear and bending only of control beams A-1, B-1.

II. Shear and bending and torsion of control beams A-2, B-2.

III. Shear and bending and torsion of strengthened beams A-3, B-3.

Details of beam models for Set A and Set B: 


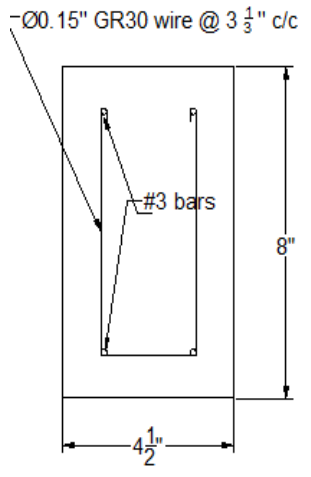

Beam A-1
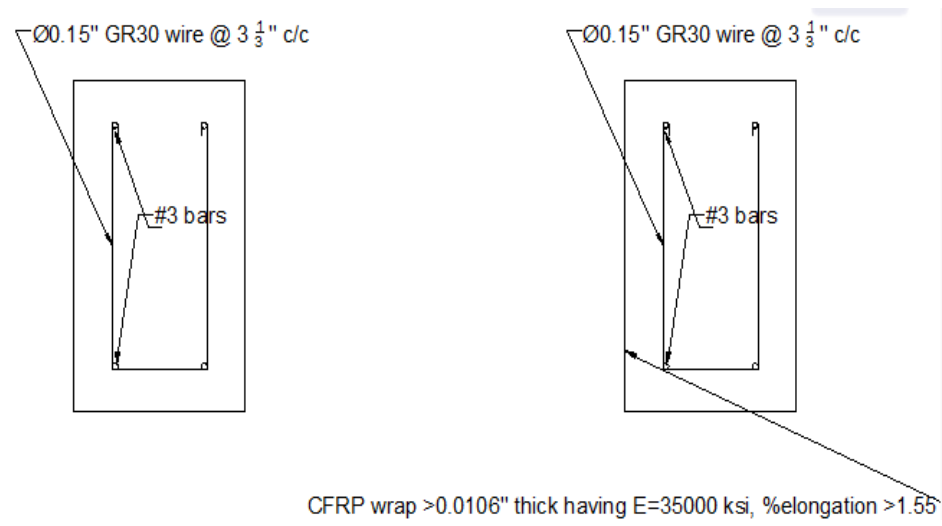

Beam A-2
Beam A-3

Figure 3-1 Beam Model Details for Test Set A

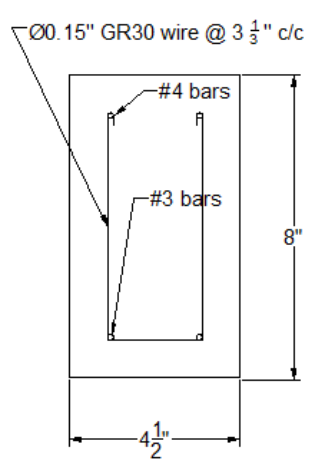

Beam B-1
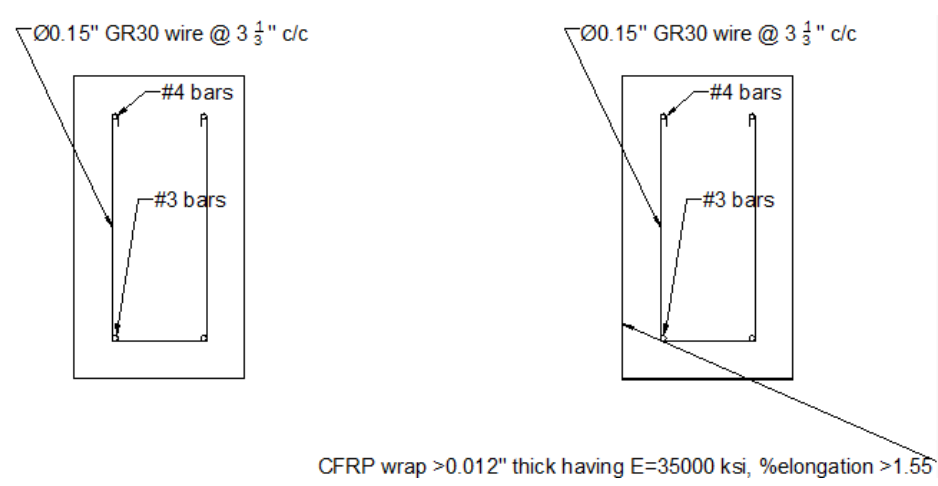

Beam B-2

Beam B-3

Figure 3-2 Beam Model Details for Test Set B 
The overall length of each beam was 9' -2', 7' was the clear span, and 13' 'was the sleeve length of supports for clamping. The side cover of concrete was 3/4', and top and bottom concrete cover was $1 / 2$, .

One and one half inch of lumber was used as formwork with the interior surfaces greased with shrinkage resistant oil to ease removal and prevent shrinkage as shown in Figure 33.

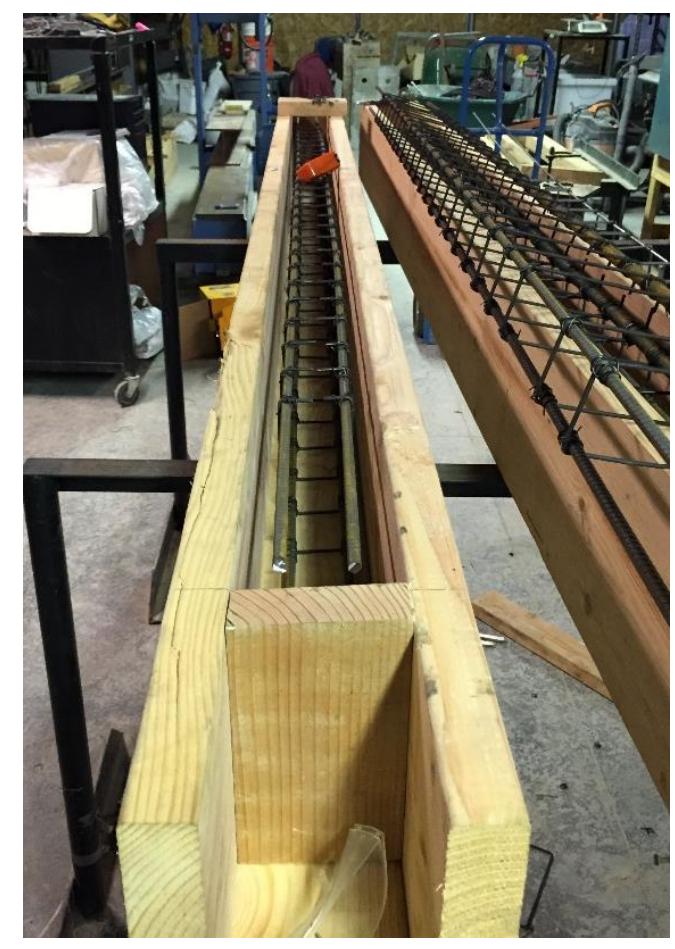

Figure 3-3 Formwork for the Beams

The length of longitudinal reinforcements in all beams was 104', (8'8'). Thirty-one grade 30 steel wire transverse reinforcements (as described later in this chapter) were spaced on 3.3', on centers, and were extended into the supports as shown in Figure 3-4. 


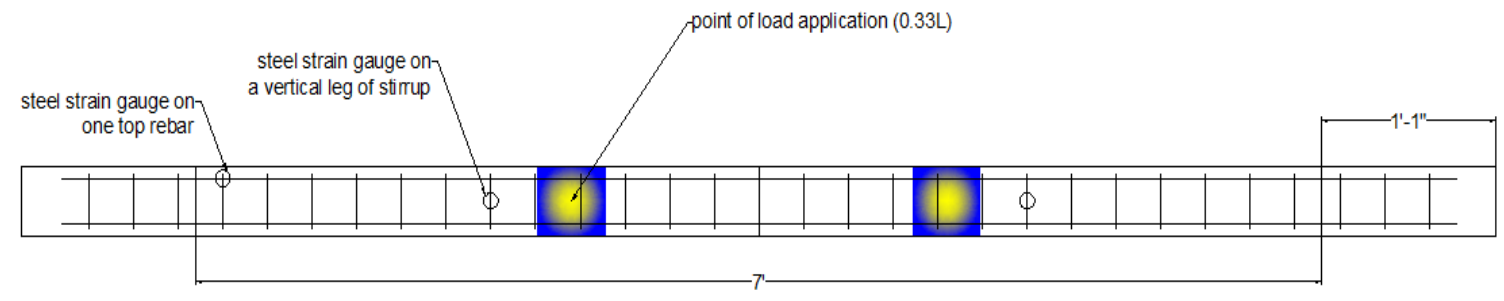

Figure 3-4 Longitudinal and Transverse Reinforcement Layouts

\subsubsection{Main Testing Frame}

The main testing frame consisted of a 50-kip capacity hydraulic actuator mounted on top of the test frame. The eccentricity was provided by secondary $\mathrm{W} 5 \times 16$ steel beams from the center of the machine load to the main eccentric cantilever beams. Figures 3-5, 6, and 7 show the main testing frame and the torsional loading set up in the system.

The testing frame was braced with a square tube to provide lateral support against tipping during torsional load application. The bracing element was anchored to floor through four $5 / 8$ ' bolts into the floor. 


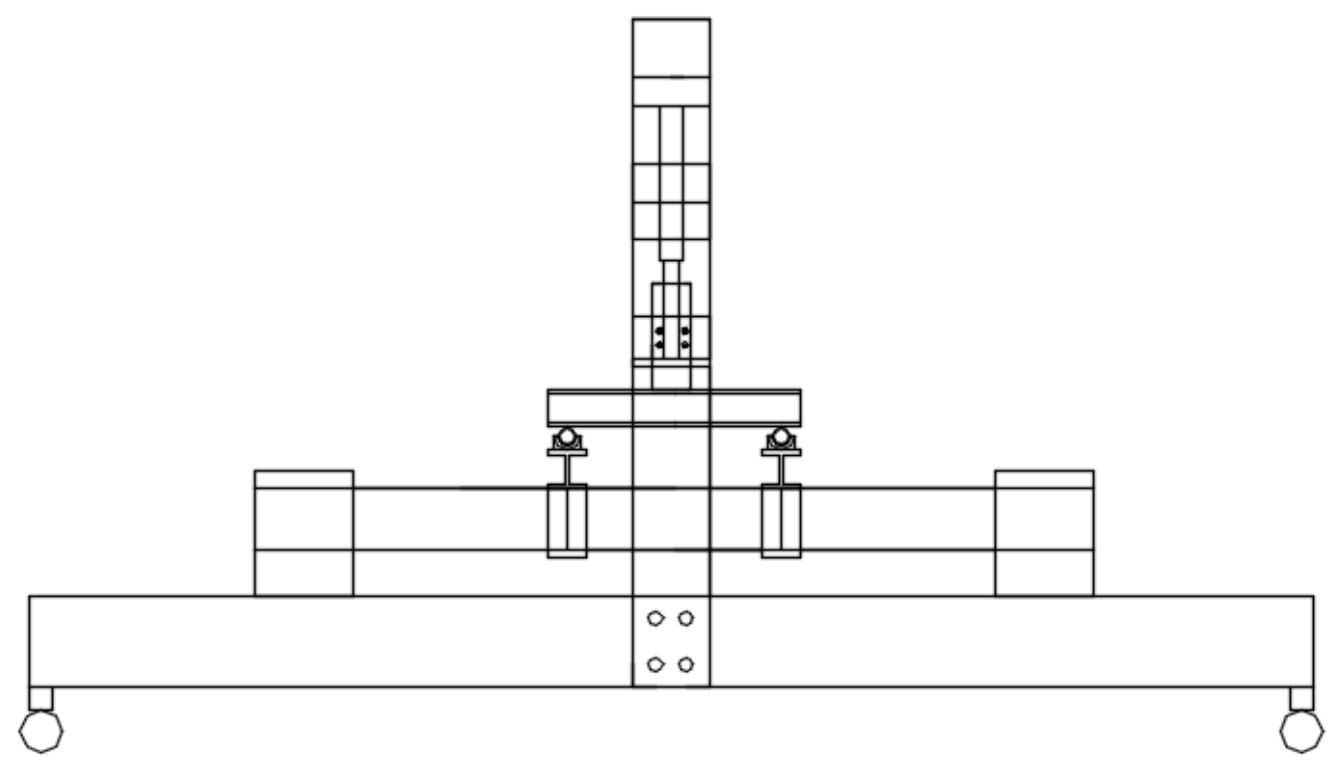

Figure 3-5 Front View of the Main Loading Frame

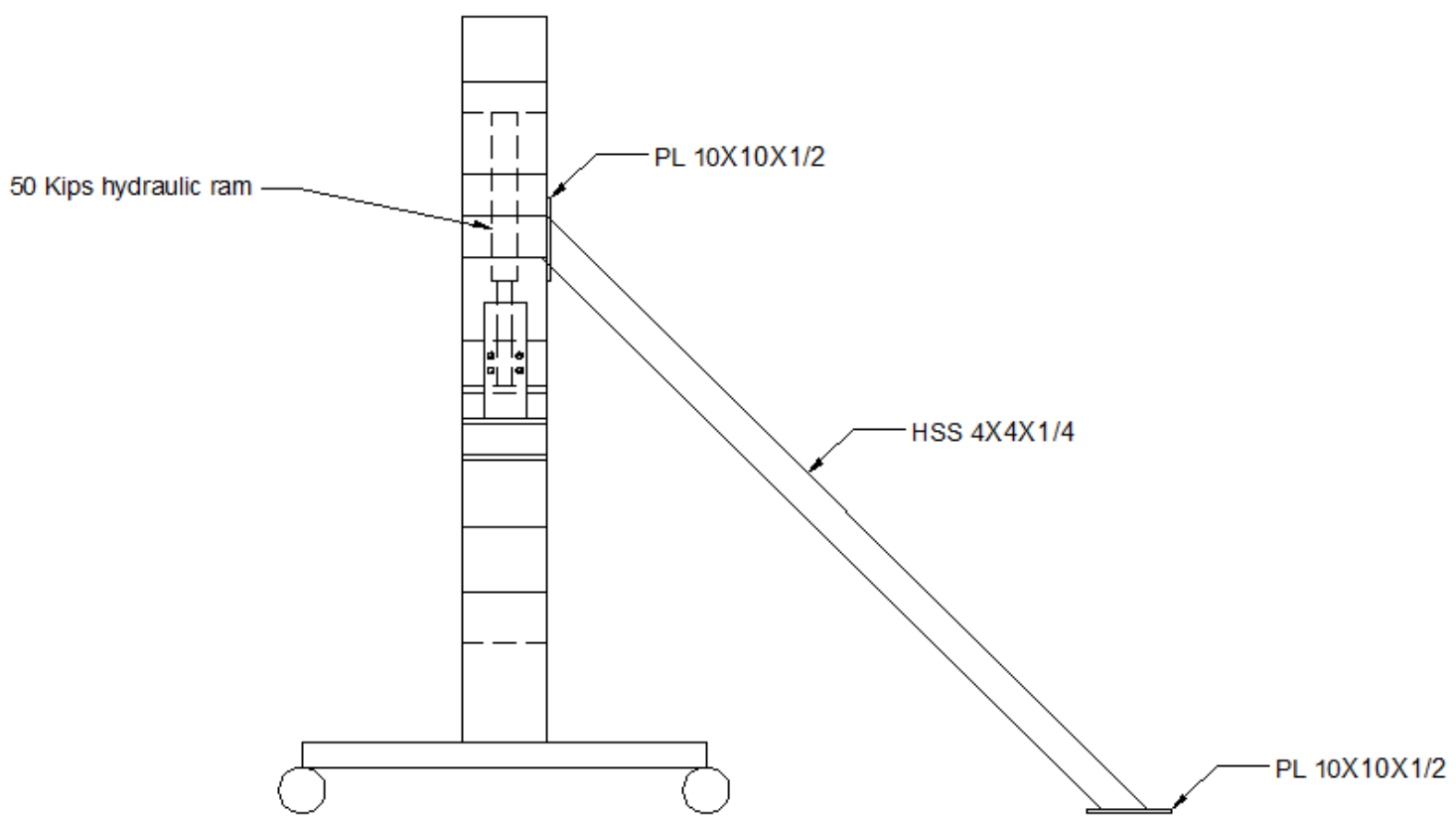

Figure 3-6 Side View of the Main Loading Frame 


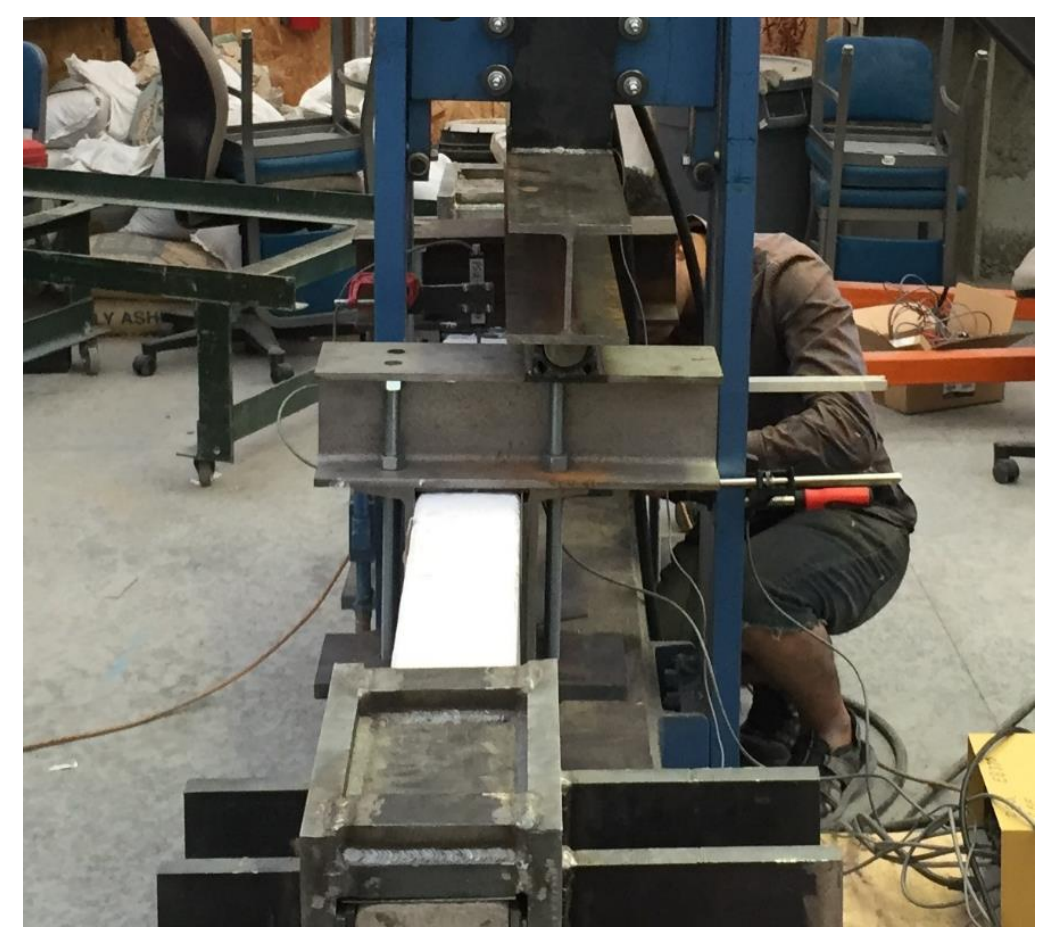

Figure 3-7 Eccentric Beams providing Torsion

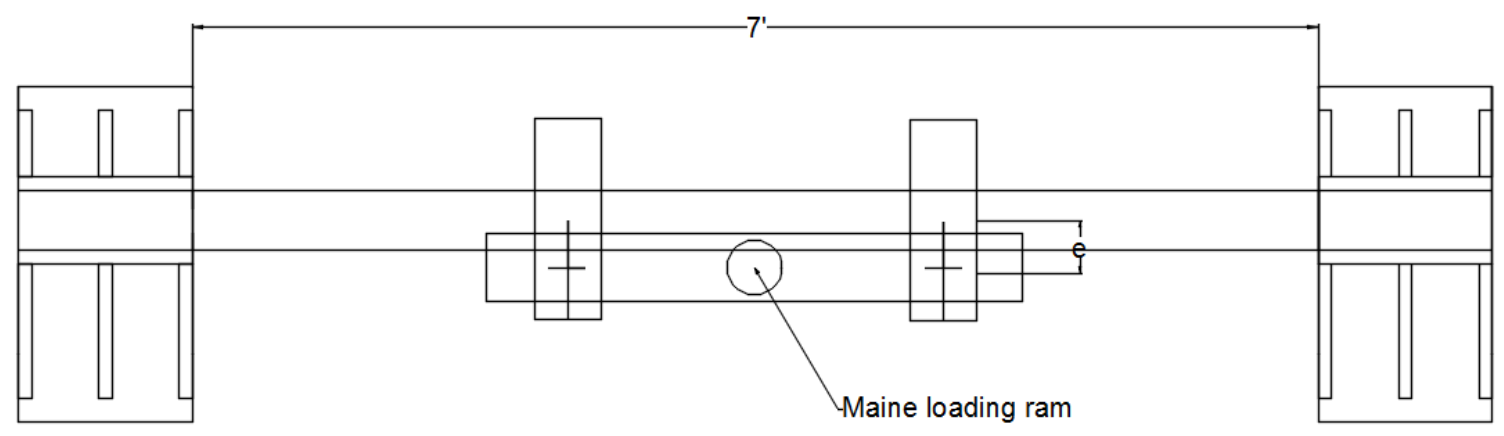

Figure 3-8 Plan View of the Test Set-up 


\subsubsection{Supports}

Since the beams were modeled as spandrel beams continuous at both ends, there were negative moments at the ends. Simulating this support in a laboratory can be through some configurations to consider partial fixity. However in this testing program the supports were intended to be fixed at the ends to facilitate calculations of bending moments, and to provide sufficient lateral stability for torsion. The supports herein were made of a structural steel of grade 50 with 1" thick plates assembled to ensure adequate rigidity against induced bending, shear, and torsional loads. At each end, the supports were clamped to the base beam of the frame through $4-3 / 4 " \varnothing \varnothing$ all-thread bars firmly, and they could be removed once the test was done. Different elements of the supports were welded together using welded grooves of 1/4" thickness of E70XX weld material. Five inch spaced stiffeners were attached to each side of a support to prevent the lateral displacement of supports due to torsional moments that might cause premature failure in the supports. Achieving full fixity in supports in laboratory might be difficult, thus to account for differential rotations, a Linear Variable Differential Transducer (LVDT) was attached to one support to capture lateral displacements through which lateral rotations could be calculated. The supports were designed to allow axial deformation in the beam specimens to reduce the degree of complexity in stress analysis by releasing axial stresses. The supports were designed as multi-purpose supports to allow differentiating systems (i.e. with torsion and without torsion). The clearance from the bottom of beams to the base of the main beam of the test frame was set at 6" to allow for sufficient 
vertical deflections and room for failure modes to occur. Details of the supports are shown in Figures 3-9 and 3-10.

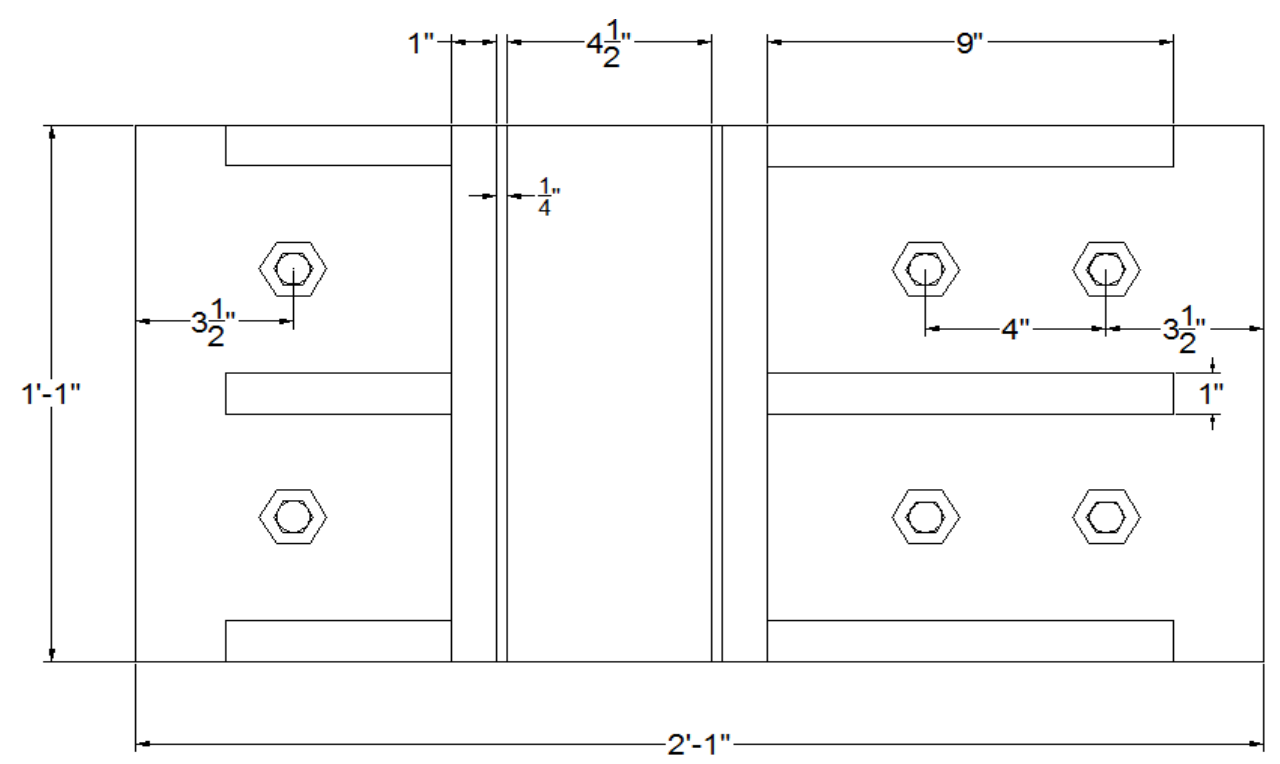

Figure 3-9 Top View of the Beam Supports

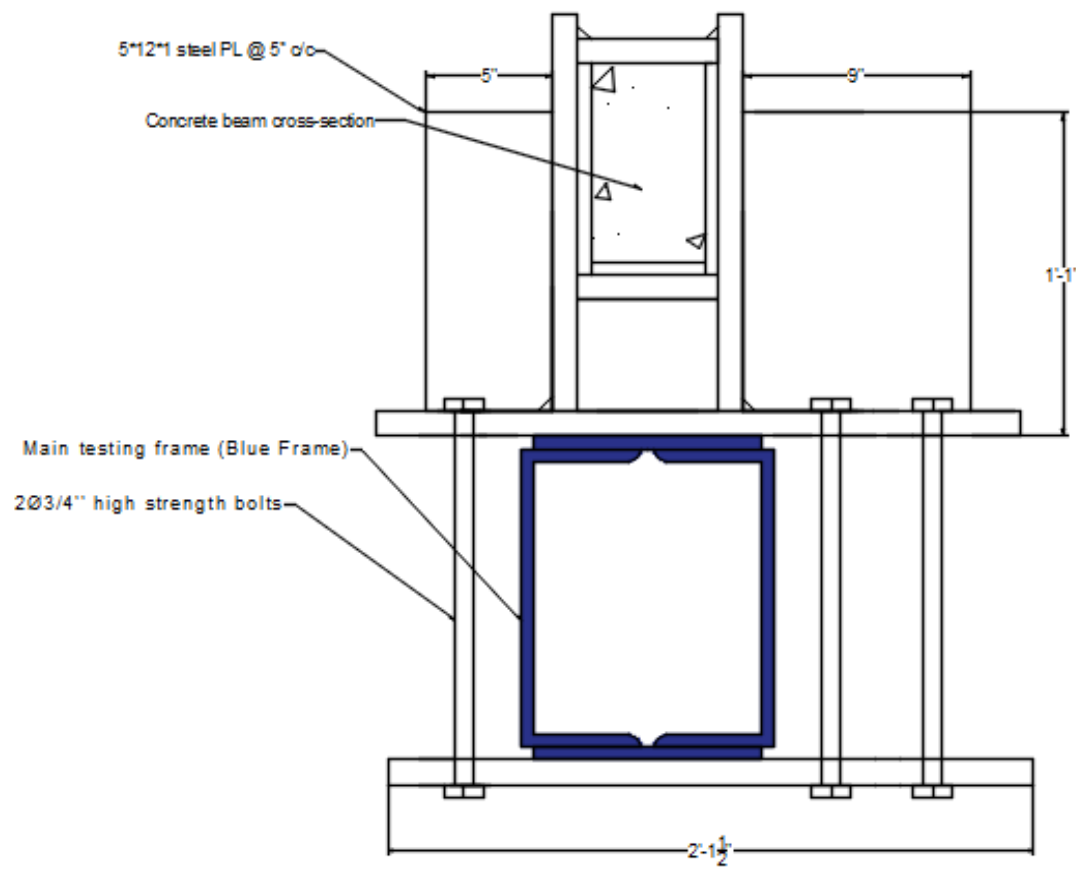

Figure 3-10 Side View of the Supports 
Inner faces of the supports were shimmed with $1 / 4$ " steel plates to provide additional room for dimensional tolerances and adjustment in eccentricities within $1 / 2$ "'.

\subsubsection{Points of Load Application}

The test was carried out by two eccentric loads from the beam axis to better visualize the reality. Adding more points of load applications would give more realistic results compared to the real beam in its actual slab-beam construction, but for laboratory tests two-point loads were deemed sufficiently accurate. At each point of load, which was located at one-third of the span (2.33'), two C9×20 A36 steel channels were attached back-to-back to the beam specimen, a 3/4" thick plate was attached at the bottom, and a W5 $\times 16$ A36 section was attached at its top. The load eccentricity in the beam prototype was crucial to be kept in the laboratory to maintain torsion-to-shear ratio. Referring to the calculations of the beam prototype, there were 3.25 " and 4' eccentricity (from beam centerline to the point-of-load application) for both sets of the beam models, and for convenience, 4" eccentricity was adopted for both sets of the test. The main testing frame, (called the Blue Frame), has one point of load applications through its load ram. To create two point loads applied eccentrically, a secondary beam was used along with a solid bar and cup, which allowed free rotation at the joints to safely transfer the load from the load frame to the points of load applications. The secondary beam was made of W5×16 A36 steel. Calculations were made to ensure that there wouldn't be excessive deflections due to expected ultimate loads. All connections were bolted using $\emptyset 3 / 4^{\prime \prime}$ A490 bolts as shown in Figure 3-11. 


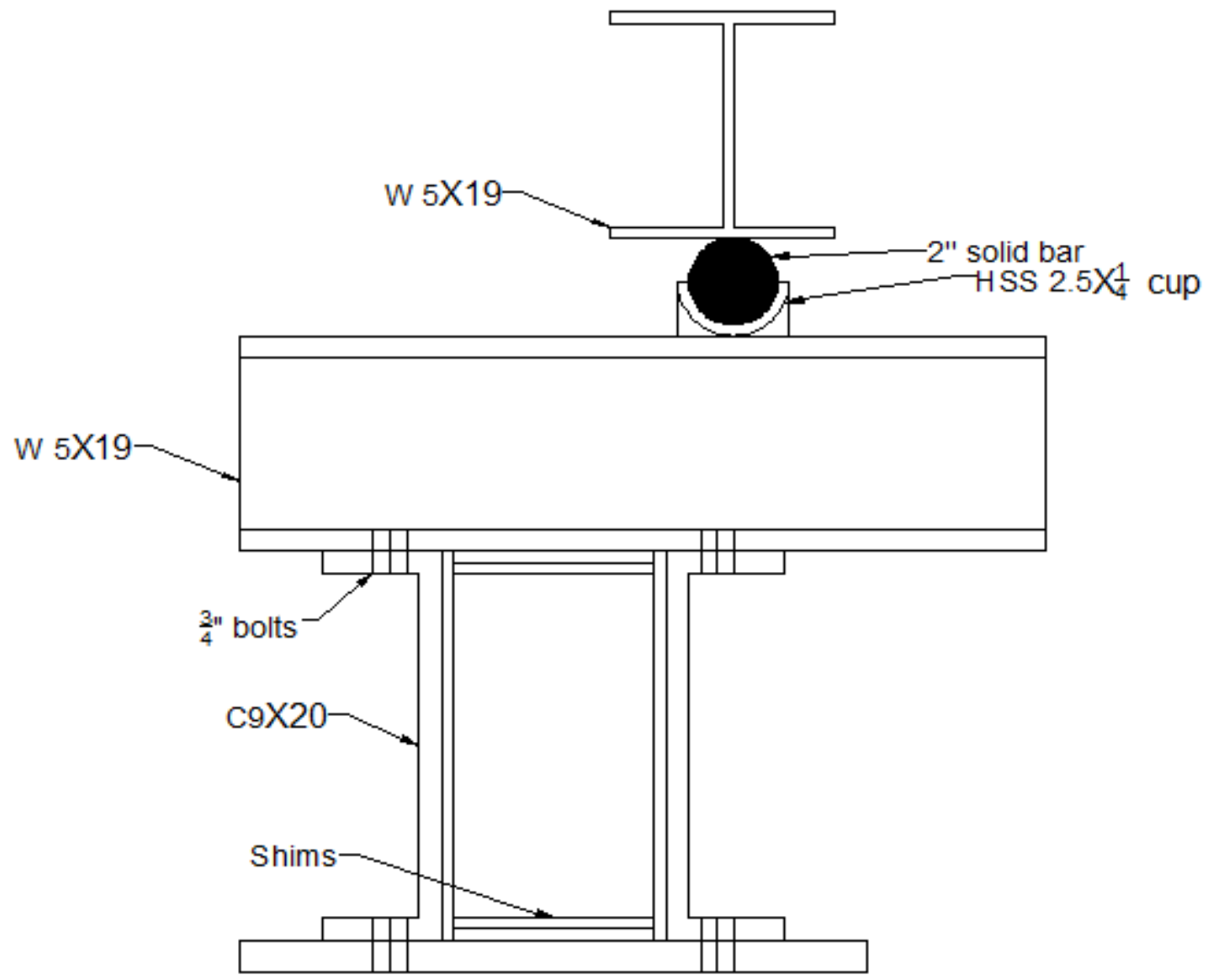

Figure 3-11 Eccentric Beams Set-up 


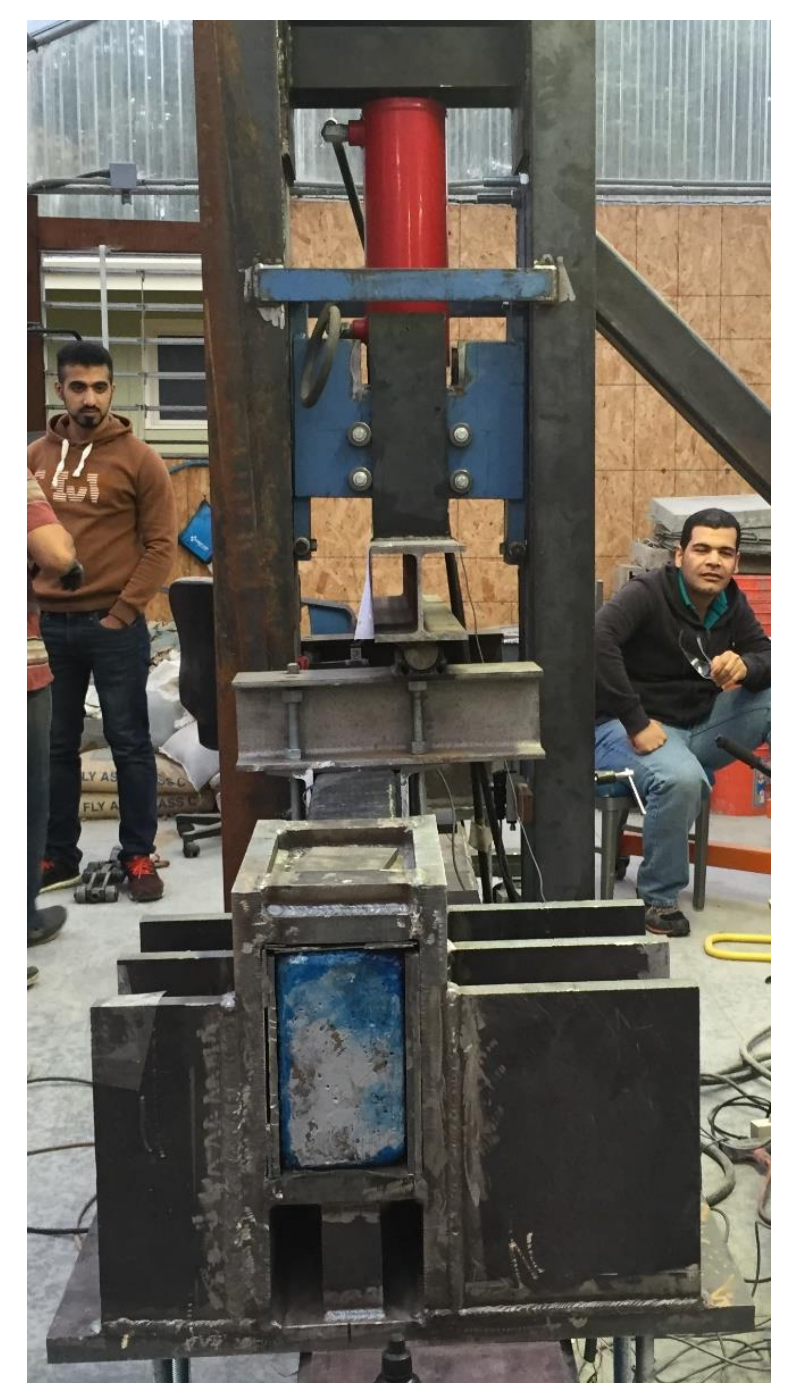

Figure 3-12 Loading Set-up of the Test

\subsubsection{Instrumentation}

\subsubsection{Location of Strain Gauges and LVDTs}

Locations of strain gauges and LVDS's are shown in figures 3-13 through 3-16 for all specimens. 
For A-1 and B-1 specimens:

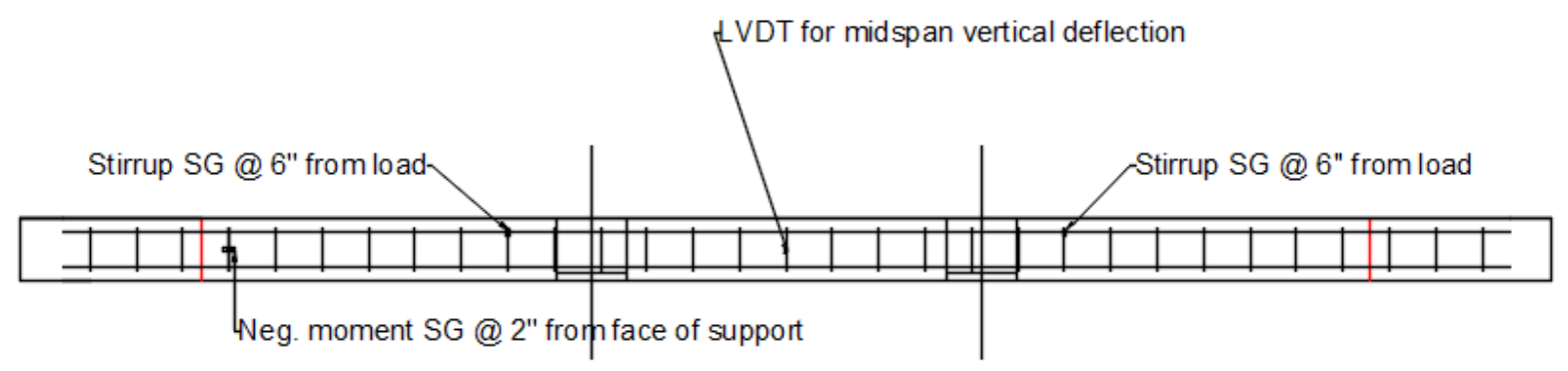

Figure 3-13 Plan View of Specimens A-1 and B-1 Instrumentations

For A-2 and B-2 specimens:

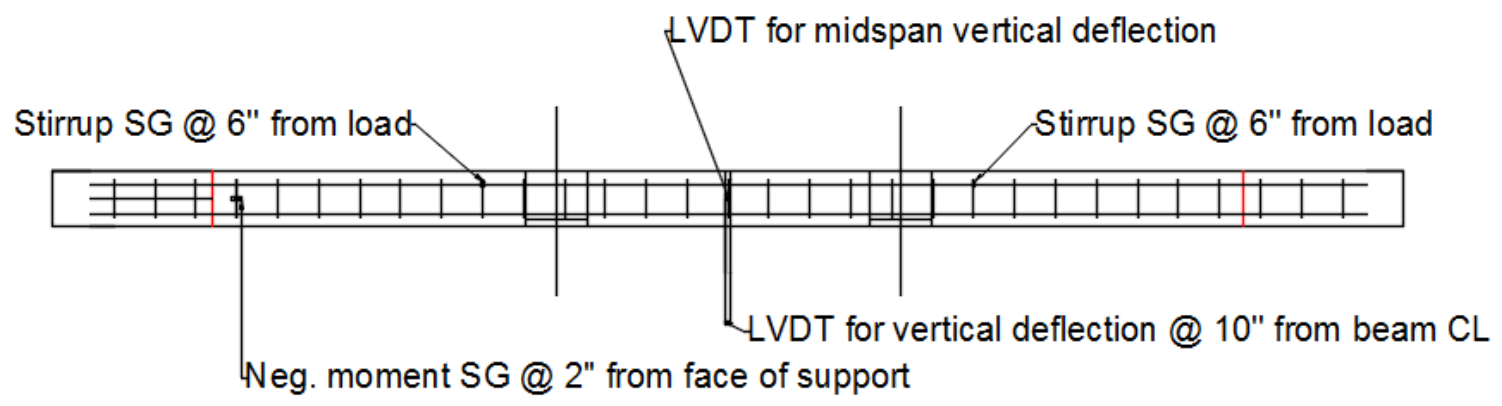

Figure 3-14 Plan View of Specimens A-2 and B-2 Instrumentations

For A-3 and B-3 specimens:

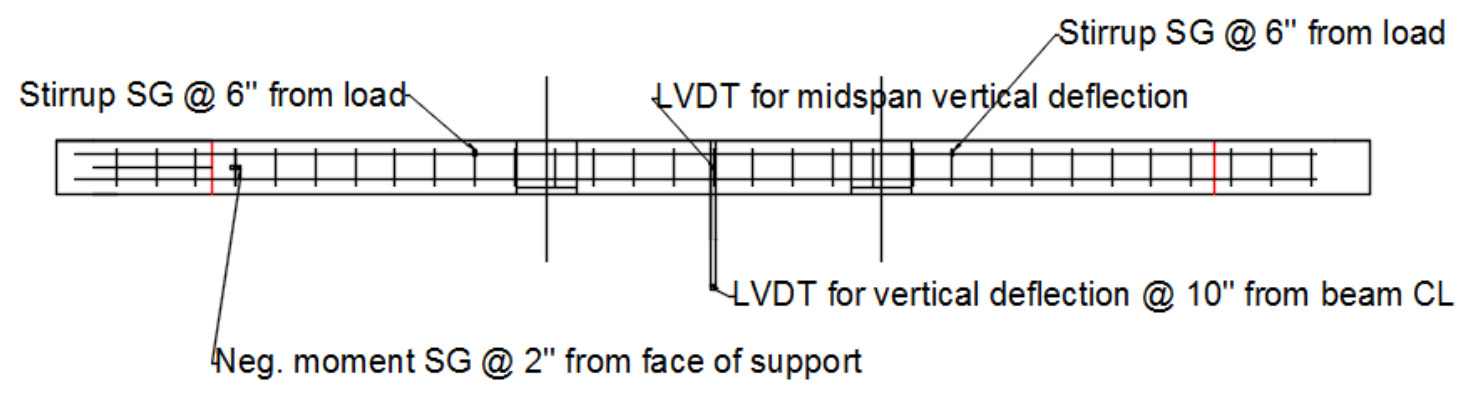

Figure 3-15 Plan View of Specimens A-3 and B-3 Instrumentations 


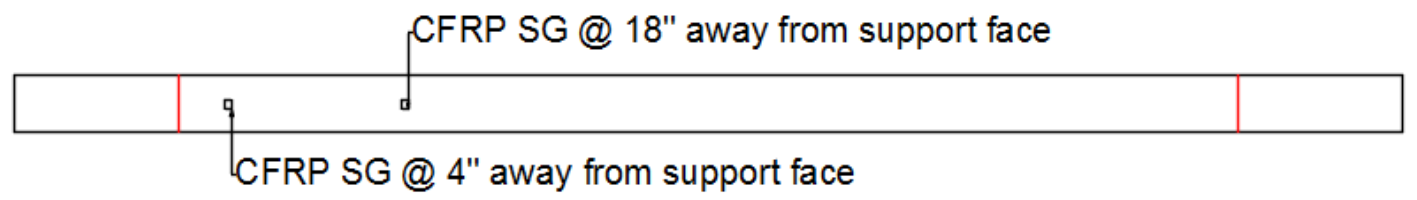

Figure 3-16 Side View of Specimens A-3 and B-3 Instrumentations

\subsubsection{Measuring Torque and Twist Angles}

Torque measurement: The applied torque was measured by multiplying the force at the center of the roller by the horizontal distance to the beam centerline (which is set to 4 inches), as shown below:

$$
T=P . e=\frac{Q \cdot e}{2}
$$

Angle of twist measurement: The twisting angles were measured by the use of two 2'"capacity LVDT's, one located at the centerline of the beam at mid-span (measuring vertical deflection as well), and the other LVDT located at 10 inches away from the first LVDT. The difference between the two readings divided by the horizontal distance (10 inches) gave twisting angle, as explained below:

$$
\varnothing=\tan ^{-1} \frac{\Delta_{1}-\Delta}{l^{\prime}}
$$

Where:

$\Delta_{-1}=$ vertical deflection at 10 inches away from beam CL (inches)

$\Delta=$ mid-span vertical deflection (inches)

$l^{\prime}=10$ inches 


\subsection{Properties of Strain Gauges}

Strain gauges were placed at some points of interest to measure the strain distributions in transverse and longitudinal steel reinforcements, as well as the CFRP fibers. The properties of commercial brand of the strain gauges for CFRP and steel reinforcements are tabulated in Table 3-1.

\section{Table 3-1 Strain Gauge Properties}

\begin{tabular}{|c|c|c|c|c|}
\hline Brand name & Resistance & Temp. Coeff. & $\begin{array}{c}\text { Temp. } \\
\text { sensitivity }\end{array}$ & \# of faces \\
\hline Omega & $120.4 \Omega$ & $10.8\left(\frac{10^{-6}}{k}\right)$ & $93 \pm 10\left(\frac{10^{-6}}{k}\right)$ & 2 \\
\hline
\end{tabular}

Note: strain gauges of CFRP and steel reinforcements are identical!

For the purpose of attaching strain gauges, the areas to which the strain gauges were attached were ground to smooth and flat surfaces so that strain gauges could function properly. Then, glue was poured onto the strain gauge length (usually plastered together by tape) just before attaching it to the flattened steel surface. Before testing any specimens, the strain gauges were checked using a voltmeter to ensure their proper working conditions. For transverse reinforcements, two strain gauges were attached to one vertical leg near the points of load applications, just few inches away from where the loads were applied as shown in Figures 3-17 and 3-18. 


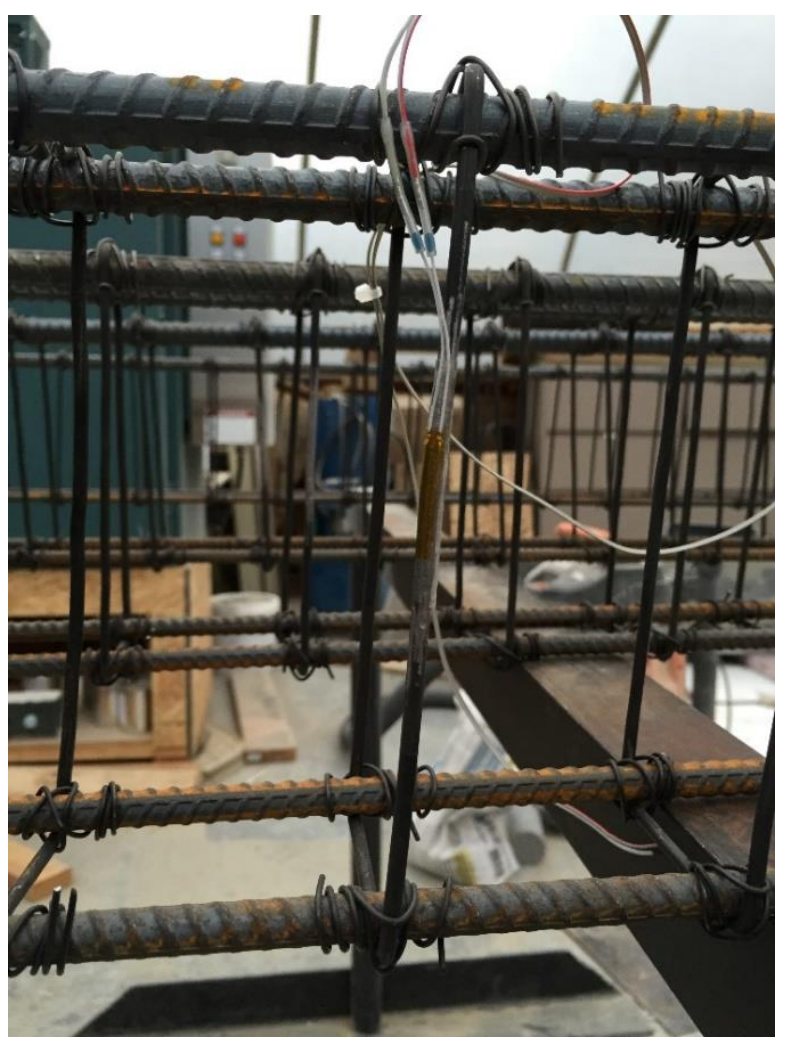

Figure 3-17 Strain Gauge Installed on 0.15', Steel Wire Gauges

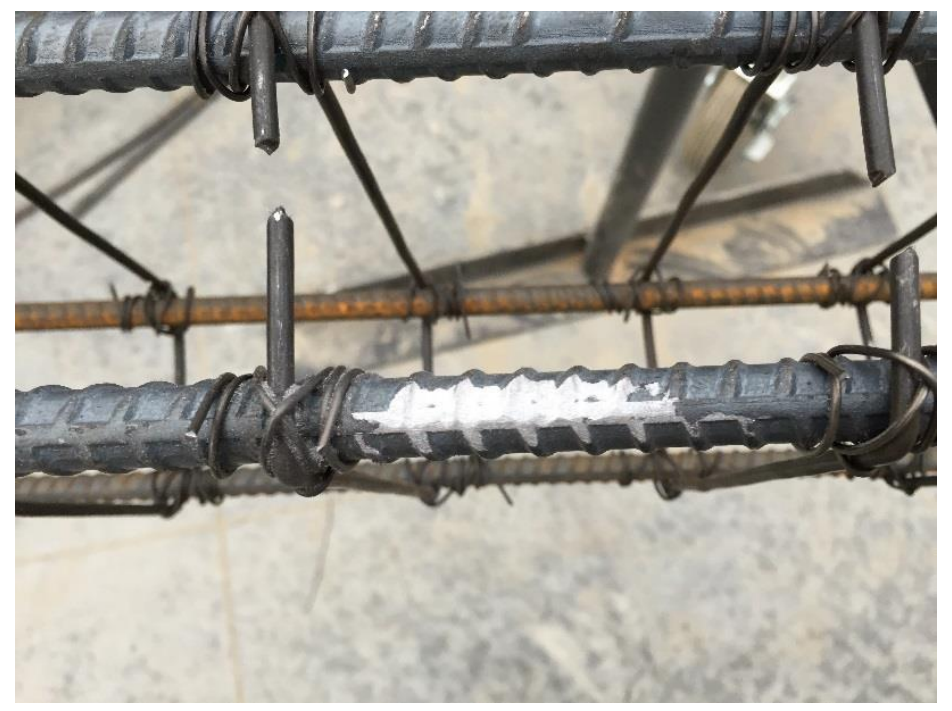

Figure 3-18 Surface Grinding of a Longitudinal Rebar for Strain Gauge Attachment 
For CFRP materials, strain gauges were attached near the steel strain gauges (as shown in Figure 3-19 to capture strains in the same area. Through testing the steel wires, it was clear that the strain gauges started to detach after yielding occurred in the steel wires since the steel wire would need a bigger size (diameter) to stay intact for more strains up until failure. However, detecting yielding of steel in the transverse direction was deemed enough data.

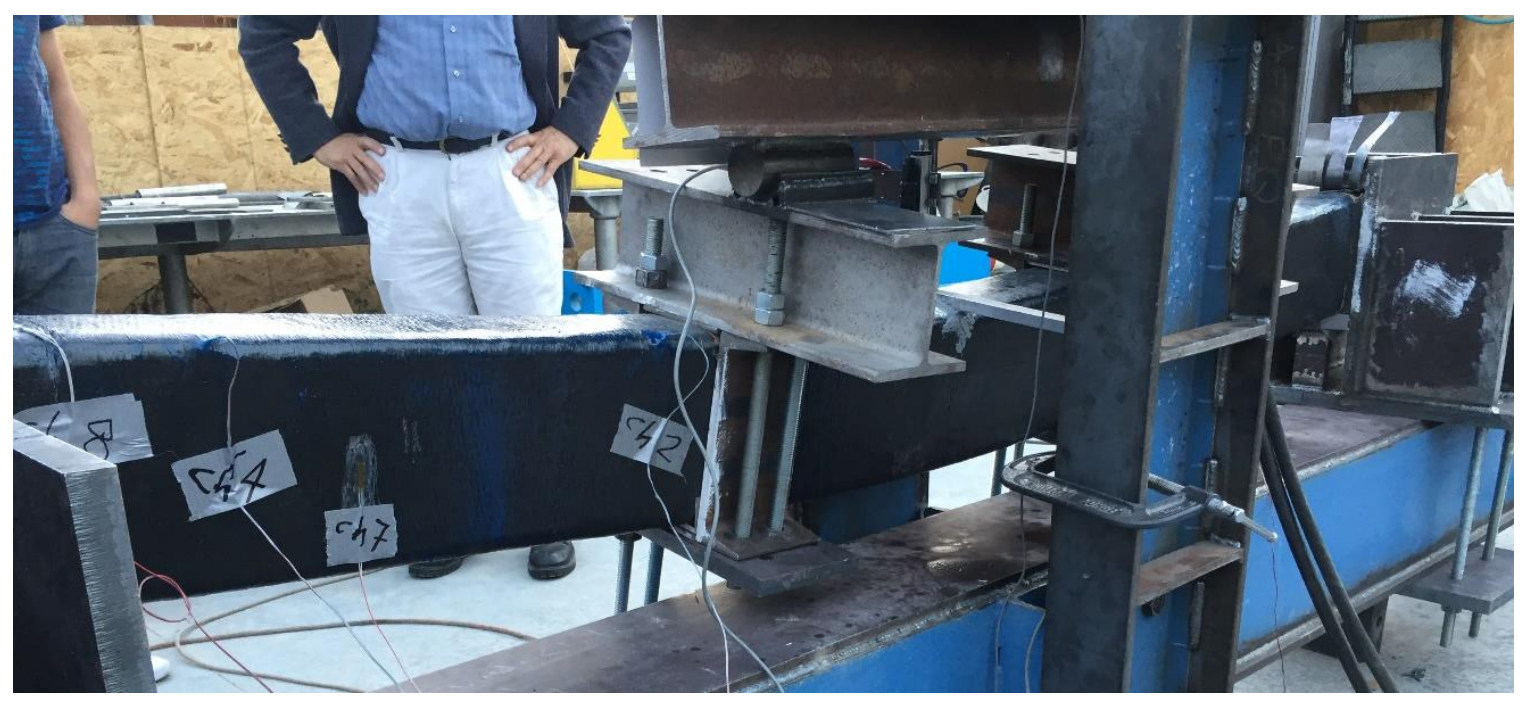

Figure 3-19 Locations of Strain Gauge Set-up on CFRP Sheets

\subsection{Materials}

\subsubsection{Steel Reinforcements}

As shown in model details, longitudinal reinforcements were \#3 and \#4 bars. These steel bars were tested in this experiment according to ASTM E8 for their mechanical properties to ensure their capacities ( $f_{y}, E_{s}, \%$ of elongation). The actual yield strength 
was found to be more than manufacture's specification (60 ksi). The results are-shown in Figures 3-20 and 3-21.

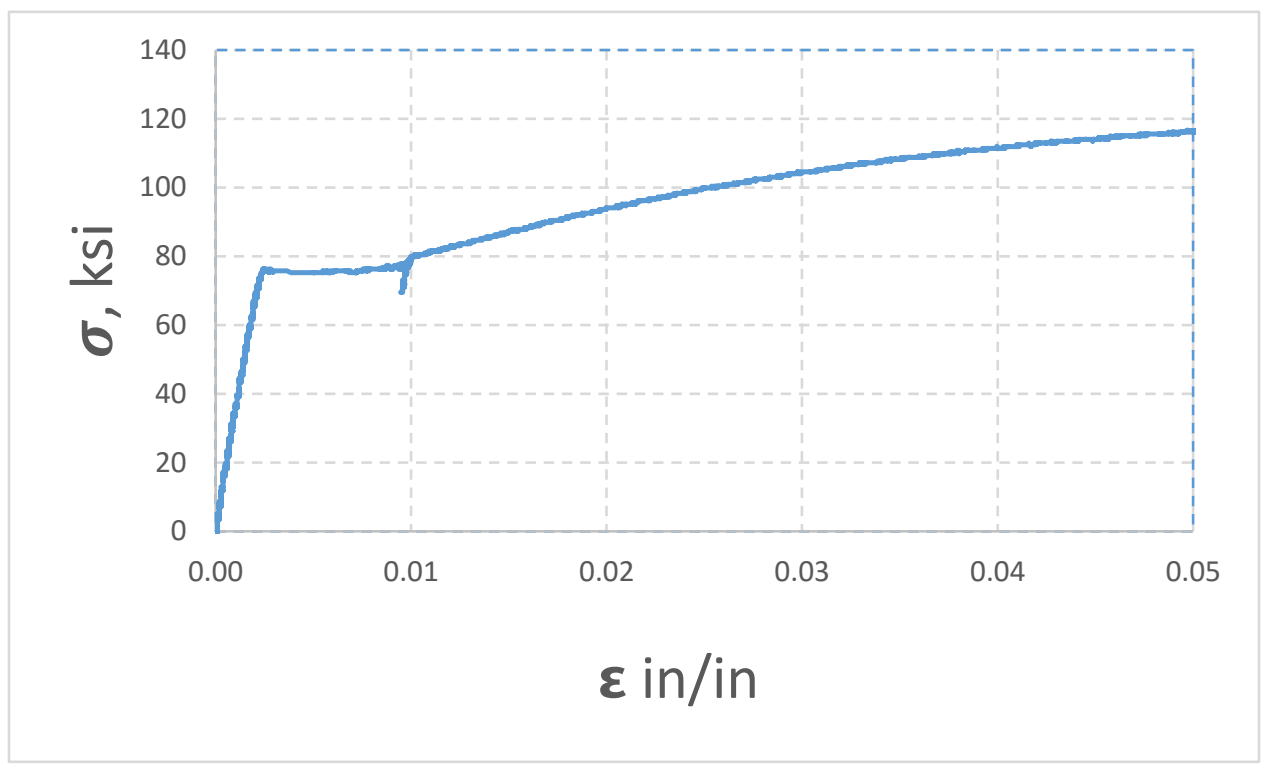

Figure 3-20 Stress-Strain Diagram for \#3 Steel Rebar

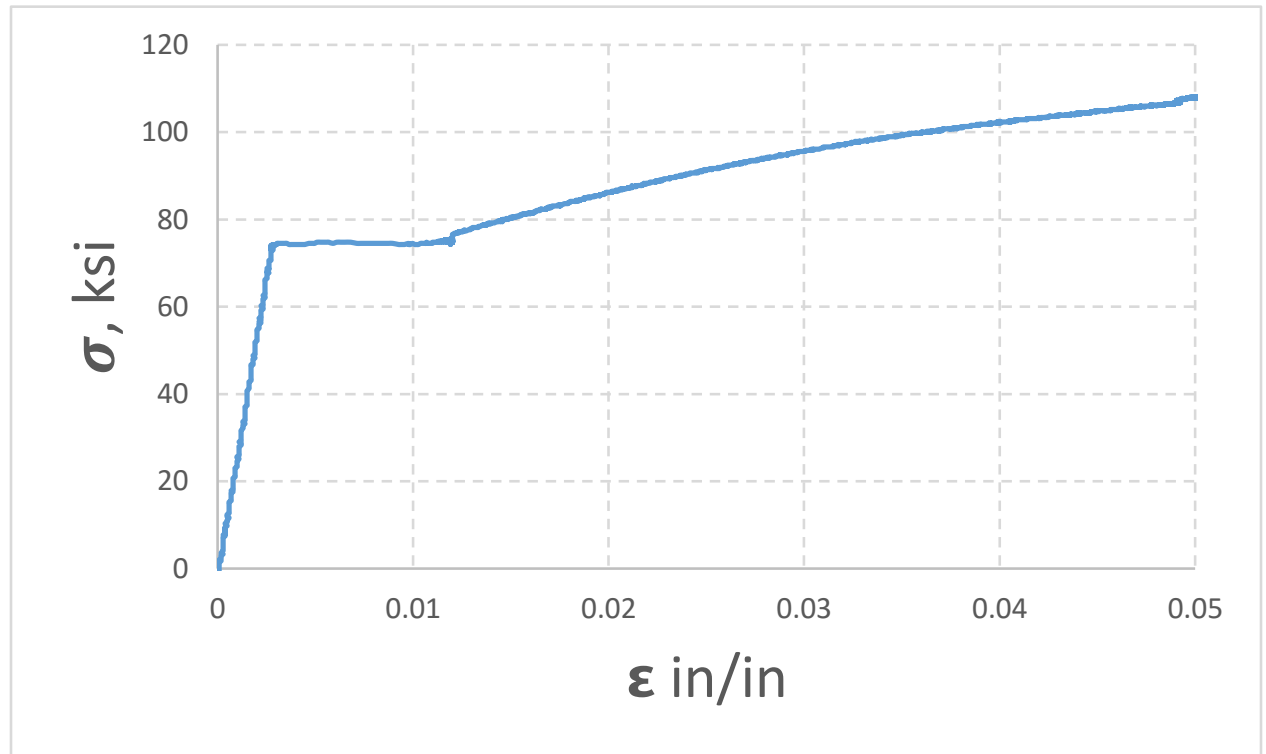

Figure 3-21 Stress-Strain Diagram for \#4 Steel Rebar 
For transverse steel, as per design calculations, \#7 wire gauges were used as 90 degree open stirrups which is commonly used. A sample of these is shown in Figure 3-22.

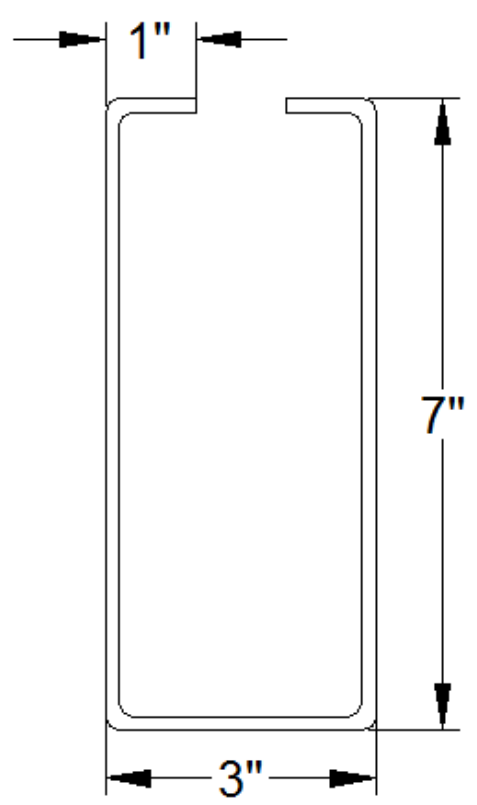

Figure 3-22 A Sample of \#7 Steel Wire Gauge Used as Transverse Reinforcement Two samples the wires were also tested in this experiment and the yield strength was about $32 \mathrm{ksi}$. The stress-strain diagrams of one sample of 10"' long wire is shown in Figure 3-23 (see appendix for the other test). 


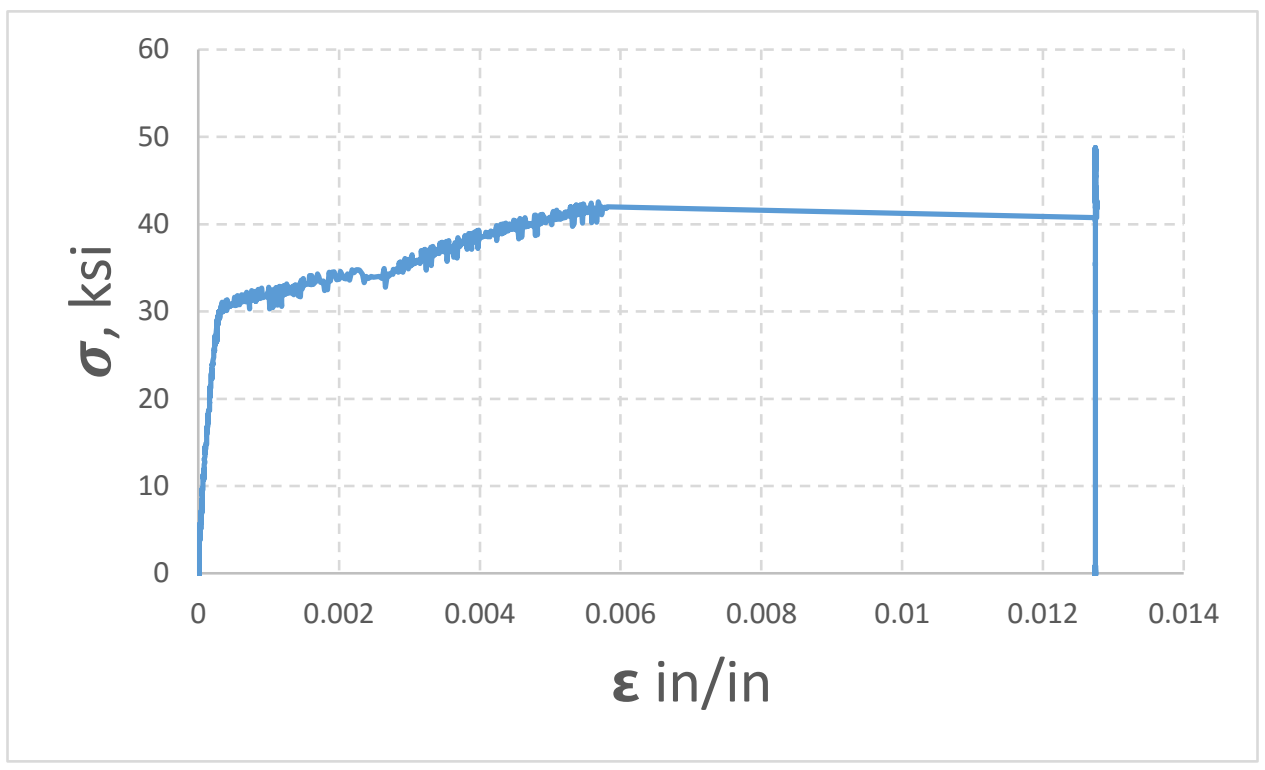

Figure 3-23 Stress-Strain Diagram for \#7 Wire Gauge (Test 1)

\subsubsection{Concrete}

Normal strength concrete was proposed for use in this research with the following properties:

$\mathrm{f}^{\prime} \mathrm{c}=4000$ psi.

Max Agg. Size: 3/4’,

Slump: 3', 4',

Cement used: Portland cement type I/II.

The original plan was to mix the concrete at the laboratory, but due to the large amount of concrete needed for the specimens, ready-mixed concrete was used. For quality control, each beam specimen had three concrete cylinders for compressive strength tests, as is 
described by ASTM, and an average would be taken same day a beam was tested.

Portland Concrete's ready-mix concrete came with the following specifications:

$f^{\prime} \mathrm{c}=4000$ psi.

Cement content: 6 sacks $/ y d^{3}$.

Slump: 3 1/2”'.

Max Agg. size: 3/4"’.

Air content: $4 \%$.

\subsubsection{Carbon Fiber Reinforced Polymer}

Per design calculations for the beam models, minimum thickness of 0.0042 "' was roughly estimated to achieve adequate torsional strength. Commercially, FRP materials come with different brands, each with their own standard thicknesses. In this research, MBrace cf130 high strength unidirectional CFRP was chosen as the strengthening material for test \#3 for each set. This FRP composite was used in wet layup installation with three adhesive components as discussed in the upcoming section.

The details of MBrace of 130 are:

- Fiber material: high strength fibers.

- Tensile strength of fibers: $720 \mathrm{ksi}$.

- Areal weight: $0.062 \mathrm{lb} / \mathrm{ft}^{2}$.

- Standard roll width: 20".

- Nominal thickness, tf: $0.0065^{\prime \prime}$. 
- Color: black.

Samples with fibers oriented in $0^{\circ}$ with respect to the longitudinal axis of the tensile test coupon had the following mechanical properties:

- Tensile strength: $550 \mathrm{ksi}$.

- Modulus of elasticity: $33000 \mathrm{ksi}$.

- Ultimate strain: $1.67 \%$.

Samples with fibers oriented in $90^{\circ}$ with respect to the longitudinal axis of the tensile test coupon had the following mechanical properties:

- Tensile strength: 0 ksi.

- Modulus of elasticity: $33000 \mathrm{ksi}$.

- Ultimate strain: N/A.

The stress-strain diagram for MBrace cf 130 provided by the manufacturer (BASF) was linear up to failure as shown in Figure 3-24. 


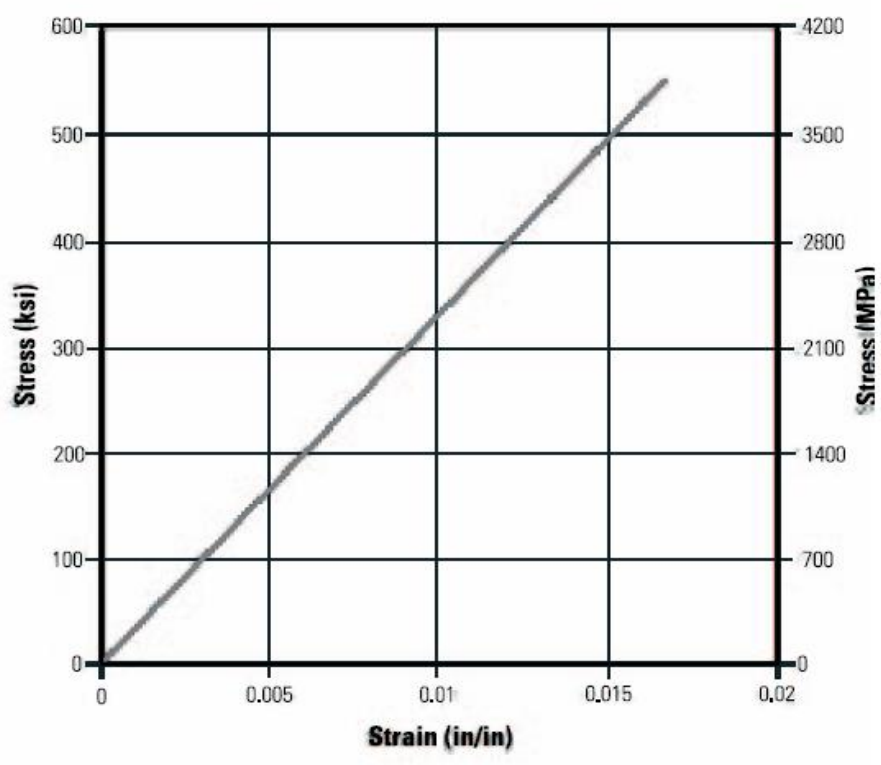

Figure 3-24 Stress-Strain Diagram for CFRP (Courtesy of BASF, the Chemical Company)

\subsubsection{Adhesives}

To install MBrace cf 130, per roll the following three components were used in conjunction with each other as suggested by the manufacturer's data sheet $\left(20^{\prime \prime} \times 162^{\prime}\right)$ :

- Primer - MBrace P 3500

- $\quad$ Putty - MBrace F 2000

- Saturant - MBrace SAT 4500

Details of each component and its procedure, as suggested by the manufacturer, are described below:

\subsubsection{MBrace $P$ 3500}

This low-adhesive product is free flowing liquid used as a penetrating medium viscosity primer before using the main adhesive MBrace 4500. It eases load transfer at the 
interface of CFRP and concrete and it is unshrinkable. The manufacturer's mechanical and physical properties of the product are tabulated below:

Table 3-2 Primer Epoxy Properties

\begin{tabular}{|c|c|}
\hline Mixed density & $1.07 \pm 0.02 \mathrm{Kg} / \mathrm{L}$ \\
\hline Coverage & $4-6 \mathrm{~m}^{2} / \mathrm{Kg}$ \\
\hline $\begin{array}{c}\text { Bond strength to concrete (ASTM } \\
\text { D4541) }\end{array}$ & $>1 \mathrm{MPa}$ or concrete failure \\
\hline Volume solids & $100 \%$ \\
\hline Pot life & 40 Minutes at $25^{\circ} \mathrm{C}$ \\
\hline Tack free time & 6 Hours at $25^{\circ} \mathrm{C}$ \\
\cline { 2 - 2 } & 3 Hours at $40^{\circ} \mathrm{C}$ \\
\hline
\end{tabular}

The surfaces where MBrace P 3500 was applied had to be regular, clean of any grease, oil, contaminates, or dust. The liquid was then applied by using a roller or a brush at the rate of 4-6 $\mathrm{m}^{2} / \mathrm{kg}$, and had to be allowed to dry in order to use other the materials. It was considered tack free at a standard temperature of 20-25C.

\subsubsection{MBrace F 2000}

Depending on density and porosity of the subsurface, this product was used to level small surface offsets, to seal cracks prior to epoxy injection, and to prepare a smooth layer on to which the MBrace system was applied. It was used after the application of the foregoing product, MBrace $\mathrm{P} 3500$, at a rate of $100-250 \mathrm{ft}^{2} / \mathrm{gal}$. It consists of two components $(\mathrm{A}+\mathrm{B})$. Both components were mixed at the rate of 3:1 volume-based and 100:30 weightbased corresponding to the ratio of component A to $\mathrm{B}$. when mixed. The product had a grey color. The surfaces that were already tack-free of the primer coat were lightly 
sanded and cleared of dust, oil, or any other surface contaminates. The subsequent application of the MBrace system was applied after 48 hours from the time the MBrace F 2000 was applied. Density was given as $75.8 \mathrm{lb} / \mathrm{ft}^{3}$ and the manufacturer's mechanical and physical properties of the product are shown in Tables 3-3, 3-4, and 3-5.

Table 3-3 Tensile Properties of the Putty Epoxy

\begin{tabular}{|c|c|}
\hline Yield strength & $1800 \mathrm{psi}$ \\
\hline Yield strain & $1.5 \%$ \\
\hline Modulus of elasticity & $260 \mathrm{ksi}$ \\
\hline Ultimate strength & $2200 \mathrm{psi}$ \\
\hline Ultimate strain (rupture) & $7 \%$ \\
\hline Poisson's ratio & 0.48 \\
\hline
\end{tabular}

Table 3-4 Compressive Properties of the Putty Epoxy

\begin{tabular}{|c|c|}
\hline Yield strength & $3300 \mathrm{psi}$ \\
\hline Yield strain & $4 \%$ \\
\hline Modulus of elasticity & $155 \mathrm{ksi}$ \\
\hline Ultimate strength & $3300 \mathrm{psi}$ \\
\hline Ultimate strain (rupture) & $10 \%$ \\
\hline
\end{tabular}

Table 3-5 Flexural Properties of the Putty Epoxy

\begin{tabular}{|c|c|}
\hline Yield strength & $3800 \mathrm{psi}$ \\
\hline Yield strain & $4 \%$ \\
\hline Modulus of elasticity & $130 \mathrm{ksi}$ \\
\hline Ultimate strength & $4000 \mathrm{psi}$ \\
\hline Ultimate strain (rupture) & $7 \%$ \\
\hline
\end{tabular}




\subsubsection{MBrace SAT 4500}

This was a 100\% solid epoxy used to encapsulate the MBrace cf 130 fiber fabrics onto the concrete surface to provide a quality CFRP laminate. It came after the MBrace F 2000 was applied and it set after 48 hours. This product also consists of two components $(\mathrm{A}+\mathrm{B})$ similar to previous products, and was mixed at the rate of 3:1 volume-based and 100:30 weight-based corresponding to the ratio of component A to B. when mixed. The product had a blue color. The use of this product and the MBrace cf 130 was simultaneous. They were both applied at the same moment that the MBrace of 130 was applied, right after this saturant was applied, and before it gets tacky. A film of 18-22 milli-inch was made through the surface of the previously sanded coat, and the MBrace cf 130 fabrics were applied on it until it was saturated. Later, this product was applied again to finish the first layer of the application. If additional layers were desired, the procedure was applied consistently. Density was given as $61.3 \mathrm{lb} / \mathrm{ft}^{3}$ and the manufacturer's mechanical and physical properties of the product are shown in Tables 36, 3-7, and 3-8.

Table 3-6 Tensile Properties of the Saturant Epoxy

\begin{tabular}{|c|c|}
\hline Yield strength & $7900 \mathrm{psi}$ \\
\hline Yield strain & $2.5 \%$ \\
\hline Modulus of elasticity & $440 \mathrm{ksi}$ \\
\hline Ultimate strength & $8000 \mathrm{psi}$ \\
\hline Ultimate strain (rupture) & $3.5 \%$ \\
\hline Poisson's ratio & 0.4 \\
\hline
\end{tabular}


Table 3-7 Compressive Properties of the Saturant Epoxy

\begin{tabular}{|c|c|}
\hline Yield strength & $12500 \mathrm{psi}$ \\
\hline Yield strain & $5 \%$ \\
\hline Modulus of elasticity & $380 \mathrm{ksi}$ \\
\hline Ultimate strength & $12500 \mathrm{psi}$ \\
\hline Ultimate strain (rupture) & $5 \%$ \\
\hline
\end{tabular}

Table 3-8 Flexural Properties of the Saturant Epoxy

\begin{tabular}{|c|c|}
\hline Yield strength & $20000 \mathrm{psi}$ \\
\hline Yield strain & $3.8 \%$ \\
\hline Modulus of elasticity & $540 \mathrm{ksi}$ \\
\hline Ultimate strength & $20000 \mathrm{psi}$ \\
\hline Ultimate strain (rupture) & $5 \%$ \\
\hline
\end{tabular}

\subsection{CFRP Coupons for Tensile Strength}

Tensile properties were important for material specifications, quality control, structural analysis and design, as well as research and development. To verify the manufacture's tensile parameters, seven CFRP samples were tested in this study in accordance with ASTM D3039 and D7565. A recap of the notes on ASTM requirements are briefly discussed below:

From ASTM D7565:

- Flat FRP specimens must be cut from a shop-manufactured laminate. The ultimate force per unit width is determined from the maximum forced before failure. 
- Some variation in results may arise from resin content, ply thickness, void content, degree of curing, and gripping type. So care must be taken to ensure minimal variations.

- At least five samples per test condition must be taken. Thickness is not required to be measured.

- Minimum width for unidirectional specimens must be 1 ',

- Care must be taken to avoid notches, under cuts, rough or uneven surfaces, and delamination caused by improper machining methods.

- Edges must be flat and parallel. Label each specimen without affecting its behavior.

- The machine testing the specimens must have certified calibrations that are up to date.

- What must be recorded is $\mathrm{P}_{\max }$, and if stiffness is desired, record load strain relationship and the failure strain

$$
F^{*}=\frac{P \max }{w}
$$

For tensile stiffness,

$$
\begin{gathered}
f i=\frac{p i}{w} \\
k^{*}=\frac{\Delta p}{w} /_{\Delta \varepsilon}
\end{gathered}
$$

From ASTM D3039:

- A thin rectangular flat specimen is mounted in the grips and monotonically loaded up to failure.

- Specimen length $($ minimum $)=$ grip length $+2 w+$ gauge length 
- Recommended lengths are:

Table 3-9 CFRP Sampling Size

\begin{tabular}{|c|c|c|}
\hline Type & Specimen width & Specimen length \\
\hline $0^{\circ}$ unidirectional fibers & $0.5^{\prime \prime}$ & $10^{\prime \prime}$ \\
\hline $90^{\circ}$ unidirectional fibers & $1^{\prime \prime}$ & $7^{\prime \prime}$ \\
\hline balanced and symmetric & $1^{\prime \prime}$ & $10^{\prime \prime}$ \\
\hline
\end{tabular}

- Measure width at three locations in the gauge section.

- The test is in strain control (if possible) so it breaks within 1-10 minutes.

- Strain controlled speed $=0.01 / \mathrm{min}$.

Constant head speed test $=0.05 \mathrm{in} / \mathrm{min}$

- Try to define the mode of failure using one of the designated codes provided by ASTM D3039.

- Stress-strain behavior would either be linear or bilinear.

For this test, seven specimens were taken with 10', overall length. The tabs consisted of carbon aluminum tabs with thickness $3 \mathrm{~mm}$. The CFRP fabrics were cut using a heavy utility shear, impregnated onto the tab surfaces by using epoxy, and were allowed to dry for 48 hours. At the middle of the gauge length, a train gauge was attached to measure strain. The surface of the CFRP at that location was ground to a level surface to ease the strain caption at that point. Eventually, the tabs were funneled at the ends as suggested by 
ASTM D3039. A schematic representation of the specimens is:
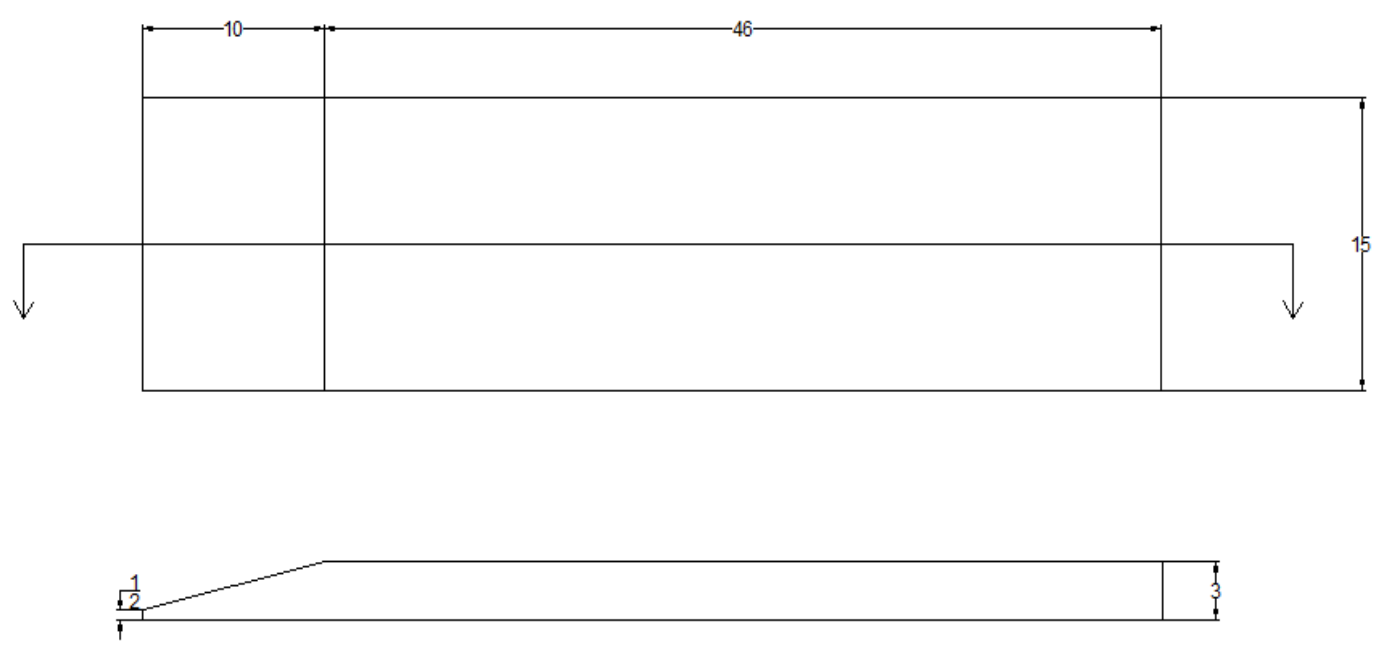

Figure 3-25 A CFRP Tensile Coupon Tab (Dimensions in mm.

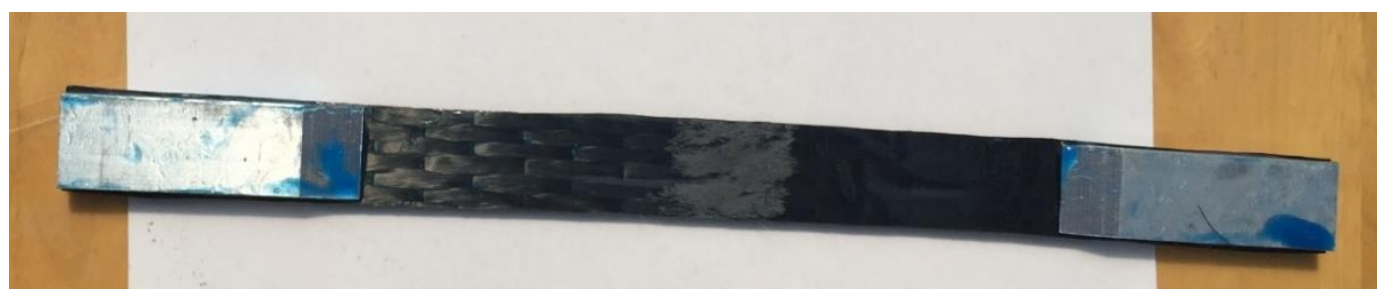

Figure 3-26 A View of a Prepared Sample 


\subsection{CFRP Application Procedure}

\subsubsection{CFRP Tensile Coupons}

\subsubsection{Required Materials and Tools}

- A smooth surface plywood of size $3^{\prime} \times 3^{\prime}$.

- Two plastic paddles.

- Two small containers for epoxy preparation.

- Nylon hand gloves.

- Nylon sheets of size $12^{\prime \prime} \times 24^{\prime \prime}$ with minimum thickness $0.07 \mathrm{~mm}$. Here, $0.084 \mathrm{~mm}$ thickness was used.

- A brush for spreading epoxy.

- MBrace SAT 4500 components A \& B, epoxy components.

- Aluminum tabs of dimensions explained earlier.

- CFRP sheet sample of size $12^{\prime \prime} \times 12^{\prime \prime}$, here, $8^{\prime \prime} \times 13^{\prime \prime}$ sheet was used. 


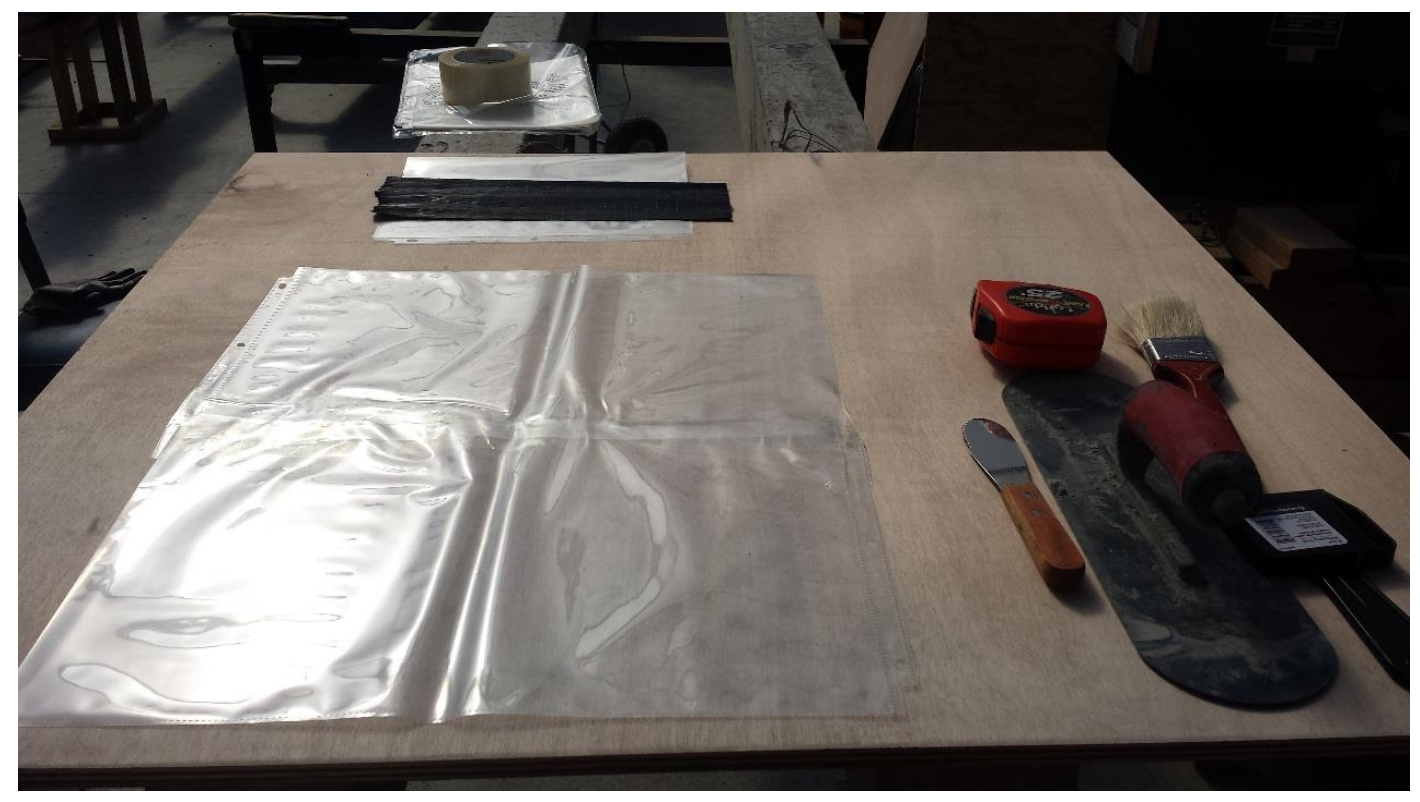

Figure 3-27 CFRP Coupon Materials and Tools

\subsubsection{Application Procedure}

- Lay the square plywood board on a level surface.

- Place the transparent nylon sheet on the board.

- Mix the epoxy, MBrace SAT 4500. First, use $75 \mathrm{gm}$ of part A, the blue substance, and mix it for at least three minutes, then add 25 gm of part B, the white substance, and mix both of them for another three minutes simultaneously.

- Pour the formulated epoxy onto the nylon sheet surface. The thickness of the epoxy applied is not of importance. Pour as much as you feel enough epoxy has been placed, normally 4" away from the edges of the CFRP sheet. 


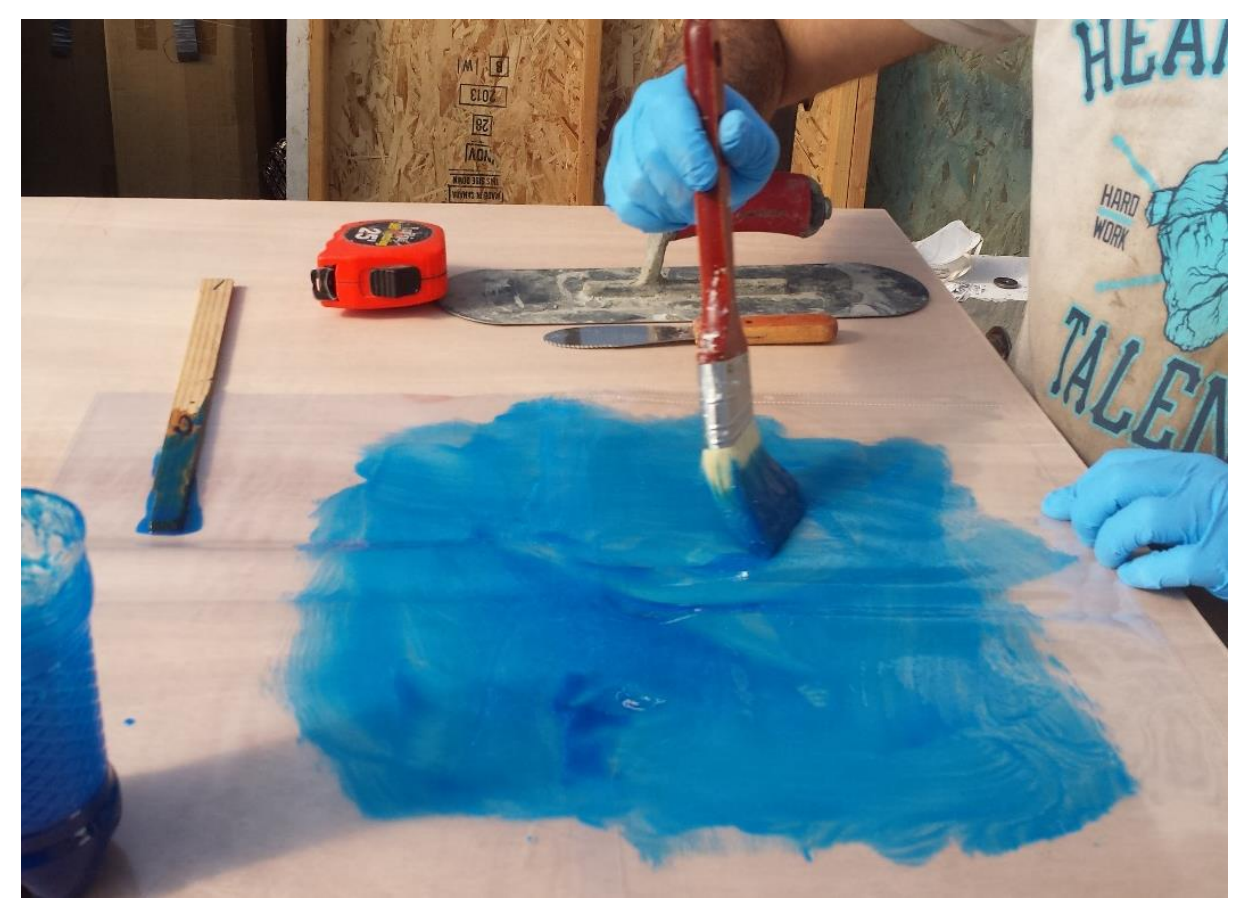

Figure 3-28 Placement of Epoxy Resin onto the Nylon Sheet

- Place the dry CFRP sample onto the resin surface and use the paddle to impregnate the fabrics until visual bleeding of the resin on the top surface of the sheet is seen. Make sure the paddle is only applied in the direction of fabrics. 


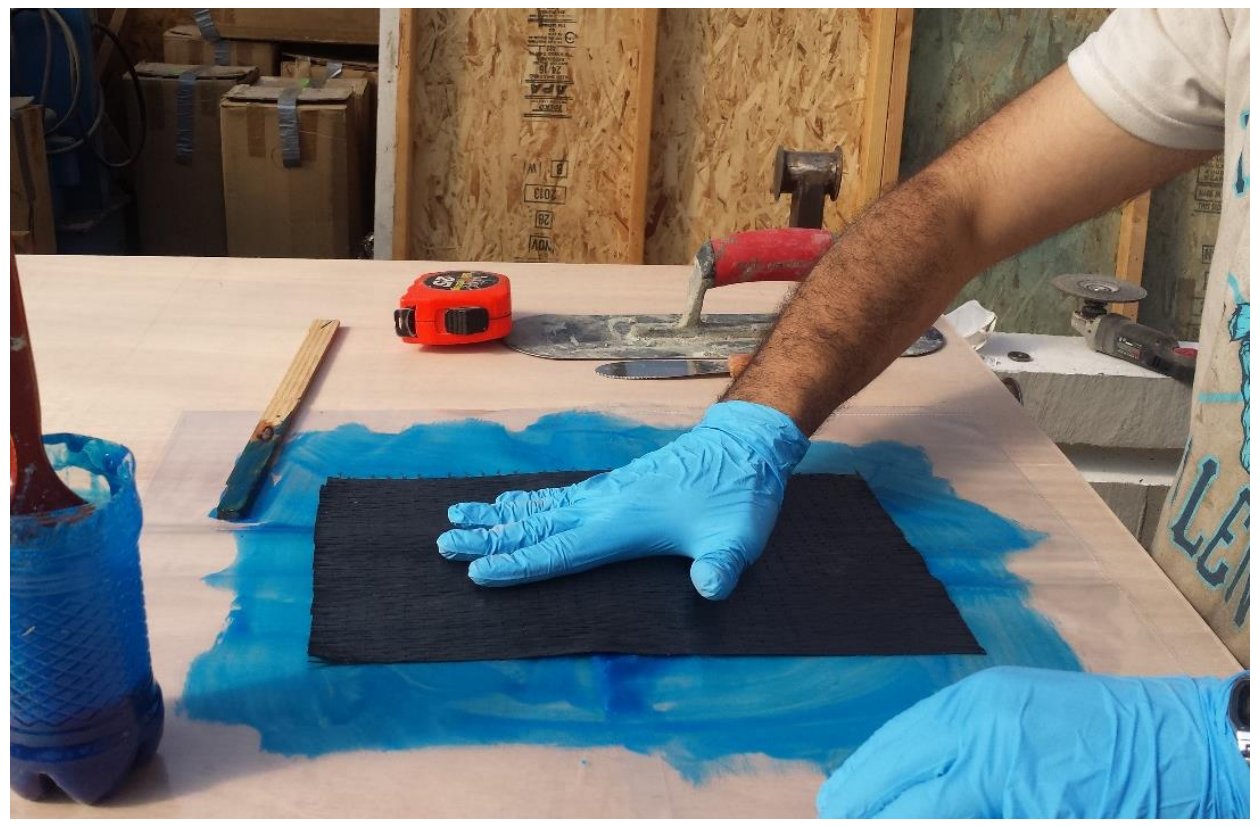

Figure 3-29 Placement of the CFRP Sample Sheet onto the Base Layer of Epoxy

- Pour another layer of epoxy resin onto the CFRP surface and spread it well using the brush in the direction of fabrics only.

- Place the second layer of nylon sheet on the second resin coat and use the paddle to squeeze out the resin in the direction of fabrics. Continue pressing using the paddle until no significant resin comes out. Orient the paddle 15 degrees in this stage to have the best performance. 


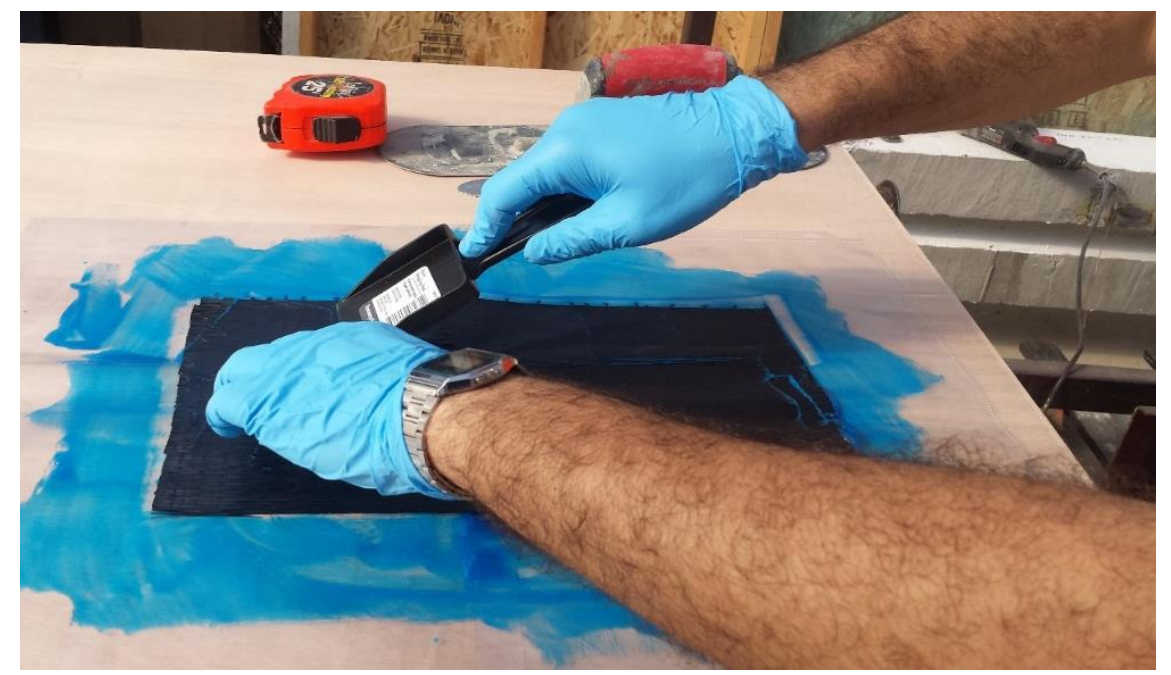

Figure 3-30 Squeezing out the Epoxy

- Take the sample with nylons on to a dry and warm place for curing overnight. Twenty four hours is adequate for curing.

- Even though no additional heavy weight is needed to make sure the samples would be flat. Some steel plates, if available, can be are placed on top of the samples just to make a flatter surface (until here, the process has taken about 30 minutes). 


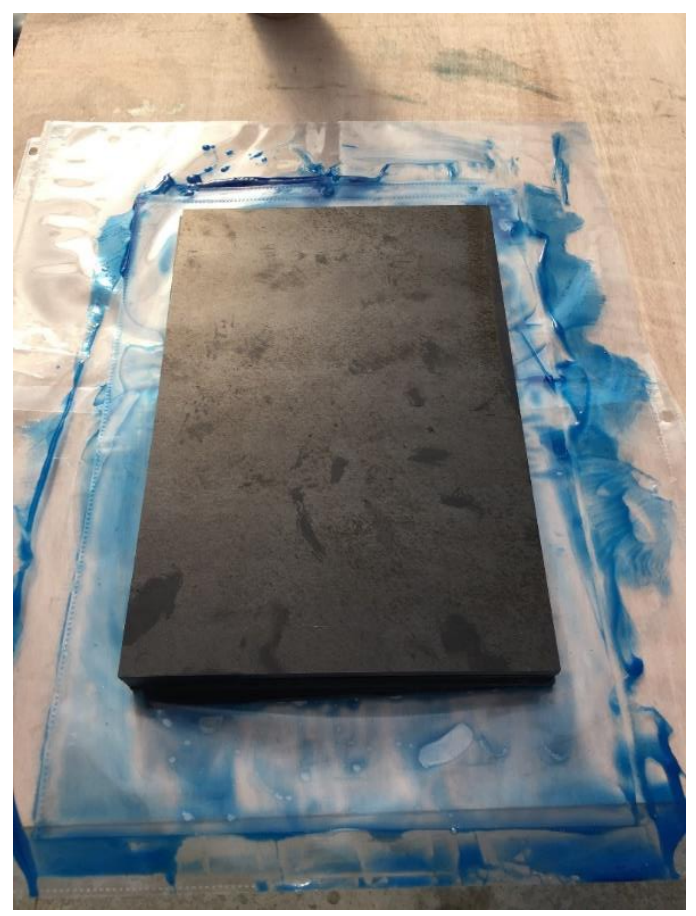

Figure 3-31 the End of the Sample Preparation (with Some Weights on)

- Use markers to label the samples.

- After 24 hours, prepare the aluminum tabs and sand interior surfaces along with the tab area in the CFRP cured sample.

- Cut the size of CFRP samples using a high quality shear or utility scissors. The sample size is $15 \mathrm{~mm} \times 250 \mathrm{~mm}$.

- Use epoxy to attach the tabs to the samples.

- Grind the mid length of each sample to installing a strain gauge.

- The samples are now ready to be tested.

\subsubsection{CFRP Attachment Procedure}

The application procedure which was the final task of the experimental program consisted of three stages as mentioned earlier in section 3.3. There were three epoxy 
types to be applied before the final MBrace cf 130 was wrapped. The wrapping was extended into the supports to make sure that support cracks would be avoided. The strengthening scheme was $90^{\circ}$ - the fibers were oriented perpendicularly on the beam axis, which gave the most effectiveness for shear and torsion.

The CFRP sheets were cut into the proper dimensions, and the application procedure is schematically explained below:

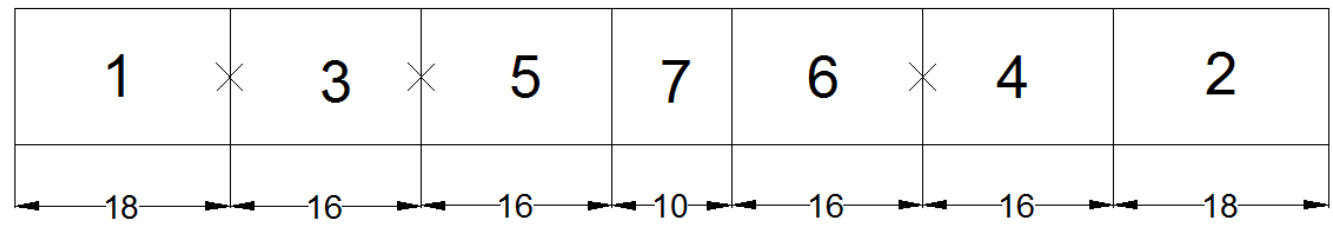

Figure 3-32 A Schematic Representation of CFRP Sheet Installations in Order

Table 3-10 Dimensions of CFRP Sheets

\begin{tabular}{|c|c|c|}
\hline Sheet no. & Length (in) & Width (in) \\
\hline 1 & 29 & 18 \\
\hline 2 & 29 & 18 \\
\hline 3 & 29 & 20 \\
\hline 4 & 29 & 20 \\
\hline 5 & 29 & 20 \\
\hline 6 & 29 & 20 \\
\hline 7 & 29 & 18 \\
\hline
\end{tabular}


Before the application of epoxies started, the beam edges were rounded. In this work, a fillet of about $3 / 4$ " was made at the edges to prevent premature fracture of fibers at the edges since the edges were sharp. Then, the whole concrete surface was ground to remove laitance and contaminants to create a strong concrete surface. Many pores and holes emerged when the surface was ground using a "masonry grinder." Big holes and irregular edges were filled out with cement mortar, as shown. For the cement mortar application, the beam was cleaned by water shedding to remove the dust that settled during grinding process. After the cement mortar was cured, we ground the spots where the cement mortar was applied on so that the beams would have a leveled surface. The application of epoxies onto the CFRP sheets started after the beam was prepared in this manner.

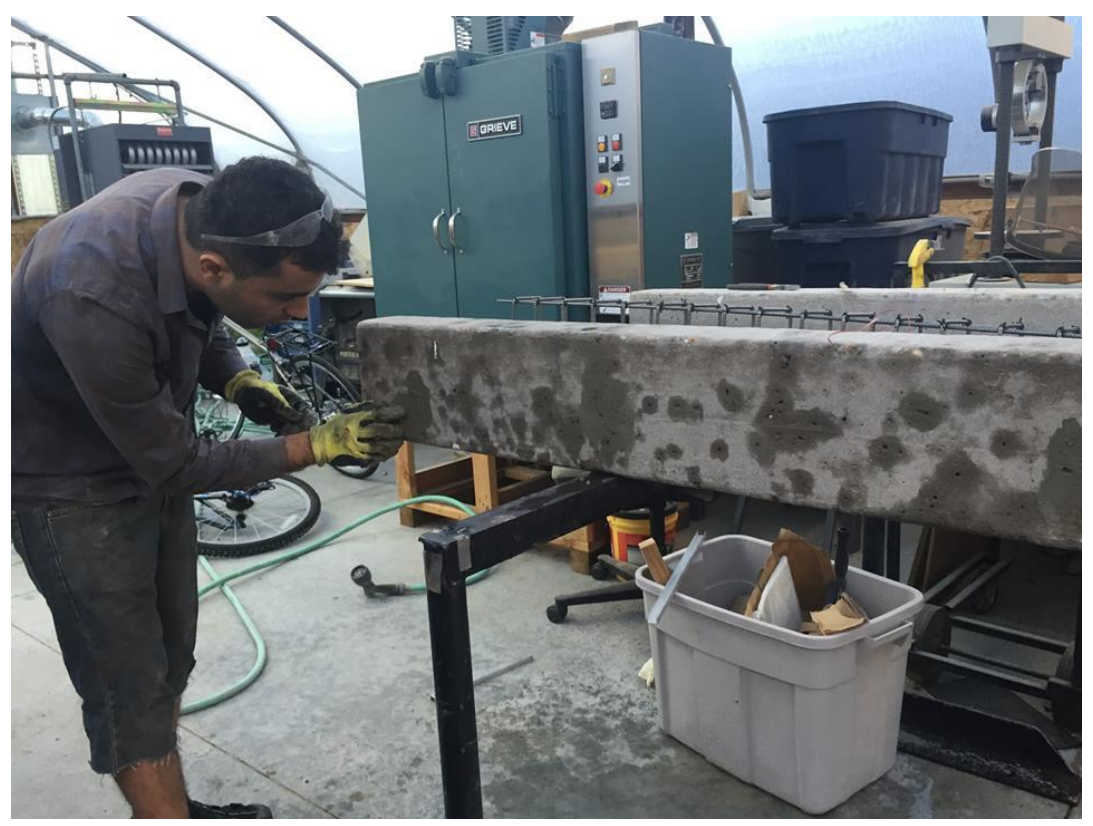

Figure 3-33 Rounding the Edges of Concrete Beams 


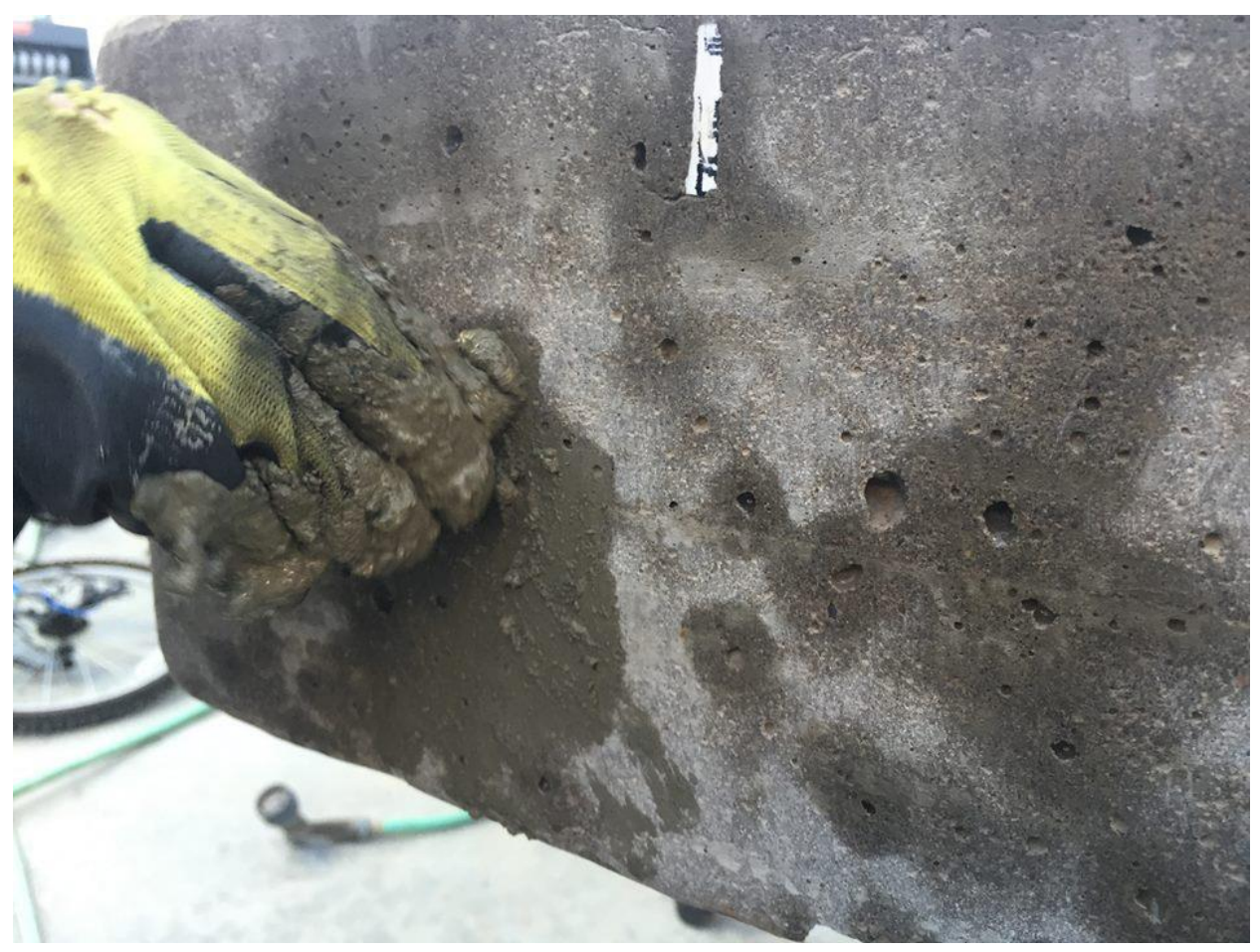

Figure 3-34 Cement Mortar around the Holes on the Surface

\subsubsection{MBrace P3500}

The following steps were used to outline the application of the primer epoxy to the concrete surface. This type of epoxy was the first epoxy to be used before the other two epoxy products, as prescribed by the manufacture, BASF Corporation.

- Clean the surface of concrete by grinding to remove all laitance, oil, or other contaminants, and make the surface reasonably rough.

- Mix components A and B together by weight ratio of 100:30 respectively. Each time, mix about 100 grams of component $\mathrm{A}$ for three minutes alone, and then add 30 grams of component B to it, and remix the combination for additional three minutes. This 
would keep the epoxy workable within its setting time. Repeat this every time the epoxy is finished.

- Using a brush, apply the epoxy thoroughly to the entire surface of the beam, and make sure that all of the voids on the surface are filled with it.

- The surface is hot and tacky. Leave it for 24 hours to become tack free in order to be ready for the next epoxy application.

\subsubsection{MBrace F2000}

- After 24 hours from MBrace P3500, the tack free surface must be insured that it is clean from dust or any contaminants, usually using air compressor is adequate

- Mix components A and B together by weight ratio of 100:30 respectively. Each time, mix about 100 grams of component $\mathrm{A}$ for three minutes alone, and then add 30 grams of component $\mathrm{B}$ to it and remix the combination for additional three minutes. This would keep the epoxy workable within its setting time. Repeat this step every time the epoxy is finished.

- Using a steel spring towel, spread the epoxy through the holes or spots with irregular geometry only. Press the epoxy using the trowel well so that the epoxy fills out the holes. This epoxy doesn't necessarily need to be applied onto the entire surface. However, spreading a very thin layer of the epoxy through the entire surface is recommended. Thick layers of the epoxy are not recommended.

- After finishing, leave the surface for another 24 hours in order to attach the CFRP sheets along with MBrace SAT4500. 


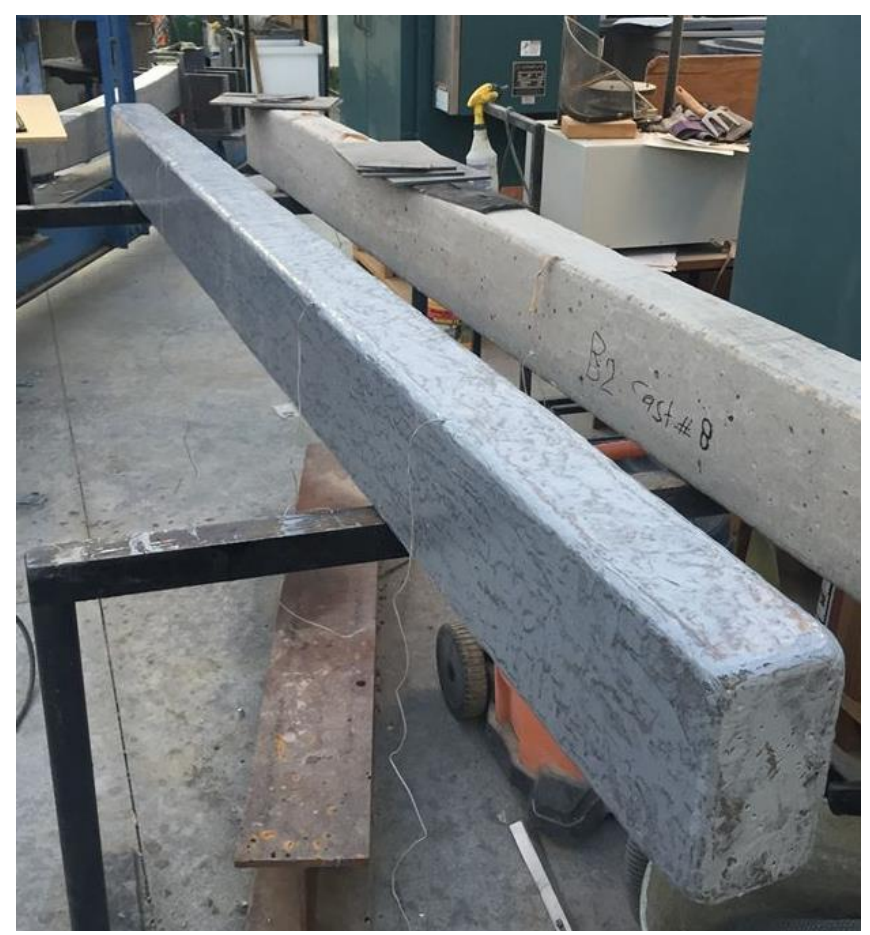

Figure 3-35 the Beam Surface Coated by MBrace F2000 (Putty)

\subsubsection{MBrace SAT4500}

- The surface coated by the previous two epoxies must be cleaned from any contaminant or dust. Usually an air compressor application is adequate.

- Cut the CFRP sheets into proper dimensions suitable for the application. This must be done before starting to mix the epoxy in this stage. Leave 4", overlap length for both transverse and longitudinal direction in order to prevent early delamination, as suggested by the manufacturer.

- Mix components A and B together by weight ratio of 100:30 respectively. Each time, mix about 100 grams of component $\mathrm{A}$ for three minutes alone, and then add 30 grams of component $\mathrm{B}$ to it and remix the combination for additional three minutes. That 
would keep the epoxy workable within its setting time. Repeat this step every time the epoxy is finished.

- Since the CFRP sheets in this roll came with 20 "' sheet width, each time, coat about 20 " of epoxy on the surface of the beam using a brush and attach for sheet, and then another 20" for another sheet attachment.

- After attaching the sheet, press it using a solid roller to squeeze out the epoxy underneath the sheet and also so that the epoxy bleeds through the fabrics.

- Pour another layer of epoxy onto the attached CFRP sheet so that the whole system is saturated with epoxy and squeeze it again using the same roller.

- Provide about 4"' overlap distance from both longitudinal direction of fibers and adjacent sheets coming over this sheet. It is preferred to start wrapping in a symmetrical manner from the ends to the mid-span.

- Leave the beam with the CFRP sheets attached for at least 72 hours to get full curing. 


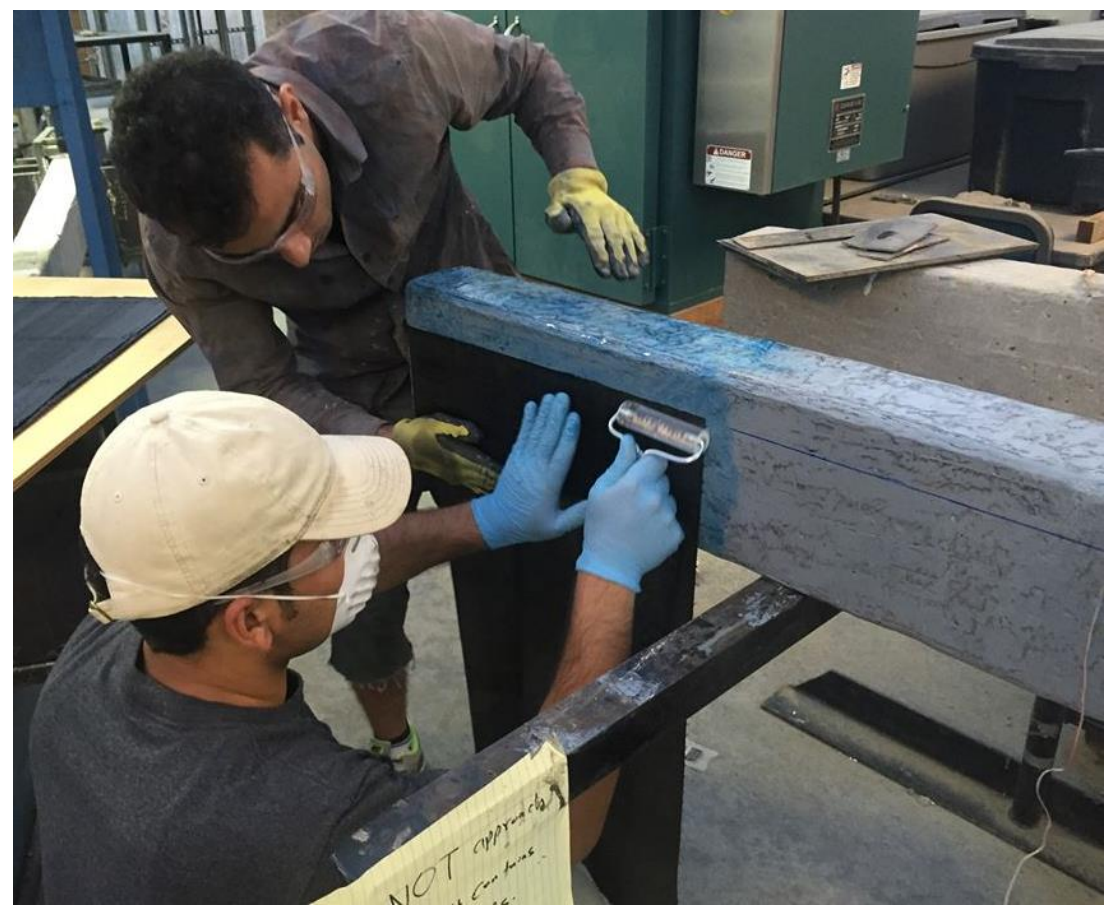

Figure 3-36 Application of CFRP Sheets and MBrace SAT 4500
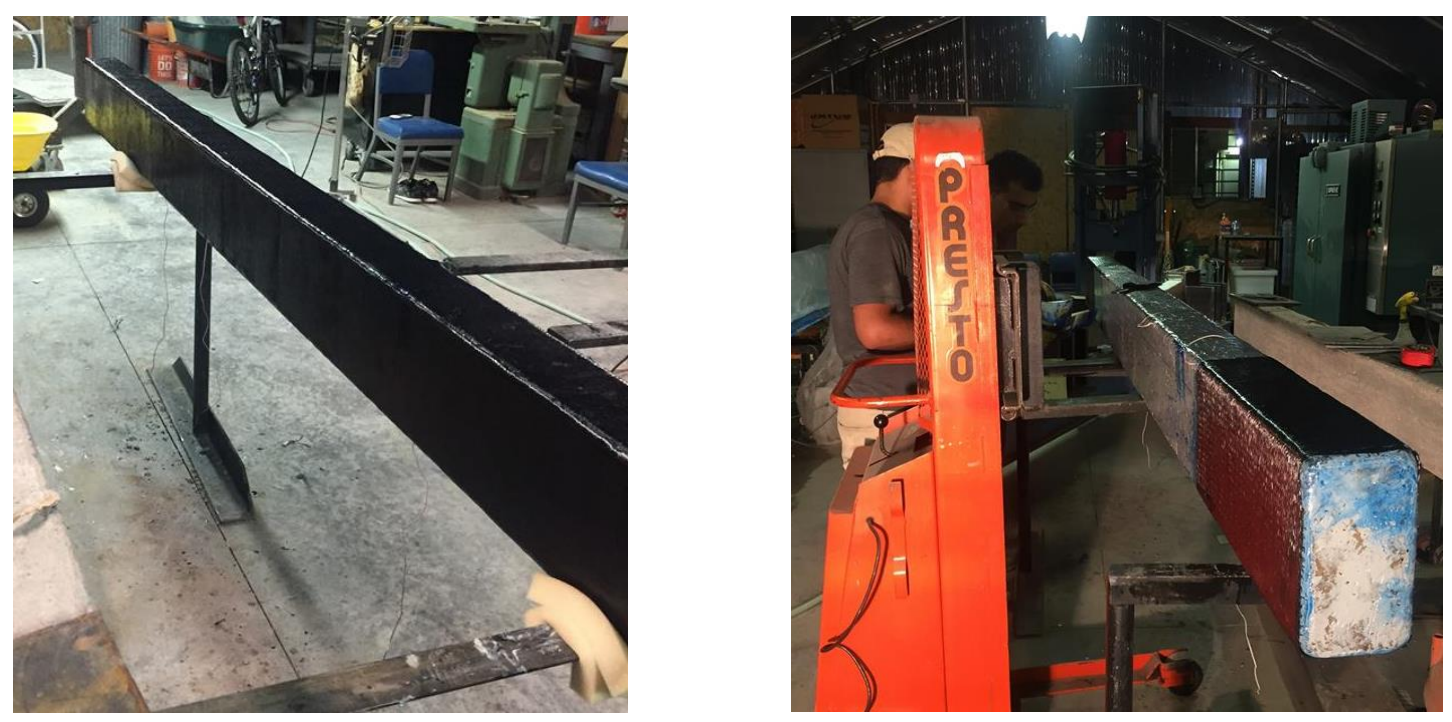

Figure 3-37 the Beam Fully Wrapped with CFRP 


\section{Chapter 4 Experimental Results}

The experimental program as described in Chapter three comprised of six tests divided into two main groups as tabulated as follows:

Table 4-1 Test Beams

\begin{tabular}{|c|c|c|c|}
\hline $\begin{array}{c}\text { Beam } \\
\text { Group }\end{array}$ & $\begin{array}{c}\text { Beam } \\
\text { Designation }\end{array}$ & Description & Loading Scheme \\
\hline \multirow{2}{*}{ A } & A-1 & $\begin{array}{c}\text { Un-strengthened (control } \\
\text { beam 1) }\end{array}$ & Shear and bending \\
\cline { 2 - 4 } & A-2 & $\begin{array}{c}\text { Un-strengthened (control } \\
\text { beam 2) }\end{array}$ & $\begin{array}{c}\text { Shear, bending and } \\
\text { torsion }\end{array}$ \\
\cline { 2 - 4 } & A-3 & Strengthened & $\begin{array}{c}\text { Shear, bending and } \\
\text { torsion }\end{array}$ \\
\hline \multirow{2}{*}{ B } & B-1 & $\begin{array}{c}\text { Un-strengthened (control } \\
\text { beam 1) }\end{array}$ & \begin{tabular}{c} 
Shear and bending \\
\cline { 2 - 4 }
\end{tabular} \\
\cline { 2 - 4 } & B-2 & $\begin{array}{c}\text { Un-strengthened (control } \\
\text { beam 2) }\end{array}$ & $\begin{array}{c}\text { Shear, bending and } \\
\text { torsion }\end{array}$ \\
\hline
\end{tabular}

Details of each beam were described in Chapter 3 . The concrete strength of the ready-mix concrete was significantly higher than the designated strength which was 4000 psi. Thus it was desirable to do the mix design at on-site in the lab. For this purpose, the mix design for 4000 psi was prepared (details of the original mix design are in the appendix).

Another point was that the supports were designed to be so stout that the beams would be gripped well to provide perfect fixity. Dimensional tolerances from both the supports and concrete beams played a great role in the fixity at the end. The development length of the negative rebar also affected the fixity as will be discussed in the subsequent sections per beam. 


\subsection{CFRP Tensile Coupons}

Seven tensile coupons, as described in Chapter 3, were made and tested using the Instron Machine, 100 kips capacity, located in Mechanical Engineering laboratory at Ondine Building at PSU. The CFRP samples were prepared using wet-layup technique with dimensions and geometrics explained in the previous chapter.

The dimensions are shown in Table 4-2.

Table 4-2 CFRP Coupons Details

\begin{tabular}{|c|c|c|c|c|c|}
\hline Sample & Location & $\begin{array}{l}\text { Thickness } \\
\text { (in) }\end{array}$ & $\begin{array}{c}\text { Av. } \\
\text { Thickness } \\
\text { (in) }\end{array}$ & Width (in) & $\begin{array}{l}\text { Av. Width } \\
\quad \text { (in) }\end{array}$ \\
\hline \multirow{3}{*}{ S-1 } & A & 0.020 & \multirow{3}{*}{0.020} & 0.660 & \multirow{3}{*}{0.676} \\
\hline & B & 0.022 & & 0.690 & \\
\hline & $\mathrm{C}$ & 0.020 & & 0.680 & \\
\hline \multirow{3}{*}{ S-2 } & A & 0.025 & \multirow{3}{*}{0.025} & 0.650 & \multirow{3}{*}{0.663} \\
\hline & B & 0.025 & & 0.650 & \\
\hline & $\mathrm{C}$ & 0.025 & & 0.690 & \\
\hline \multirow{3}{*}{ S-3 } & $\mathrm{A}$ & 0.700 & \multirow{3}{*}{0.713} & 0.025 & \multirow{3}{*}{0.0223} \\
\hline & B & 0.720 & & 0.021 & \\
\hline & $\mathrm{C}$ & 0.720 & & 0.021 & \\
\hline \multirow{3}{*}{ S-4 } & $\mathrm{A}$ & 0.715 & \multirow{3}{*}{0.707} & 0.025 & \multirow{3}{*}{0.025} \\
\hline & B & 0.710 & & 0.025 & \\
\hline & $\mathrm{C}$ & 0.697 & & 0.025 & \\
\hline \multirow{3}{*}{$S-5$} & $\mathrm{~A}$ & 0.670 & \multirow{3}{*}{0.675} & 0.025 & \multirow{3}{*}{0.027} \\
\hline & $\mathrm{B}$ & 0.691 & & 0.030 & \\
\hline & $\mathrm{C}$ & 0.665 & & 0.026 & \\
\hline \multirow{3}{*}{ S-6 } & A & 0.777 & \multirow{3}{*}{0.764} & 0.021 & \multirow{3}{*}{0.026} \\
\hline & $\mathrm{B}$ & 0.75 & & 0.029 & \\
\hline & $\mathrm{C}$ & 0.765 & & 0.028 & \\
\hline \multirow{3}{*}{ S-7 } & A & 0.69 & \multirow{3}{*}{0.675} & 0.025 & \multirow{3}{*}{0.024} \\
\hline & $\mathrm{B}$ & 0.675 & & 0.025 & \\
\hline & $\mathrm{C}$ & 0.662 & & 0.022 & \\
\hline
\end{tabular}


The load rate which is recommended by ASTM is $0.01-0.05 \mathrm{in} / \mathrm{min}$. in this test, a 0.02 in/min was used and gave favorable results. For measuring displacement through which the strain could be determined, a laser extensometer and strain gauge were attached to the center of each coupon, as shown in Figure 4-1.

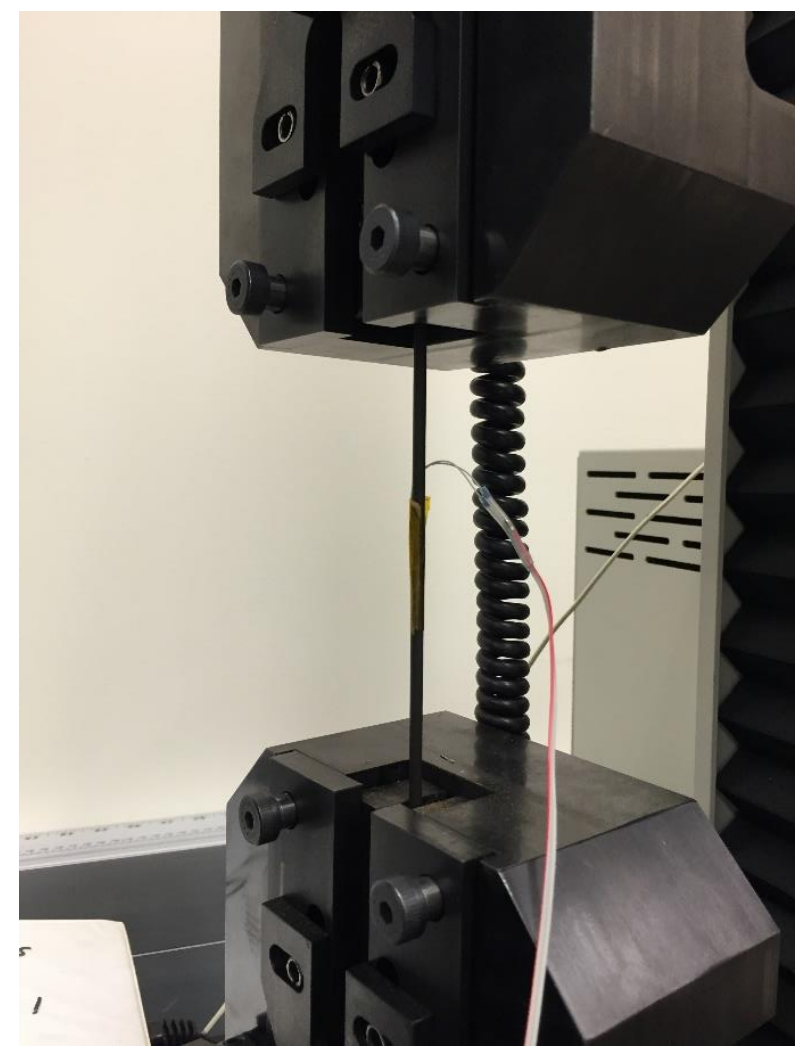

Figure 4-1 S-1 CFRP Tensile Coupon Test

The stress-strain diagram for S-1 sample is shown in Figure 4-2, and Table 4-3 shows a summary of CFRP tensile coupon test results. 


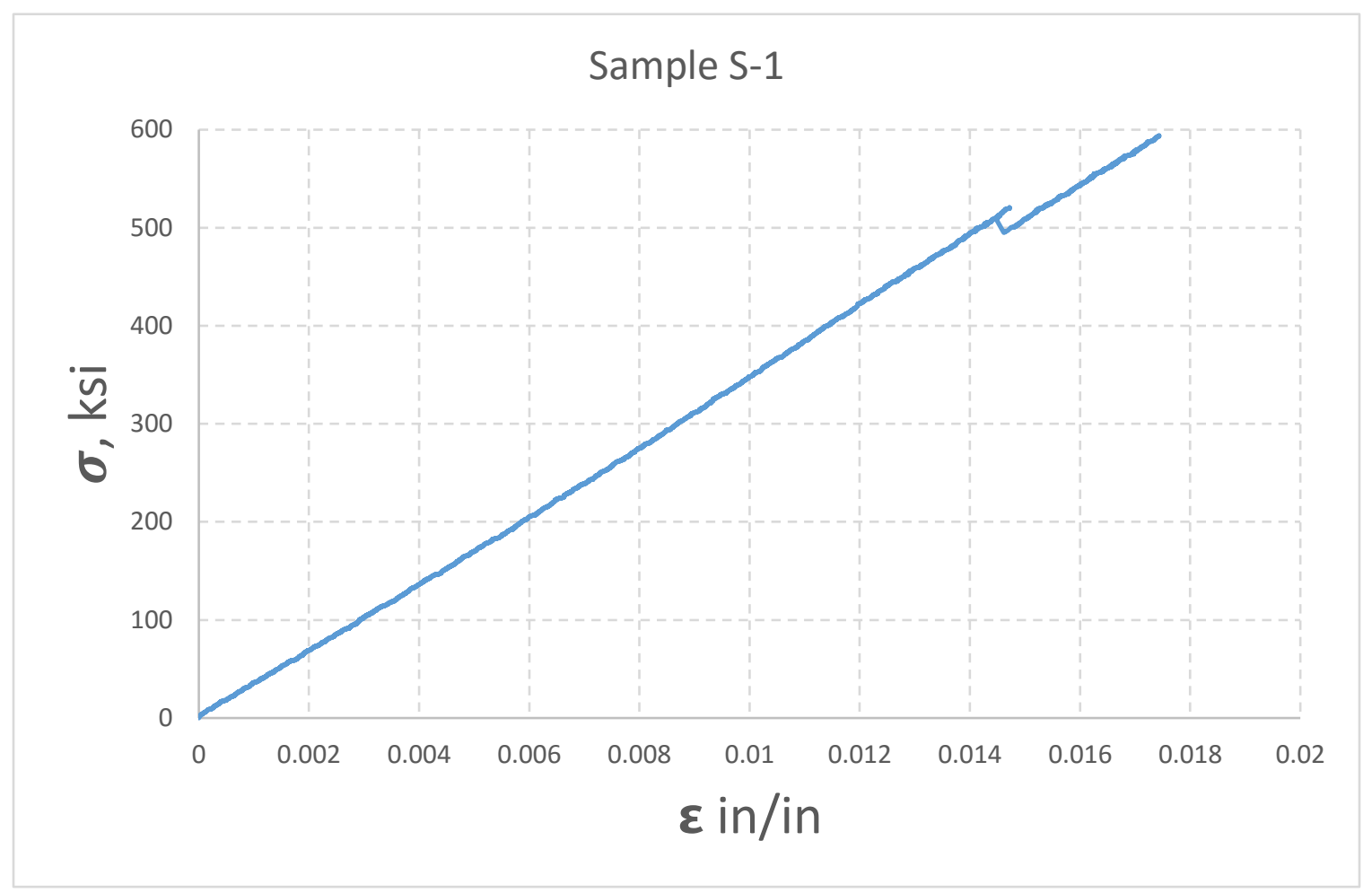

Figure 4-2 Stress-Strain Diagram of Coupon S-1

Table 4-3 Summary of CFRP Tensile Coupon Results

\begin{tabular}{|c|c|c|c|c|}
\hline Sample & $\begin{array}{c}\text { Max Load } \\
(\mathrm{kips})\end{array}$ & $\begin{array}{c}\text { Max Stress } \\
(\mathrm{ksi})\end{array}$ & $\mathrm{E}_{\mathrm{f}}(\mathrm{ksi})$ & $\begin{array}{c}\text { Max Strain at } \\
\text { Failure (in/in) }\end{array}$ \\
\hline S-1 & 2.612 & 594 & 34500 & 0.0174 \\
\hline S-2 & 1.959 & 464 & 37300 & 0.012 \\
\hline S-3 & 2.021 & 436 & - & 0.0172 \\
\hline S-4 & 1.749 & 381 & - & 0.0147 \\
\hline S-5 & 2.044 & 465 & - & 0.0132 \\
\hline S-6 & 2.145 & 432 & - & 0.0136 \\
\hline S-7 & 1.986 & 453 & - & 0.0128 \\
\hline
\end{tabular}

\subsection{Standard Test for Concrete Compression and Modulus of Elasticity}

Per ASTM C469-02, each beam specimen has one or two samples for static modulus of elasticity test from which concrete strength, f'c, was determined. The load rate used in 
the test was is $1 \mathrm{kip} / \mathrm{sec}$ using a 250-kips capacity MTS machine located at South Greenhouse Laboratory on PSU campus, as shown in Figure 4-3. The deformations for strain were measured using two small LVDTs, $1 / 2$ '” capacity each. One cylinder for the A3 test was analyzed and results are shown in Figure 4-4. Other tests results are provided in the appendix.

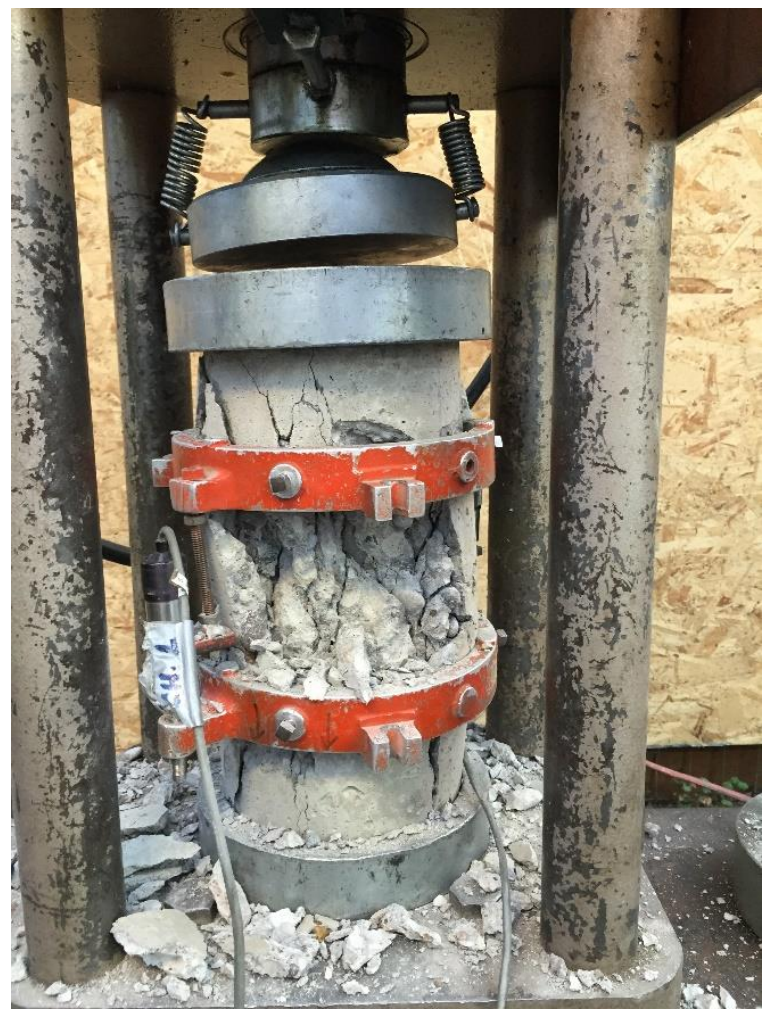

Figure 4-3 Compression Test of Concrete Cylinders 


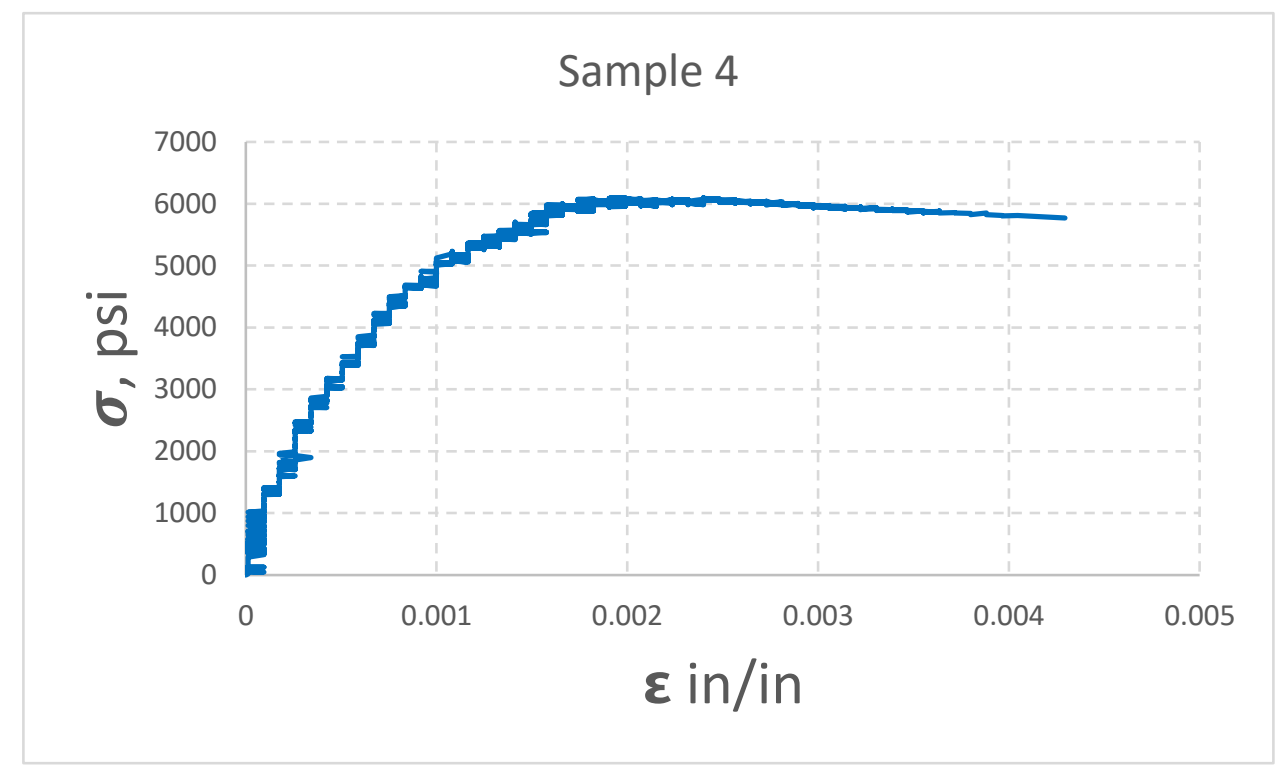

Figure 4-4 Stress-Strain Diagram of a Sample of A-3 Beam Specimen

Concrete capacity, f'c is 6098 psi and the modulus of elasticity measured from $40 \%$ of $f_{c}$ strength was $4315020 \mathrm{psi}$. It is noted that the strain at the maximum stress was 0.002 , as expected.

\subsection{Concrete Tensile Splitting Test}

Per ASTM 496C-04, two concrete cylinders were loaded transversely to determine their tensile splitting strengths, as explained in Chapter 3.

The strength was calculated from the following equation:

$$
\mathrm{T}=\frac{2 p}{\pi D L}
$$

Where $\mathrm{D}=6$ ', $\mathrm{L}=12$ ',

The results are as follows: 
Table 4-4 Tensile Splitting Test Results

\begin{tabular}{|c|c|c|}
\hline Sample & Failure Load (lbs) & Strength (psi) \\
\hline 1 & 56480 & 499 \\
\hline 2 & 55960 & 494 \\
\hline
\end{tabular}
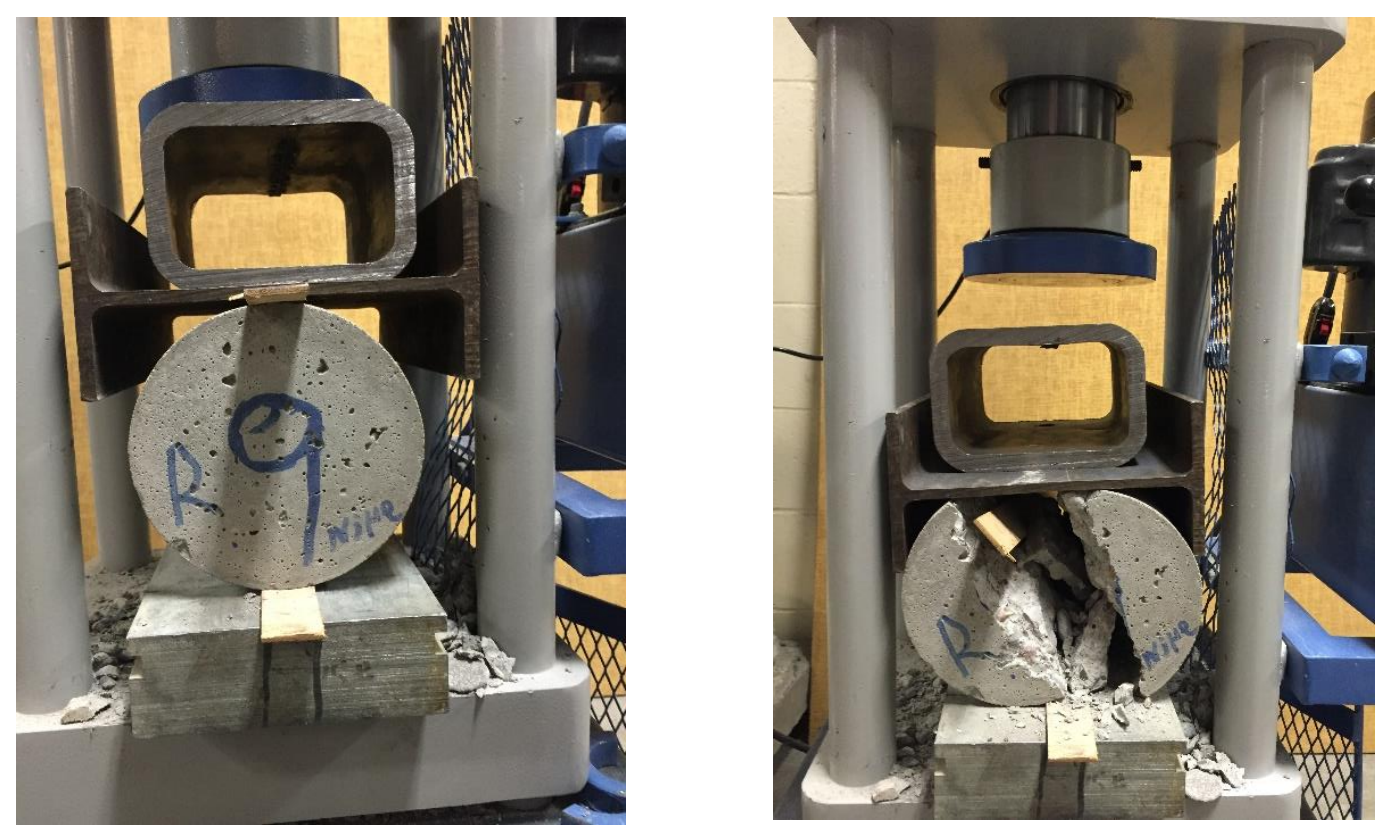

Figure 4-5 Tensile Splitting Failure of a B-1 Test Cylinder (a Typical Sample)

\subsection{Beam Tests}

All beams were tested using a 50-kips load cell capacity. For each beam, three concrete cylinders of standard size 6 " $\times 12$ ' were tested. An analogue computer data acquisition system was used to record the data from the load cell, strain gauges, and LVDTs.

Rotation was calculated from the LVDT data. 


\subsubsection{Control Beam, A-1}

Beam A-1 was an un-strengthened control beam. The loading on this beam created shear and bending, without torsion. The concrete strength results are shown in Table 4-5; all samples were standard 6" 12 " cylinders.

\section{Table 4-5 Concrete Cylinder Results for Beam A-1}

\begin{tabular}{|c|c|}
\hline Sample & $\begin{array}{c}\text { Comp. } \\
\text { Strength (psi) }\end{array}$ \\
\hline 1 & 6440 \\
\hline 2 & 6207 \\
\hline 3 & 6430 \\
\hline Average & 6459 \\
\hline
\end{tabular}

Figure 4-6 shows the load-deflection response of beam A-1. The load-deflection behavior followed a typical concrete beam behavior, reaching a maximum load of 14.4 kips. Strain in the longitudinal reinforcement at the face of the support where maximum negative moment was expected to occur did reach its yield strength (max strain of about 0.01 ). Stirrup strain gauges near the loading points indicated that the strain in stirrups reached yield strength (0.0005). Please refer to Figure 3-19 for stress-strain diagram of transverse reinforcements. 


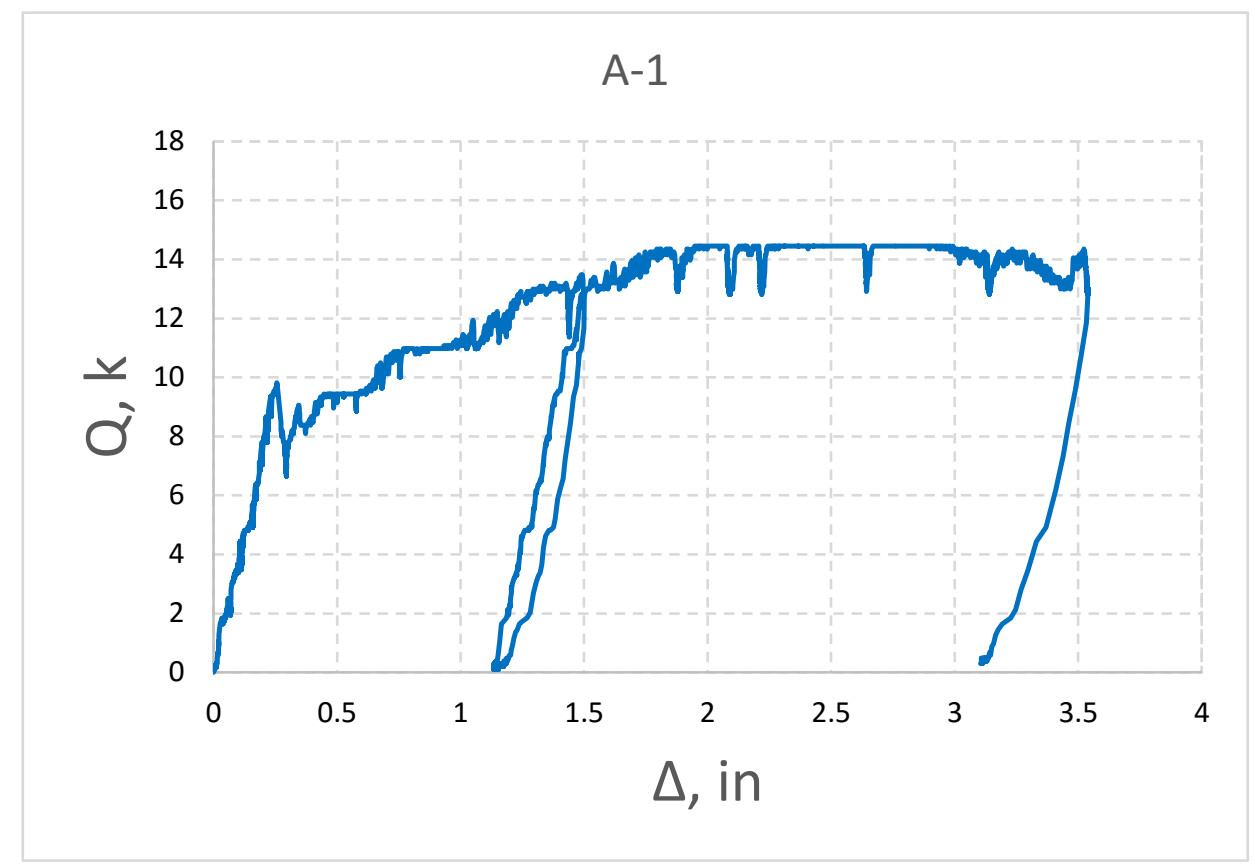

Figure 4-6 Load-Deflection Curve of Beam A-1

Due to a technical issue during the test, the system was unloaded and then reloaded making the test go through two cycles. At load about 10 kips, it dropped by about 3 kips. This was considered to have been caused by the concrete fracture inside the support sleeve, making the beam behave more like a simply supported beam. Flexural cracks began to initiate at 4 kips, before diagonal shear cracks formed. The crack width stayed very small (about $0.1 \mathrm{~mm}$ ) until 9 kips, and then suddenly it increased to $0.5 \mathrm{~mm}$. The failure type was shear-flexure with excessive cracks at the mid-span followed by midspan concrete spalling as shown in Figures 4-7 and 4-8. 


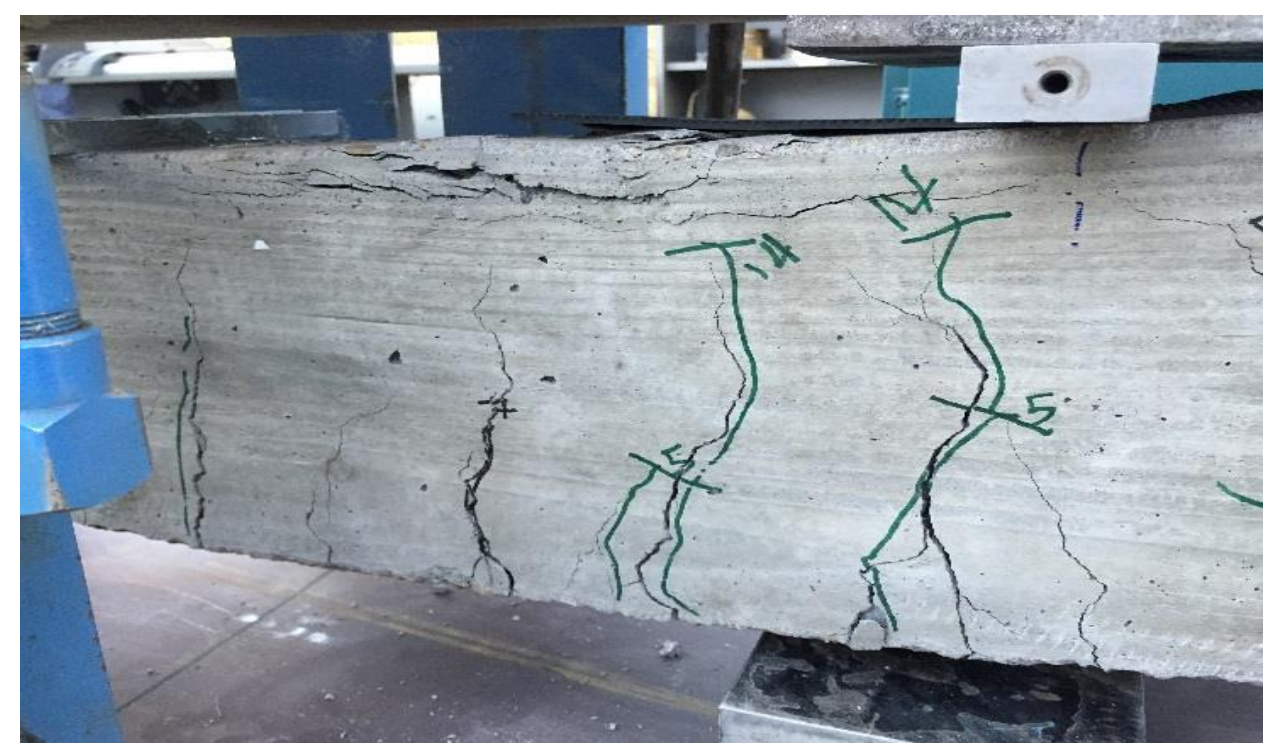

Figure 4-7 Concrete Spalling at Mid-Span

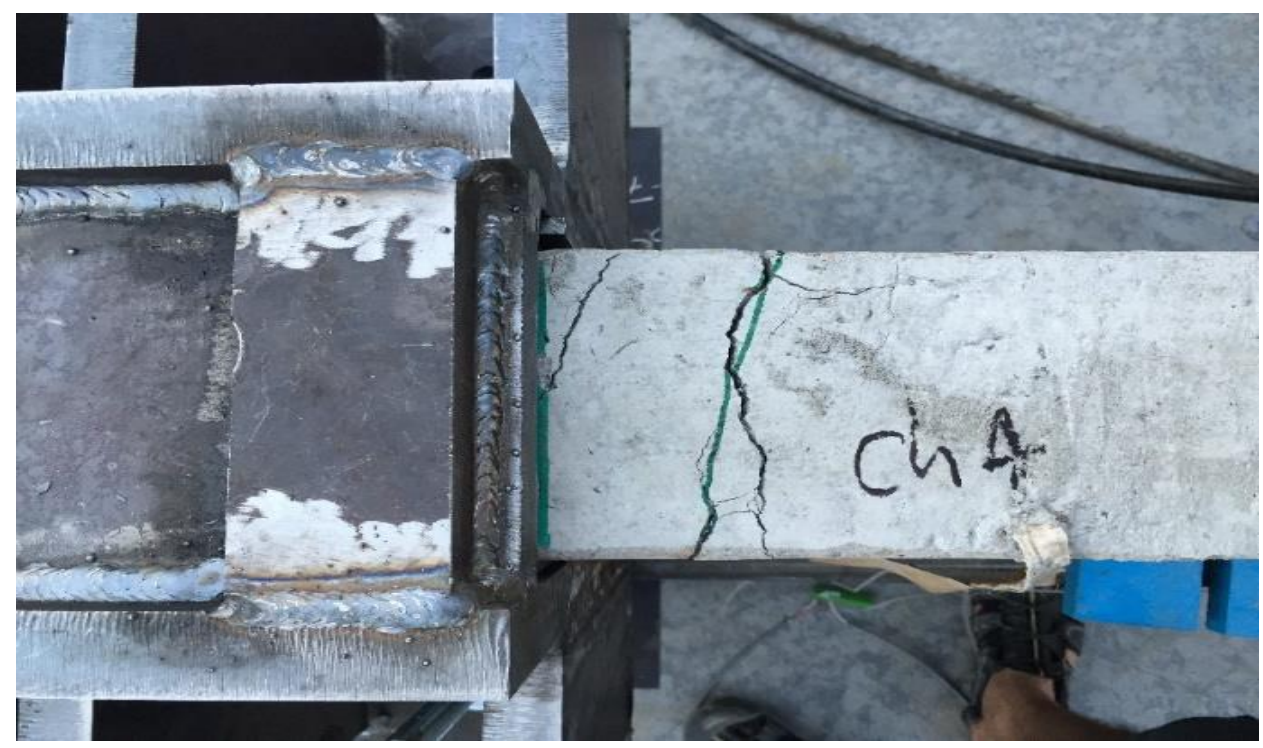

Figure 4-8 Excessive Cracks at the Ends

Degree of fixity at the ends during initial load stages appeared high by visual inspection.

The supports were intended to provide full fixity in which hinging occurred near the ends 
and the final failure occurred near the mid-span. For the purpose of analysis at loads higher than 10 kips, it may be considered that the beam was simply supported because the concrete in the support zone, inside the 13" sleeve, was substantially crushed (Figure 49) and thus most of its stiffness was lost. This is evident in Figure 4-5 where the initial stiffness is about 20 kips per inch and the stiffness drops to about 4 kips per inch after the peak load. This is compatible with the stiffness ratio of fixed ended beam to partially fixed beam, which is about 5 to 1 .

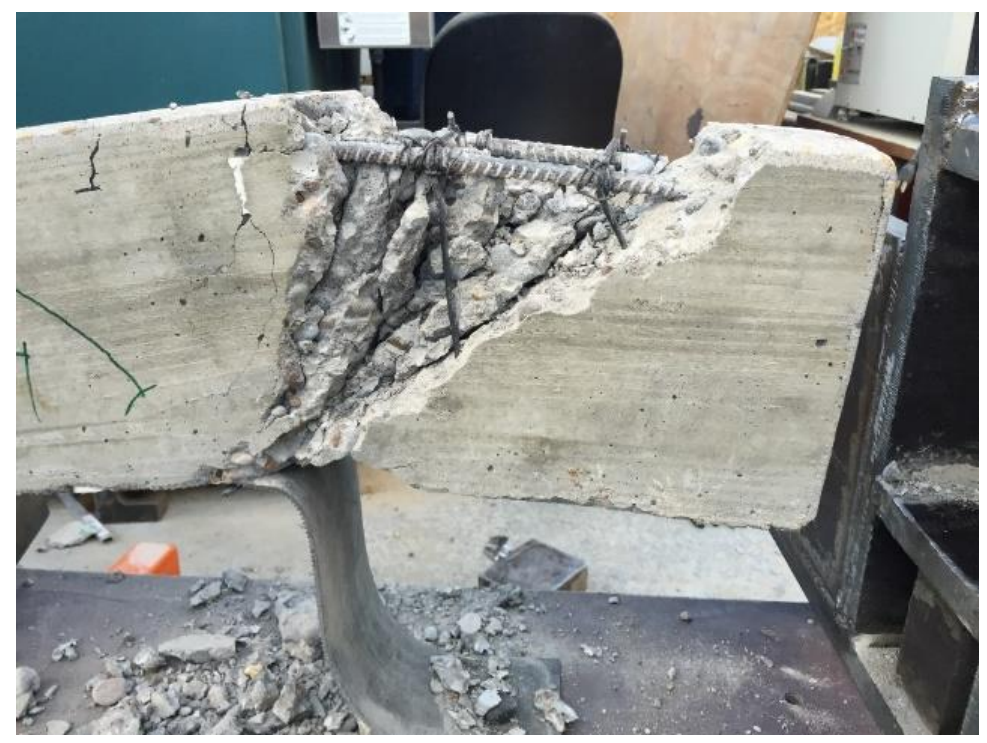

Figure 4-9 Concrete Crush in the Support Sleeve Zone

Summary of information about Beam A-1 is in Table 4-6. 
Table 4-6 Summary of A-1 Specimen

\begin{tabular}{|c|c|}
\hline Beam designation & A-1 \\
\hline Avg. compressive strength & $6459 \mathrm{psi}$ \\
\hline Mid-span yield deflection & $0.25^{\prime \prime}$ \\
\hline Mid-span ultimate deflection & $3.52^{\prime \prime}$ \\
\hline Max stirrup strain & 0.00175 \\
\hline Max -M steel strain & 0.0099 \\
\hline Ultimate load capacity & 14.5 kips \\
\hline Maximum crack width & 5 mm \\
\hline Failure type & $\begin{array}{c}\text { Shear-flexure } \\
\text { with mid-span } \\
\text { concrete spalling }\end{array}$ \\
\hline
\end{tabular}

Ductility is the amount of energy dissipation under the load-deflection curve or torquetwist curve, which can be obtained by integrating the area under the load-deflection or torque-twist curves. However, many researchers have used simplified ratios (ratio of ultimate divided by yield), also used in this thesis:

$$
\begin{gathered}
\text { Flexural } \mu=\frac{\Delta_{u}}{\Delta_{y}} \\
\text { Torsional } \mu=\frac{\emptyset_{u}}{\emptyset_{y}}
\end{gathered}
$$

For Specimen A-1:

Flexural ductility $=\frac{\Delta u}{\Delta y}=\frac{3.528}{0.251}=14$ 


\subsubsection{Control Beam, A-2}

Beam A-2 was a control specimen designed based on "medium level" load, and was subjected to moment, shear and torque. Please refer to Table 4-1 for a summary information about all test specimens.

The concrete strength samples were tested the results are shown in Table 4-7, all samples were standard 6"x12" cylinders.

\section{Table 4-7 Concrete Strength of A-2 Specimen}

\begin{tabular}{|c|c|}
\hline Sample & $\begin{array}{c}\text { Comp. } \\
\text { Strength (psi) }\end{array}$ \\
\hline 1 & 6066 \\
\hline 2 & 6090 \\
\hline 3 (138.6 pcf) & 5392 \\
\hline 4 (138.2 pcf) & 5751 \\
\hline Average & 5825 \\
\hline
\end{tabular}


Figure 4-10 shows a view of the test specimen while being prepared for testing and Figure 4-11 shows the mechanism of torsional loading system.

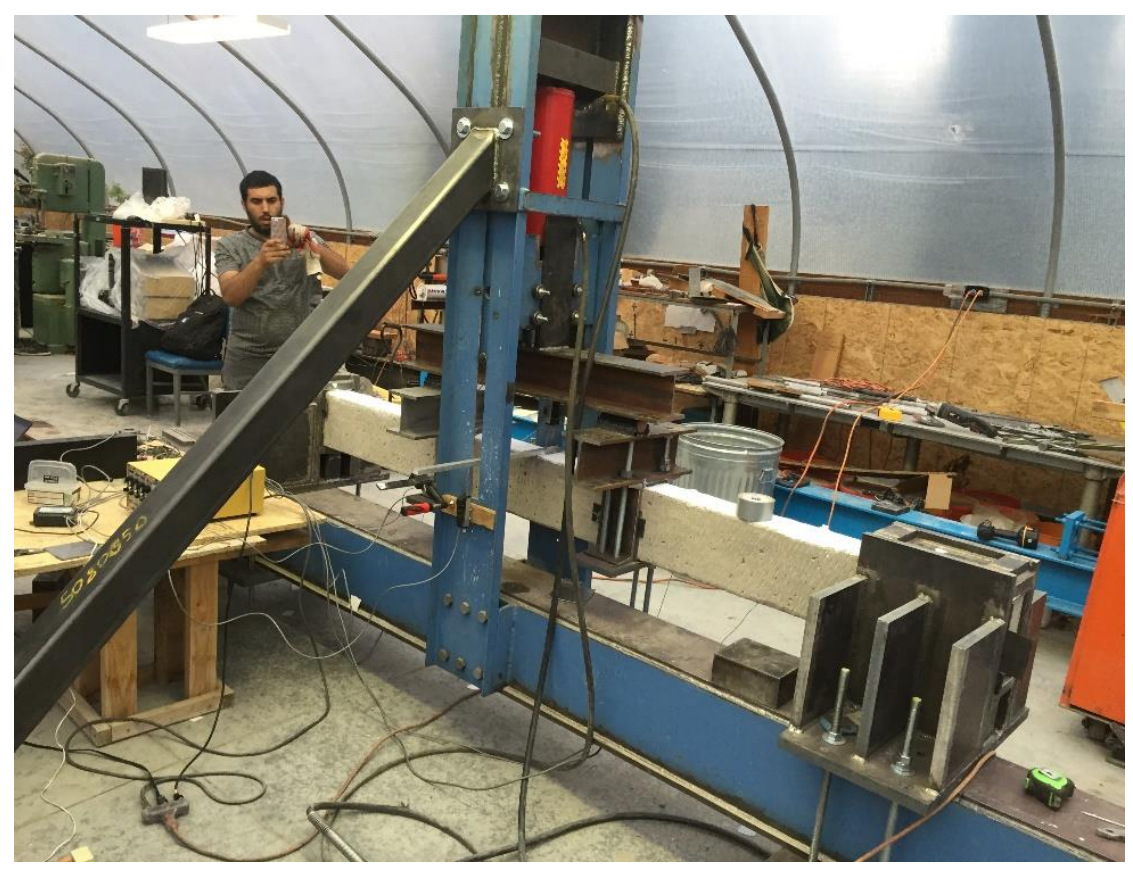

Figure 4-10 A-2 Specimen Prepared for Testing

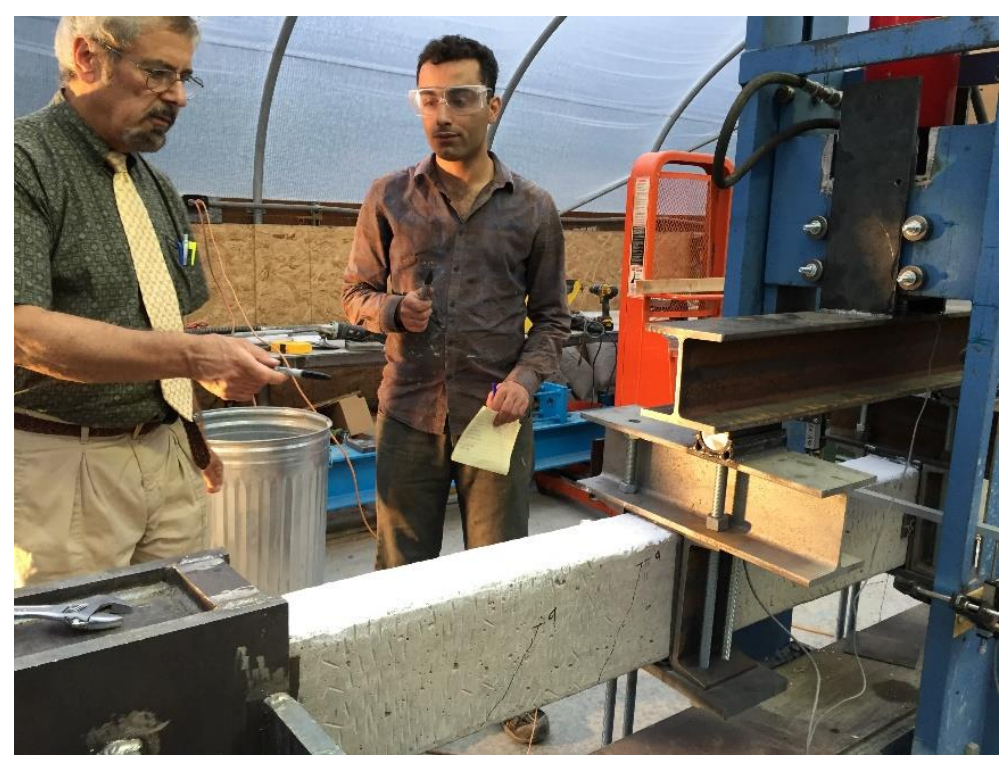

Figure 4-11 Torsional Load Application, A-2 Specimen 
The load-deflection curve of this specimen, A-2, is shown in Figure 4-12.

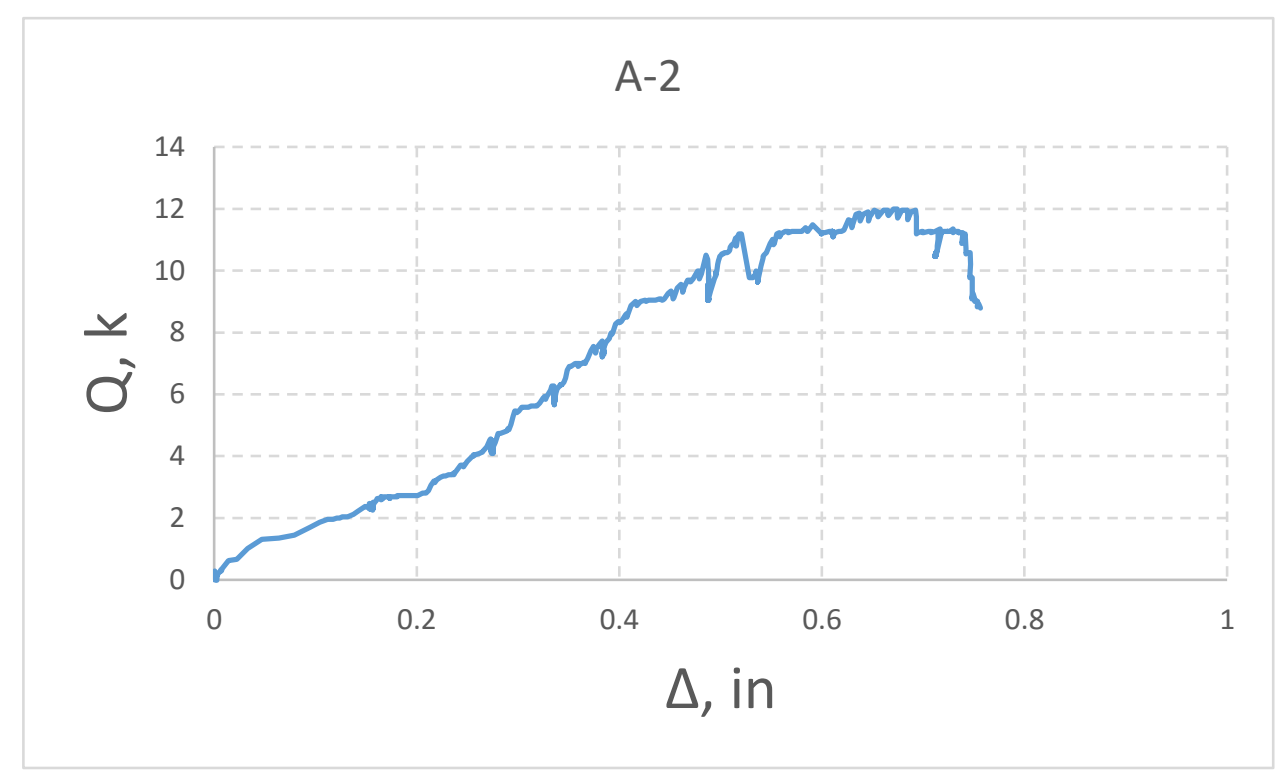

Figure 4-12 Load-Deflection Curve of A-2 Specimen

Flexural ductility $=\frac{0.756}{0.406}=1.8$

This test started with hairline flexural cracks at 2 kips, and then helical torsional cracks propagated near the support starting from $1 \mathrm{~mm}$. At $10 \mathrm{kips}$ the crack widths opened rapidly and reached $2 \mathrm{~mm}$ after less than one kip additional load. Soon after, the helical cracks opened up widely, to about $5 \mathrm{~mm}$, and the specimen failed without substantial deflection. No concrete spalling occurred at any place across the span, even in the support region. The negative steel reinforcement strain gauge read strain of 0.0029 , which just exceeded its yield limit, but soon after yield the beam failed under torsion without undergoing any extra deformation. The transverse reinforcements exceeded their yield limit $(0.0005)$ as well, and the maximum value was 0.0009 . The fact that the stirrup wires 
were open at the top caused or substantially contributed to early torsional failure. The torsional cracks were mostly seen on the sides of the beam from the points of load application to the end supports, i.e., the "torques regions" of the beam. The beam sustained the overall load of 11.9 kips and mid-span deflection of 0.75 inch.

The torque-twist curve of A-2 is shown in Figure 4-13.

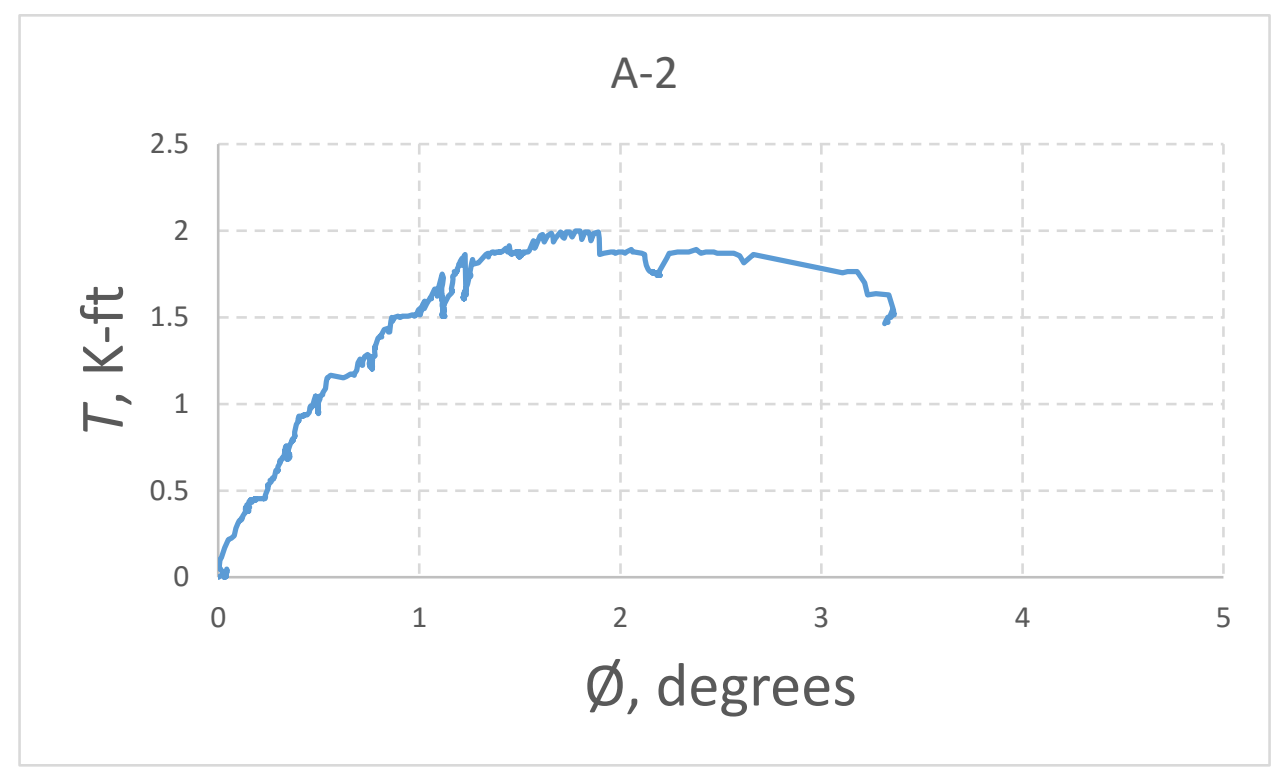

Figure 4-13 Torque-Twist Curve of A-2 Specimen

Torsional ductility $=\frac{3.362}{0.902}=3.7$

The following table outlines the test main results: 
Table 4-8 Summary of A-2 Specimen

\begin{tabular}{|c|c|c|}
\hline Beam designation & $\mathrm{A}-2$ & Comments \\
\hline Failure type & torsion & \\
\hline Maximum load, Q & $11.9 \mathrm{kips}$ & \\
\hline Maximum torque, $\mathrm{T}$ & $2 \mathrm{k}-\mathrm{ft}$ & \\
\hline $\begin{array}{c}\text { Maximum } \\
\text { deflection, } \Delta\end{array}$ & $0.75 \mathrm{in}$ & $>0.0005\left(\epsilon_{y t}\right)$ \\
\hline $\begin{array}{c}\text { Maximum twisting } \\
\text { angle, } \varnothing\end{array}$ & 3.36 degrees \\
\hline $\begin{array}{c}\text { Maximum stirrup } \\
\text { strain, } \epsilon_{t}\end{array}$ & 0.00944 & $>0.002\left(\epsilon_{y}\right)$ \\
\hline $\begin{array}{c}\text { Maximum }-\mathrm{M} \\
\text { reinforcement } \\
\text { strain, } \epsilon_{s}\end{array}$ & 0.00292 & \\
\hline Flexural ductility & 1.8 & \\
\hline Torsional ductility & 3.7 & \\
\hline
\end{tabular}

Figure 4-14 shows the side view of A-2 specimen at torsional failure and Figure 4-15 shows the top view at failure. 


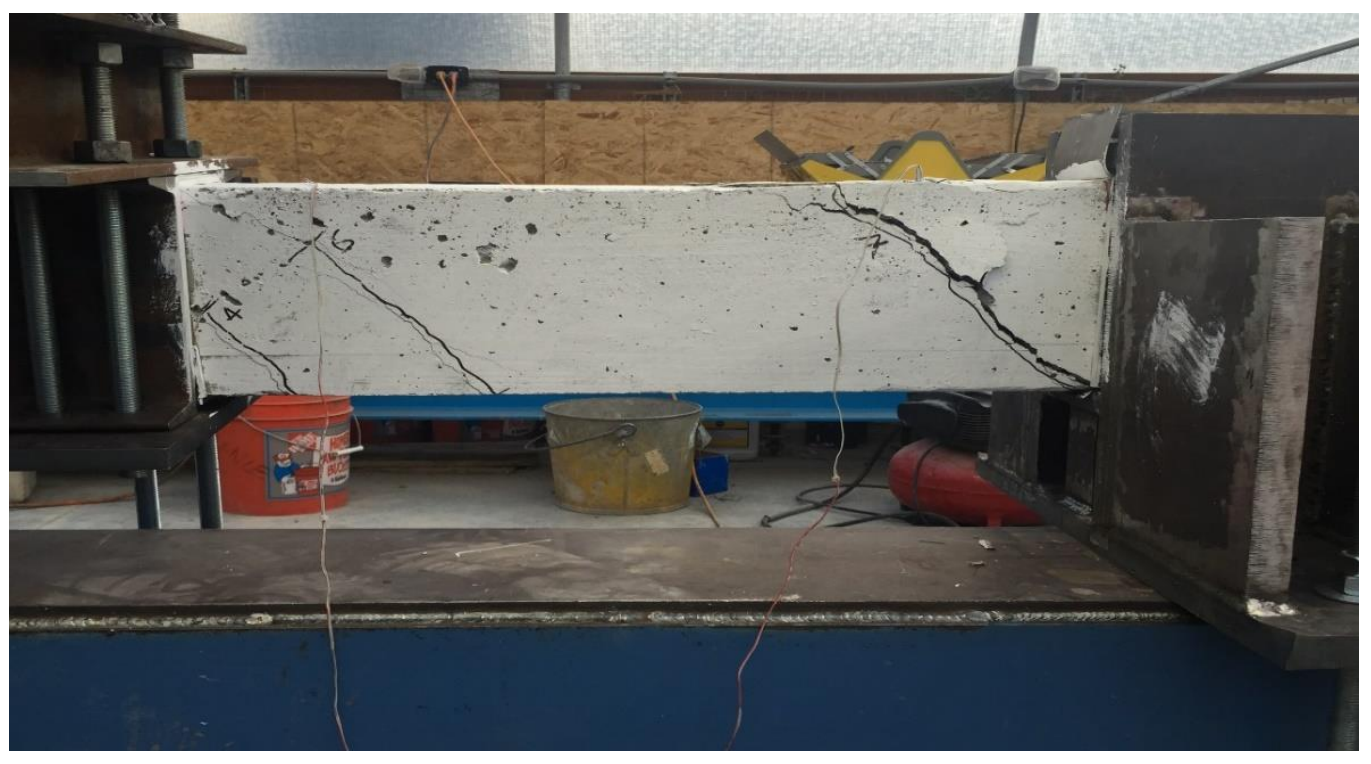

Figure 4-14 Side View of A-2 Specimen at Torsional Failure

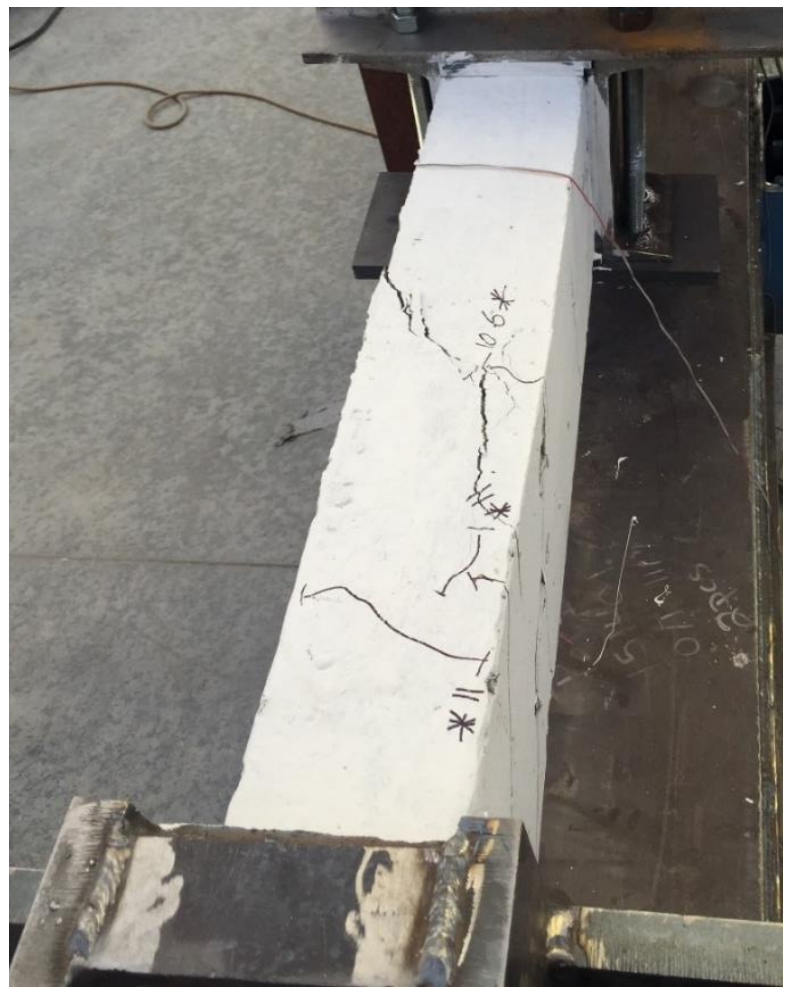

Figure 4-15 Top View of A-2 Specimen at Failure 


\subsubsection{Strengthened Beam, A-3}

Beam A-3 was the same as the control specimens A-1 and A-2 (designed based on "medium level" load), except that this specimen was strengthened by one layer of CFRP wrap. This specimen was subjected to moment, shear and torque, so its behavior can be compared to specimen A-2. Please refer to Table 4-1 for a summary information about all test specimens.

The concrete cylinder strength results are shown in Table 4-9, all samples were standard 6"x12" cylinders.

\section{Table 4-9 Concrete Strength of A-3 Specimen}

\begin{tabular}{|c|c|}
\hline Sample & $\begin{array}{c}\text { Comp. } \\
\text { Strength (psi) }\end{array}$ \\
\hline 1 & 6098 \\
\hline 2 & 6210 \\
\hline Average & 6154 \\
\hline
\end{tabular}

The CFRP cured for eight days prior to the test. The load-deflection curve is shown in figure 4-16. 


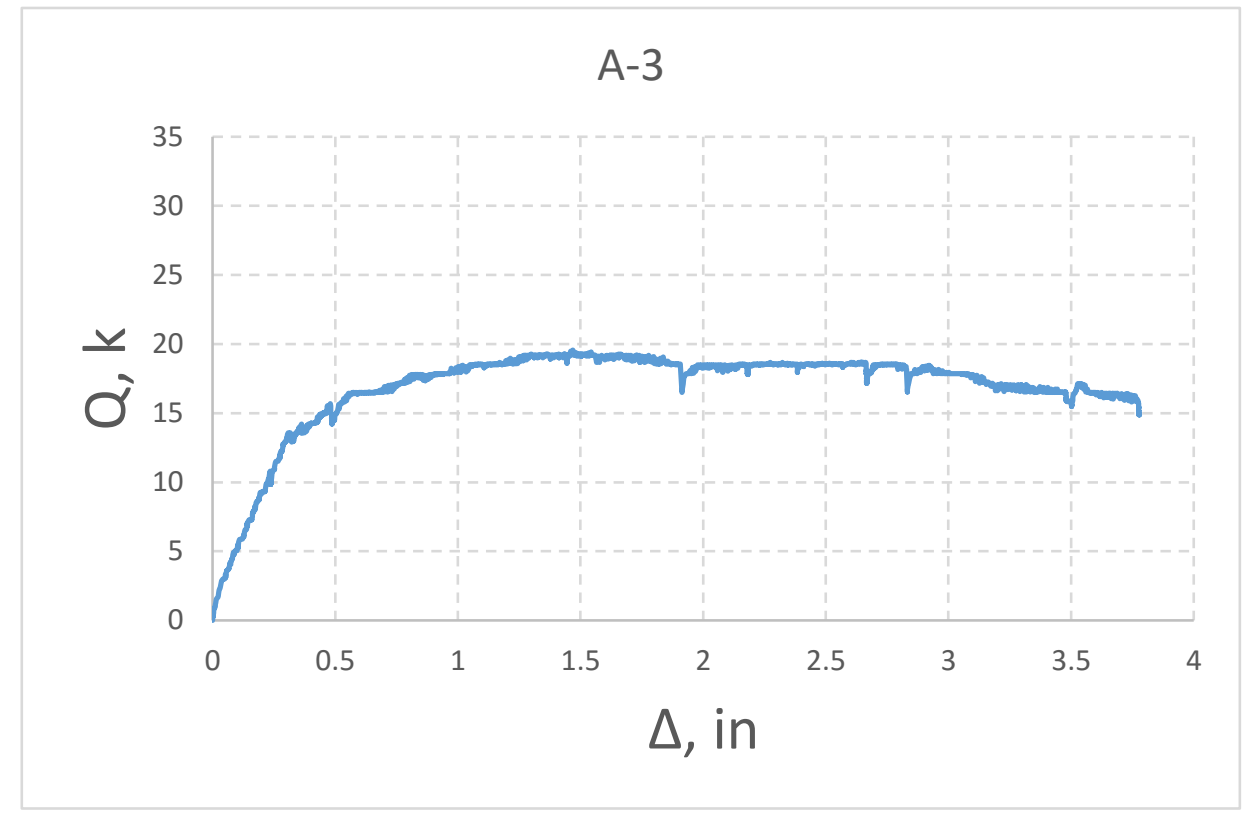

Figure 4-16 Load-Deflection Curve for Beam A-3

Flexural ductility $=\frac{3.776}{0.33}=11.4$

The beam carried a maximum of 19.5 kips, which was significantly higher than A-2 capacity. The stirrups underwent large deformations, as outlined in the following table. The negative moment strain gauge read 0.0199, which was a good indicator that the CFRP wrap provided very good confinement to delay premature failure due to the lack of development length, as the concrete crush would be delayed. At failure, the shear cracks inside the support were noted after removing the CFRP sheets for investigation. It was also observed that the cracks were more uniformly distributed throughout the whole span. Flexural cracks were formed along with shear cracks only in the support area. No concrete crush was noted in this test around mid-span.

The torque-twist curve for beam A-3 is shown in Figure 4-17. 


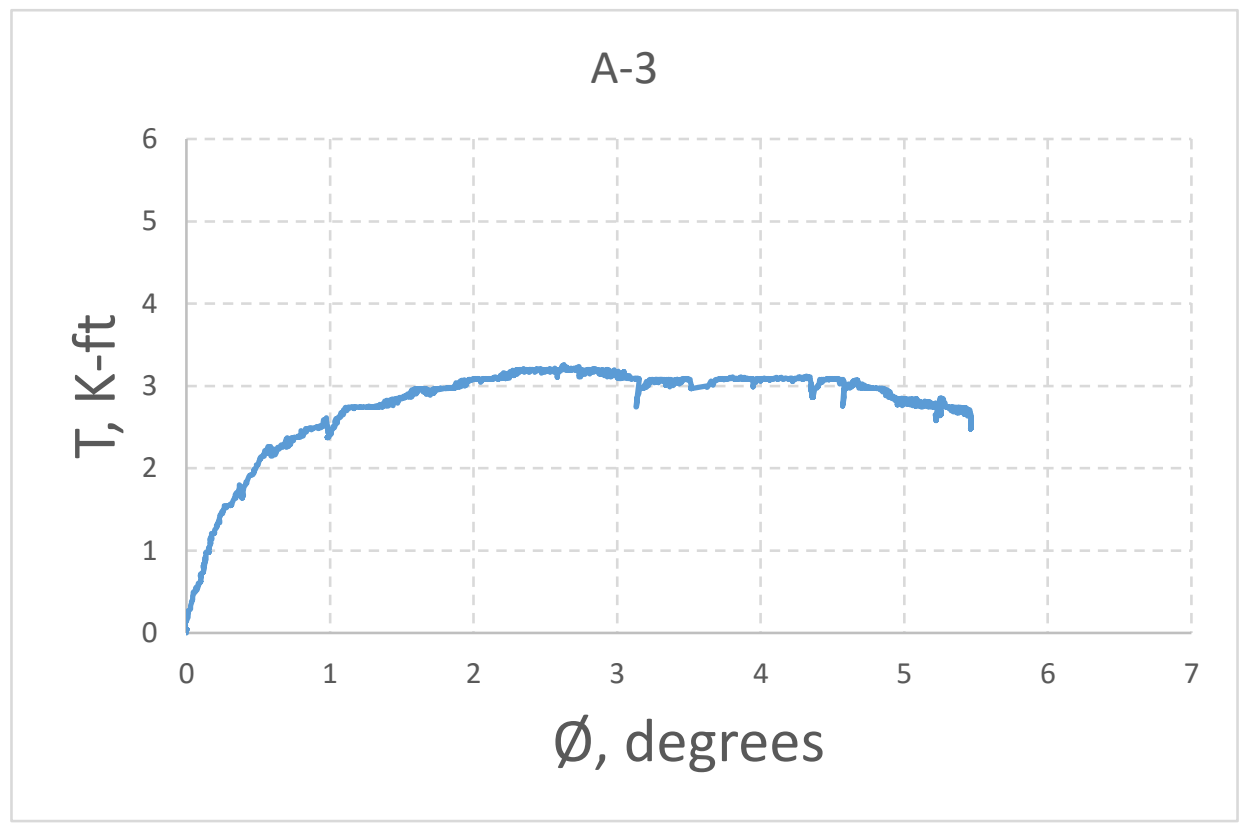

Figure 4-17 Torque-Twist Curve for Beam A-3

The torsional behavior of the beam was greatly enhanced for this specimen because no shear or helical cracks were seen until failure. In the previous beam specimen, A-2, the beam failed under torsion and two helical loops formed at each side of the load application. No such cracks were-apparent in this test. The beam failed in a flexural mode failure, which is more desirable as shown in Figure 4-18.

The Torsional ductility $=\frac{5.465}{0.544}=10$. 
The following table shows the test main results:

Table 4-10 Summary of A-3 Specimen

\begin{tabular}{|c|c|c|}
\hline Beam designation & A-3 & Comments \\
\hline CFRP curing time & Eight days & \\
\hline Failure type & $\begin{array}{c}\text { Flexure with shear } \\
\text { cracks inside supports }\end{array}$ & \\
\hline Maximum load, Q & 19.5 kips & \\
\hline Maximum torque, $\mathrm{T}$ & $3.26 \mathrm{k}$-ft & \\
\hline Maximum deflection, $\Delta$ & 4 in & Strain $>>0.0005$ \\
\hline Maximum twisting angle, $\emptyset$ & 5.46 degrees & Strain $>>0.002$ \\
\hline Maximum stirrup strain, $\epsilon_{t}$ & 0.00322 & Strain is $25 \%$ of rupture \\
strain of $\epsilon_{f e}=1.67 \%$ )
\end{tabular}




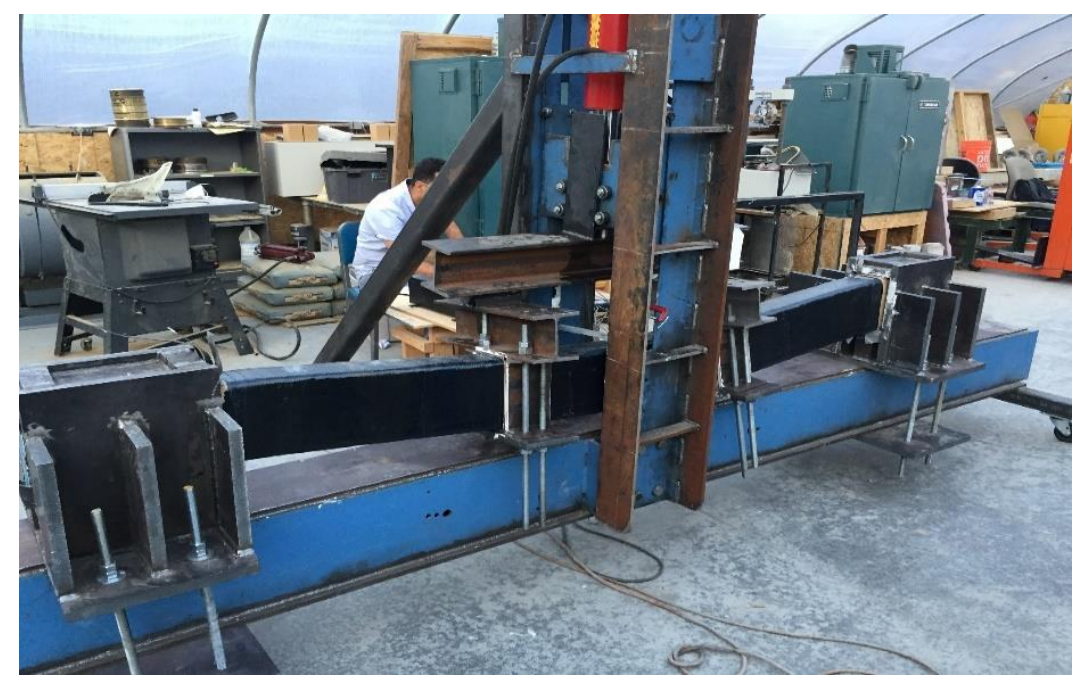

Figure 4-18 A-3 Specimen under Excessive Deformation at Failure

Another beam was tested having the same detail as A-3 with CFRP sheets cured for a month. For this beam the data were inadvertently not recorded. The beam failed at 20.8 kips and its overall behavior appeared to be very similar to specimen A-3.

\subsubsection{Control Beam, B-1}

This beam specimen was the same as beam A-1 except it was designed based on a higher design load. It was subjected to shear and bending, without torsion. Please refer to Chapter 3 for a description of the test specimens.

The concrete strength samples are tested the results are as follows, all samples were standard 6" $\mathrm{x} 12$ " cylinders: 
Table 4-11 Concrete Cylinder Results for B-1 Specimen

\begin{tabular}{|c|c|}
\hline Sample & $\begin{array}{c}\text { Comp. } \\
\text { Strength (psi) }\end{array}$ \\
\hline 1 & 6623 \\
\hline 2 & 6273 \\
\hline Average & 6448 \\
\hline
\end{tabular}

This test was performed through one cycle monotonic loading. The load-deflection curve (shown in Figure 4-19) followed a typical concrete beam load-deflection curve. The beam carried a total load of 15.9 kips, which is higher than that of the first beam (A-1) which had a lower longitudinal reinforcement ratio. First hairline flexural cracks formed at 5 kips. When the load reached 11 kips, extensive flexural cracks near the supports began to form. At $\mathrm{Q}=16 \mathrm{kips}$, which was just prior to the maximum load, the flexural cracks width was $2 \mathrm{~mm}$, and diagonal shear cracks $1 \mathrm{~mm}$. 
It was apparent that no concrete crushing occurred in the support sleeves at all stages of loading. The beam failed in shear before reaching flexural strength near supports.

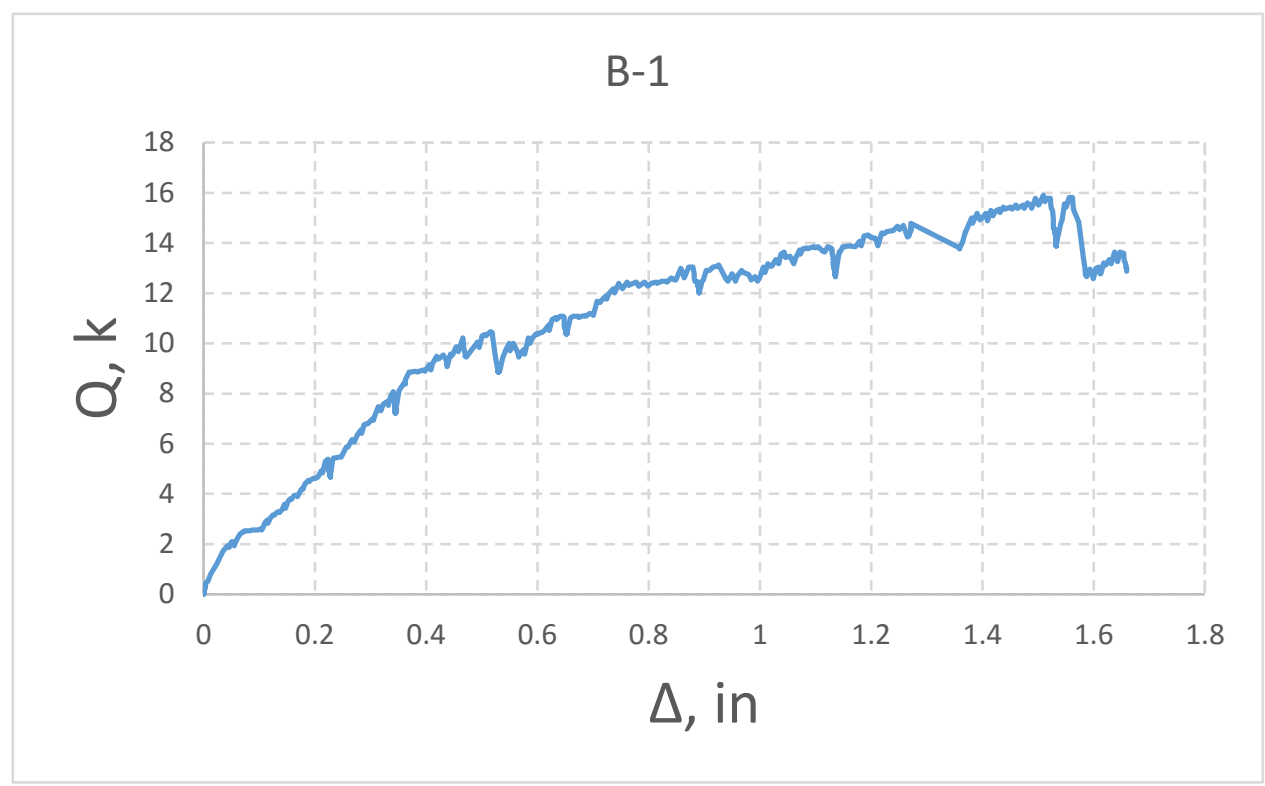

Figure 4-19 Load-Deflection Curve for Beam B-1

The maximum deflection was 1.6 " and the beam did not undergo large vertical deflection as compared to specimen A-1. The yield deflection (the end point of the initial stiffness) was about $0.5 \%$. Both transverse steel strain gauges recorded a great amount of strain beyond yield strain. The longitudinal steel at the negative moment region reached a strain of 0.0009 , which is about half of yield strain (0.002). The cracks opened very widely from the point of load application to the support. One side of the support did not show considerable cracks. Failure was due to shear, hence no visible signs of a "flexure" failure was evident at mid-span, i.e., no concrete compression spalling. 
Test results for specimen B-1 are shown in Table 4-12, and Figures 4-20 and 4-21 show the shear failure zone.

Table 4-12 Summary of B-1 Specimen

\begin{tabular}{|c|c|}
\hline Beam designation & B-1 \\
\hline Avg. compressive strength & $6448 \mathrm{psi}$ \\
\hline Mid-span yield deflection & $0.39^{\prime \prime}$ \\
\hline Mid-span ultimate deflection & $1.65^{\prime \prime}$ \\
\hline Max stirrup strain & 0.0011 \\
\hline Max -M steel strain & $\mathrm{NA}$ \\
\hline Ultimate load capacity & $15.9 \mathrm{kips}$ \\
\hline Maximum crack width & $7.5 \mathrm{~mm}$ \\
\hline Failure type & Shear \\
\hline
\end{tabular}


Flexural ductility $=\frac{1.659}{0.394}=4.2$

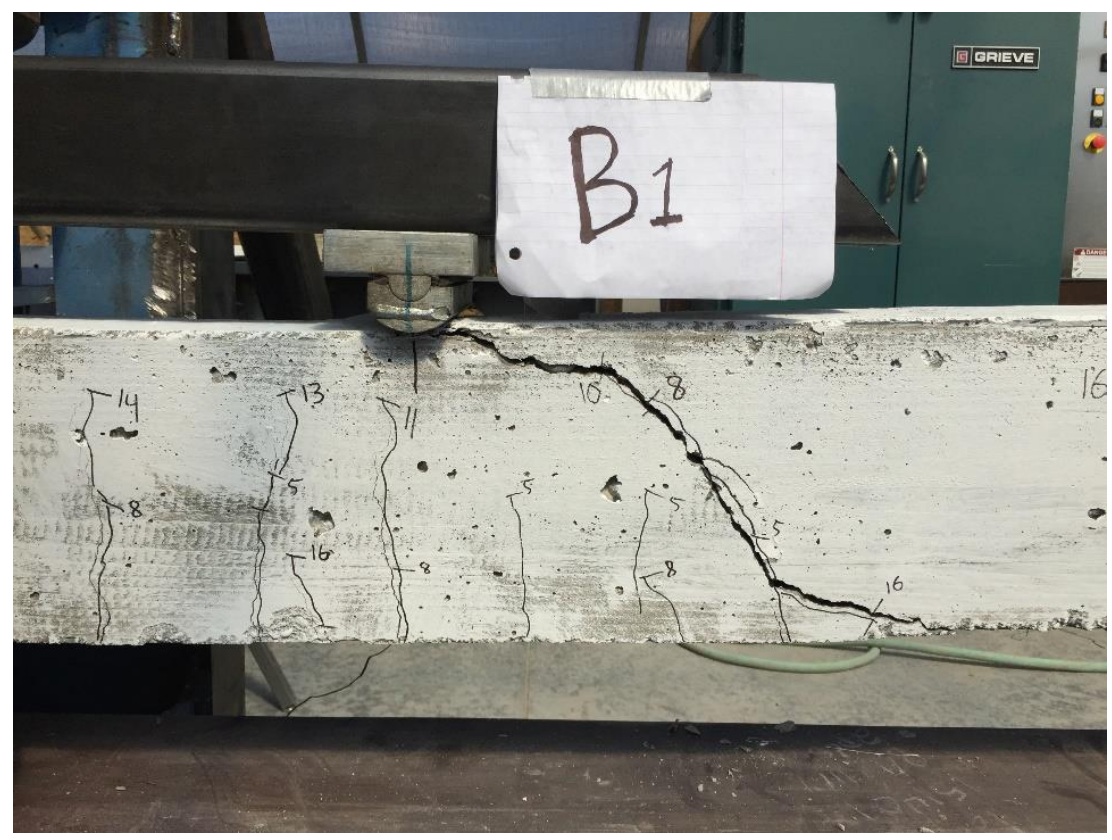

Figure 4-20 Shear Failure of B-1 Beam

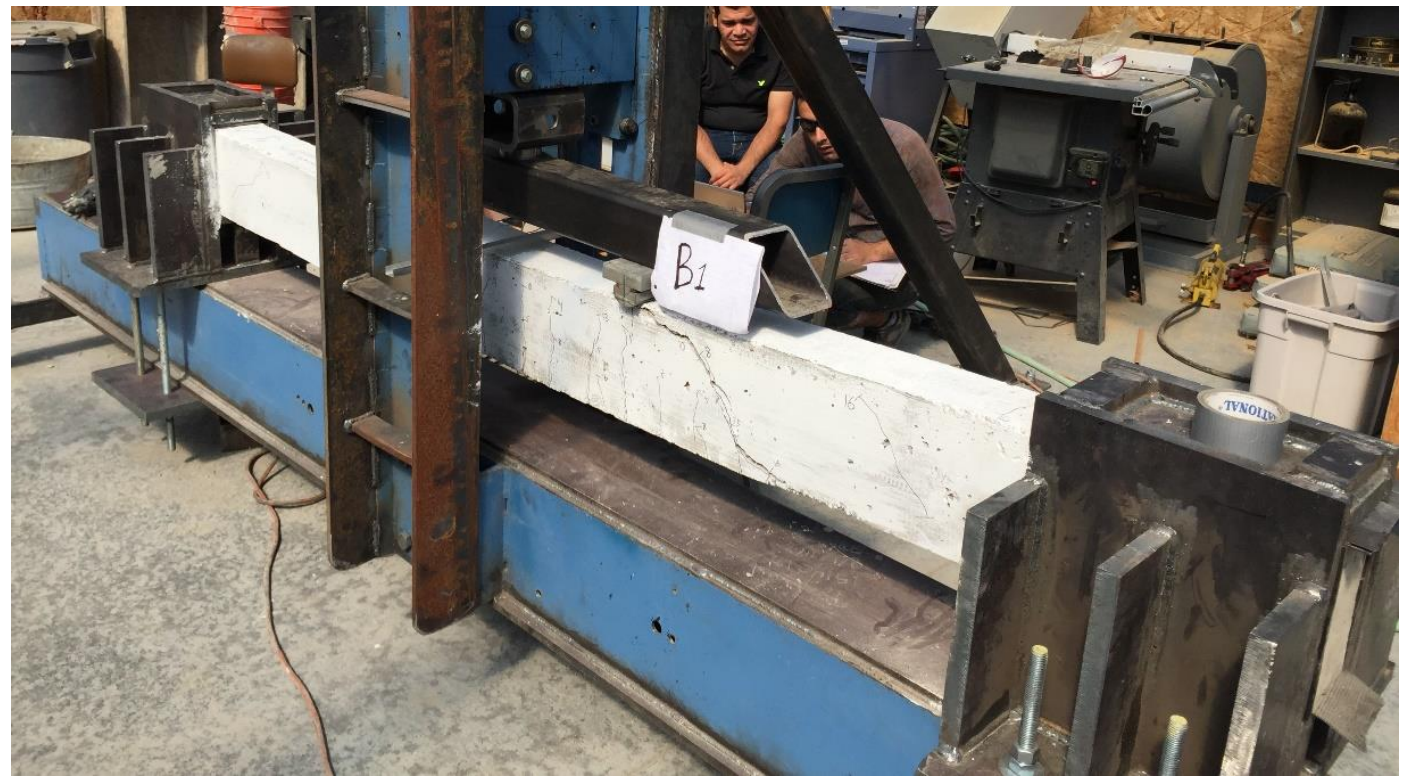

Figure 4-21 B-1 Specimen Test 


\subsubsection{Control Beam, B-2}

Beam B-2 was a control specimen designed based on "high level" load, and was subjected to moment, shear and torque. Please refer to Table 4-1 for a summary information about all test specimens.

The concrete strength samples are tested the results are shown in Table 4-13, all samples were standard 6"x12" cylinders.

Table 4-13 Concrete Strength of B-2 Specimen

\begin{tabular}{|c|c|}
\hline Sample & $\begin{array}{c}\text { Comp. } \\
\text { Strength (psi) }\end{array}$ \\
\hline $1(138.4$ pcf) & 5940 \\
\hline $2(139.9$ pcf) & 5895 \\
\hline 3 (141.4 pcf) & 6071 \\
\hline Average & 5969 \\
\hline
\end{tabular}

The load-deflection behavior of specimen B-2 is shown in Figure 4-22. 


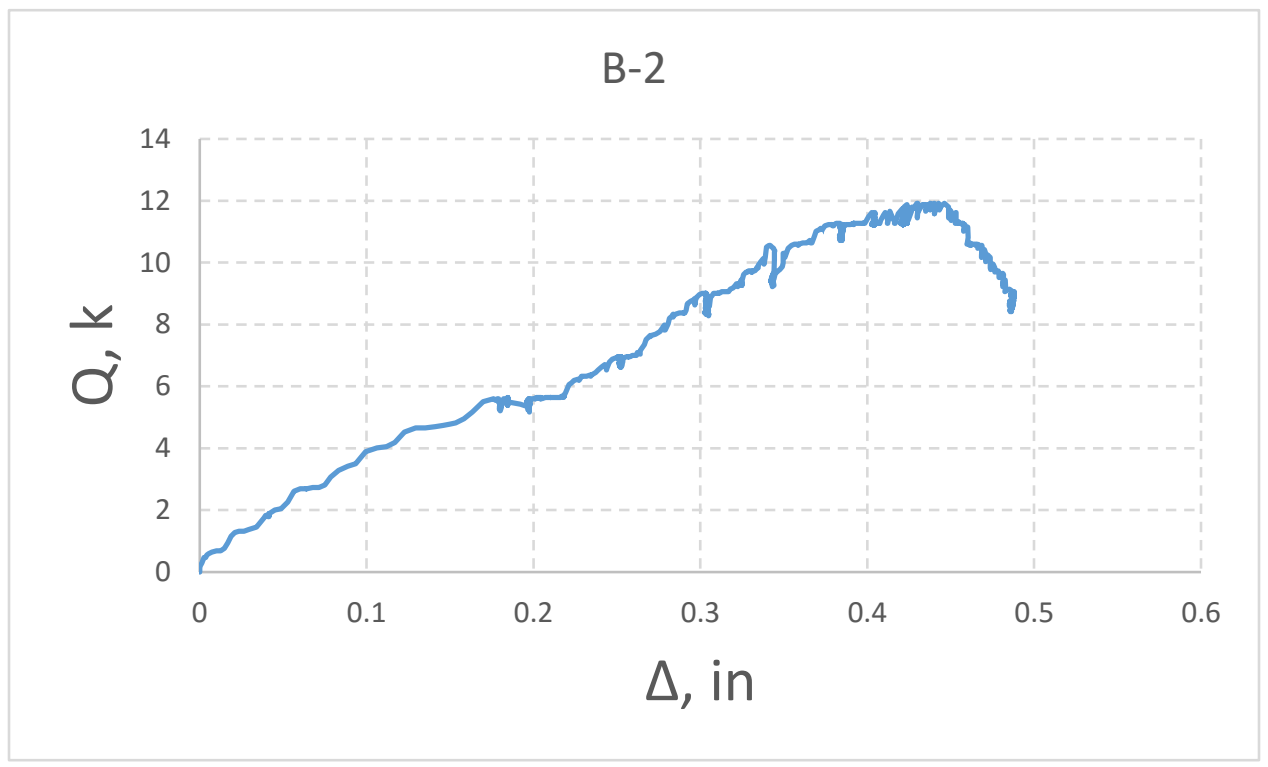

Figure 4-22 Load-Deflection Curve of B-2 Specimen

The beam failed under torsion loading in a brittle matter, similar to A-2. Two helical loops at each side of third span at the ends formed, and failed the beam soon after it was loaded as shown in Figure 4-24 and 4-25. First, helical cracks propagated from the ends at 9 kips with $0.5 \mathrm{~mm}$ width. The maximum crack width across the torsional cracks was $4.5 \mathrm{~mm}$, the maximum load was $11.9 \mathrm{kips}$, and maximum mid-span deflection was 0.48 inch. The negative steel reinforcement strain gauge recoded 0.0008 , which was only $40 \%$ of yield strain. The longitudinal steel did not reach yield strain and the stirrups barely reached their yield strain. The maximum strain recorded for transverse reinforcement was 0.0008 .

Flexural ductility $=\frac{0.488}{0.342}=1.4$

The torque-twist behavior of B-2 is shown in Figure 4-23. 


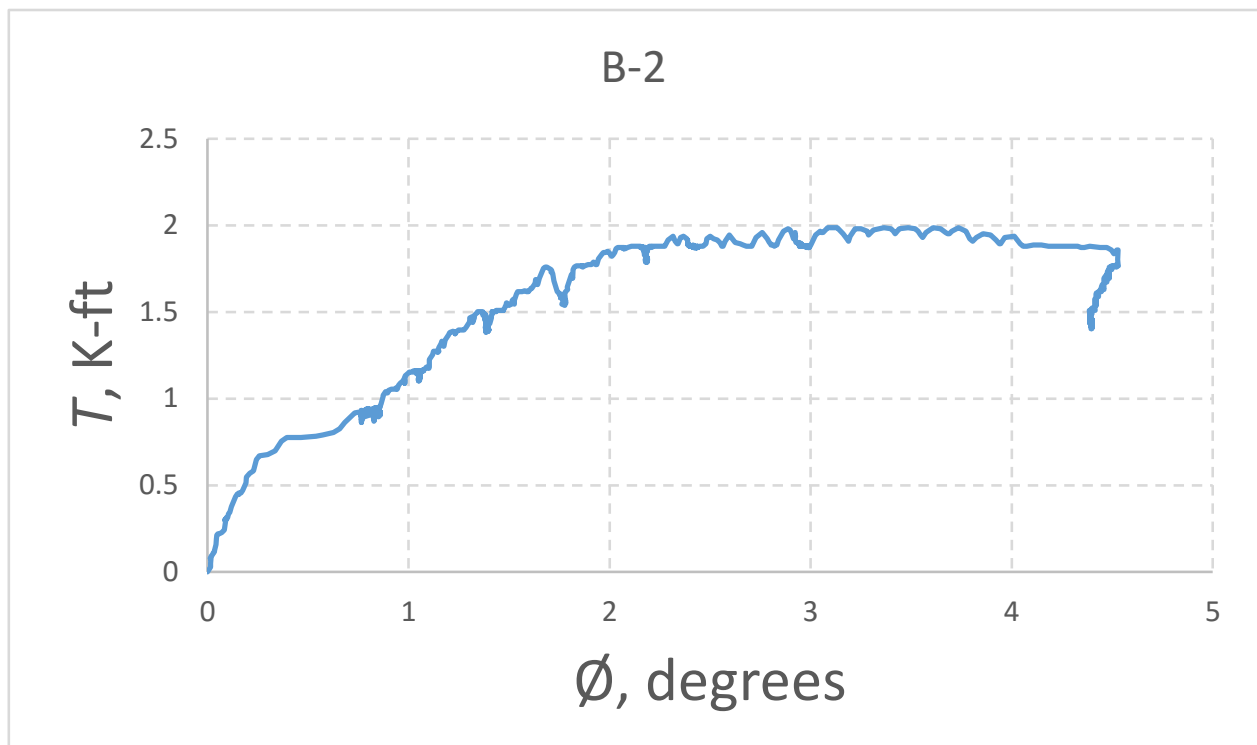

Figure 4-23 Torque-Twist Curve of B-2 Specimen

Torsional ductility $=\frac{4.395}{1.395}=3.1$

Table 4-14 shows the main results. 
Table 4-14 Summary of B-2 Specimen

\begin{tabular}{|c|c|c|}
\hline Beam designation & B-2 & Comments \\
\hline Failure type & torsion & \\
\hline Maximum load, $\mathrm{Q}$ & 11.9 kips & \\
\hline Maximum torque, $\mathrm{T}$ & $1.98 \mathrm{k}-\mathrm{ft}$ & \\
\hline $\begin{array}{c}\text { Maximum deflection, } \Delta \\
\varnothing\end{array}$ & $0.48 \mathrm{in}$ & \\
\hline $\begin{array}{c}\text { Maximum twisting angle, } \\
\varnothing\end{array}$ & 4.53 degrees & \\
\hline $\begin{array}{c}\text { Maximum stirrup strain, } \\
\epsilon_{t}\end{array}$ & 0.0006 & \\
\hline $\begin{array}{c}\text { Maximum -M } \\
\text { reinforcement strain, } \epsilon_{s}\end{array}$ & 0.0008 & $<0.002$ \\
\hline Flexural ductility & 1.4 & \\
\hline Torsional ductility & 3.1 & \\
\hline
\end{tabular}

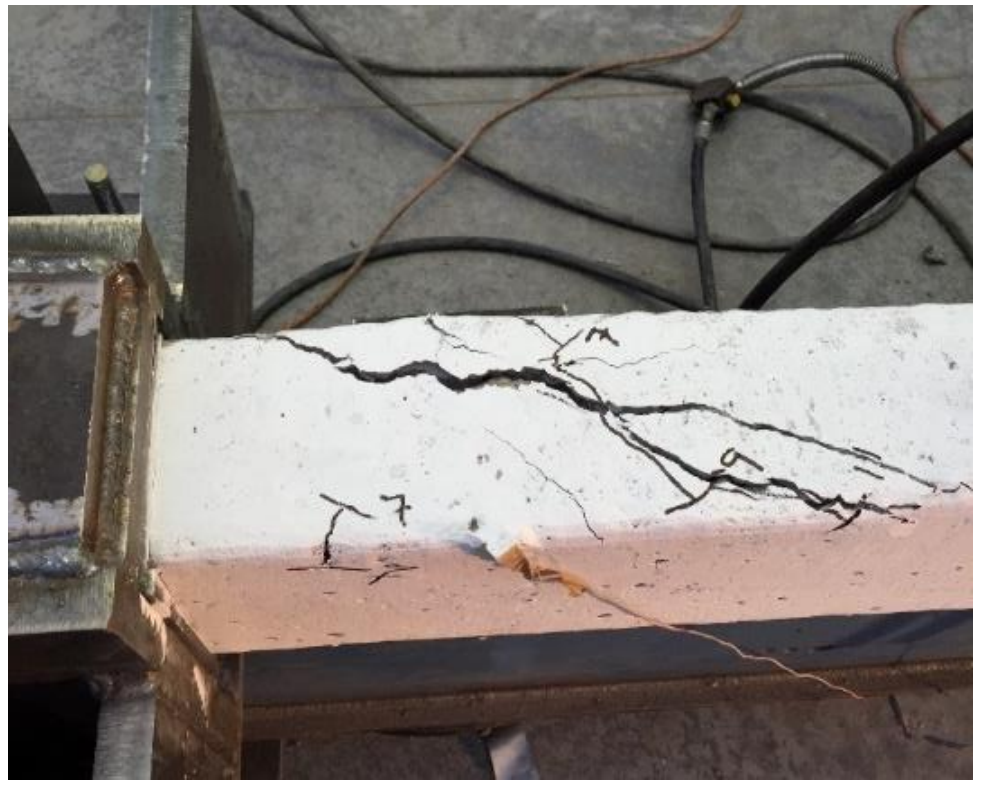

Figure 4-24 Top View of B-2 Specimen at Failure under Torsional Load 


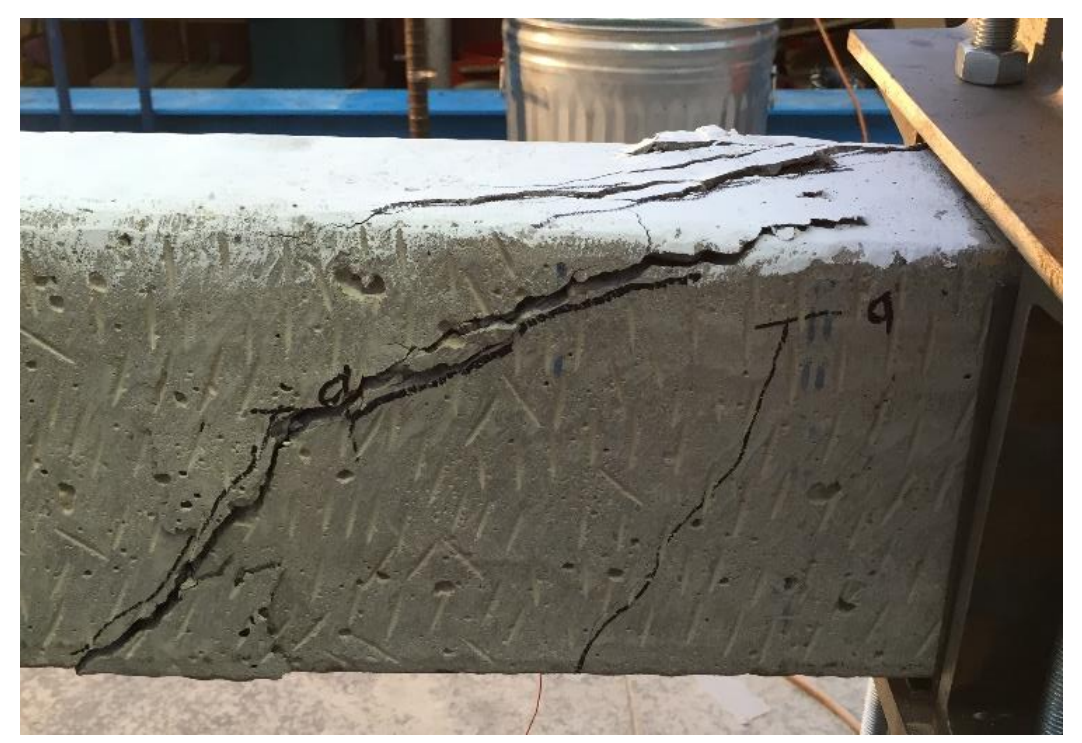

Figure 4-25 Side View of B-2 Specimen at Failure under Torsional Load

\subsubsection{Strengthened Beam, B-3}

Beam B-3 was the same as the control specimens B-1 and B-2 (designed based on "high level" load), except that this specimen was strengthened with one layer of CFRP wrap. This specimen was subjected to moment, shear and torque, so its behavior can be compared to specimen B-2. Please refer to Table 4-1 for a summary of information about all test specimens.

The concrete strength samples are tested the results are shown in Table 4-15, all samples were standard 6"'x12"' cylinders. 
Table 4-15 Concrete Strength of B-3 Specimen

\begin{tabular}{|c|c|}
\hline Sample & $\begin{array}{c}\text { Comp. } \\
\text { Strength (psi) }\end{array}$ \\
\hline 1 & 6030 \\
\hline 2 & 6119 \\
\hline 3 & 6412 \\
\hline Average & 6187 \\
\hline
\end{tabular}

The CFRP had seven days for curing prior to the test. The load-deflection curve is shown in Figure 4-26.

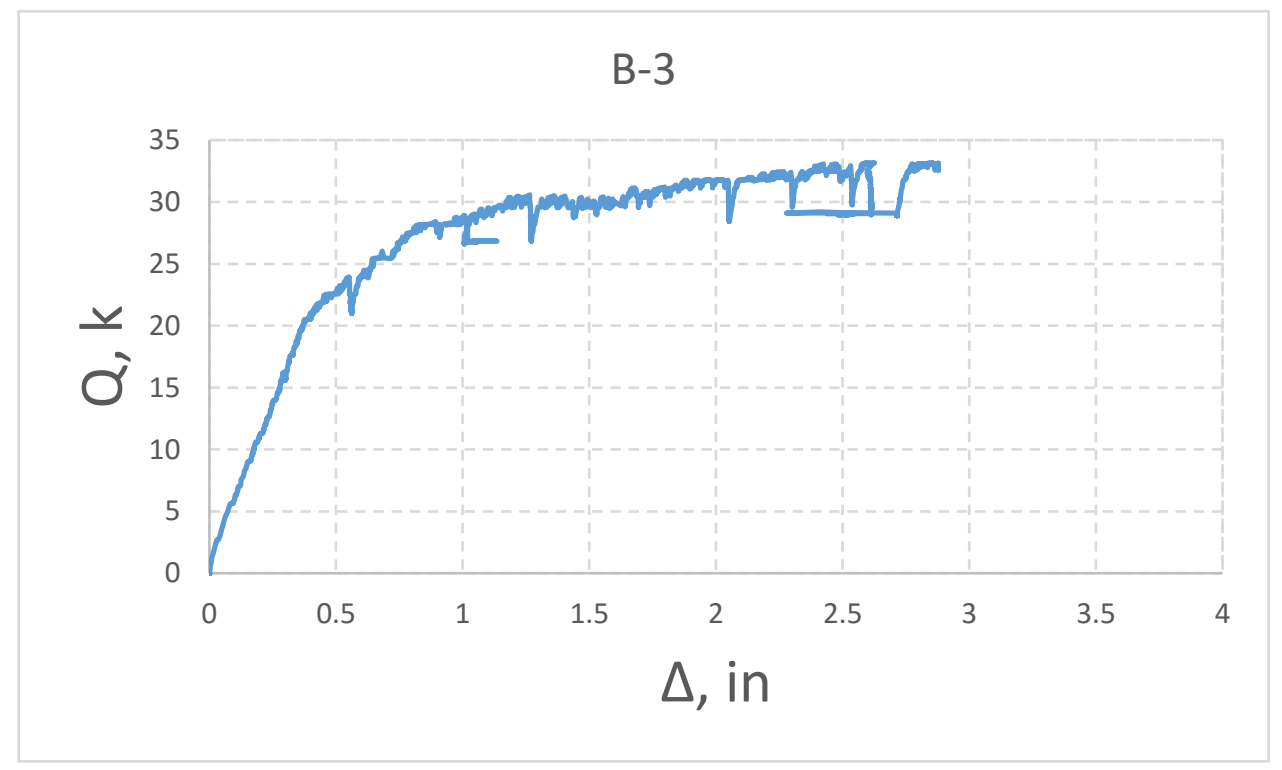

Figure 4-26 Load-Deflection Curve for B-3 Specimen

Flexural ductility $=\frac{2.88}{0.39}=7.4$ 
Through the test, no de-bonding due to flexure was noted. Flexural cracks were distributed only between the points of load application. The width of cracks was relatively small — about $2.5 \mathrm{~mm}$. The CFRP composite was successful in mitigating shear cracks between point loads and the supports. Inside the supports small shear cracks were noted, and at the face of supports the concrete crushed and formed two hinges at both ends which carried a high concentration of flexural, shear, and torsional stresses.

Under torsional loading, the torque-twist curve is shown in Figure 4-27.

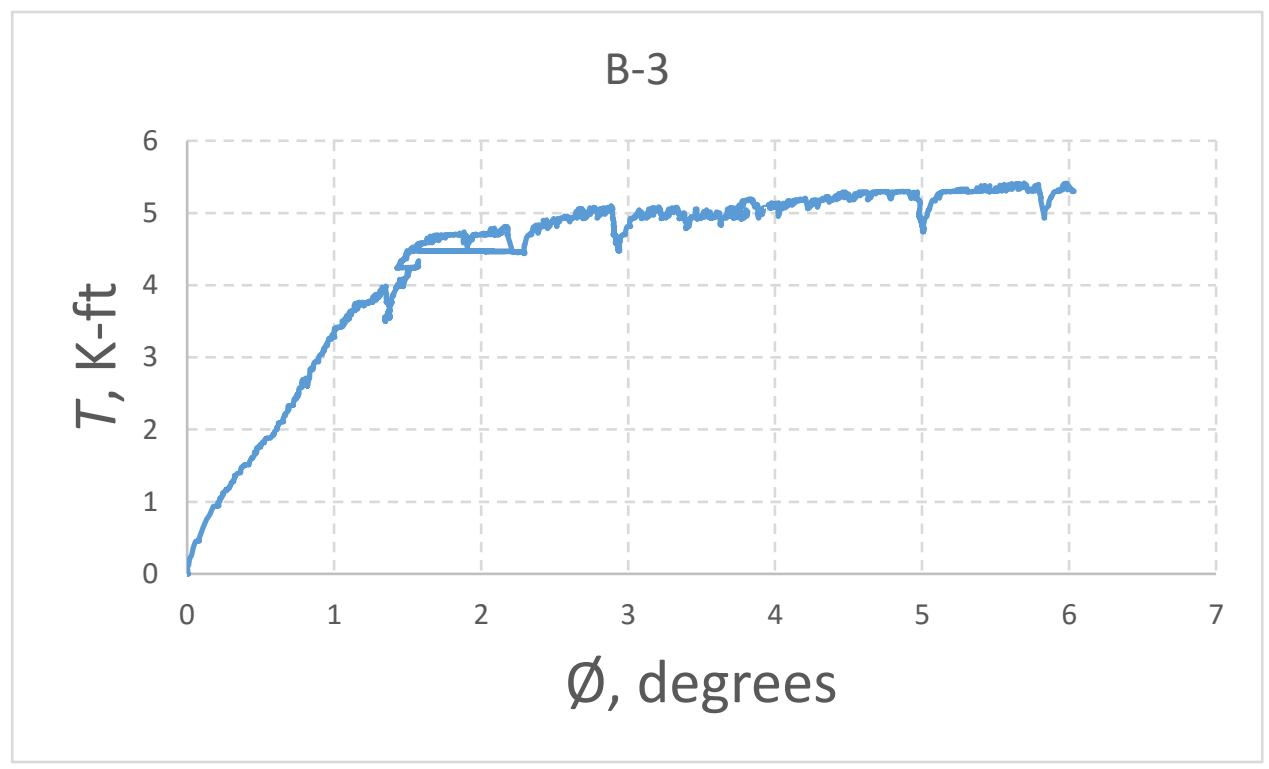

Figure 4-27 Torque-Twist Curve for B-3 Specimen

The maximum torque in the test was $5.52 \mathrm{k}$ - $\mathrm{ft}$ and the maximum rotation was 6 degrees, as shown in Figure 4-27. No helical cracks were observed after the CFRP wrap was removed. 
The rotation was almost at a plateau while the torque, which had a lot of ductility, was increasing linearly.

Torsional ductility $=\frac{6.03}{1.161}=5.2$

Compared to B-2, which failed under torsional stress by forming two large helical cracks at each side of the supports, the behavior of this specimen was enhanced and the mode of failure changed to flexure. The beam underwent large deformations without CFRP delamination, as shown in Figure 4-29. The CFRP composite effectively resisted shear and torsional stresses.

Figure 4-28 shows effective CFRP strain development in B-3 Specimen. It is worth to note that CFRP strain did not develop until after substantial cracks formed in the beam, as shown in Figure 4-28.

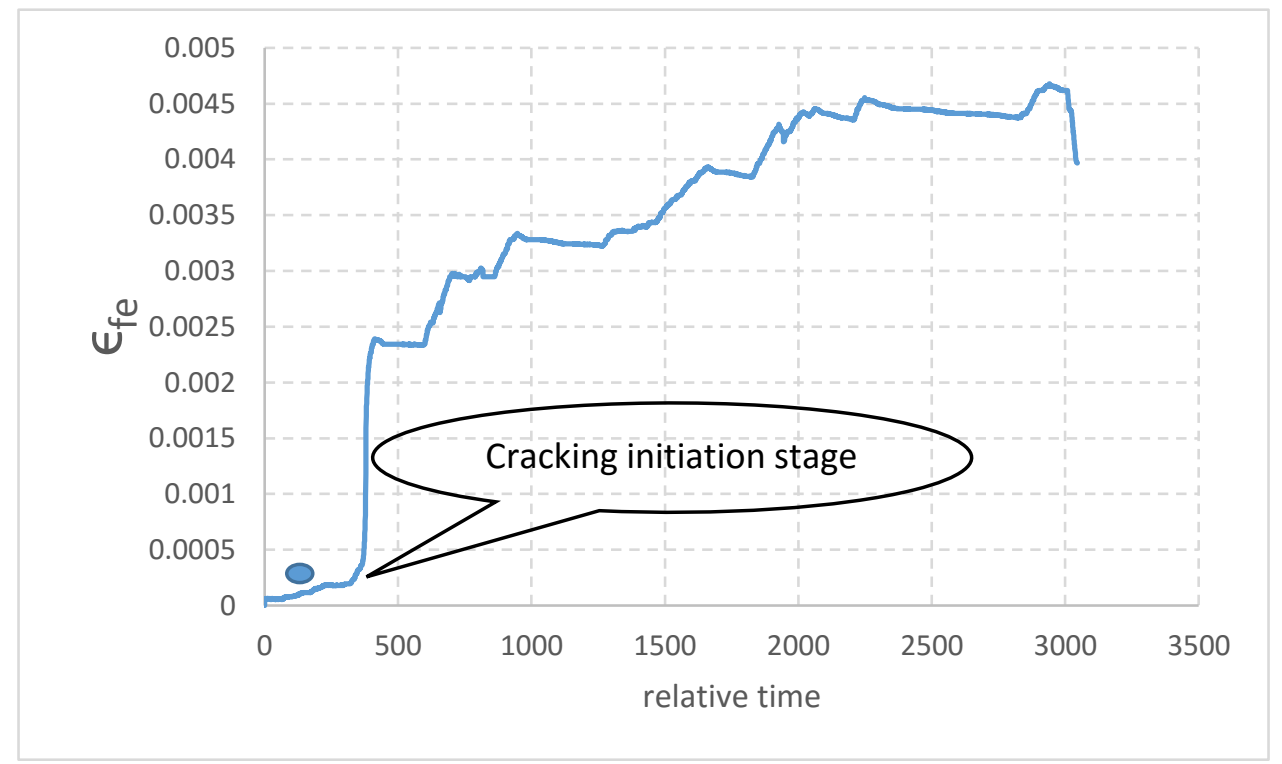

Figure 4-28 CFRP Strain Development in B-3 Specimen 
Table 4-16 summarizes the tests main results.

Table 4-16 Summary of B-3 Specimen

\begin{tabular}{|c|c|c|}
\hline Beam designation & B-3 & Comments \\
\hline CFRP curing time & Seven days & \\
\hline Failure type & $\begin{array}{c}\text { Flexure with shear cracks } \\
\text { inside supports }\end{array}$ & \\
\hline Maximum load, Q & 33.1 kips & Strain $>>0.0005$ \\
\hline Maximum torque, $\mathrm{T}$ & $5.52 \mathrm{k}-\mathrm{ft}$ & \\
\hline Maximum deflection, $\Delta$ & 2.88 in & Strain is $28 \%$ of rupture \\
Maximum twisting angle, $\varnothing$ & 6 degrees,$\epsilon_{f u}=1.67 \%$ \\
\hline Maximum stirrup strain, $\epsilon_{t}$ & 0.00129 & strain \\
\hline Maximum $-M$ & - & \\
\hline Maximum CFRP strain, $\epsilon_{f e}$ & 0.00467 & \\
\hline Flexural ductility & 7.4 & \\
\hline Torsional ductility & 5.2 & \\
\hline
\end{tabular}

The cracks at the hinges were as large as $6 \mathrm{~mm}$ at failure as shown in Figure 4-29 and 430. 


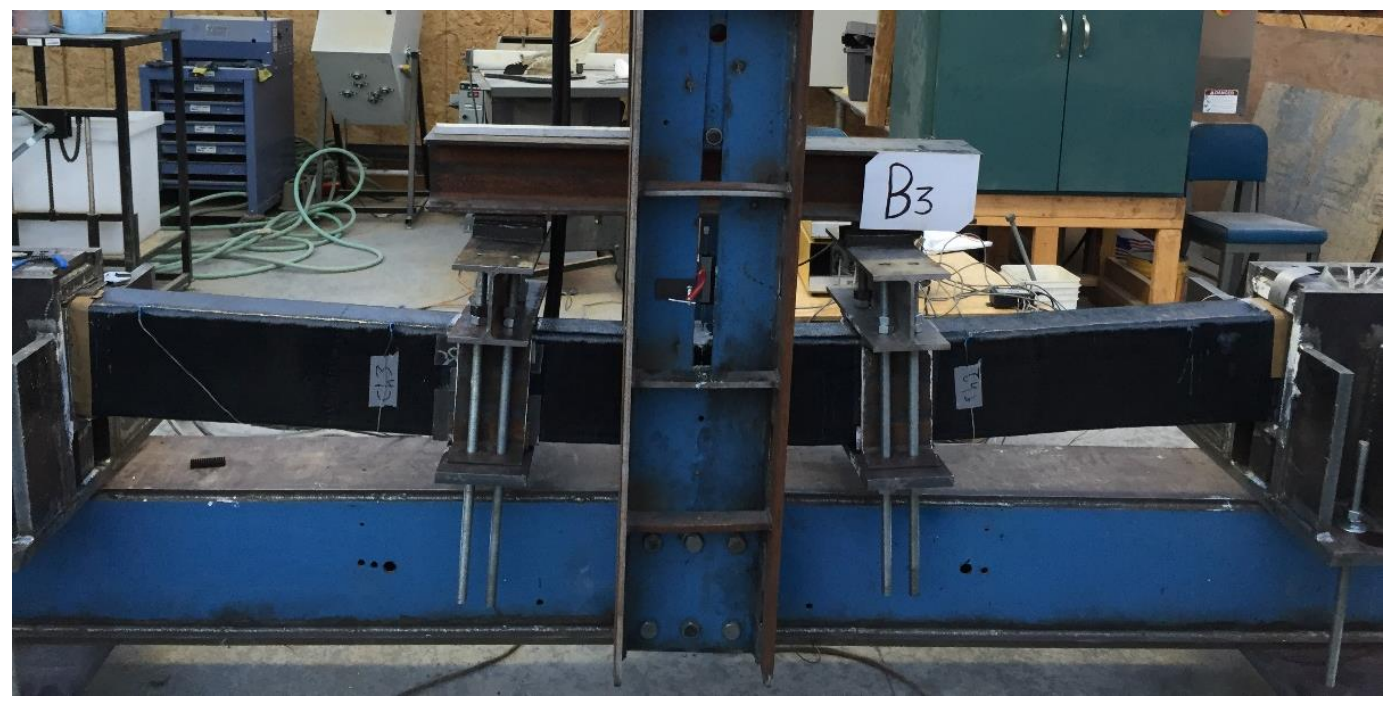

Figure 4-29 B-3 Specimen under Excessive Deformation

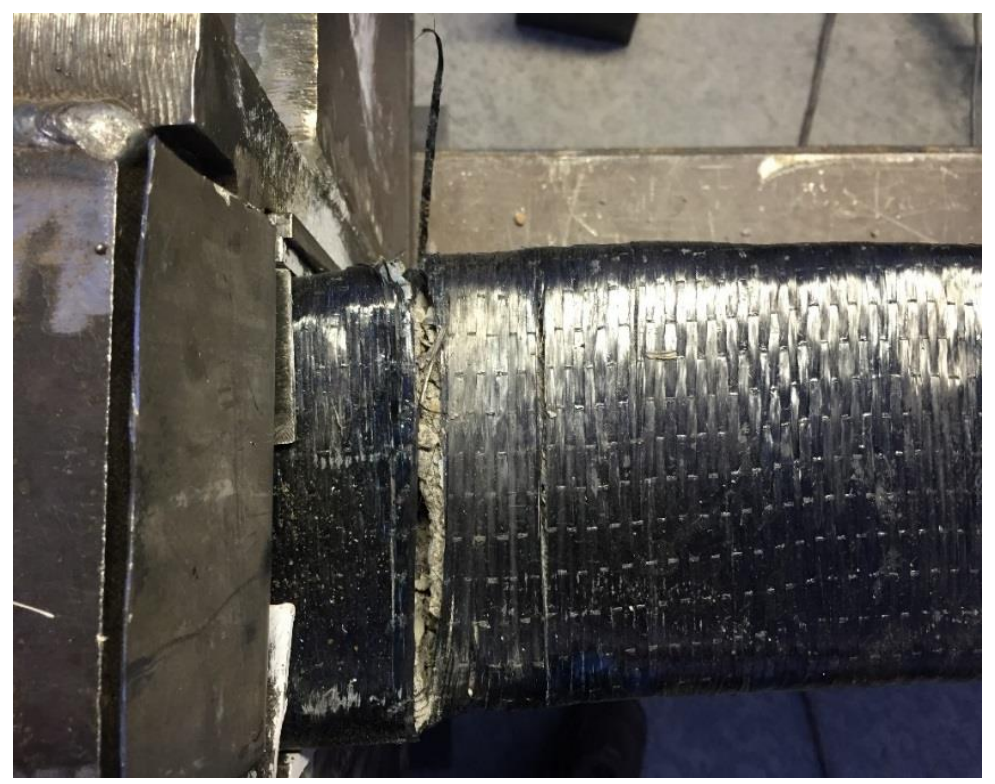

Figure 4-300 Flexural Cracks at Failure of B-3 Specimen

As shown in Figure 4-31, the beam showed flexural cracks and no helical cracks were observed after the CFRP wrap was removed. 


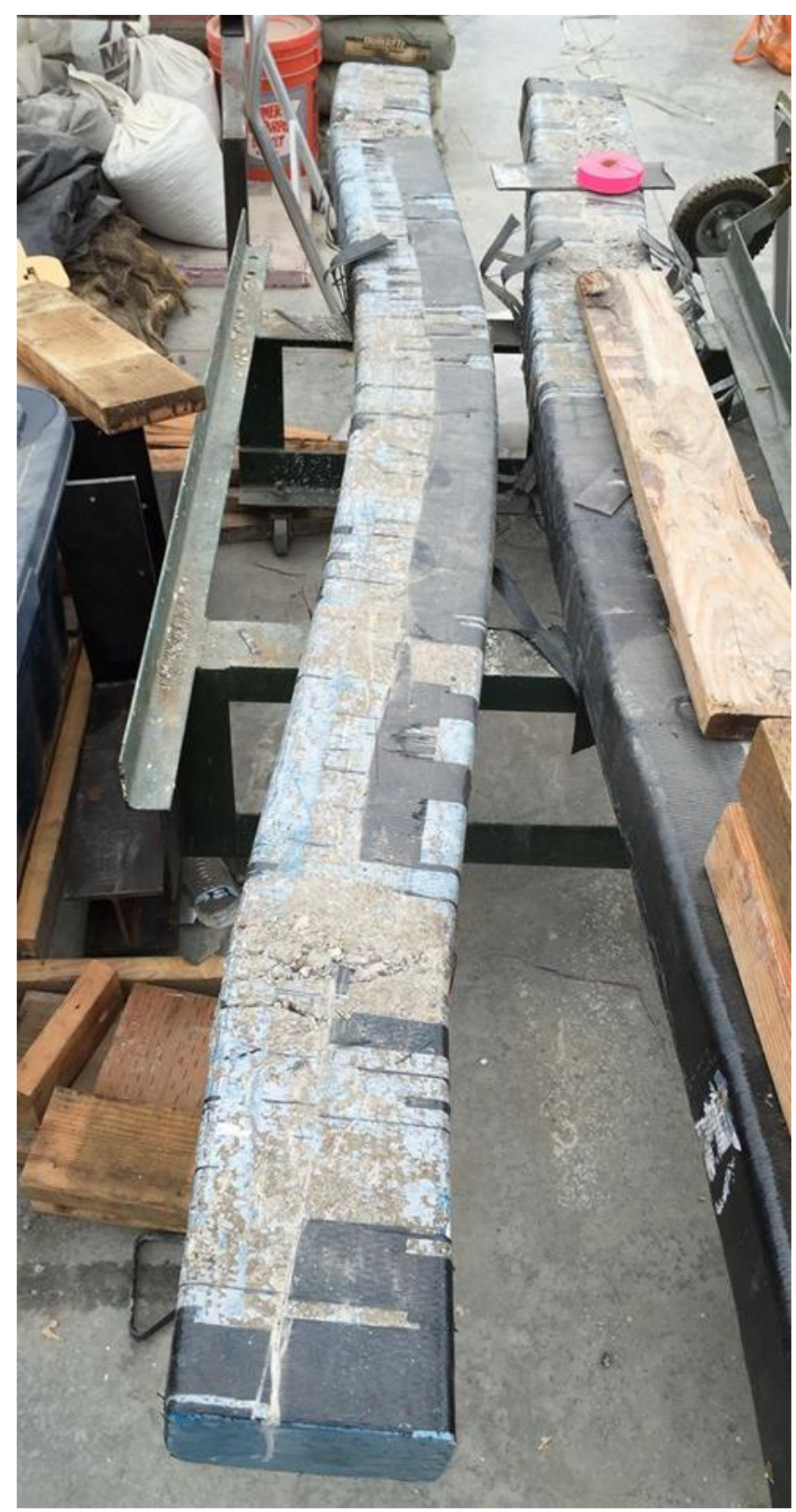

Figure 4-31 Cracks in B-3 Beam after CFRP sheets' Removal 


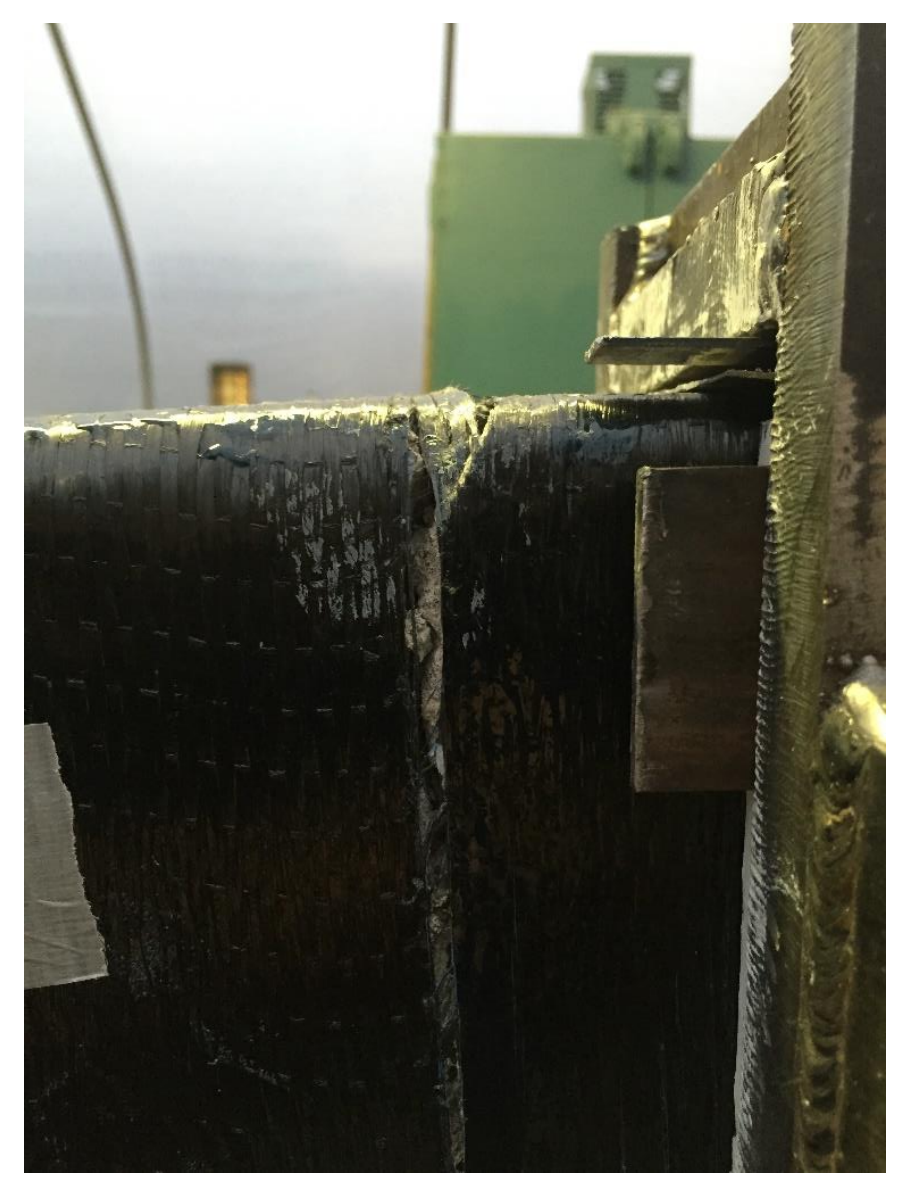

Figure 4-31 Side View of Flexural Cracks at Failure of Specimen B-3

\subsection{Crack Patterns of Tested Specimens}

Figures 4-32 through 4-37 show crack patterns of all tested specimens. 


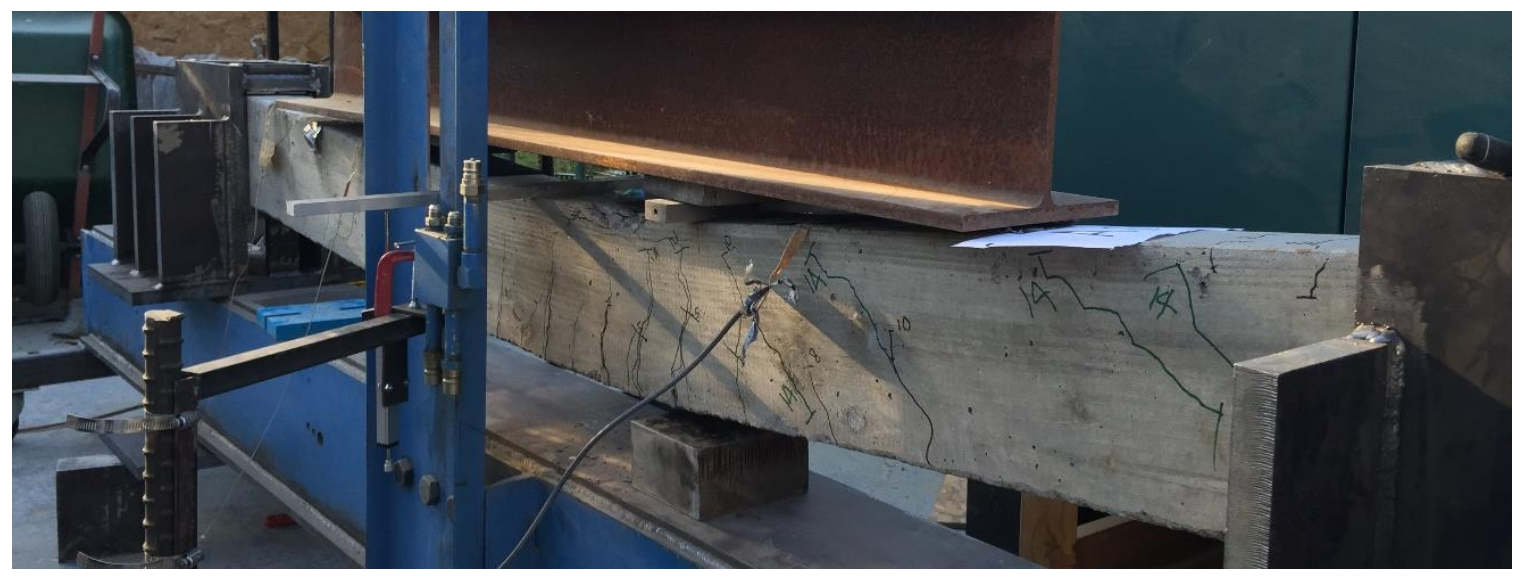

Figure 4-32 Crack Pattern of A-1 Specimen

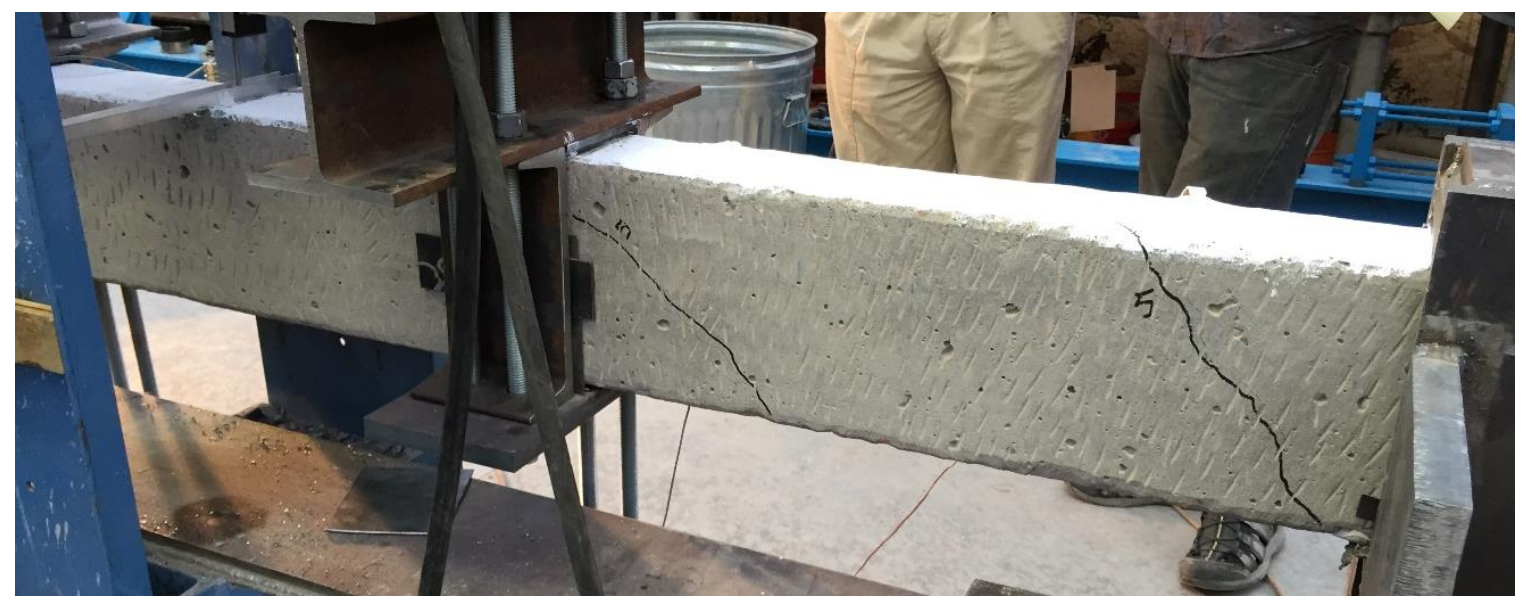

Figure 4-33 Crack Pattern of A-2 Specimen 


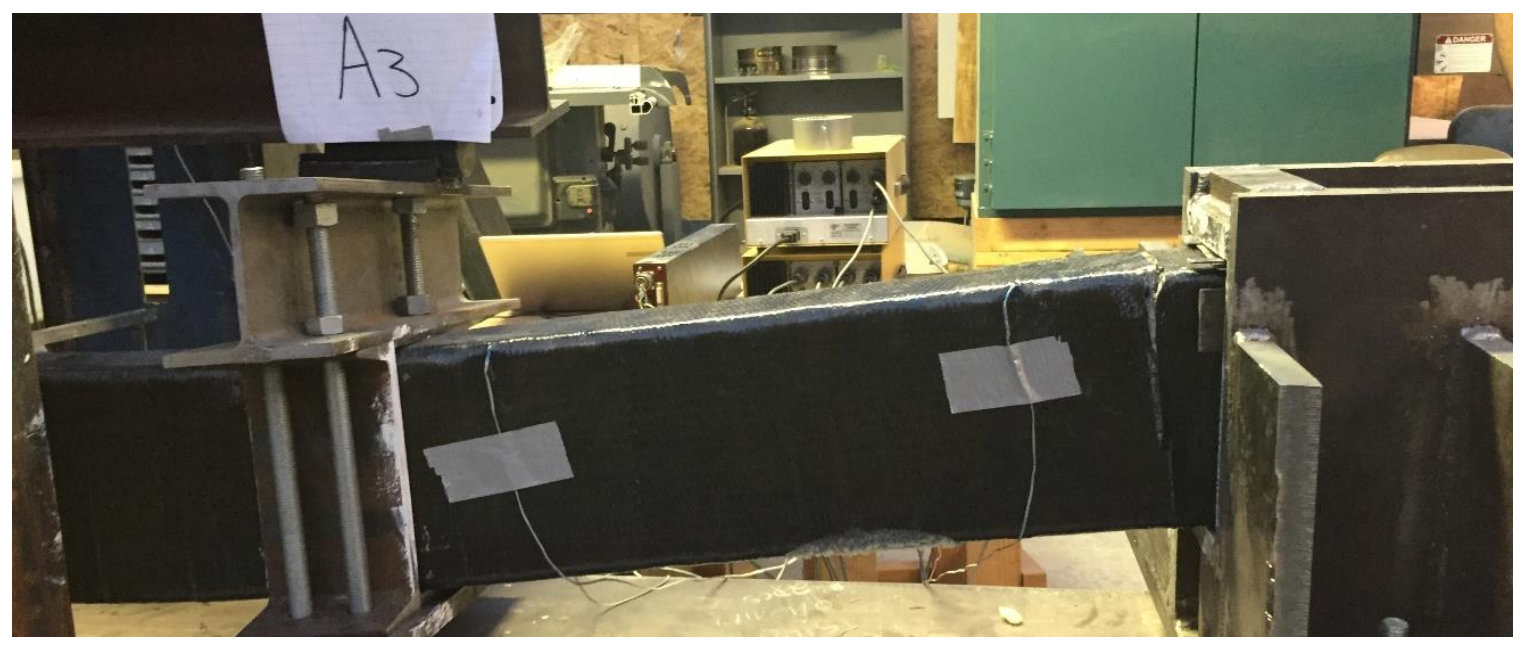

Figure 4-34 Crack Pattern of A-3 Specimen

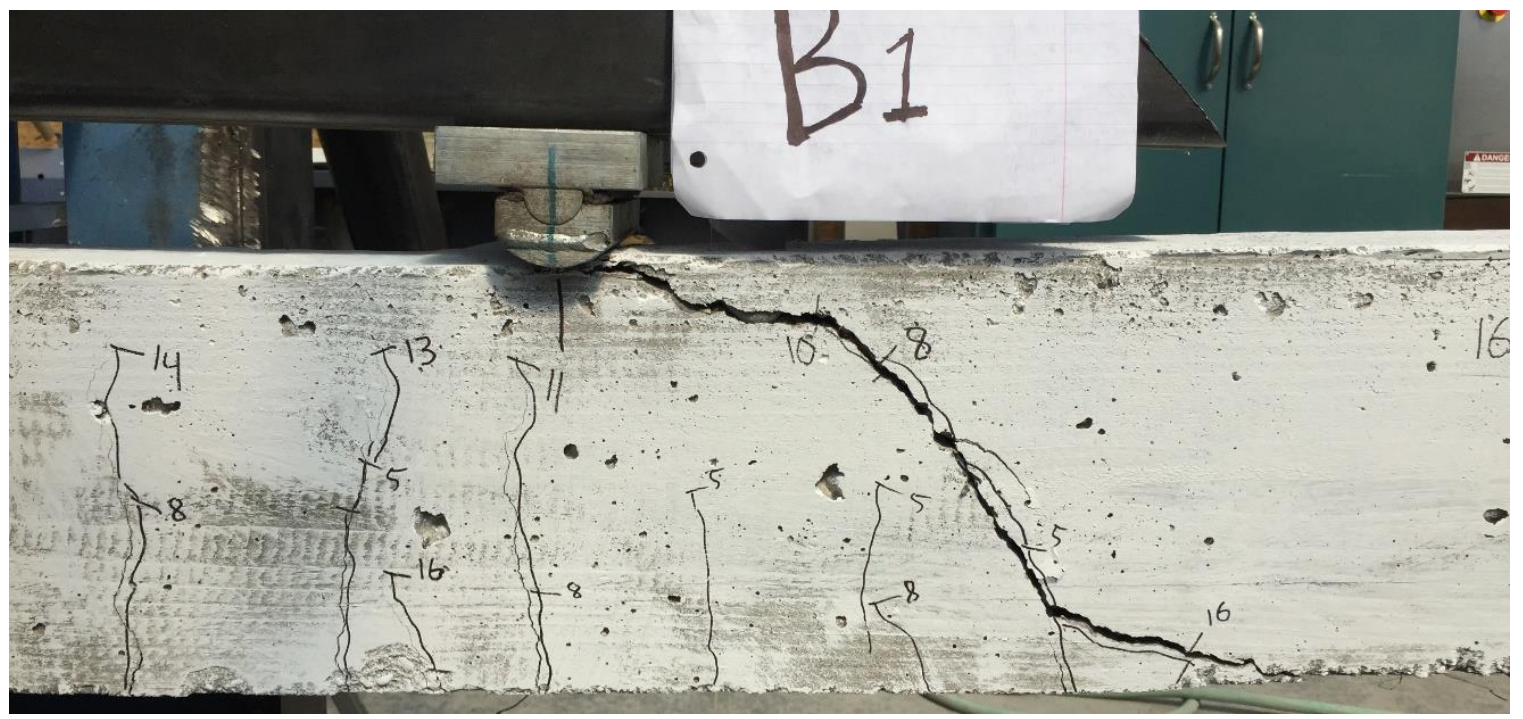

Figure 4-35 Crack Pattern of B-1 Specimen 


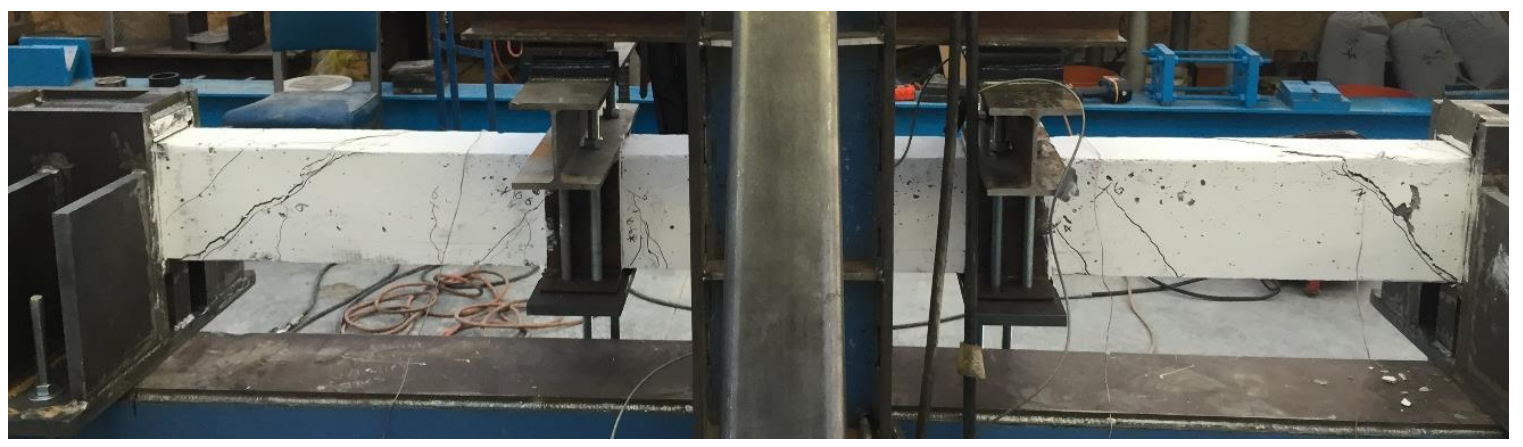

Figure 4-37 Crack Pattern of B-2 Specimen

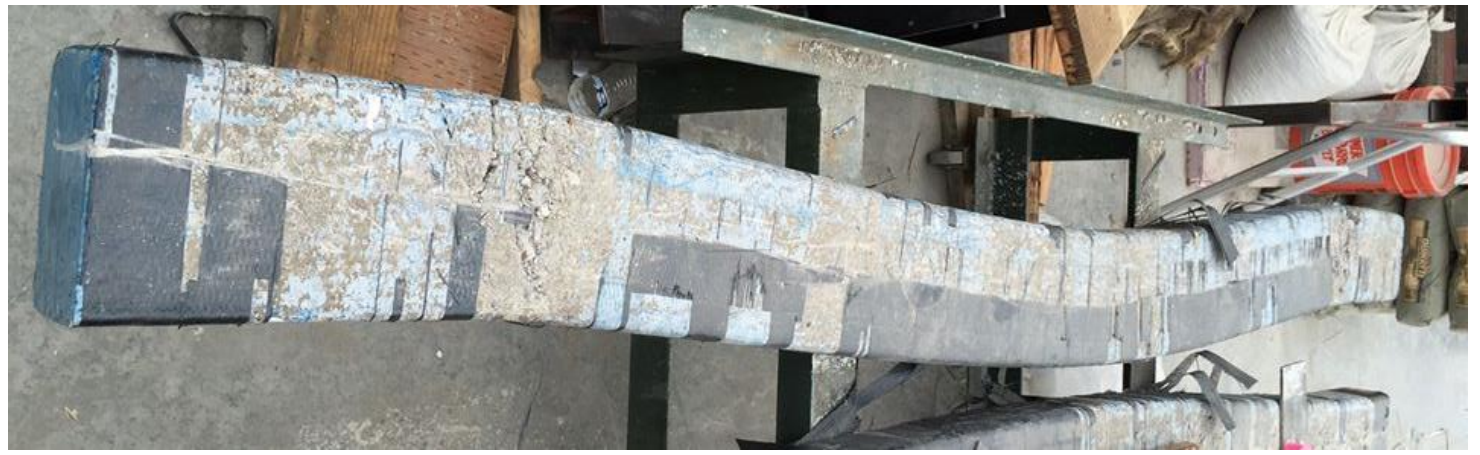

Figure 4-36 Crack Pattern of B-3 Specimen

\subsection{Comparison of Beams' Behavior}

Figures 4-38 and 4-39 demonstrate the overall load-deflection behavior of Set A and Set B specimens combined. Please Refer to Table 4-1 for beam designations. 


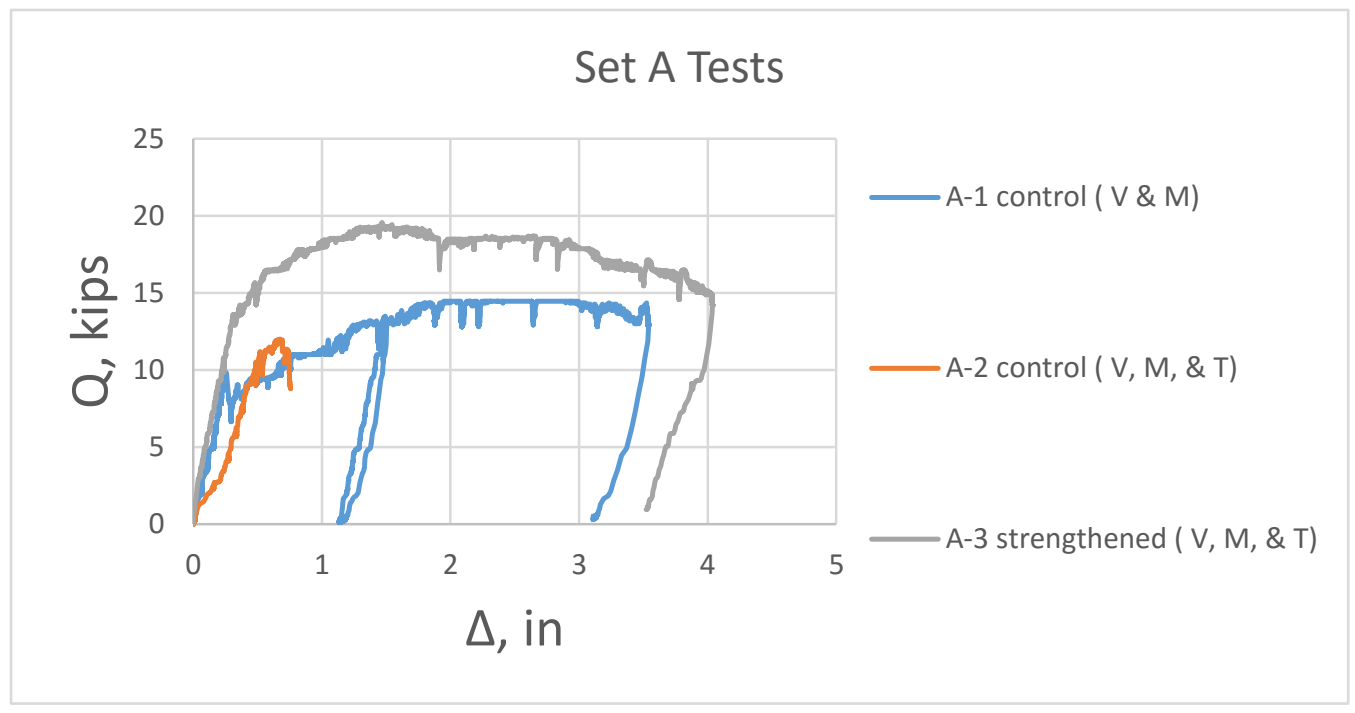

Figure 4-38 Load-Deflection Behavior of Set A Beams

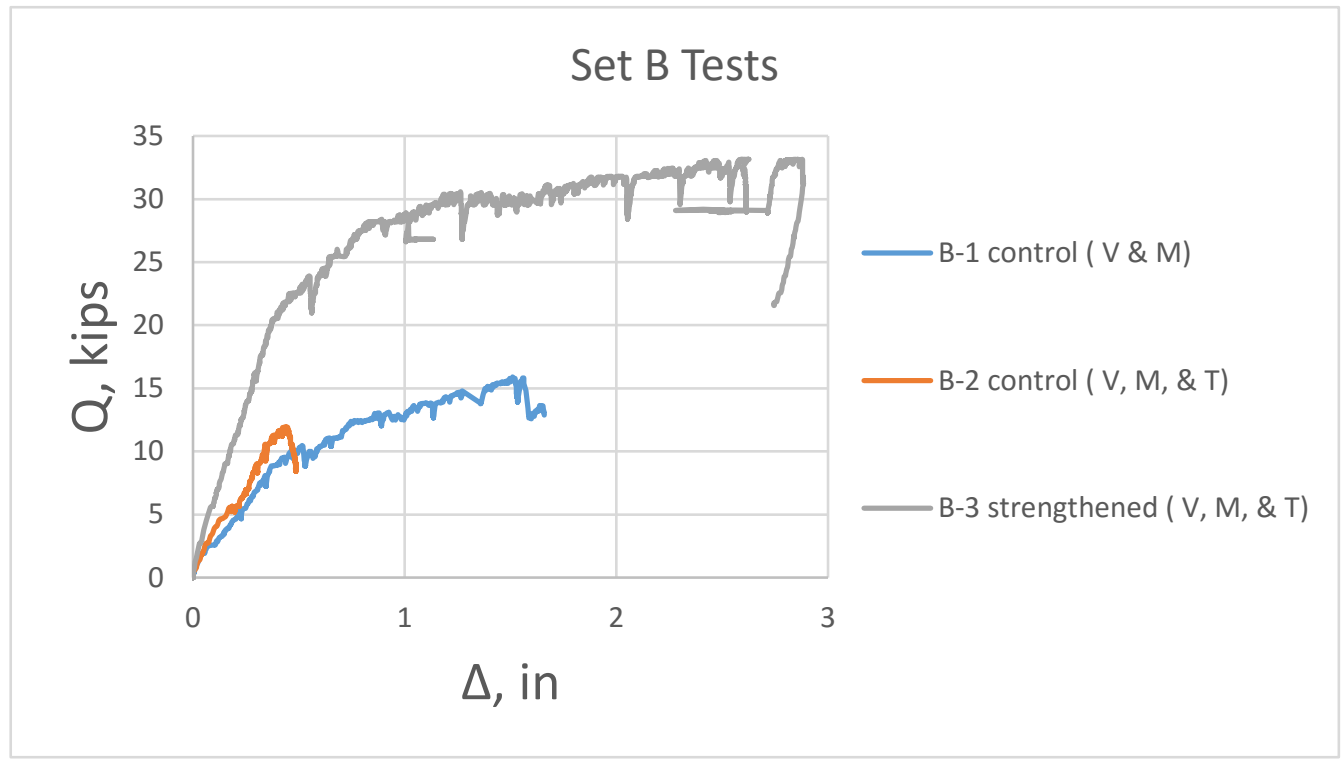

Figure 4-39 Load-Deflection Behavior of Set B Beams 
It can be noted that A-1 and B-1 specimens behaved better that A-2 and B-2 specimens because they were tested without torsion. Having torsional loads in latter specimens deteriorated the overall behavior and compromised their capacity. It is also obvious that the CFRP application for A-3 and B-3 beams was very effective and gave a significant additional capacity to A-2 and B-2 beams as shown in Figures 4-38 and 4-39. From a ductility point of view, it is obvious that the application of torsion in A-2 and B-2 specimens reduced the ductility substantially due to brittle nature of torsion failure. Moreover, the behavior shows drastic increase in ductility when CFRP sheets are installed. CFRP application to A-3 and B-3 beams changed the torsional mode of failure to flexure, hence it enhanced the overall behavior and ductility.

Figure 4-40 through 4-43 show the bar diagrams of comparative capacities and ductility of all beams. The application of CFRP met the goal of meeting and exceeding the strength and ductility demands of the control beams 
For strength:

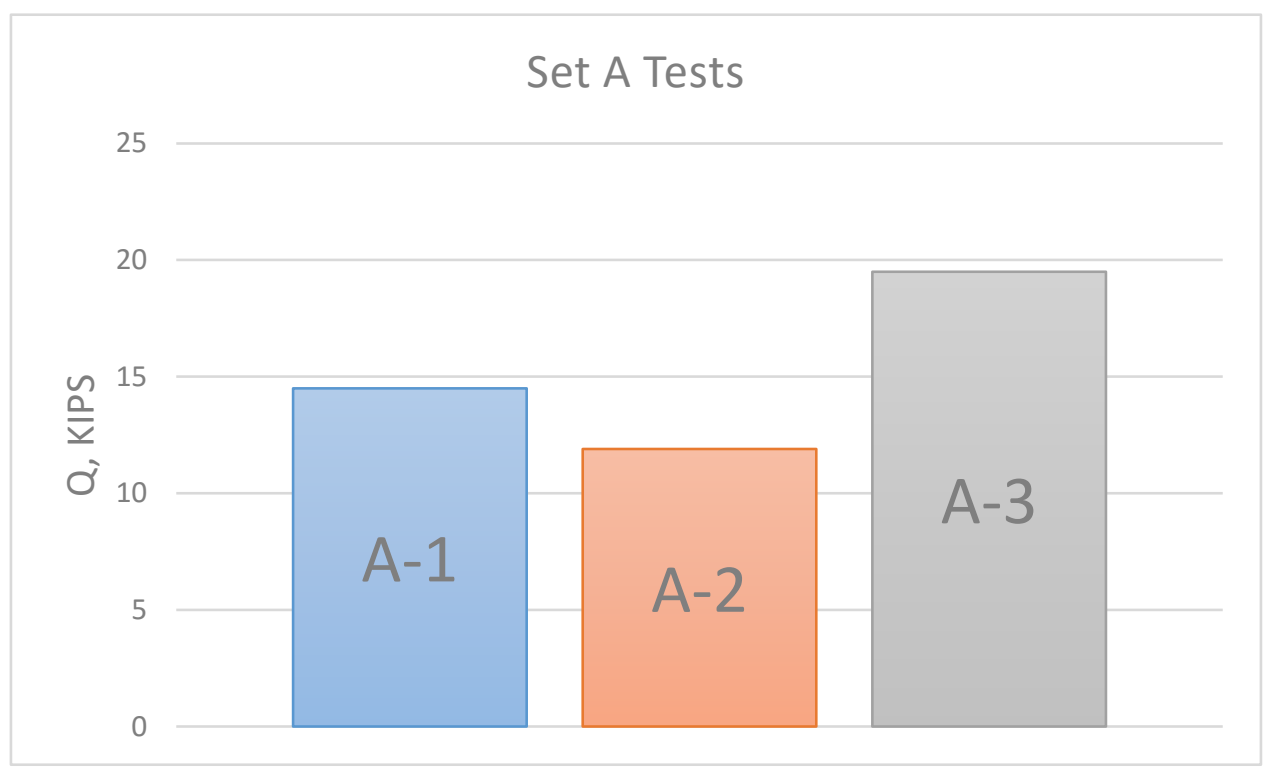

Figure 4-40 Strength Comparison of Set A Beams

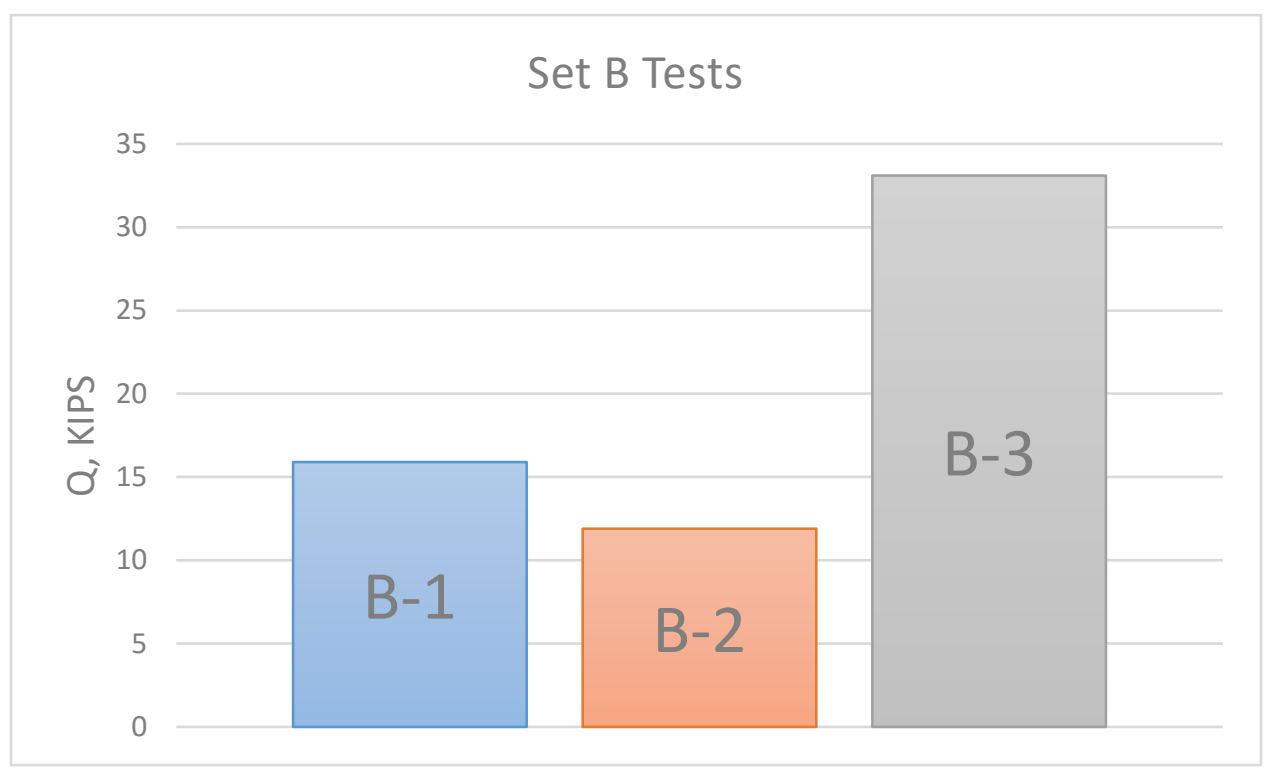

Figure 4-41 Strength Comparison of Set B Beams 
For ductility:

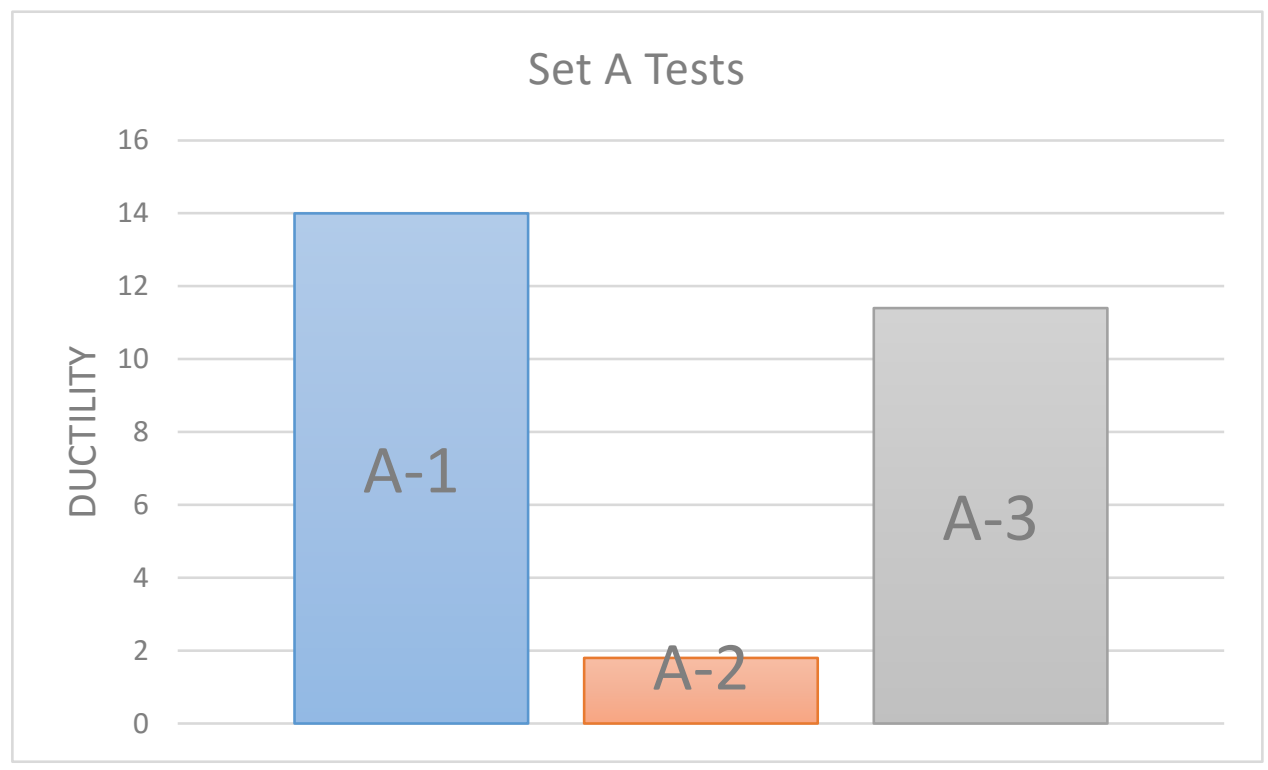

Figure 4-42 Ductility Comparison of Set A Beams

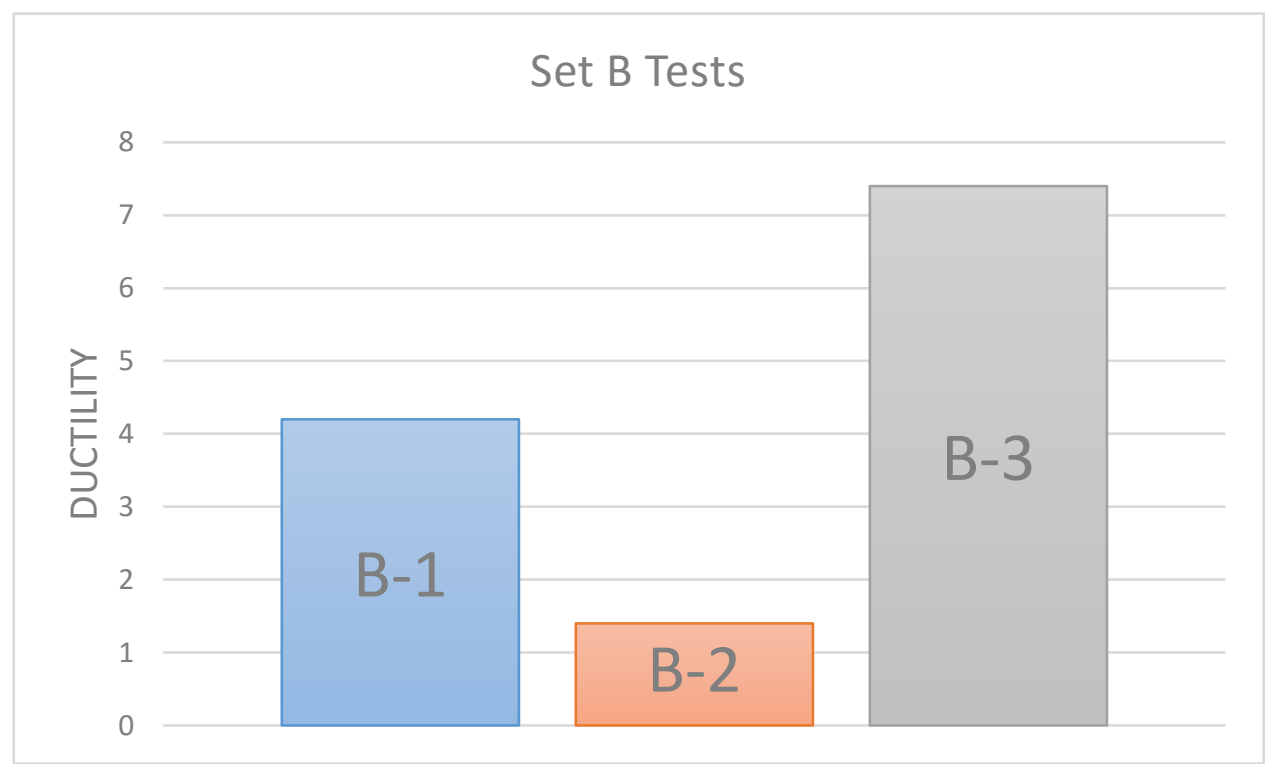

Figure 4-43 Ductility Comparison of Set B Beams 


\section{Chapter 5 Theoretical Analysis and Comparison with Experimental Results}

All beams were analyzed using ACI 318-14 provisions for shear, bending moment, and torsion without CFRP sheets. For strengthened beams, ACI 440-2R was used along with FIB 2001 expressions for ultimate moment and torsion capacity respectively. An average $\mathrm{f}^{\prime} \mathrm{c}$ for all six beams was taken for simplification since they were all close to about 6200 psi. An average value of 6174 psi was assumed for all analysis purposes.

\subsection{Specimen A-1, medium live load, subjected to $V$ and $M$}

Flexural moment strength:

$$
\begin{aligned}
& \mathrm{f}^{\prime} \mathrm{c}=6174 \mathrm{psi} \\
& \mathrm{f}_{\mathrm{y}}=75 \mathrm{ksi} \\
& \mathrm{f}_{\mathrm{y}}=30 \mathrm{ksi} \\
& \mathrm{E}_{\mathrm{s}}=29000 \mathrm{ksi}
\end{aligned}
$$

$$
\begin{aligned}
& \text { Assume } \mathrm{f}_{\mathrm{s}}=\mathrm{f}_{\mathrm{y}} \\
& \beta_{1}=0.85-\frac{\mathrm{f}^{\prime} \mathrm{c}-4000}{1000} \times 0.05 \text { for }^{\prime}{ }_{\mathrm{c}}>4000 \mathrm{psi} \\
& \beta_{1}=0.85-\frac{6174-4000}{1000} \times 0.05=0.741 \\
& 0.85 \mathrm{f}^{\prime} \text { c. } \mathrm{a} . \mathrm{b}=\mathrm{A}_{\mathrm{s} \cdot \mathrm{f}_{\mathrm{y}}} \\
& 0.85 \times 6.17 \times(0.741 c) \times 4.5=0.22 \times 75 \\
& \mathrm{c}=0.94{ }^{\prime},
\end{aligned}
$$


$M_{n}=A_{s} \cdot f_{y}\left(d-\frac{a}{2}\right)$

$\mathrm{M}_{\mathrm{n}}=0.22 \times 75\left(7.16-\frac{0.698}{2}\right)$

$\mathrm{M}_{\mathrm{n}}=112.4 \mathrm{k}-\mathrm{in}=9.3 \mathrm{k}-\mathrm{ft}$

For fixed-fixed beam, $M=\frac{6 p \cdot l}{27}>>=\frac{27 M}{6 l}$

$\mathrm{P}=\frac{27 \times 9.3}{6 \times 7}=5.98 \mathrm{kips}$

$\mathrm{Q}_{\mathrm{b}}=2 \mathrm{P}=11.96$ kips

$<\mathrm{Q}_{\mathrm{p}}=14.4 \mathrm{kips}$

Shear strength:

$\mathrm{V}_{\mathrm{c}}=2 \sqrt{f^{\prime}} \cdot b_{w} \cdot d$

$\mathrm{V}_{\mathrm{c}}=2 \times \frac{\sqrt{6174}}{1000} \times 4.5 \times 7.16=5 \mathrm{kips}$

$\mathrm{V}_{\mathrm{s}}=\frac{\text { Av.fyt.d }}{\mathrm{s}}$

$\mathrm{V}_{\mathrm{s}}=\frac{0.0353 \times 30 \times 7.16}{3}=2.53 \mathrm{kips}$

$\mathrm{V}_{\mathrm{t}}=\mathrm{V}_{\mathrm{c}}+\mathrm{V}_{\mathrm{s}}=7.53$ kips

$\mathrm{Q}_{\mathrm{v}}=15.3$ kips. The experimental result was $14.4 \mathrm{kips}$ at failure. Loading was terminated due to excessive deflection, but large shear cracks and flexural cracks appeared.

Moreover, shear failure happened.

\subsection{Specimen A-2, medium live load, subjected to V, M, and T}

$\mathrm{f}_{\mathrm{c}}=6174 \mathrm{psi}$ 
$\mathrm{f}_{\mathrm{y}}=75 \mathrm{ksi}$

Shear and flexure capacities are similar to A-1.

$\mathrm{M}_{\mathrm{n}}=9.3 \mathrm{k}-\mathrm{ft}$

$\mathrm{V}_{\mathrm{n}}=7.53 \mathrm{kips}$

Torsion analysis:

Since the beam didn't have closed stirrups, ACI 318-14 does not account for a transverse steel contribution to the ultimate torsional strength. Cracking torque was counted as the ultimate torque:

$\mathrm{T}_{\mathrm{c}}=4 \sqrt{f^{\prime} c} \frac{A c p^{2}}{P c p}$

$\mathrm{A}_{\mathrm{cp}}=\mathrm{b} \cdot \mathrm{h}=36 \mathrm{in}^{2}$

$\mathrm{p}_{\mathrm{cp}}=2(\mathrm{~b}+\mathrm{h})=25 \mathrm{in}$

$\mathrm{T}_{\mathrm{cr}}=16.3 \mathrm{k}-\mathrm{in}=1.36 \mathrm{k}-\mathrm{ft}$

$\mathrm{Q}_{\mathrm{t}}$ based on $\mathrm{T}_{\mathrm{cr}}=2 \times \frac{12}{4} \times 1.33=8.16$ kips Failure occurred due to torsion. The load was 12 kips for A-1, and 11.92 kips for B-2. The failure loads were identical indicating no longitudinal reinforcement contributed to torsion, and likewise, with the open stirrups.

\subsection{Specimen A-3. Strengthened subjected to V, T, M}

$\mathrm{f}_{\mathrm{c}}=6174 \mathrm{psi}$

$f_{y}=75 \mathrm{ksi}$ 
$\mathrm{E}_{\mathrm{s}}=290000 \mathrm{ksi}$

$V_{n}=\left(V_{c}+V_{s}+\psi_{f} V_{f}\right)$

ACI 440.2R Eqn 11-2

Shear strength provided by CFRP sheets was:

$\mathrm{V}_{\mathrm{f}}=\frac{\varphi_{f} A_{v f} f_{f e}(\sin \alpha+\cos \alpha) d_{f}}{s_{f}}$

ACI 440.2R Eqn 11-3

$\mathrm{A}_{\mathrm{vf}}=2 \mathrm{n} \cdot \mathrm{t}_{\mathrm{f}} \cdot \mathrm{w}_{\mathrm{f}}$

ACI 440.2R Eqn 11-4

$\mathrm{f}_{\mathrm{fe}}=\varepsilon_{\mathrm{fe}} \cdot \mathrm{E}_{\mathrm{f}}$

ACI 440.2R Eqn 11-5

Combining ACI enq's 11-3 through 11-5 and setting $\mathrm{w}_{\mathrm{f}}=\mathrm{sf}$ for full wrapped beam,

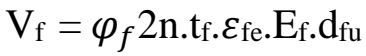

$\varphi_{\mathrm{f}}=0.95$ from ACI

ACI 440.2R sets effective strain value to 0.004 for shear strength calculation based on

CFRP. This value comes from numerous testing by Priestly et al. (1996).

For A-3 and B-3, $\mathrm{n}=1$

$\mathrm{t}_{\mathrm{f}}=0.0065^{\prime}$

$\mathrm{E}_{\mathrm{f}}=33000 \mathrm{ksi}$

$\mathrm{d}_{\mathrm{fu}}=8^{\prime \prime}$

$V_{f}=0.95 \times 2 \times 1 \times 0.0065 \times 0.004 \times 33000 \times 8=13$ kips

$\mathrm{V}_{\mathrm{t}}=\mathrm{V}_{\mathrm{c}}+\mathrm{V}_{\mathrm{s}}+\psi \mathrm{V}_{\mathrm{f}}=20.53$ kips

$\mathrm{Q}_{\mathrm{v}}=41 \mathrm{kips}$

according to this, shear failure also did not happen 
Torsion analysis:

$T_{n}=T_{s}+T_{f}$

Ts $=0$ for open

stirrups

Based on FIB 2001,

$\mathrm{T}_{\mathrm{f}}=\frac{2 E_{f} \varepsilon_{f w_{f}} t_{f} b h}{s_{f}}$

for full wrap, $\mathrm{w}_{\mathrm{f}}=\mathrm{s}_{\mathrm{f}}$

Effective strain was determined through bond length:

$\mathrm{L}_{\mathrm{e}}=\sqrt{\frac{t_{f} E_{f}}{\sqrt{f^{\prime \prime}}}}$

$\varepsilon_{f e}=\frac{0.33 w_{f}}{L_{e} S_{f}}$

$\mathrm{L}_{\mathrm{e}}=\sqrt{\frac{0.0065 \times 33000}{\frac{\sqrt{6174}}{1000}}}=52.25^{\prime \prime}$

$\varepsilon_{\mathrm{fe}}=\frac{0.33}{52.25}=0.0063$

$\left(37.7 \%\right.$ of $\left.\varepsilon_{\mathrm{fu}}\right)$

$\mathrm{T}_{\mathrm{f}}=2 \times 33000 \times 0.0063 \times 0.0065 \times 4.5 \times 8=97.3 \mathrm{k}-\mathrm{in}=8.1 \mathrm{k}-\mathrm{ft}$.

$\mathrm{Q}_{\mathrm{t}}=2 \times \frac{8.1}{4 / 12}=48.6 \mathrm{kips}$

The above means that torsion failure was yet to occur. Torsion failure did not happen during the test. Also, delamination of fibers near the supports was noticed, but not fiber rupture. The increase in capacities of A-3 and B-3 was due to flexural strength of the confined RC section. Since each section had different details, capacities varied from A-3 
to B-3. The ratio of longitudinal reinforcement between A-3 and B-3 was the ratio between A-3 and B-3 loads.

Figure 5-1 shows ACI recommendations for concrete strength as affected by confinement.

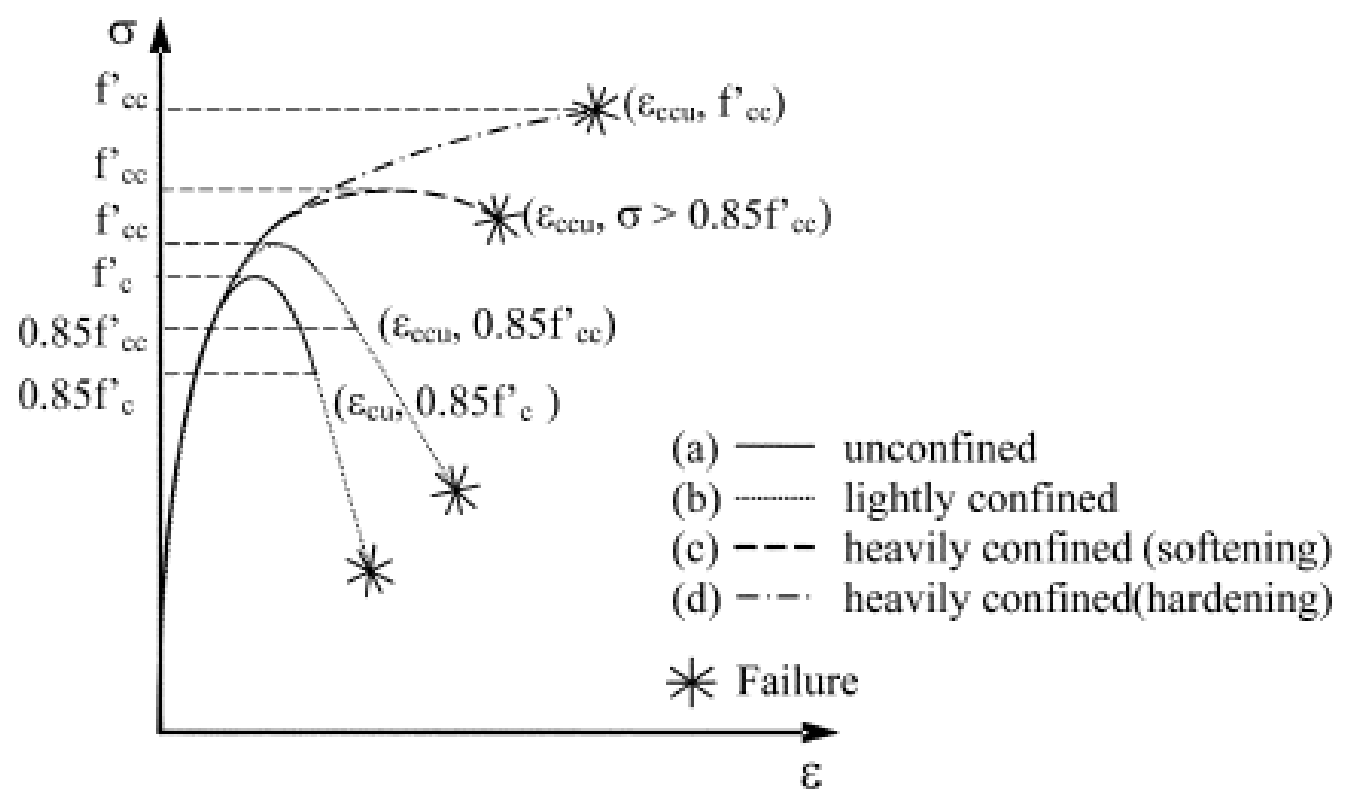

Figure 5-1 ACI Recommendations for Concrete Strength through Different Confinement Types

$$
\begin{aligned}
& f_{c}=\left\{\begin{array}{cc}
E_{c} \in_{s}-\frac{\left(E_{c}-E_{2}\right)^{2}}{4 f^{\prime} c} \epsilon_{c}{ }^{2} & 0 \leq \epsilon_{c} \leq \epsilon_{t}{ }^{\prime} \\
f^{\prime}{ }_{c}+E_{2} \in_{c} & \epsilon_{t}^{\prime} \leq \epsilon_{c} \leq \epsilon_{c c u}
\end{array}\right. \\
& E_{2}=\frac{f^{\prime} c c-f \prime c}{\epsilon_{c c u}} \\
& \epsilon_{t}^{\prime}=\frac{2 f^{\prime} c}{E_{C}-E_{2}}
\end{aligned}
$$

ACI 440.2R eqn 12-2c 


$$
\begin{aligned}
& f_{c c^{\prime}}=f_{c}{ }^{\prime}=\psi f_{3} .3 \kappa a f l \\
& f_{l}=\frac{2 E_{f} n t_{f} \in_{f e}}{D} \\
& \varepsilon_{f e}=\kappa \varepsilon . \varepsilon f_{u} \\
& \epsilon_{c c u}=\in_{c}{ }^{\prime}\left(1.5+12 k_{b} \frac{f_{l}}{f^{\prime} c}\left(\frac{\epsilon_{f e}}{\epsilon_{c}{ }^{\prime}}\right)^{0.45}\right) \\
& \varepsilon_{c c u} \leq 0.01 \\
& \kappa_{a}=1 \\
& \kappa_{\varepsilon}=0.58
\end{aligned}
$$

After applying the equations to a concrete cylinder, the following numbers were determined:

$$
\begin{aligned}
& \mathrm{f}^{\prime}{ }_{c}=6097 \mathrm{psi} \\
& \mathrm{f}^{\prime}{ }_{c c}=13376 \mathrm{psi} \\
& \mathrm{E}_{\mathrm{c}}=4315 \mathrm{ksi} \\
& \epsilon_{c}{ }^{\prime}=0.001988 \\
& \epsilon_{c c u}=0.00859
\end{aligned}
$$


The stress- strain curves are plotted as follows:

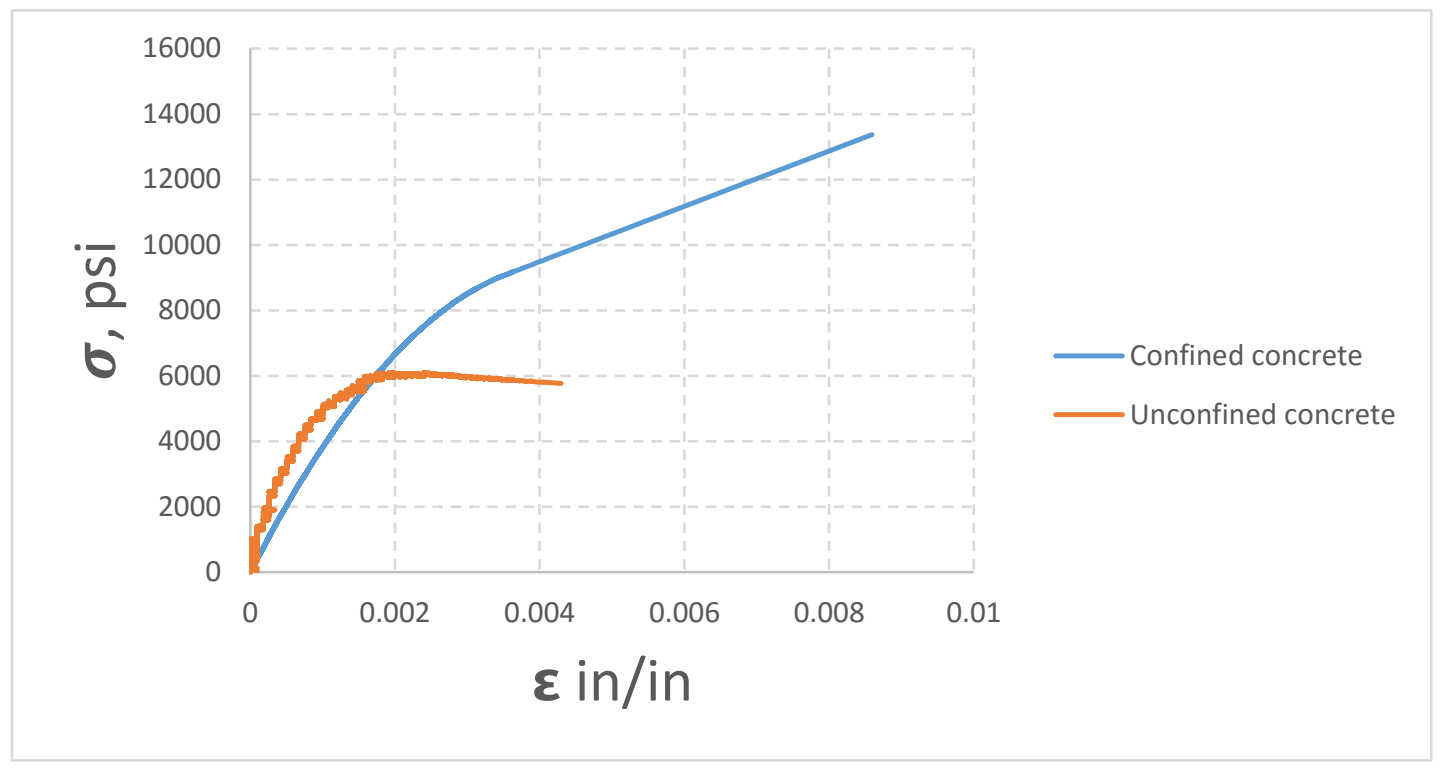

Figure 5-2 Confinement Effects on Concrete Strength Suggested by ACI 440.2R-35

Considering concrete confinement through CFRP sheets give concrete more compressive strains, still reinforcement undergoes larger deformation which analytically moment capacity can be found from moment curvature analysis. Approximately, moment capacity under CFRP application of A-3 beam is: $112.4 \times \frac{f s=94 k s i}{f y=75 \mathrm{ksi}}=140.8 \mathrm{k}-\mathrm{in}=11.7 \mathrm{k}-\mathrm{ft}$ as shown in Figure 5-3. 


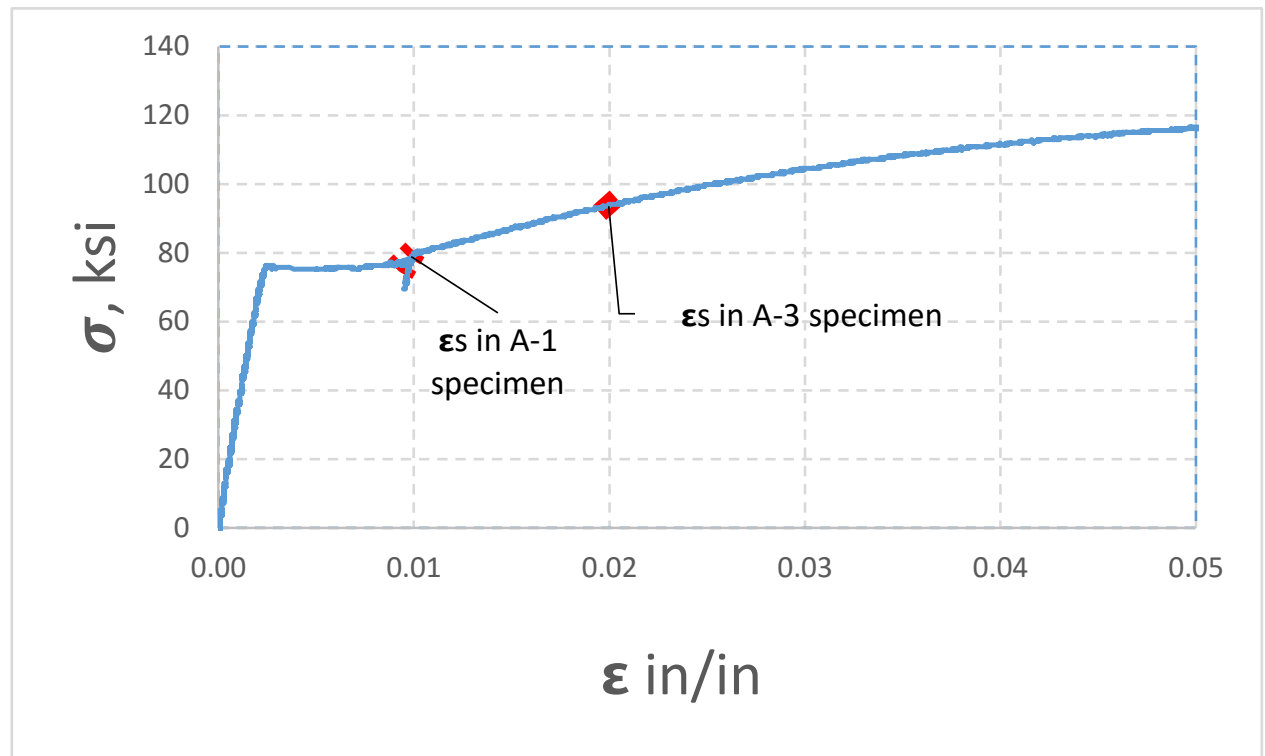

Figure 5-3 Strain Hardening in A-3 Specimen

For fixed-fixed beam, $M=\frac{6 p \cdot l}{27}>>P=\frac{27 M}{6 l}$

$\mathrm{P}=\frac{27 \times 11.7}{6 \times 7}=7.52 \mathrm{kips}$

$\mathrm{Q}_{\mathrm{b}}=2 \mathrm{P}=15 \mathrm{kips}$

\subsection{Specimen B-1, high live load, subjected to V, and M}

Flexural moment strength:

$f_{c_{c}}=6174 \mathrm{psi}$

$f_{y}=75 \mathrm{ksi}$

$\mathrm{f}_{\mathrm{yt}}=30 \mathrm{ksi}$

$\mathrm{E}_{\mathrm{s}}=29000 \mathrm{ksi}$ 


$$
\begin{aligned}
& \text { Assume } \mathrm{f}_{\mathrm{s}}=\mathrm{f}_{\mathrm{y}} \\
& \beta_{1}=0.85-\frac{f^{\prime} c-4000}{1000} \times 0.05 \text { for } f^{\prime}{ }_{c}>4000 p s i \\
& \beta_{1}=0.741 \\
& 0.85 \mathrm{f}^{\prime} \text { c. a.b }=\mathrm{A}_{\mathrm{s} . \mathrm{f}_{\mathrm{y}}} \\
& 0.85 \times 6.17 \times(0.741 c) \times 4.5=0.398 \times 75 \\
& \mathrm{c}=1.7{ }^{\prime}, \\
& \mathrm{M}_{\mathrm{n}}=A_{s} \cdot f_{y}\left(d-\frac{a}{2}\right) \\
& \mathrm{M}_{\mathrm{n}}=0.398 \times 75\left(7.1-\frac{1.264}{2}\right) \\
& \mathrm{M}_{\mathrm{n}}=193 \mathrm{k}-\mathrm{in}=16 \mathrm{k}-\mathrm{ft}
\end{aligned}
$$

For fixed-fixed beam, $M=\frac{6 P . l}{27} \gg P=\frac{27 M}{6 l}$

$$
\begin{aligned}
& \mathrm{P}=\frac{27 \times 16}{6 \times 7}=10.3 \mathrm{kips} \\
& \mathrm{Q}_{\mathrm{b}}=2 \mathrm{P}=20.6 \mathrm{kips}>15.9 \mathrm{kips}
\end{aligned}
$$

Shear strength:

$$
\begin{aligned}
& \mathrm{V}_{\mathrm{c}}=2 \sqrt{f^{\prime}} \cdot b_{w} \cdot d \\
& \mathrm{~V}_{\mathrm{c}}=2 \times \frac{\sqrt{6174}}{1000} \times 4.5 \times 7.1=5 \mathrm{kips} \\
& \mathrm{V}_{\mathrm{s}}=\frac{A v \cdot f y t . d}{s}
\end{aligned}
$$


$\mathrm{V}_{\mathrm{s}}=\frac{0.0353 \times 30 \times 7.16}{3}=2.53 \mathrm{kips}$

$\mathrm{V}_{\mathrm{n}}=\mathrm{V}_{\mathrm{c}}+\mathrm{V}_{\mathrm{s}}=7.53 \mathrm{kips}$

$\mathrm{Q}_{\mathrm{v}}=15$ kips $\approx 14.44$ kips. Failure occurred under shear as shown in Chapter 4.

\subsection{Specimen B-2, high live load, subjected to V, M, and T}

Similar to B-1, and A-1, B-2 had the following results:

$\mathrm{M}_{\mathrm{n}}=16 \mathrm{k}-\mathrm{ft}$

$\mathrm{V}_{\mathrm{n}}=7.53$ kips

$\mathrm{T}_{\mathrm{n}}=1.36 \mathrm{k}-\mathrm{ft}$

\subsection{Specimen B-3. Strengthened subjected to V, T, M}

Results from A-3 beam for torsion and shear can be used for B-3 as well. Failure occurred under flexure. The theoretical capacity would be based on strain hardening of steel reinforcement because of confinement provided by CFRP sheets. Through confinement, concrete can take more compression and thus steel can go for strain hardening as it is shown in figure 3-17 in Chapter 3. A more rigorous analysis is needed to estimate the actual theoretical capacity of strengthened beams having CFRP sheets oriented transversely. The same mechanism was discussed in detail in Section 5.3. The failure loads of strengthened beams are less than estimated shear and torsion capacities based on proposed formulas by ACI code and other researchers, but more than their respective control beam bending moment capacities. 
Table 5-1 Summary of Theoretical and Experimental Capacities and Modes of Failure

\begin{tabular}{|c|c|c|c|c|c|c|}
\hline Specimen & $\begin{array}{l}\text { Live } \\
\text { Load }\end{array}$ & $\begin{array}{l}\text { Mode } \\
\text { of } \\
\text { Loading }\end{array}$ & $\begin{array}{c}\text { Theoretic } \\
\text { al } \\
\text { Capacity } \\
\text { Q }\end{array}$ & $\begin{array}{c}\text { Theoretical } \\
\text { Mode of } \\
\text { Failure }\end{array}$ & $\begin{array}{c}\text { Experimental } \\
\text { Capacity Q }\end{array}$ & $\begin{array}{c}\text { Experimental } \\
\text { Mode of } \\
\text { Failure }\end{array}$ \\
\hline $\begin{array}{c}\text { A-1 } \\
\text { Control } \\
\text { Unwrappe } \\
\text { d }\end{array}$ & $\begin{array}{c}\text { Medium, } \\
125 \text { psf }\end{array}$ & $V \& M$ & 11.96 & Flexure & 14.5 & Shear-flexure \\
\hline $\begin{array}{c}\text { A-2 } \\
\text { Control } \\
\text { Unwrappe } \\
\text { d }\end{array}$ & $\begin{array}{c}\text { Medium, } \\
125 \text { psf }\end{array}$ & $\begin{array}{c}V \& M \\
\& T\end{array}$ & 8.16 & Torsion & 11.9 & Torsion \\
\hline $\begin{array}{c}\text { A-3 } \\
\text { Wrapped }\end{array}$ & $\begin{array}{c}\text { Medium, } \\
125 \text { psf }\end{array}$ & $\begin{array}{c}V \& M \\
\& T\end{array}$ & 15 & Not torsion & 19.5 & Flexure \\
\hline $\begin{array}{c}\text { B-1 } \\
\text { Control } \\
\text { Unwrappe } \\
\text { d }\end{array}$ & $\begin{array}{l}\text { High, } \\
250 \text { psf }\end{array}$ & $V \& M$ & 15 & Shear & 14.4 & Shear \\
\hline $\begin{array}{c}\text { B-2 } \\
\text { Control } \\
\text { Unwrappe } \\
\text { d }\end{array}$ & $\begin{array}{l}\text { High, } \\
250 \text { psf }\end{array}$ & $\begin{array}{c}V \& M \\
\& T\end{array}$ & 8.16 & Torsion & 11.9 & Torsion \\
\hline $\begin{array}{c}\text { B-3 } \\
\text { Wrapped }\end{array}$ & $\begin{array}{l}\text { High, } \\
250 \text { psf }\end{array}$ & $\begin{array}{c}V \& M \\
\& T\end{array}$ & - & Not torsion & 33.1 & Flexure \\
\hline
\end{tabular}




\section{Chapter 6 Summary, Conclusions, and Recommendations}

\subsection{Summary}

This study attempted to perform a realistic strengthening that includes shear, flexure, and torsion loads using two-point loads. Two sets of approximately quarter-scale spandrel beams were tested. The main focus was to gain adequate torsional strength, to avoid catastrophic brittle failure, and to provide an experimental contribution to the literature.

\subsection{Conclusions}

The following conclusions can be drawn:

- Torsional loads can substantially reduce a beam load bearing capacity. Thus, if torsion is not considered in beam design or beam has deficiency in torsional reinforcement, it is necessary to strengthen the beam.

- CFRP composites in form of sheets are efficient in providing additional torsional strength. Full wrapping is the most effective configuration. In this experimental work, set A tests showed an increase of $63 \%$ of load carrying capacity of the beam through the application of CFRP sheets, while the increase in set B tests was about $180 \%$. In practical situations, only U-jackets may be feasible, but they must be properly anchored in order to provide continuous shear flow resistance mechanism at the ends of the sheets.

- FRP effective strain was much lower than maximum strain obtained from coupon tests. Strain started to develop after diagonal cracks formed in the beam. Strengthening beams that lack torsional reinforcement could avoid the torsion brittle failure and change the mode of failure to flexural. 
- Ductility of the strengthened beams were much higher than their respective reference beams both flexurally and torsionally.

- In the tests, delamination or rupture of fibers was not apparent.

- For strengthened specimens, A-3 and B-3, crack widths and diagonal cracks became much smaller in size, but increased in number, and were more uniformly distributed from the points of load application to the end supports.

- No concrete crushing or spalling occurred in the strengthened beams which was attributed to confinement provided by CFRP continuous sheets.

- Longitudinal steel reinforcements, for strengthened specimens A-3 and B-3, in the negative moment region underwent larger strains, which was attributed to the concrete sustaining higher strains through confinement.

- Theoretically, $90^{\circ}$ fibers do not have a direct effect on flexural capacity because fibers in the beam direction have zero strength. However, confinement enhanced the concrete properties, and enhanced flexural capacity as well.

- The tests were analyzed using ACI 318-14, ACI 440.2R-08, and FIB Bulletin models, and a reasonable agreement-was observed with the experimental results.

\subsection{Recommendations for Future Studies}

- Shear and torsional strength enhancement of RC beams that have inadequate or missing web reinforcement through FRP wrap.

- Effect of number of plies of FRP sheets on torsional strengthening. 


\section{References}

[1] FIB Bulletin 14. (2001). Design and Use of Externally Bonded Fiber Reinforced Polymer Reinforcement (FRP EBR) for Reinforced Concrete Structures. Lausanne, Switzerland: International Federation for Structural Concrete (fib).

[2] ACI 318-11. (2011). Building Code Requirements and Commentary. Farmington Hills, MI: American Concrete Institute.

[3] ACI 440.2R-08. (2008). Guide for the Design and Construction of Externally Bonded FRP Systems for Strengthening Concrete Structures. Farmington Hills, MI: American Concrete Institute.

[4] ASTM. (2000). Standard Test Method for Determining Tensile Properties of Fiber Reinforced Polymer Matrix Composites Used for Strengthening of Civil Structures. In A. b. standards, D3039/D3039M (pp. 105-116). West Conshohocken, PA: ASTM International.

[5] ASTM. (2005). Standard Test Method for Compressive Strength of Cylindrical Concrete Specimens. In A. b. standards, C39/ C39M-05 (Vol. 04.02, pp. 23-38). West Conshohocken, PA: ASTM International.

[6] ASTM. (2006). Standard Test Method for Splitting Tensile Strength of Cylindrical Concrete Specimens. In A. b. standards, C 496/ C 496M-04 (pp. 295-299). West Conshohocken, PA: ASTM International. 
[7] ASTM. (2006). Standard Test Method for Static Modulus of Elasticity and Poisson's

Ratio of Concrete in Compression. In A. b. standards, C469/ C469M (pp. 267-270). West Conshohocken, PA: ASTM International.

[8] ASTM. (2010). Standard Test Method for Determining Tensile Properties of Fiber Reinforced Polymer Matrix Composites Used for Strengthening of Civil Structures. In A. b. standards, D7565/D7565M. West Conshohocken, PA: ASTM International.

[9] ASTM. (2015). Standard Test Methods for Tension Testing of Metallic Materials. In A. b. standards, E8/E8M. West Conshohocken, PA: ASTM International.

[10] Bank, L. C. (2007). Composites for Construction: Structural Design with FRP Materials. New York, NY: John Wiley \& Sons.

[11] BASF the Chemical Company. (2007). MBrace cf 130 Unidirectional high strength carbon fiber fabric for the MBrace Composite Strengthening System. Shakopee, MN: BASF Construction Chemicals, LLC -Building Systems.

[12] BASF the Chemical Company. (2014). MasterBrace F 2000. Shakopee, MN: BASF Corporation Construction Systems.

[13] BASF the Chemical Company. (2014). MasterBrace P 3500, Epoxy Primer for MasterBrace FIB Fabric/ laminate System. Shakopee, MN: BASF Corporation Constructions Systems. 
[14] BASF the Chemical Company. (2014). MasterBrace SAT 4500, Epoxy

encapsulation resin for the MasterBrace Composite Strengthening System. Shakopee, MN: BASF Corporation Constructions Systems.

[15] D30, A. C. (2000). Standard Test Method for Tensile Properties of Polymer Matrix Composite Materials. ASTM D3039/3039M, 105-116.

[16] Dawood, M. B. (2013). Nonlinear Analysis of Solid and Box-section RC Beams Strengthened in Torsion with CFRP Reinforcement. Journal of Babylon University/ Engineering Sciences, 21, 11-26.

[17] Deifalla, A., \& Ghobarah, A. (2010). Full Torsional Behavior of RC Beams Wrapped with FRP:. ASCE Journal, 14, 289-300.

[18] Faulstich de Paivaa, J., Mayer, S., \& Rezende, M. C. (2006). Comparison of Tensile Strength of Different Carbon Fabric Reinforced Epoxy Composites. Materials Research, 9, 83-89.

[19] Higazy, E., \& El-Kateb, M. (2011, August). Strengthening of Reinforced Concrete Beams Under Torsion Using CFRP Sheets. 36th Conference on Our World in Concrete \& Structures. Retrieved from http://cipremier.com/100036033

[20] Matthys, S., \& Triantafillou, T. (n.d.). Shear and Torsion Strengthening With Externally Bonded FRP Reinforcement. In Composites in Construction- A Reality (pp. 203-212). ASCE Journal. 
[21] Mohammad, K. I., \& Al-Sulayfani, B. J. (2013, March). Torsional Strengthening of RC Beams with CFRP Wrap. Tikrit Journal of Engineering Sciences, 20, 1-9.

[22] Mohammadizadeh, M. R., \& Fadaee, M. J. (2009, August). Torsional Behaviour of High-Strength Concrete Beams Strengthened Using CFRP Sheets; an Experimental and Analytical Study. Scientia Iranica, 16, 321-330.

[23] Mostofinejad, D., \& Talaeitaba, S. B. (2014). Strengthening and Rehabilitation of RC Beams with FRP Overlays under Combined Shear and Torsion. Electronic Journal of Structural Engineering, 84-92.

[24] Nawy, G. E. (2009). Reinforced Concrete: A Fundamental Approach (6th ed.). Upper Saddle River, New Jersey: Prentice Hall.

[25] Panchacharam Saravanan, Abdeldjelil Belarbi. (2002). Torsional Behavior of Reinforced Concrete Beams Strengthened with FRP Composites. First FIB Congress.

[26] Salom, P., Gergely, J., \& Young, D. T. (n.d.). Torsional Strengthening of Spandrel Beams with Composite Laminates.

[27] Z. G. Guo, S. Y. Cao, W. M. Sun, \& X. Y. Lin. (2005). Experimental Study on Bond Stress-Slip Behavior between FRP Sheets and Concrete. International Institute for FRP in Construction, 77-83. 


\section{Appendix}

\section{A. Beam Prototype Calculations}

\section{Medium-to-high Live Load (125 psf)}
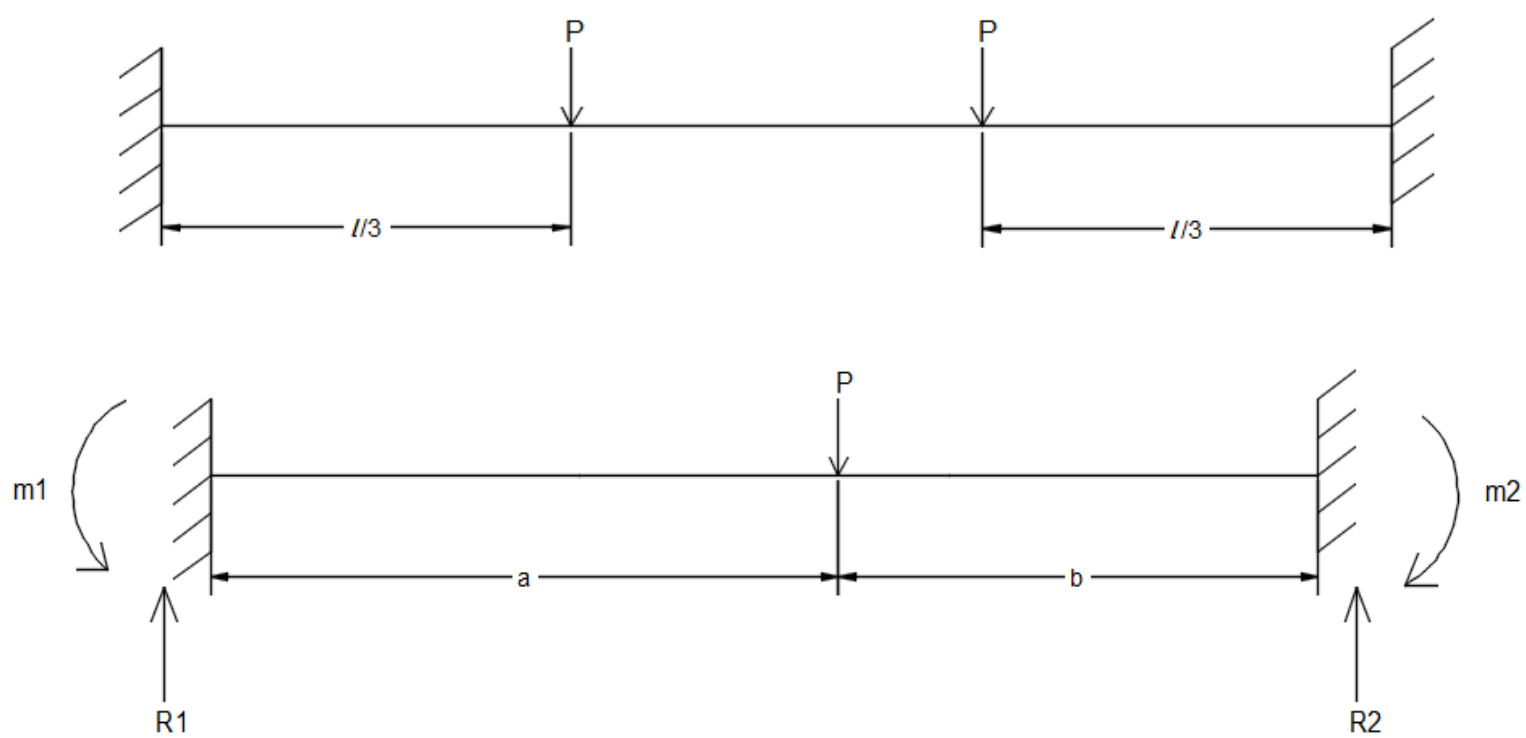

$$
\begin{aligned}
& \mathrm{R}_{1}=\frac{P \cdot b^{2}}{l^{3}}(3 a+b) \\
& \mathrm{R}_{2}=\frac{P \cdot a^{2}}{l^{3}}(a+3 b) \\
& \mathrm{M}_{1}=\frac{P \cdot a \cdot b^{2}}{l^{2}} \\
& \mathrm{M}_{2}=\frac{P \cdot a^{2} \cdot b}{l^{2}}
\end{aligned}
$$




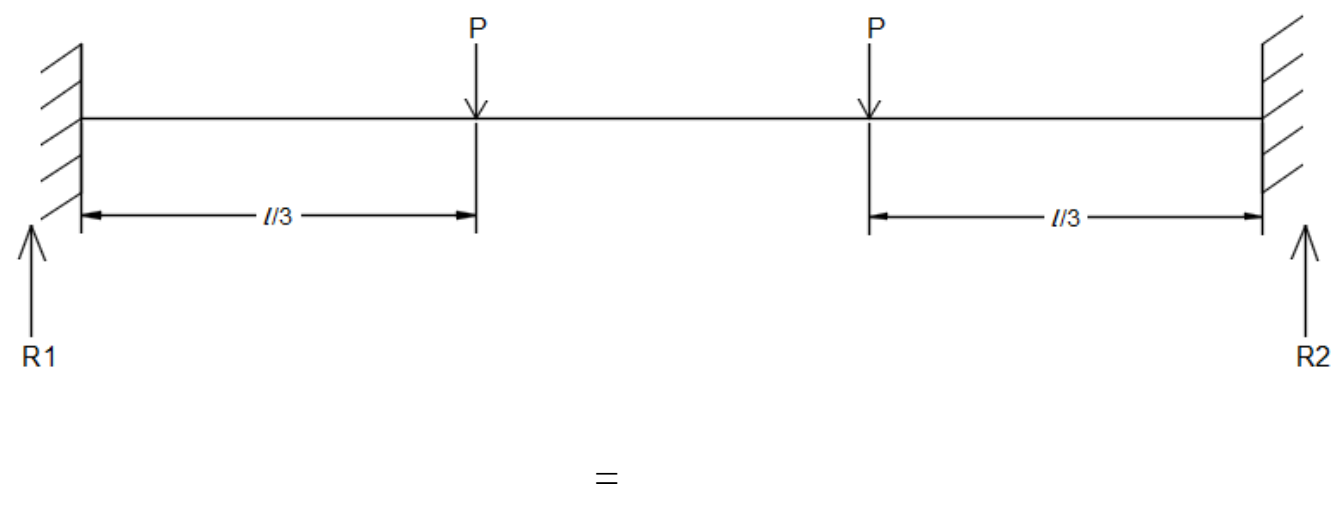

Case 1

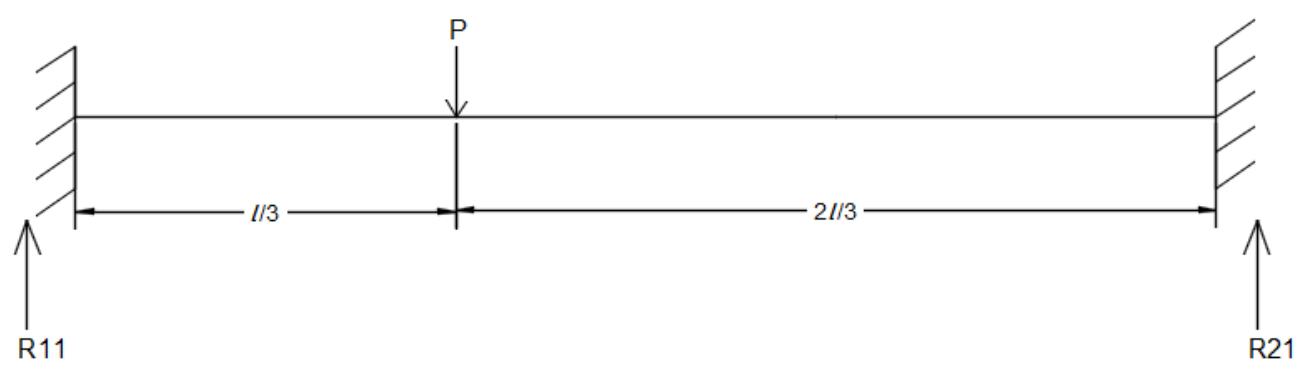

$+$

Case 2

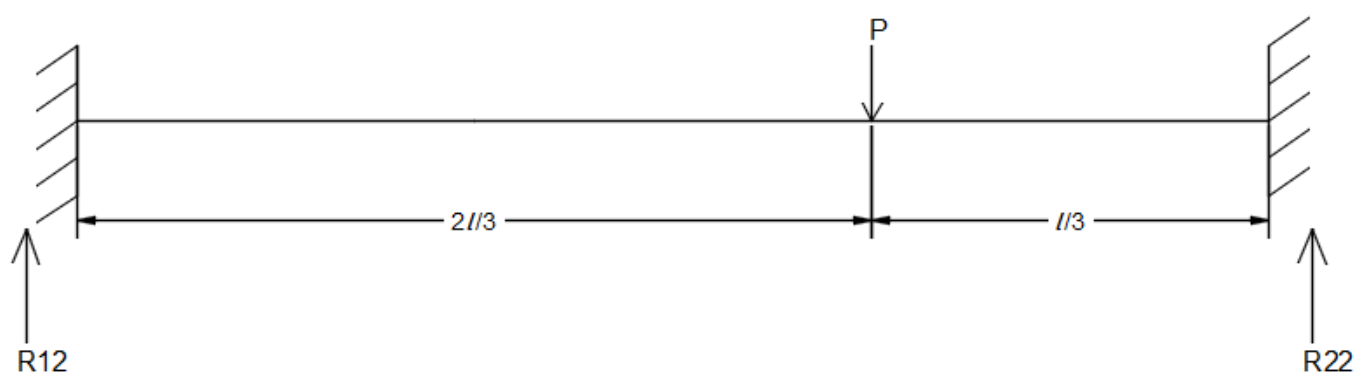




\section{Case 1}

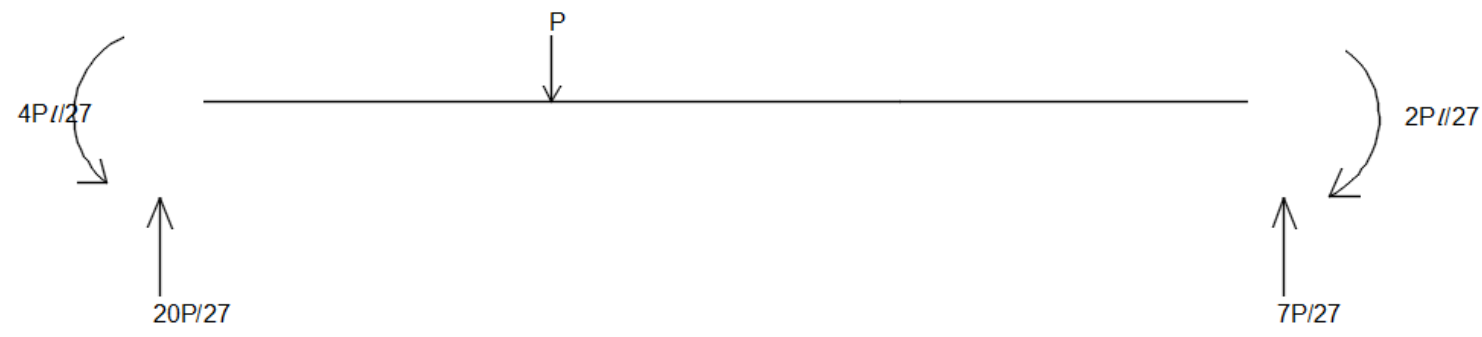

$\mathrm{R}_{11}=\frac{20}{27} P$

$\mathrm{R}_{21}=\frac{7}{27} P$

$\mathrm{M}_{11}=P . l$

$\mathrm{M}_{22}=\frac{2}{27} P \cdot l$

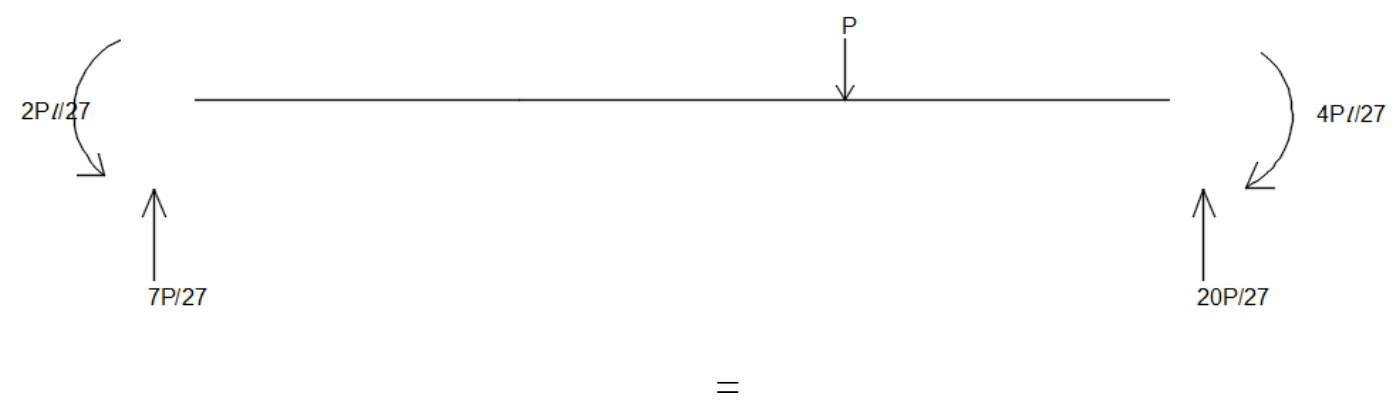

The actual beam 

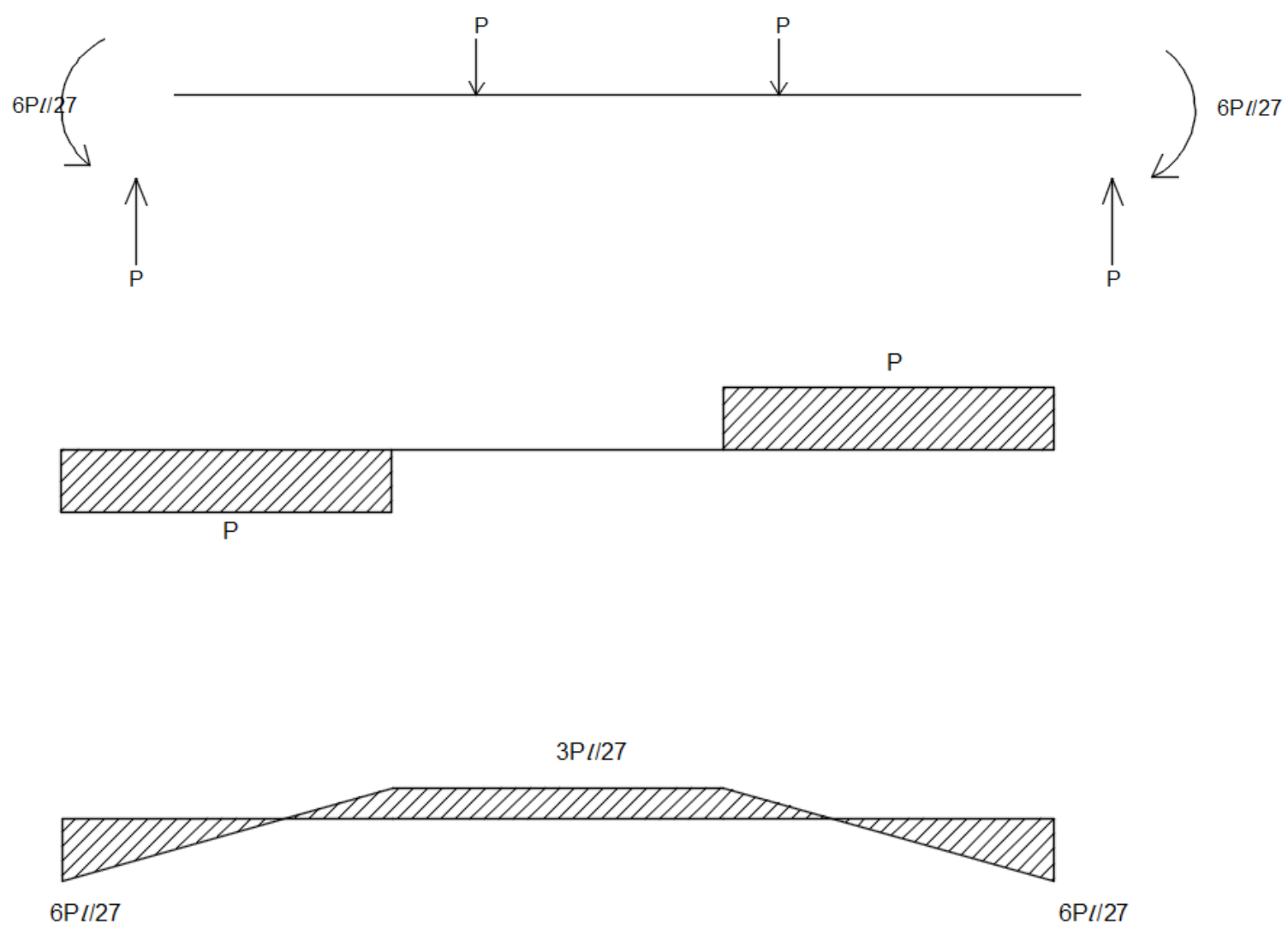

Shear and Bending Moment Diagram 

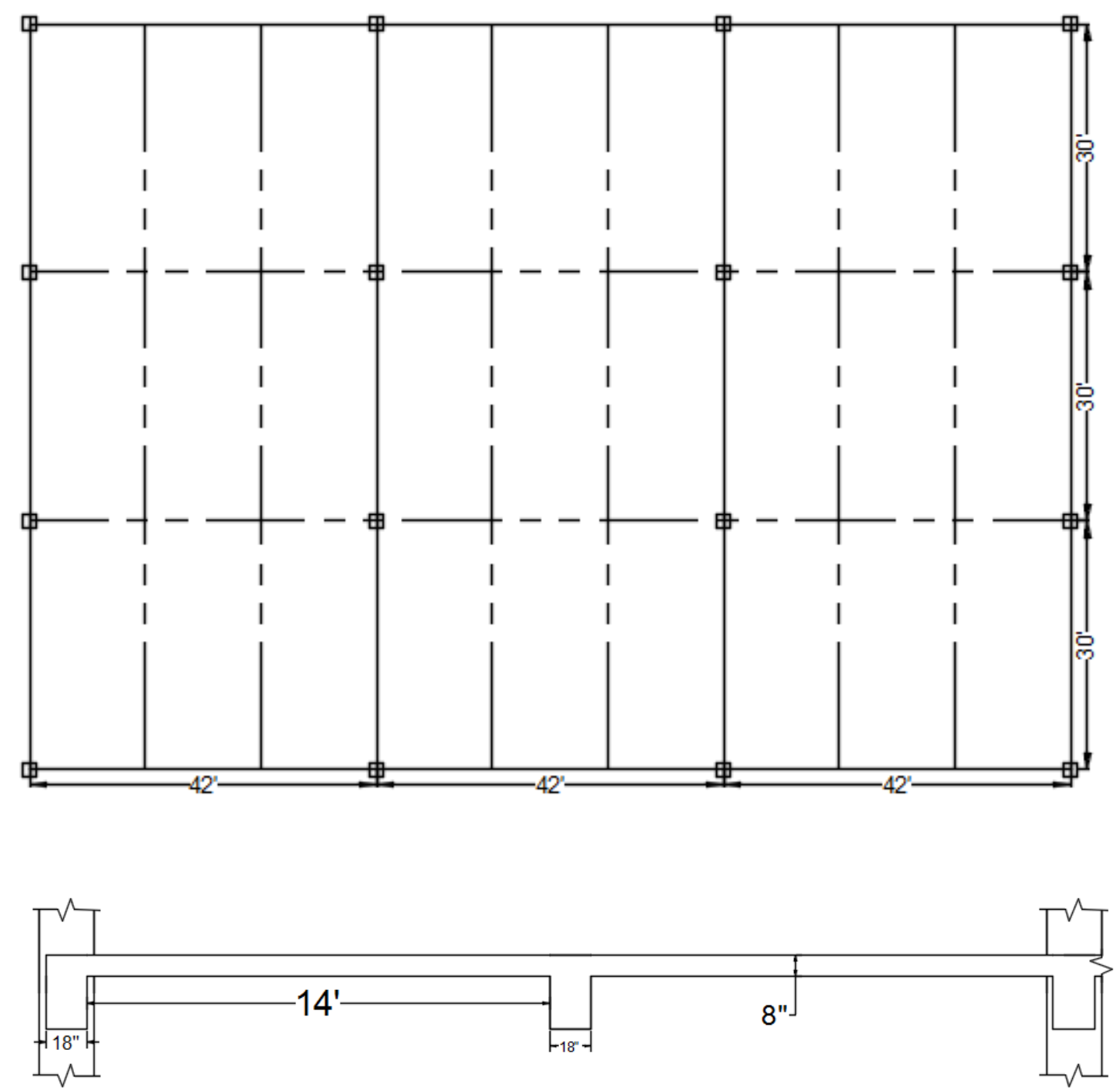

Having

$l=30^{\prime}$

$\mathrm{W}_{\mathrm{L}}=125 \mathrm{psf}$

$l_{1}=30^{\prime}$ 
$l_{2}=42^{\prime}$
$\mathrm{t}_{\mathrm{s}}=8^{\prime}$,

$\mathrm{W}_{\mathrm{D}}(\operatorname{addl})=20 \mathrm{psf}$

$\mathrm{W}_{\text {wall }}=0.75 \mathrm{k} / \mathrm{f}$

$\mathrm{f}^{\prime} \mathrm{c}=4000 \mathrm{psi}$

$\mathrm{fy}=60 \mathrm{ksi}$

Beam designed as rectangular

Column sizes $24^{\prime \prime} \times 24$ ',

Loads on the beam would be

$\mathrm{W}_{\mathrm{D}}(\mathrm{slab})=\frac{8}{12} \times 150=100 p s f$

$\mathrm{Wu}=1.2 \mathrm{~W}_{\mathrm{D}}+1.6 \mathrm{~W}_{\mathrm{L}}$

$\mathrm{Wu}=1.2(100+20)+1.6(125)$

$\mathrm{Wu}=344 \mathrm{psf}$

$\mathrm{Mu}=\frac{W u . l^{2}}{24}=0.344 \times \frac{14^{2}}{24}=2.81 k \cdot \frac{f t}{1}$

$\mathrm{W}_{\mathrm{L}}($ from slab $)=0.125 \times \frac{14}{2}=0.875 k$ 
$\mathrm{W}_{\mathrm{D}}($ from slab $)=0.12 \times \frac{14}{2}=0.84 \frac{k}{f t} / 1$

Beam self weight $=\frac{18 \times 32}{144} \times 0.15=0.6 \frac{k}{f t} / 1$

$\mathrm{W}_{\mathrm{D}}($ total $)=0.6+0.84+0.75=2.19 \mathrm{k} / \mathrm{ft} / 1$

$\mathrm{Wu}=1.2 \times 2.19+1.6 \times 0.875=4 \frac{k}{f t} / 1$

$\underline{\text { Analysis for bending moment }}$

$\mathrm{M}_{\mathrm{u}}=\frac{W u . l^{2}}{10}=\frac{4 \times 28^{2}}{10}=313.6 \mathrm{k} . f t$

$\underline{\text { Analysis for shear force }}$

$\mathrm{Vu} @$ ends $=\frac{W u . l}{2}=\frac{4 \times 30}{2}=60 k$

$\mathrm{V}_{\mathrm{u}}(\mathrm{WL} @$ midspan for partial loading $)=\frac{W u L . l}{8}=\frac{(1.6 \times 0.875) \times 30}{8}=5.25 \mathrm{k}$

Slope of Vu-diagram $=\frac{60-5.25}{15}=3.65$

$\mathrm{V}_{\mathrm{u}} @ \mathrm{~d}=60-\frac{9+29.625}{12} \times 3.65=48.25 k$

$\underline{\text { Analysis for torsional moment }}$

Slab_reaction $=1.2 \times 0.84+1.6 \times 0.875=2.408 \frac{k}{1}$

Applied torque tu $=2.81+2.408 \times \frac{9}{12}=4.616 \mathrm{k} . \mathrm{ft} / 1$

$\mathrm{T}_{\mathrm{u}}=4.616 \times \frac{30}{2}=69.24 k . f t$ 
$\mathrm{T}_{\mathrm{u}} @ \mathrm{~d}=69.24-\frac{9+29.625}{12} \times 4.616=54.38 \mathrm{k} . f t$

$\underline{\text { Flexural design }}$

$\mathrm{M}_{\mathrm{u}}=\emptyset \rho F y b d^{2}\left(1-\frac{\rho F y}{1.7 f^{\prime} c}\right)$

If we assume $\mathrm{b}=0.6 \mathrm{~d} \quad \rho=0.01 \quad \emptyset=0.9 \quad$ fy $=60 \mathrm{ksi} \quad \mathrm{z}=0.88 \mathrm{~d}$

$313.6 \times 12=0.9 \times 0.01 \times 60 \times 0.6 \times d^{3}\left(1-\frac{0.01 \times 60}{1.7 \times 4}\right)$

$d=23.354^{\prime}, \quad b=14^{\prime}$,

For better capacity and stiffness, let $\mathrm{h}=32^{\prime}, \mathrm{b}=18^{\prime}$,

$\mathrm{A}_{\mathrm{s}}=\frac{M u}{\emptyset f y . . z} \quad$ let $z=0.88 d$

Using \#9 bars, $\mathrm{d}=29.625^{\prime \prime} \gg z=26^{\prime \prime}$

$\mathrm{A}_{\mathrm{s}}=2.68 \mathrm{in}^{2}$

Using \#9 bars, $A_{b}=1$ in $^{2}$

$\mathrm{n}=\frac{A s}{A b}=\frac{2.68}{1}=2.68$ say 3 bars

$\mathrm{As}_{\min 1}=\frac{3 \sqrt{f^{\prime} c}}{f y} \cdot b w \cdot d=1.7 \mathrm{in}^{2}$ 
$A s_{\min 2}=\frac{200}{F y} b w \cdot d=1.875 i n^{2}$

$\therefore$ Use 3 \#9 bars

$\mathrm{cc}=>1,, \quad$ ok!

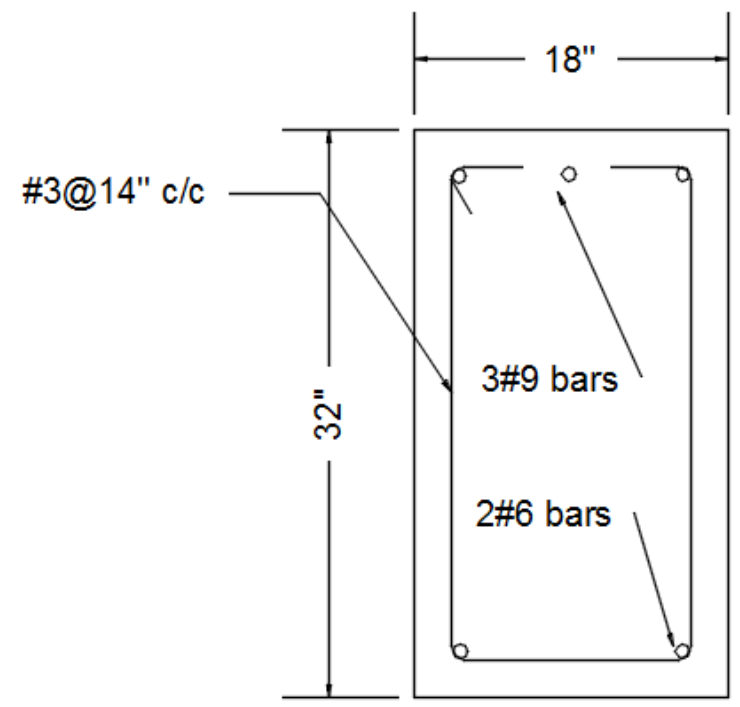

$\underline{\text { Shear design }}$

$$
\mathrm{V}_{\mathrm{c}}=2 \sqrt{f^{\prime} c} \cdot b w \cdot d=67.45 k
$$

$\mathrm{V}_{\mathrm{s}}=\frac{V u-\emptyset V c}{\emptyset}=\frac{48.25-0.75 \times 67.45}{0.75}=-3.11 k$

minimum shear reinf.

\section{Required}
$\mathrm{A}_{\mathrm{v}}>\frac{0.75 \sqrt{f^{\prime c}}}{f y} b w . s 1 \quad \gg s_{1 \max }=15.46^{\prime \prime}$
$\mathrm{A}_{\mathrm{v}}>\frac{50}{f y} b w . s 2 \quad \gg s_{2 \max }=14.66^{\prime \prime}$
$S_{\max }=\frac{d}{2} \quad \gg S_{\max }=14.875^{\prime \prime}$

$\therefore$ Use \#3@14" $c / c$ 
That is design for bending moment and shear force only!

Torsional capacity of this un-strengthened beam is

$$
\begin{aligned}
& \mathrm{T}_{\mathrm{c}}=\emptyset 4 \sqrt{f^{\prime} c} \frac{A c p^{2}}{P c p} \quad \mathrm{~A}_{\mathrm{cp}}=576 \mathrm{in}^{2} \quad \mathrm{P}_{\mathrm{cp}}=100 \mathrm{in} \\
& \mathrm{T}_{\mathrm{cr}}=52.458 \mathrm{k}-\mathrm{ft} \rightarrow \mathrm{Tu}>\mathrm{Tcr} \rightarrow \text { torsion design may be considered! } \\
& \mathrm{x}_{1}=14.625^{\prime}, \\
& \mathrm{y}_{1}=28.625^{\prime}, \\
& \mathrm{A}_{0 \mathrm{~h}}=\mathrm{x} 1 . \mathrm{y} 1=418.64 \mathrm{in}^{2} \\
& \mathrm{P}_{\mathrm{h}}=2\left(\mathrm{x}_{1}+\mathrm{y}_{1}\right)=86.5^{\prime}, \\
& \mathrm{A}_{0}=0.85 \mathrm{~A}_{\mathrm{oh}}=355.844 \mathrm{in}^{2} \\
& \varnothing \mathrm{T}_{\mathrm{n}}=\left[2 \emptyset . A_{0} . \text { At.fyt } / \mathrm{s}\right] \cot \theta \\
& \varnothing \mathrm{T}_{\mathrm{n}}=21 \mathrm{k}-\mathrm{ft}
\end{aligned}
$$


For torsion:

We have the same bending and shear diagrams, plus this torque diagram

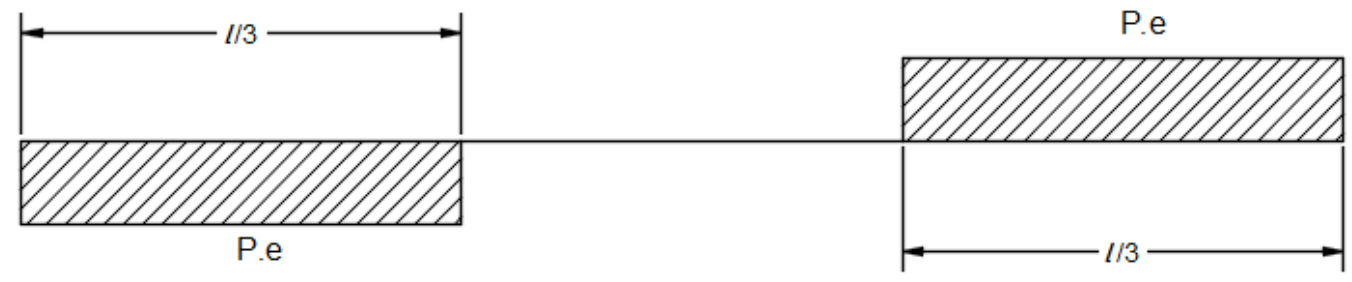

$\mathrm{e}=$ eccentricity from the beam's centerline

Scaling this prototype to $1 / 4$,

$b=4.5^{\prime}$,

$\mathrm{h}=8^{\prime}$,

$l_{n}=7$

$\mathrm{s}=3.33^{\prime \prime}$ for $\emptyset 0.15^{\prime \prime} G R 30$ wires

$\mathrm{A}_{\mathrm{s}}=0.166$ in $^{2}(2 \# 3$ bars $)$

$\mathrm{f}^{\prime} \mathrm{c}=4000 \mathrm{psi}$

fy $=60 \mathrm{ksi}$

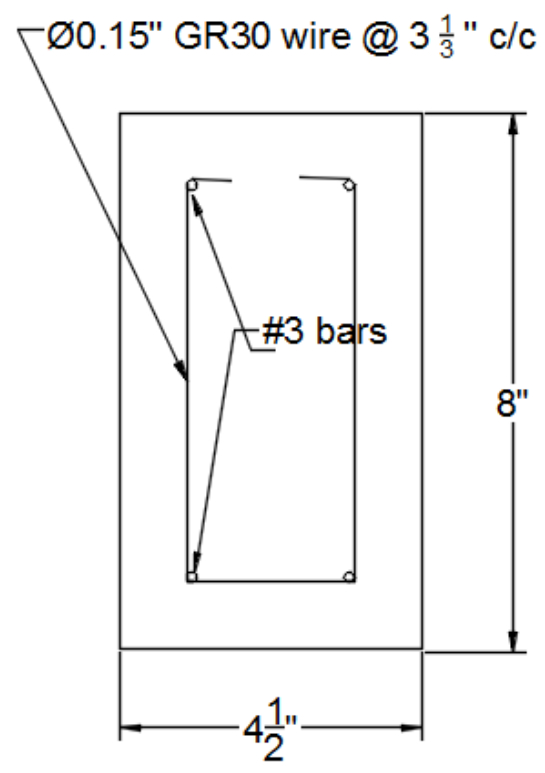

This beam is assumed to have been designed for shear and moment only; now how much additional torsional capacity can be achieved using FRP sheets?! 


\section{High Live Load (250 psf)}

Shear and moment diagrams would be the same as the previous analysis.

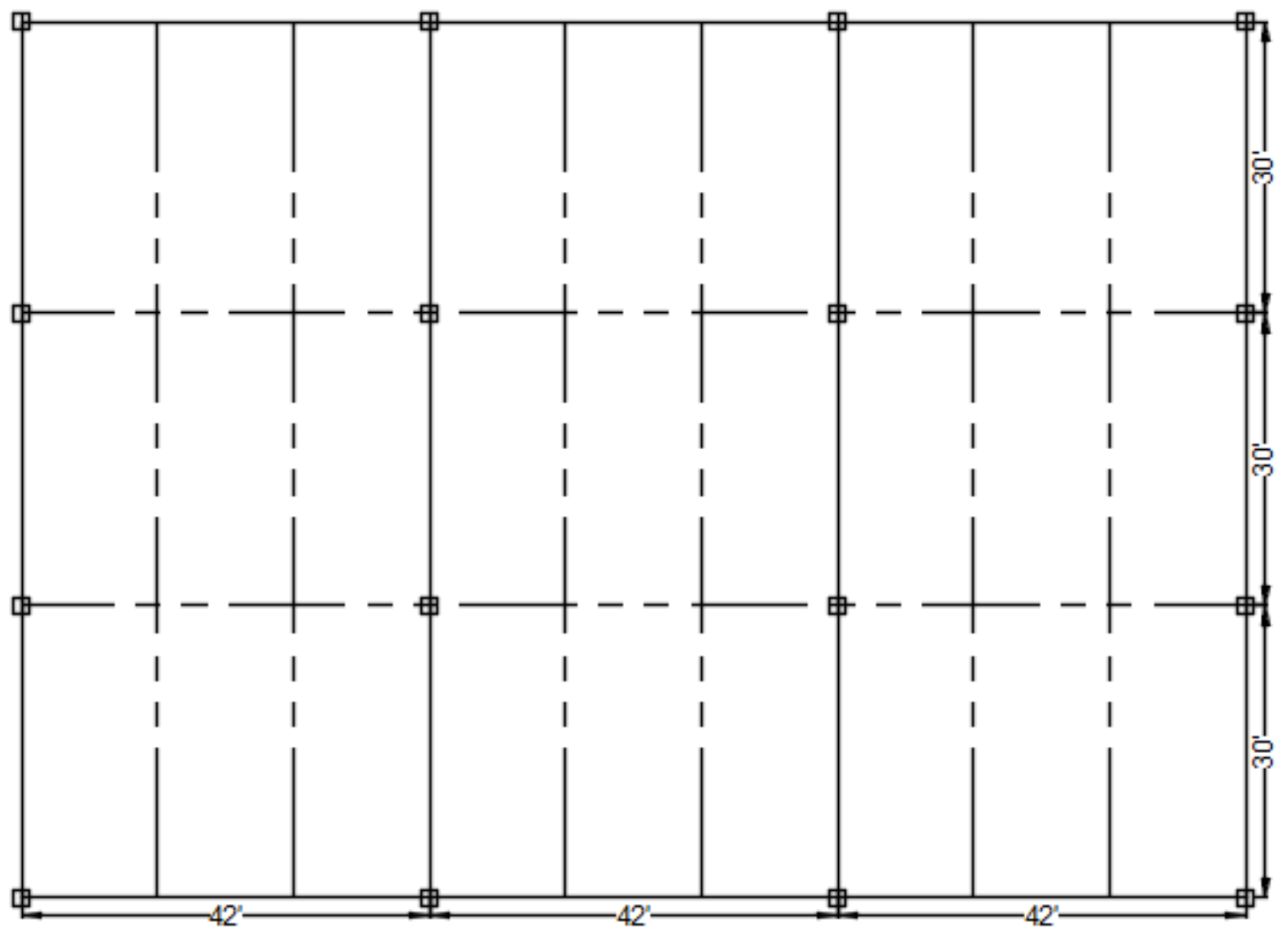

Having

$l=30$

$\mathrm{W}_{\mathrm{L}}=250 \mathrm{psf}$

$l_{1}=30^{\prime}$

$l_{2}=42^{\prime}$ 
$\mathrm{t}_{\mathrm{s}}=8$,

$\mathrm{W}_{\mathrm{D}}(\operatorname{addl})=20 \mathrm{psf}$

$\mathrm{W}_{\text {wall }}=0.75 \mathrm{k} / \mathrm{f}$

$\mathrm{f}^{\prime} \mathrm{c}=4000 \mathrm{psi}$

fy $=60 \mathrm{ksi}$

Beam designed as rectangular

$\mathrm{b} \times h=18^{\prime \prime} \times 32^{\prime \prime}($ assume $)$

Column sizes $24^{\prime \prime} \times 24^{\prime}$ '

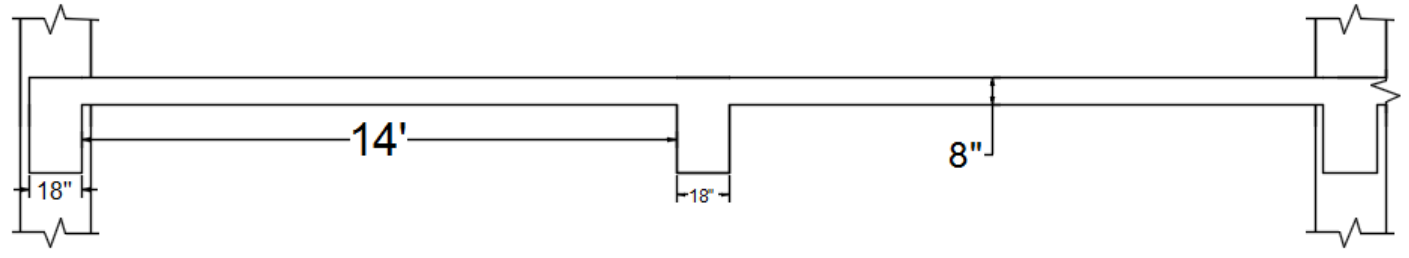

Loads on the beam would be

$$
\begin{aligned}
& \mathrm{W}_{\mathrm{D}}(\mathrm{slab})=\frac{8}{12} \times 150=100 p s f \\
& \mathrm{Wu}=1.2 \mathrm{~W}_{\mathrm{D}}+1.6 \mathrm{~W}_{\mathrm{L}} \\
& \mathrm{Wu}=1.2(100+20)+1.6(250) \\
& \mathrm{Wu}=544 \mathrm{psf}
\end{aligned}
$$


$\mathrm{M}_{\mathrm{u}}=\frac{W u \cdot l^{2}}{24}=0.544 \times \frac{14^{2}}{24}=4.44 k \cdot \frac{\mathrm{ft}}{1}$

$\mathrm{W}_{\mathrm{L}}($ from slab $)=0.25 \times \frac{14}{2}=1.75 \frac{k}{f t} / 1$

$\mathrm{W}_{\mathrm{D}}($ from slab $)=0.12 \times \frac{14}{2}=0.84 \frac{k}{f t} / 1$

Beam self-weight $=\frac{18 \times 32}{144} \times 0.15=0.6 \frac{k}{f t} / 1$

$\mathrm{W}_{\mathrm{D}}($ total $)=0.6+0.84+0.75=2.19 \mathrm{k} / \mathrm{ft} / 1$

$\mathrm{Wu}=1.2 \times 2.19+1.6 \times 1.75=5.428 \frac{k}{f t} / 1$

$\underline{\text { Analysis for bending moment }}$

$\mathrm{M}_{\mathrm{u}}=\frac{W u . l^{2}}{10}=\frac{5.428 \times 28^{2}}{10}=425.55 \mathrm{k} . \mathrm{ft}$

\section{$\underline{\text { Analysis for shear force }}$}

$\mathrm{V}_{\mathrm{u}} @ \mathrm{ends}=\frac{W u . l}{2}=\frac{5.428 \times 30}{2}=81.42 \mathrm{k}$

$\mathrm{V}_{\mathrm{u}}(\mathrm{WL} @$ mid-span for partial loading $)=\frac{W u L . l}{8}=\frac{(1.6 \times 1.75) \times 30}{8}=10.5 \mathrm{k}$

Slope of $\mathrm{V}_{\mathrm{u}}$-diagram $=\frac{81.42-10.5}{15}=4.728$

$\mathrm{V}_{\mathrm{u}} @ \mathrm{~d}=81.42-\frac{9+29.75}{12} \times 4.728=66.15 k$

$\underline{\text { Analysis for torsional moment }}$

Slab reaction $=1.2 \times 0.84+1.6 \times 1.75=3.808 \frac{k}{1}$ 
Applied torque tu $=4.44+3.808 \times \frac{9}{12}=7.296 k . f t / 1$

$\mathrm{T}_{\mathrm{u}}=7.296 \times \frac{30}{2}=109.44 k . f t$

$\mathrm{T}_{\mathrm{u}} @ \mathrm{~d}=109.44-\frac{9+29.625}{12} \times 7.296=85.956 k . f t$

$\underline{\text { Flexural design }}$

$\mathrm{M}_{\mathrm{u}}=\emptyset \rho f y b d^{2}\left(1-\frac{\rho F y}{1.7 f^{\prime} c}\right)$

If we assume $\mathrm{b}=0.6 \mathrm{~d} \quad \rho=0.01 \quad \emptyset=0.9 \quad$ fy $=60 \mathrm{ksi} \quad \mathrm{z}=0.88 \mathrm{~d}$

$425.55 \times 12=0.9 \times 0.01 \times 60 \times 0.6 \times d^{3}\left(1-\frac{0.01 \times 60}{1.7 \times 4}\right)$

$d=25.856^{\prime}, \quad b=15.513^{\prime}$,

For better capacity and stiffness, let $\mathrm{h}=322^{\prime} \quad \mathrm{b}=18^{\prime}$,

$\mathrm{A}_{\mathrm{s}}=\frac{M u}{\emptyset f y . . z} \quad$ let $z=0.88 d$

Using \#9 bars, $\mathrm{d}=29.625^{\prime \prime} \gg z=26.07^{\prime \prime}$

$\mathrm{A}_{\mathrm{s}}=3.627 \mathrm{in}^{2}$

Using \#9 bars, $\mathrm{A}_{\mathrm{b}}=1 \mathrm{in}^{2}$

$\mathrm{n}=\frac{A s}{A b}=\frac{3.627}{1}=3.6$ say 4 bars

$\mathrm{A}_{\operatorname{smin} 1}=\frac{3 \sqrt{f^{\prime} c}}{f y} \cdot b w \cdot d=1.7 \mathrm{in}^{2}$ 
$\mathrm{A}_{\mathrm{smin} 2}=\frac{200}{F y} b w \cdot d=1.875 \mathrm{in}^{2}$

$\therefore$ Use 4 \#9 bars

cc $>1 ', \quad$ ok!

$\underline{\text { Shear design }}$

$\mathrm{V}_{\mathrm{c}}=2 \sqrt{f^{\prime} c} \cdot b w \cdot d=67.45 \mathrm{k}$

$\mathrm{V}_{\mathrm{s}}=\frac{V u-\emptyset V c}{\emptyset}=\frac{66.15-0.75 \times 67.45}{0.75}=21.75 \mathrm{k}$

$\mathrm{s}=\frac{A v \cdot f y \cdot d}{V s}$ using 2 legs of \#3 bars,

$\mathrm{A}_{\mathrm{v}}=0.22 \mathrm{in}^{2}$

$\mathrm{s}=18^{\prime}$,

$\mathrm{A}_{v}>\frac{0.75 \sqrt{f \prime c}}{f y} b w . s 1 \quad \gg s_{1 \max }=$

$15.46^{\prime \prime}$

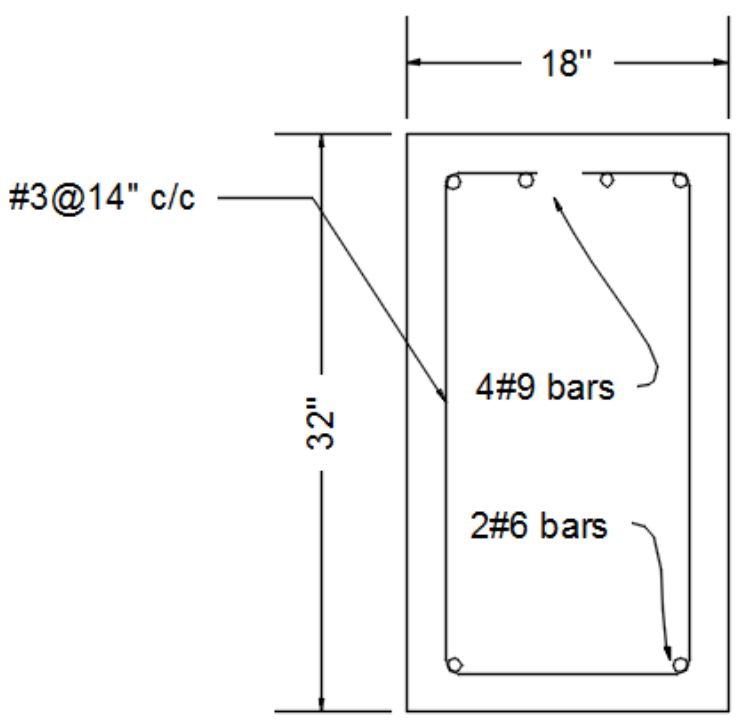

$\mathrm{A}_{\mathrm{v}}>\frac{50}{f y} b w . s 2 \quad \gg s_{2 \max }=14.66^{\prime \prime}$

$\mathrm{S}_{\operatorname{maX}}=\frac{d}{2} \quad \gg S_{\max }=14.8^{\prime \prime}$

$\therefore$ Use \#3@14"c c c

That is design for bending moment and shear force only!

Torsional capacity of this un-strengthened beam is 


$$
\begin{aligned}
& \mathrm{T}_{\mathrm{cr}}=\emptyset 4 \sqrt{f^{\prime} c} \frac{A c p^{2}}{P c p} \quad \mathrm{~A}_{\mathrm{cp}}=576 \mathrm{in}^{2} \quad \mathrm{P}_{\mathrm{cp}}=100 \mathrm{in} \\
& \mathrm{T}_{\mathrm{cr}}=52.458 \mathrm{k}-\mathrm{ft} \rightarrow \mathrm{T}_{\mathrm{u}}>\mathrm{T}_{\mathrm{cr}} \rightarrow \text { torsion design may be considered! } \\
& \mathrm{x}_{1}=14.625^{\prime}, \\
& \mathrm{y}_{1}=28.625^{\prime}, \\
& \mathrm{A}_{0 \mathrm{~h}}=\mathrm{x} 1 . \mathrm{y} 1=418.64 \mathrm{in}^{2} \\
& \mathrm{P}_{\mathrm{h}}=2\left(\mathrm{x}_{1}+\mathrm{y}_{1}\right)=86.5^{\prime}, \\
& \mathrm{A}_{0}=0.85 \mathrm{~A}_{\mathrm{oh}}=355.844 \mathrm{in}^{2} \\
& \emptyset \mathrm{T}_{\mathrm{n}}=\left[2 \emptyset \cdot A_{0} \cdot \text { At.fyt } / \mathrm{s}\right] \cot \theta \\
& \varnothing \mathrm{T}_{\mathrm{n}}=21 \mathrm{k}-\mathrm{ft}
\end{aligned}
$$

For torsion:

We have the same bending and shear diagrams, plus this torque diagram

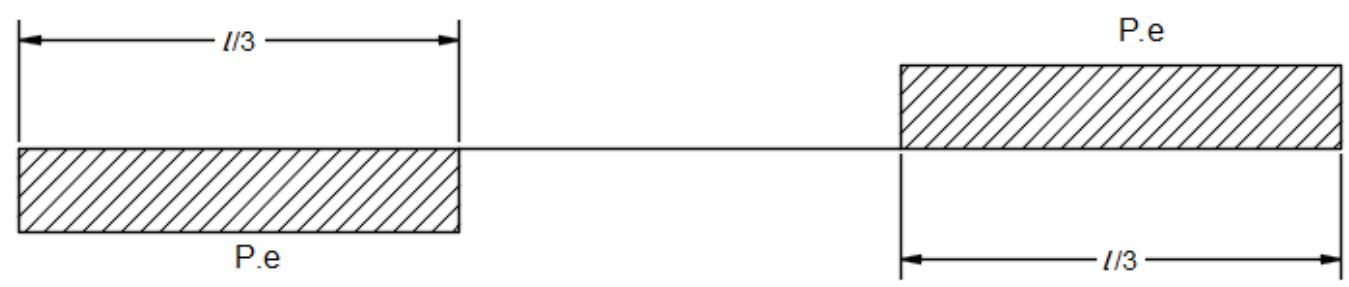

$\mathrm{e}=$ eccentricity from the beam's centerline

Scaling this prototype to $1 / 4$,

$$
\mathrm{b}=4.5^{\prime},
$$


$\mathrm{h}=8^{\prime}$,

$\ln =7$

$\mathrm{s}=3.33^{\prime \prime}$ 'for $\varnothing 0.15^{\prime \prime} G R 30$ wires

$\mathrm{A}_{\mathrm{s}}=0.225 \mathrm{in}^{2} \quad$ use $2 \# 4$ bars for negative moment and $2 \# 3$ bars for postive moment region.

$\mathrm{f}^{\prime} \mathrm{c}=4000 \mathrm{psi}$

fy $=60 \mathrm{ksi}$

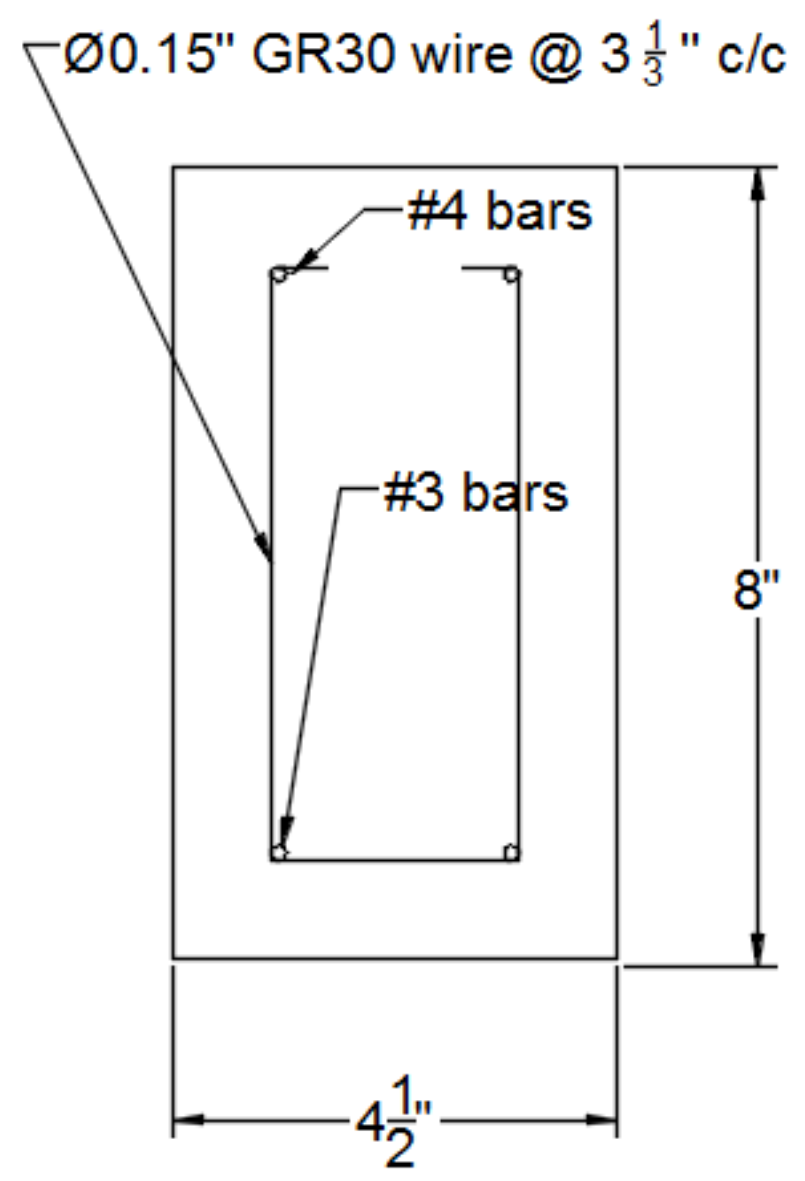

This beam is assumed to have been designed for shear and moment only; now how much additional torsional capacity can be achieved using FRP sheets?! 


\section{B. Concrete Mix Design}

For 4000 psi, based on PCA recommendations for mix design, the following quantities and details were to use for casting all concrete specimens:

CA: pea gravel (3/8'’)

$\mathrm{w} / \mathrm{c}=0.45$

Target slump: 3-4",

Target f'c $=4000$ psi

Type of concrete: non-air entrained normal weight concrete

The proportion of materials for $1 \mathrm{ft}^{3}$ is:

\begin{tabular}{|c|c|}
\hline Material & Weight (lbs) \\
\hline CA & 46 \\
\hline FA & 60 \\
\hline C & 25 \\
\hline W & 11 \\
\hline
\end{tabular}

Two samples of size $12 \times 6$ inches were tested for strength at South Greenhouse Laboratory on Portland State University campus with the following results at 28 days: 


\begin{tabular}{|c|c|}
\hline Sample & f'c (psi) \\
\hline 1 & 4134 \\
\hline 2 & 3936 \\
\hline Average & 4035 \\
\hline
\end{tabular}




\section{CFRP Tensile Tests}

Sample S-1

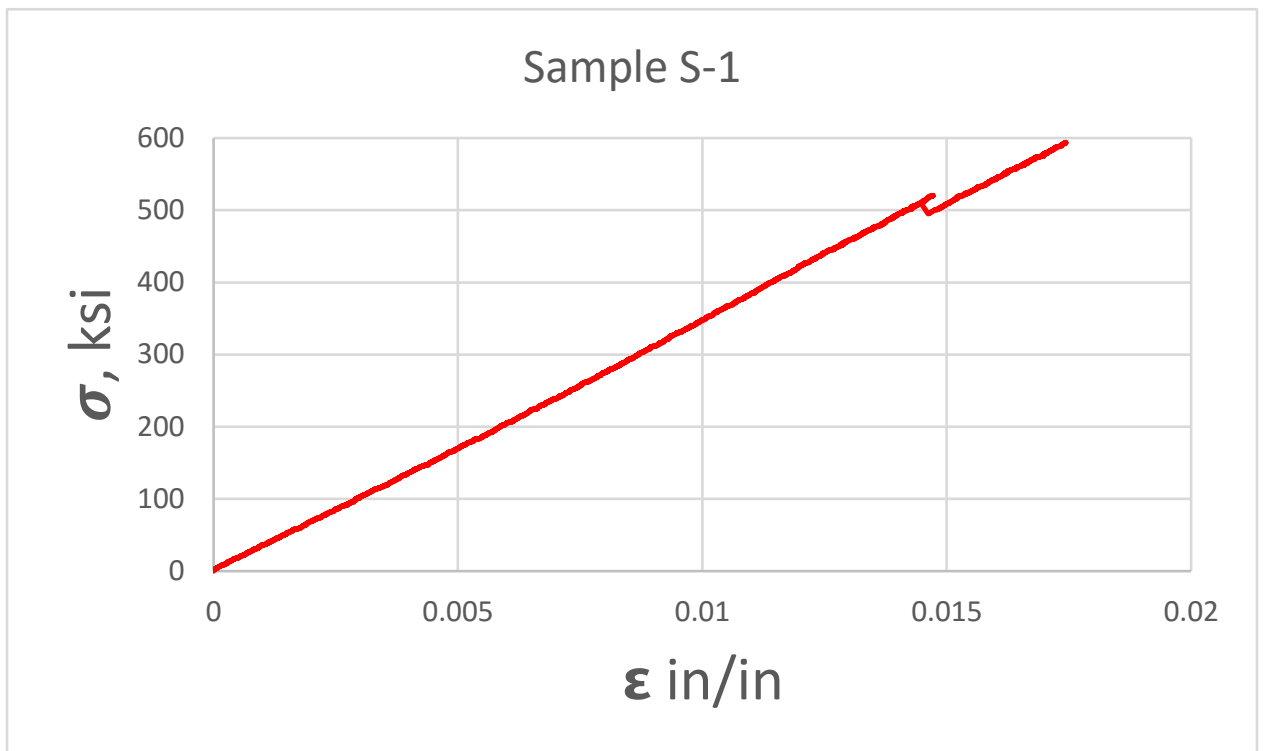

Sample S-2

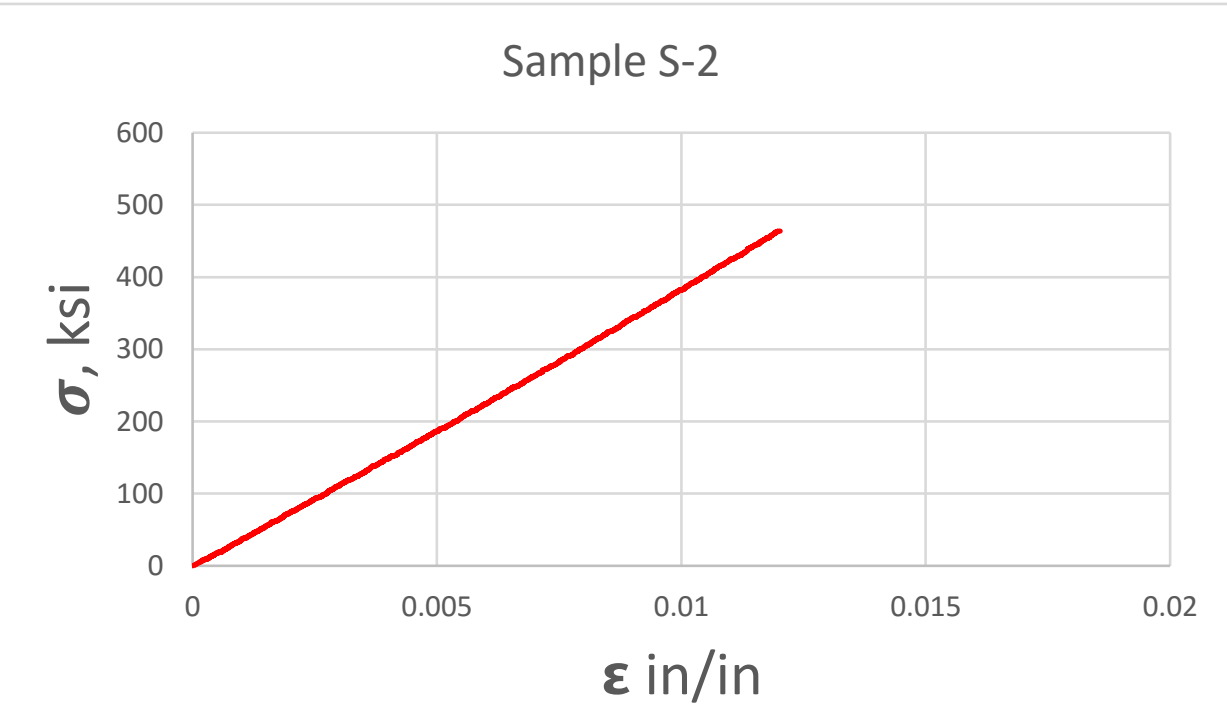




\section{Sample S-3}

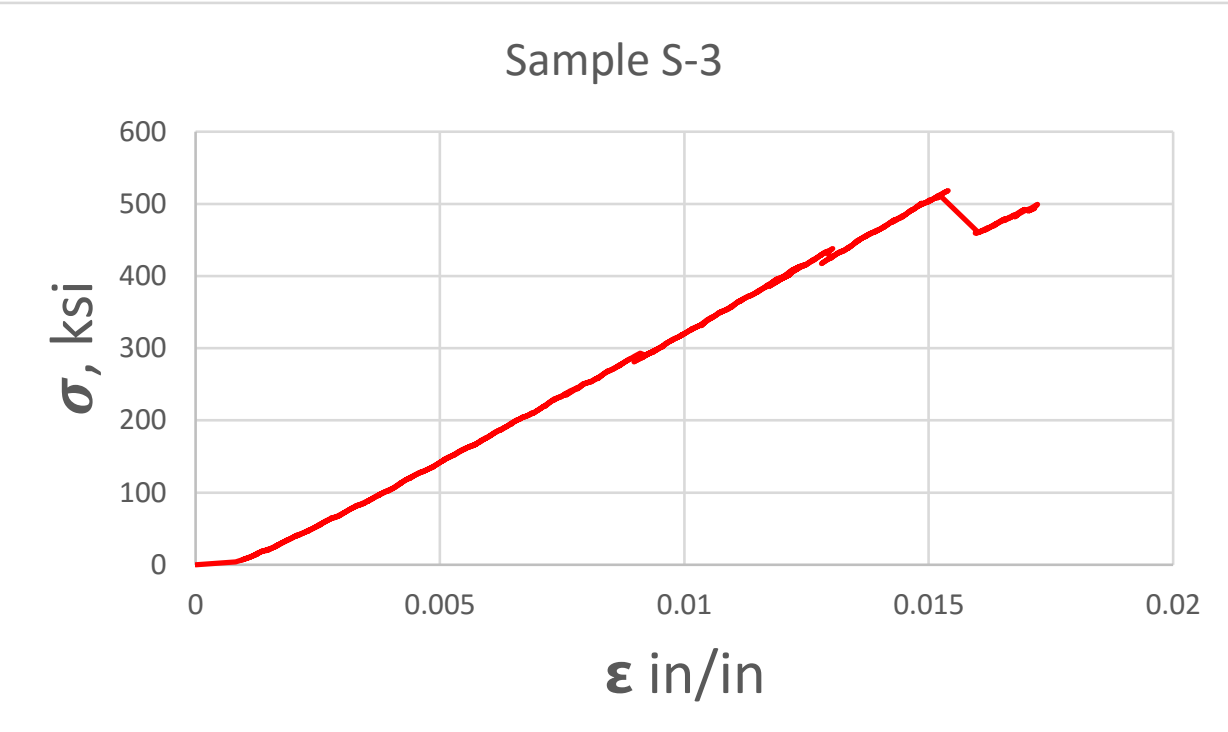

Sample S-4

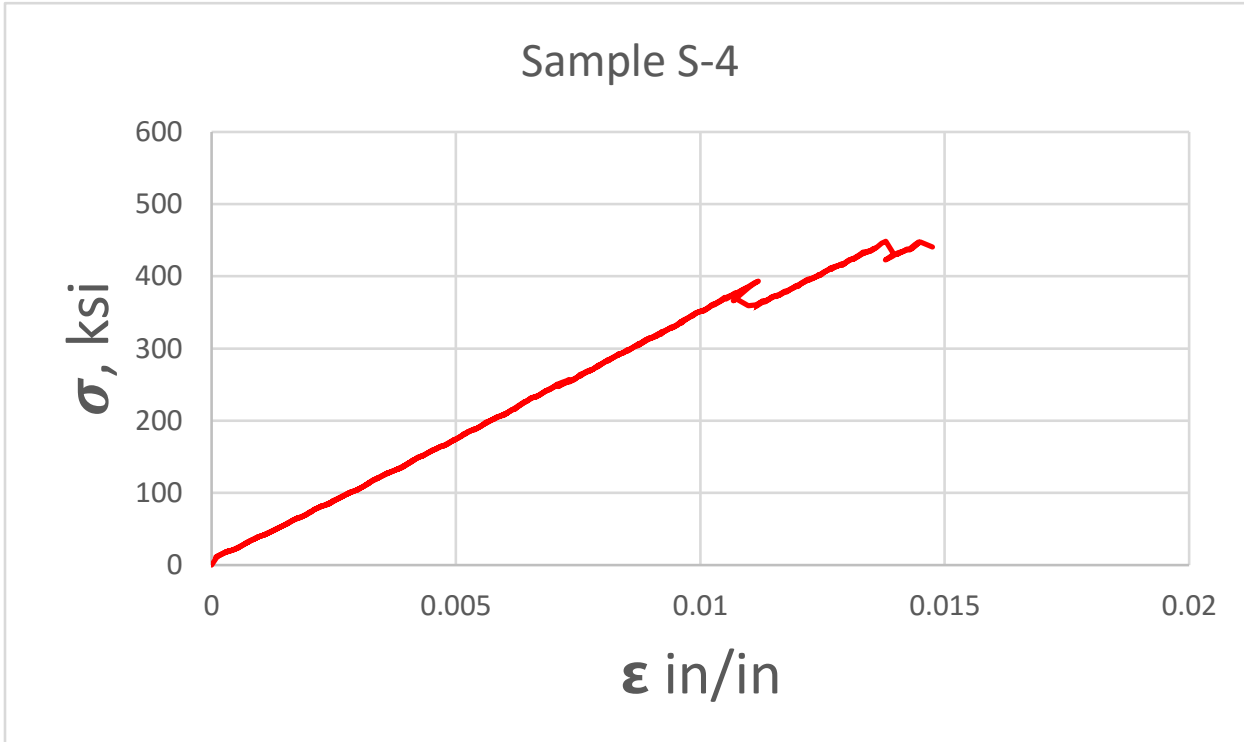




\section{Sample S-5}

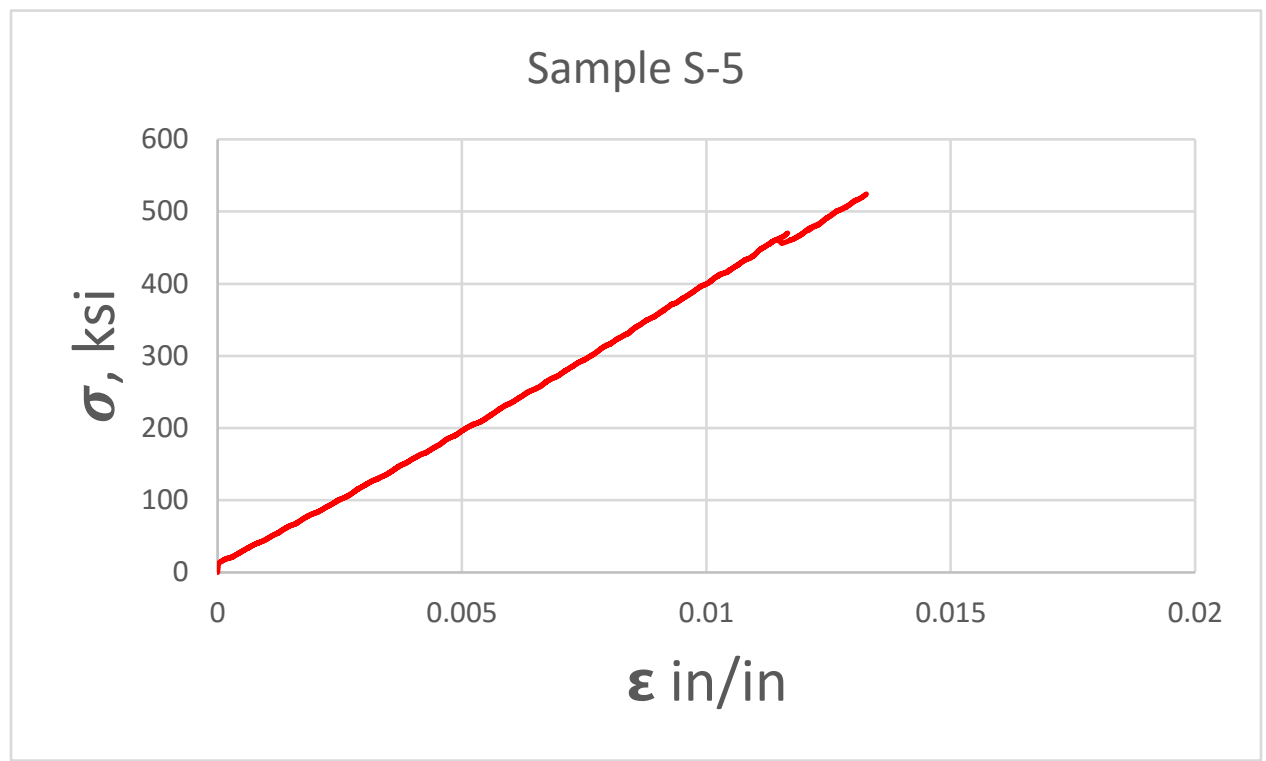

\section{Sample S-6}

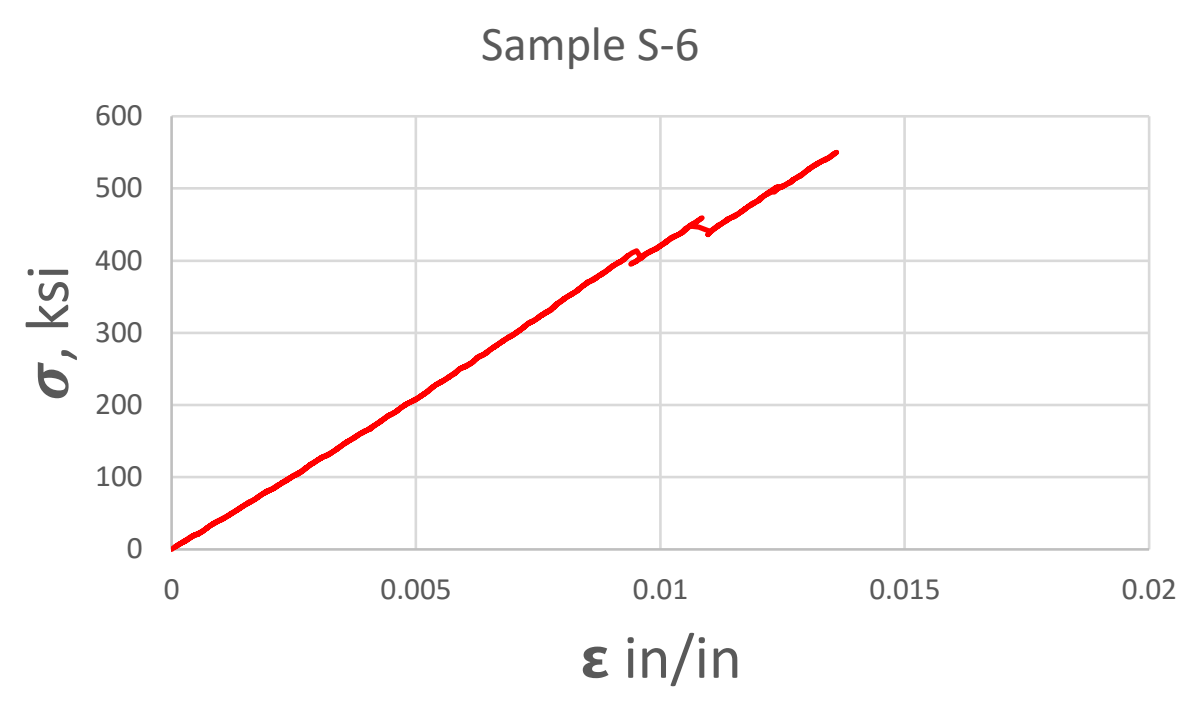




\section{Sample S-7}

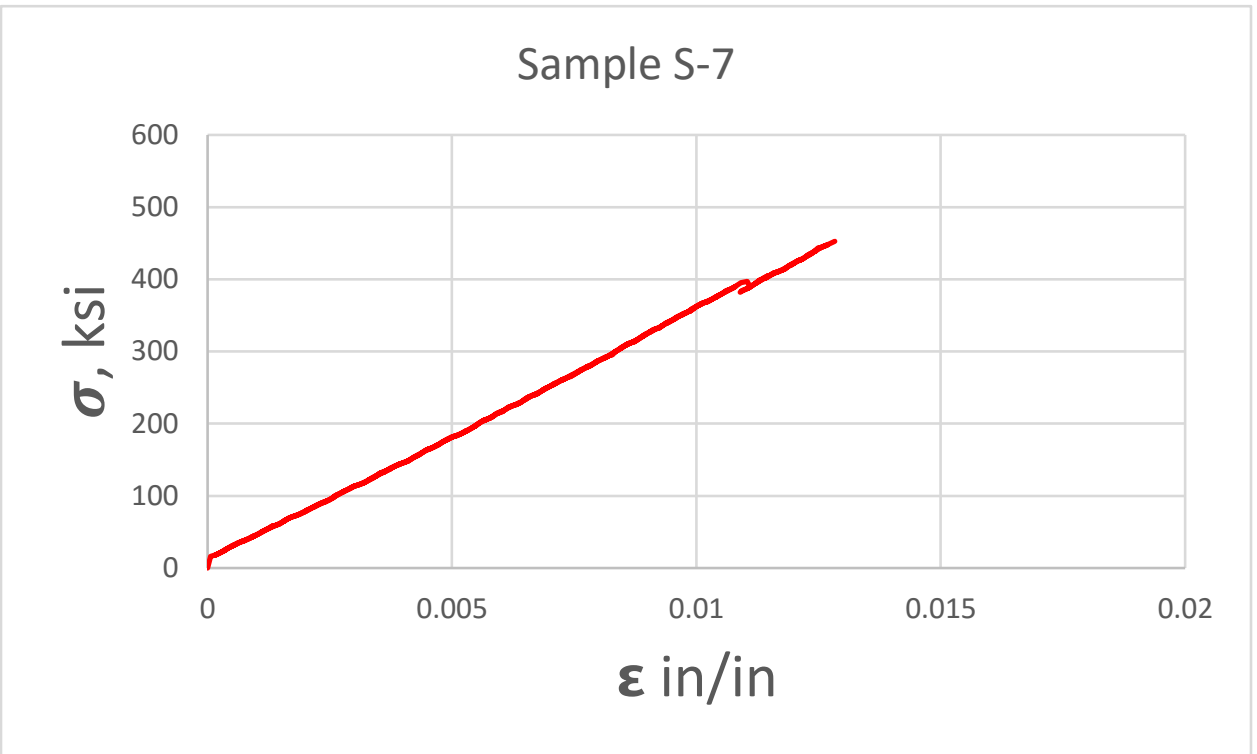




\section{Concrete Compressive Strength Tests}

\section{Sample \#1}

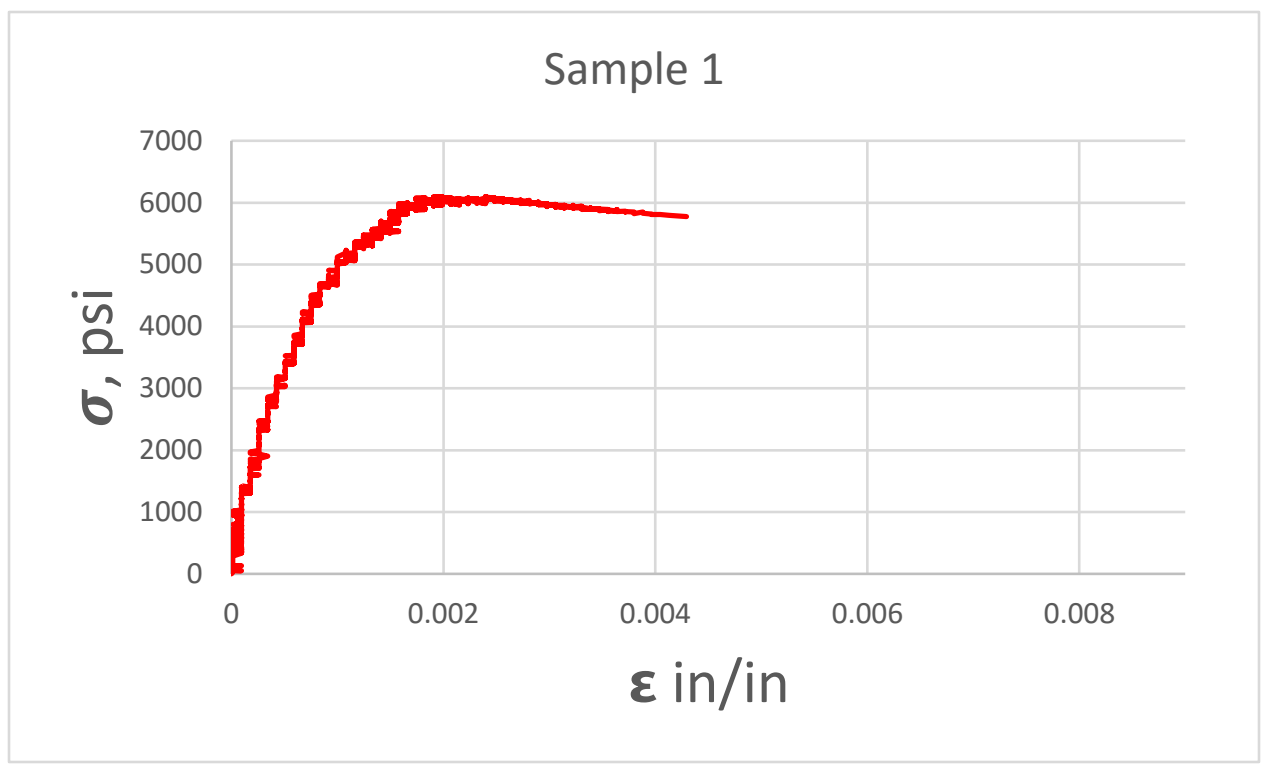

\section{Sample \#2}

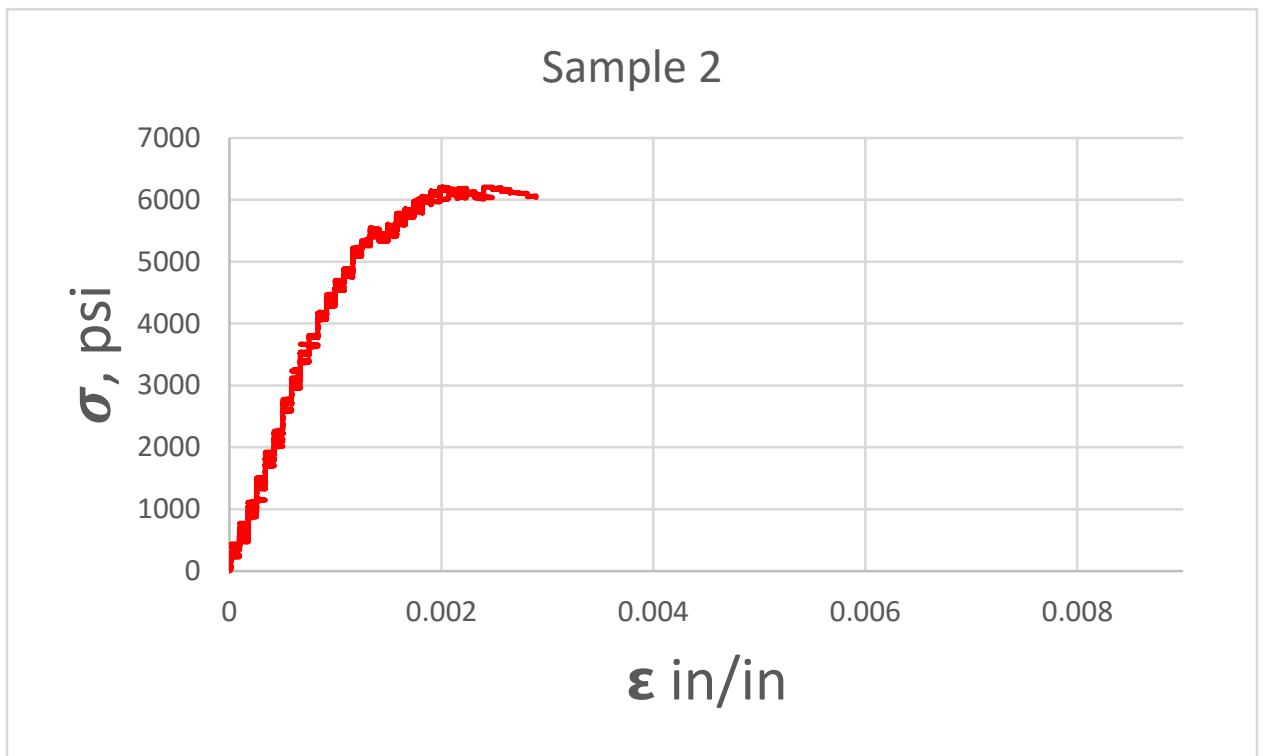




\section{Sample \#3}

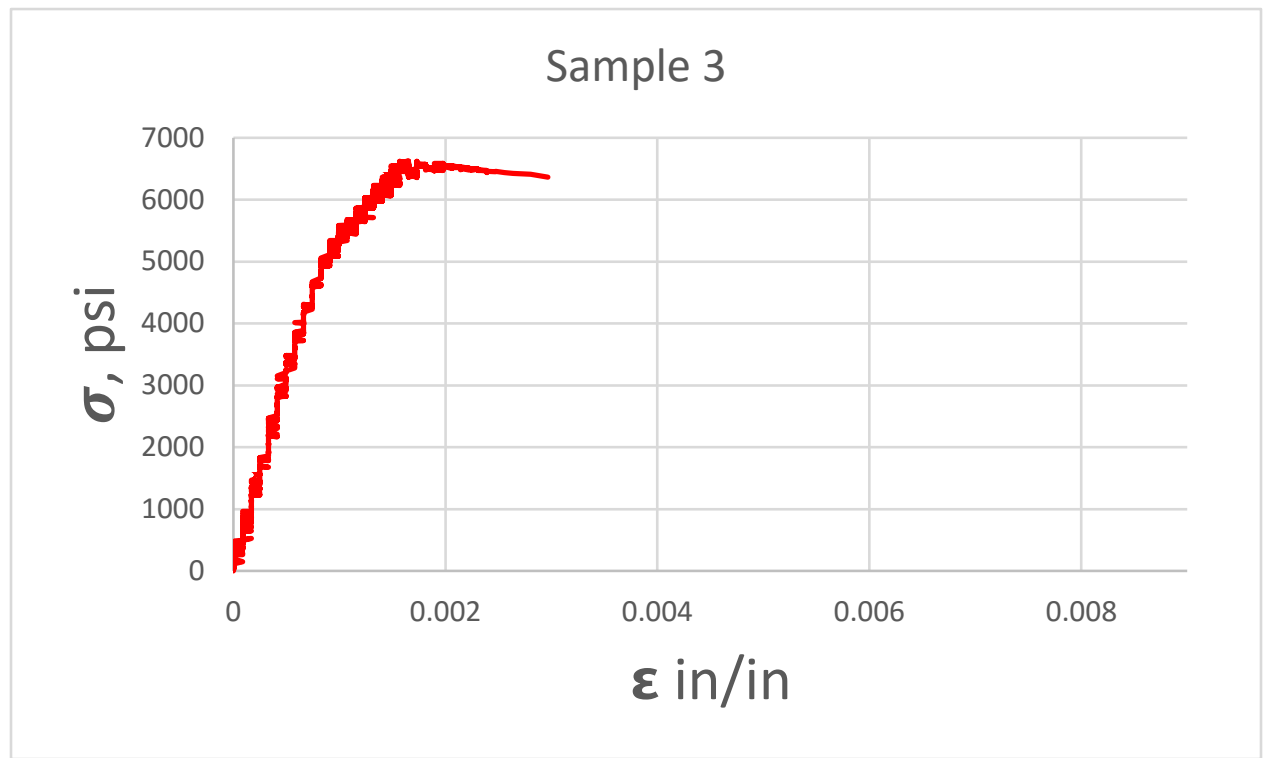

\section{Sample \#4}

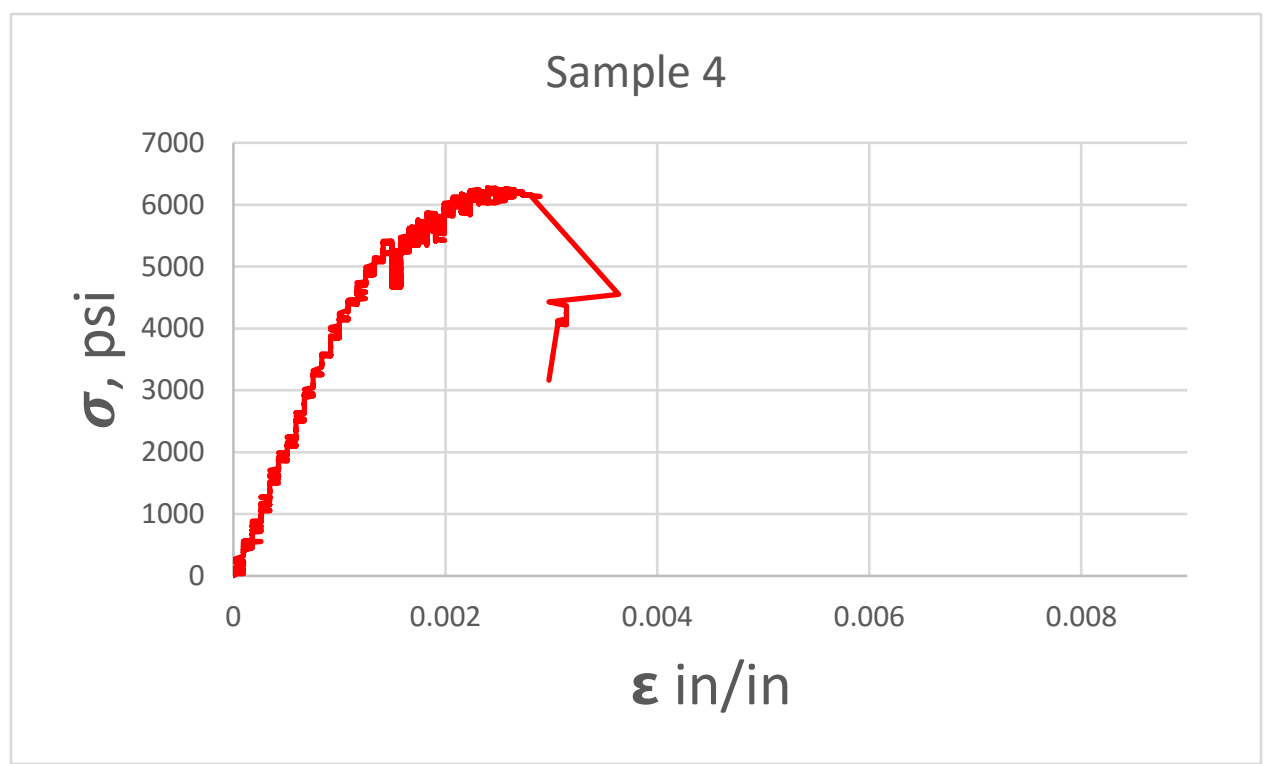




\section{Sample \#5}

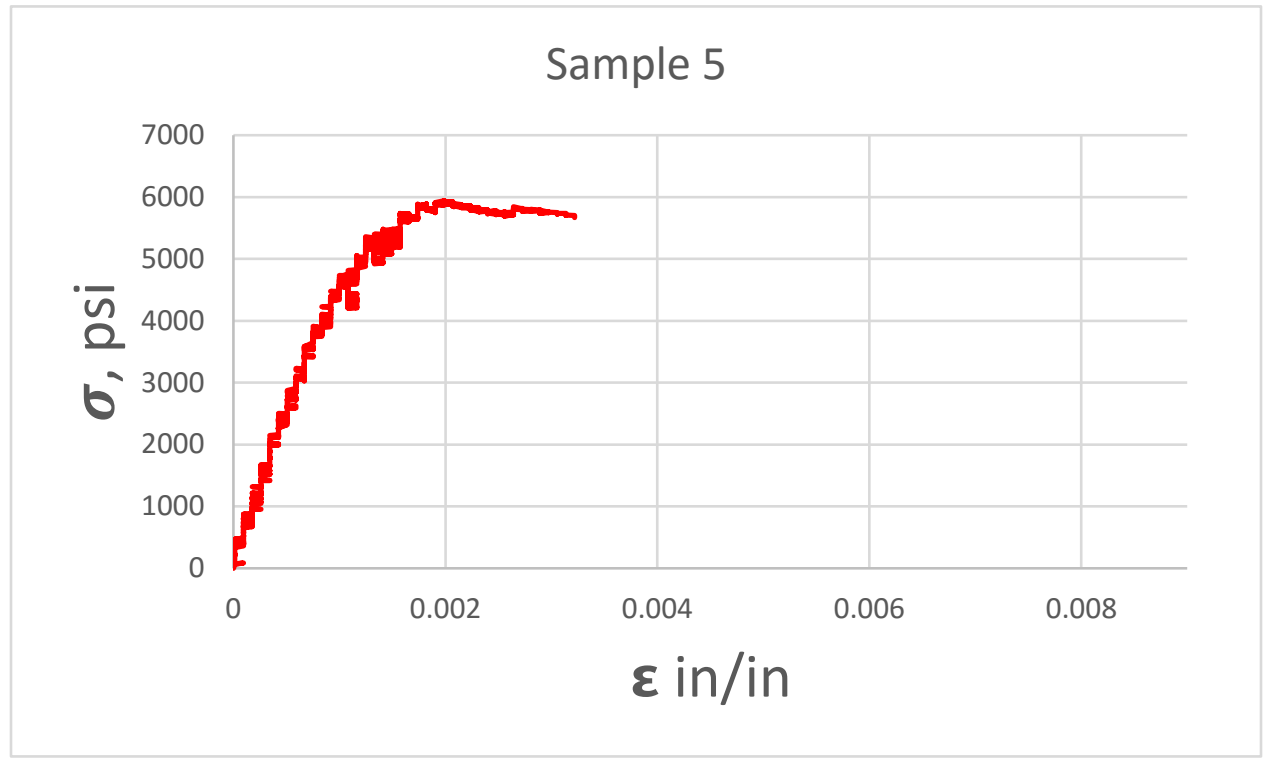

Sample \#6

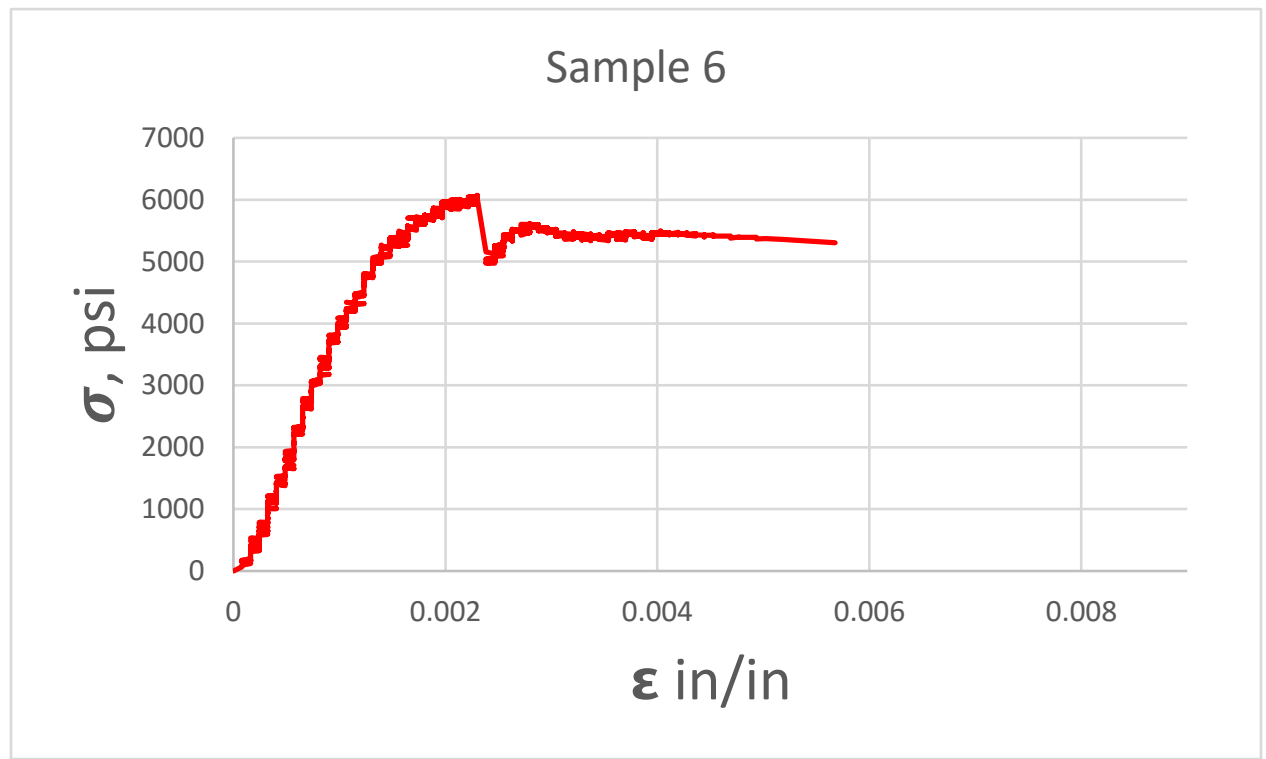




\section{Sample \#7}

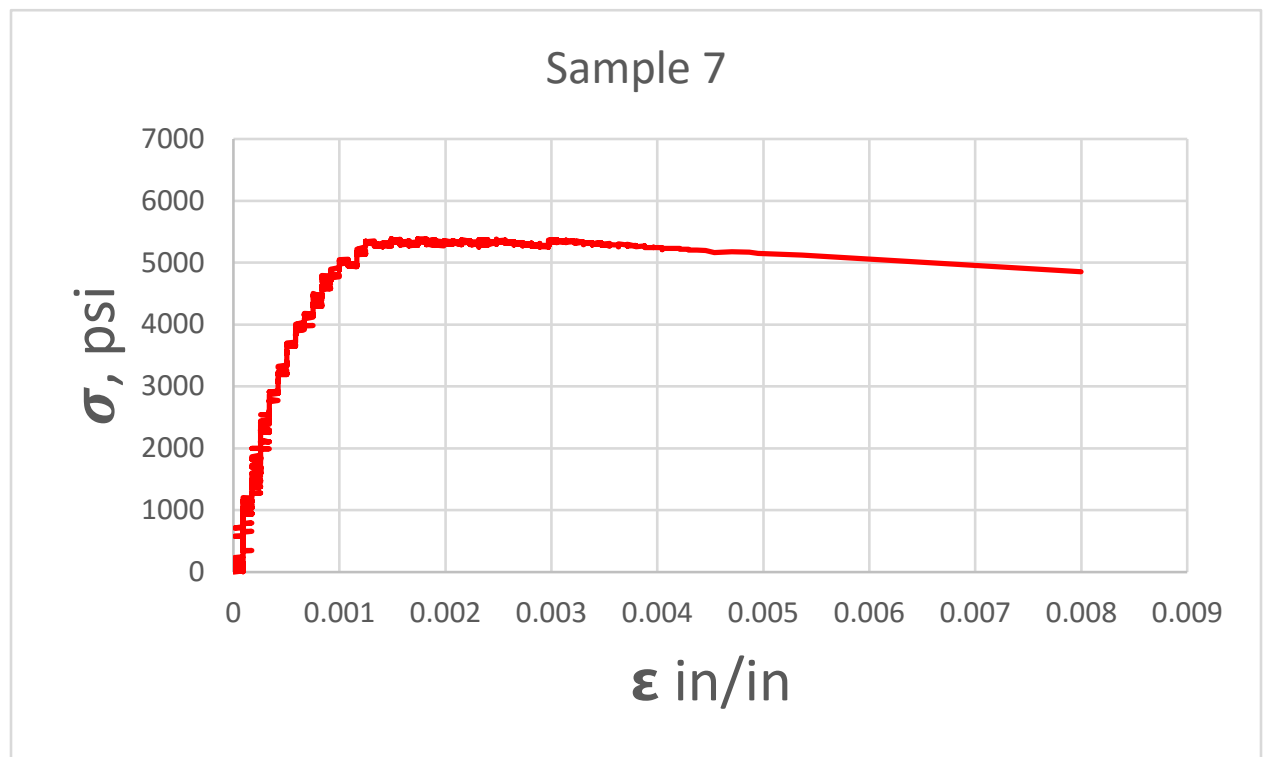

Sample \#8

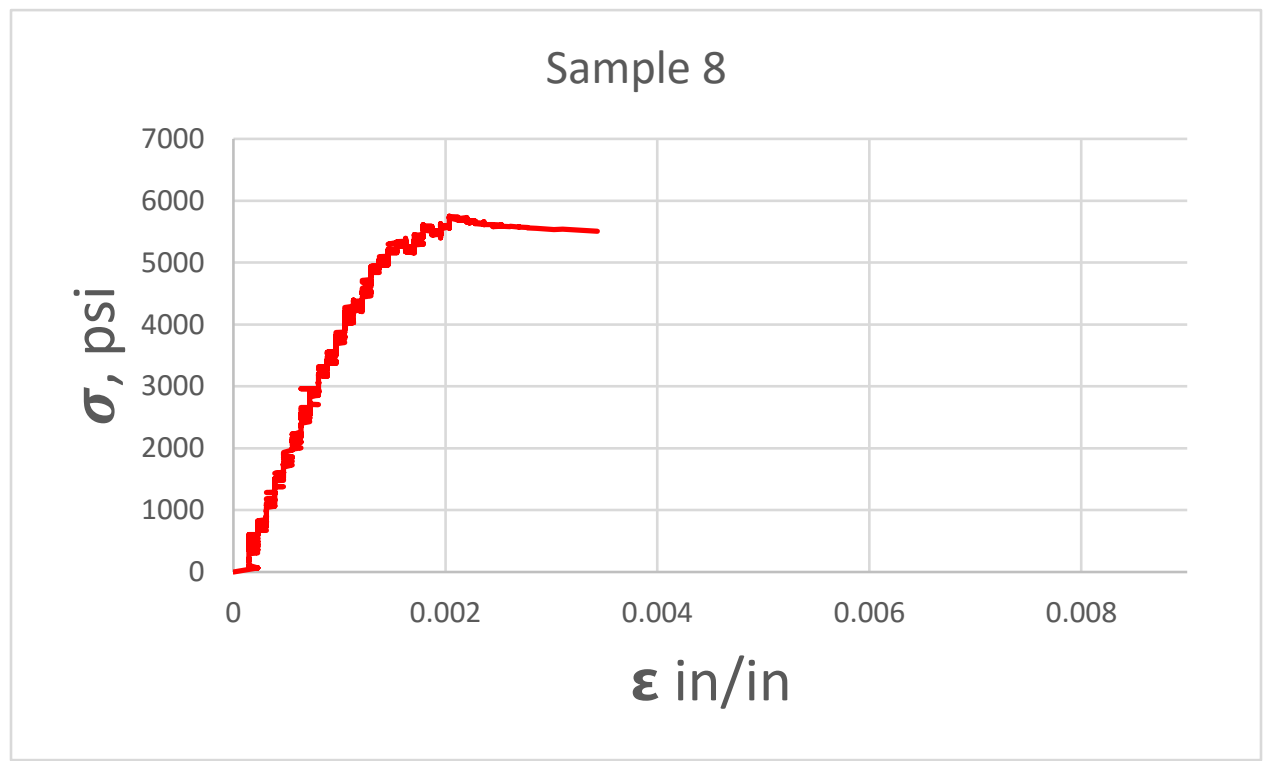




\section{E. Unit Conversion}

\section{Unit Weight}

\begin{tabular}{|c|c|c|}
\hline \multicolumn{3}{|c|}{ Unit weights } \\
\hline Material & SI & English \\
\hline Concrete & $2402.5 \mathrm{~kg} / \mathrm{m}^{3}$ & $150 \mathrm{pcf}$ \\
\hline Steel & $7848.3 \mathrm{~kg} / \mathrm{m}^{3}$ & $490 \mathrm{pcf}$ \\
\hline
\end{tabular}




\section{Other}

\begin{tabular}{|c|c|c|}
\hline \multicolumn{3}{|c|}{ Unit Conversions } \\
\hline Item & English Units & SI Units \\
\hline \multirow{3}{*}{ Length } & $1 \mathrm{ft}$ & $0.30480061 \mathrm{~m}$ \\
\hline & $1 \mathrm{in}$ & $25.4 \mathrm{~mm}$ \\
\hline & 1 yard & $0.9144 \mathrm{~m}$ \\
\hline Mass & $1 \mathrm{lb}$ & $0.4535924 \mathrm{~kg}$ \\
\hline \multirow{2}{*}{ Force } & $1 \mathrm{lb}$ & $4.448222 \mathrm{~N}$ \\
\hline & $1 \mathrm{k}$ & $4.448 \mathrm{kN}$ \\
\hline \multirow{2}{*}{ Stress } & $1 \mathrm{ksi}$ & $6.894757 \mathrm{MPa}$ \\
\hline & $1 \mathrm{psf}$ & 47.88026 PA \\
\hline \multirow{3}{*}{ Area } & $1 \mathrm{ft}^{2}$ & $0.09290 \mathrm{~m}^{2}$ \\
\hline & $1 \mathrm{in}^{2}$ & $645.2 \mathrm{~mm}^{2}$ \\
\hline & $1 \mathrm{yd}^{2}$ & $0.8361 \mathrm{~m}^{2}$ \\
\hline Mass density & $1 \mathrm{pcf}$ & $157.1 \mathrm{~N} / \mathrm{m}^{3}$ \\
\hline \multirow{2}{*}{ Force/length } & $1 \mathrm{plf}$ & $6.919 \mathrm{~N} / \mathrm{m}$ \\
\hline & $1 \mathrm{klf}$ & $6.919 \mathrm{kN} / \mathrm{m}$ \\
\hline \multirow{2}{*}{ Moment } & $1 \mathrm{k}$-in & $0.1130 \mathrm{kN}-\mathrm{m}$ \\
\hline & $1 \mathrm{k}-\mathrm{ft}$ & $1.356 \mathrm{kN}-\mathrm{m}$ \\
\hline Second moment of inertia & $1 \mathrm{in}^{4}$ & $416200 \mathrm{~mm}^{4}$ \\
\hline Section modulus & $1 \mathrm{in}^{3}$ & $16390 \mathrm{~mm}^{3}$ \\
\hline \multirow[t]{3}{*}{ Volume } & $1 \mathrm{in}^{3}$ & $16390 \mathrm{~mm}^{3}$ \\
\hline & $1 \mathrm{ft}^{3}$ & $0.02832 \mathrm{~m}^{3}$ \\
\hline & $1 \mathrm{yd}^{3}$ & $0.7646 \mathrm{~m}^{3}$ \\
\hline
\end{tabular}




\section{Scaling Factors}

\begin{tabular}{|c|c|c|c|}
\hline Item & Actual prototype & Multiplication factor & model \\
\hline $\mathrm{f}^{\prime} \mathrm{c}$ & $4000 \mathrm{psi}$ & 1 & $4000 \mathrm{psi}$ \\
\hline $\mathrm{fy}$ & $60 \mathrm{ksi}$ & 1 & $60 \mathrm{ksi}$ \\
\hline $\mathrm{b}$ & $18^{\prime}$ & $1 / 4$ & $4.5^{\prime}$ \\
\hline $\mathrm{h}$ & $32^{\prime}$ & $1 / 4$ & $8^{\prime}$ \\
\hline $\mathrm{d}$ & $28^{\prime}$ & $1 / 4$ & $7^{\prime}$ \\
\hline$l$ & $30^{\prime}$ & $1 / 4$ & $7.5^{\prime}$ \\
\hline $\mathrm{bd}$ & $560 \mathrm{in}^{2}$ & $1 / 16$ & $35 \mathrm{in}^{2}$ \\
\hline $\mathrm{A}_{\mathrm{s}}$ & $4 \mathrm{in}^{2}$ & $1 / 16$ & $1 \mathrm{in}^{2}$ \\
\hline$\rho$ & 0.00714 & 1 & 0.00714 \\
\hline $\mathrm{M}_{\mathrm{n}}$ & $1920 \mathrm{k}-\mathrm{in}$ & 64 & $30 \mathrm{k}-\mathrm{in}$ \\
\hline $\mathrm{P}_{\mathrm{n}}$ & $320 \mathrm{kips}$ & $1 / 16$ & $20 \mathrm{kips}$ \\
\hline $\mathrm{V}_{\mathrm{n}}$ & $160 \mathrm{kips}$ & $1 / 16$ & $10 \mathrm{kips}$ \\
\hline $\mathrm{V}_{\mathrm{n}} / \mathrm{bd}$ & $0.285 \mathrm{ksi}$ & 1 & $0.285 \mathrm{ksi}$ \\
\hline $\mathrm{T}_{\mathrm{n}}$ & $128 \mathrm{k}$-in & $1 / 64$ & $2 \mathrm{k}$-in \\
\hline
\end{tabular}




\section{F. Stirrup Tests}

\section{Test \#1}

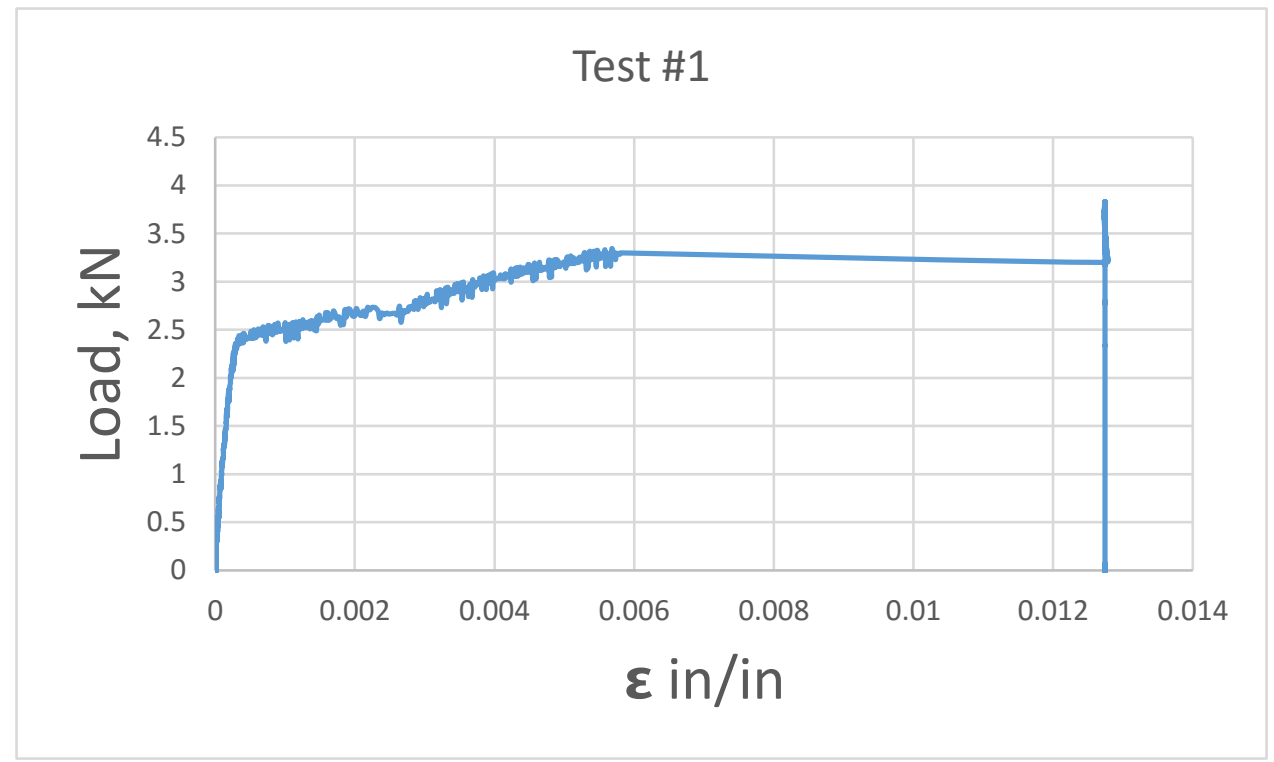

\section{Test \#2}

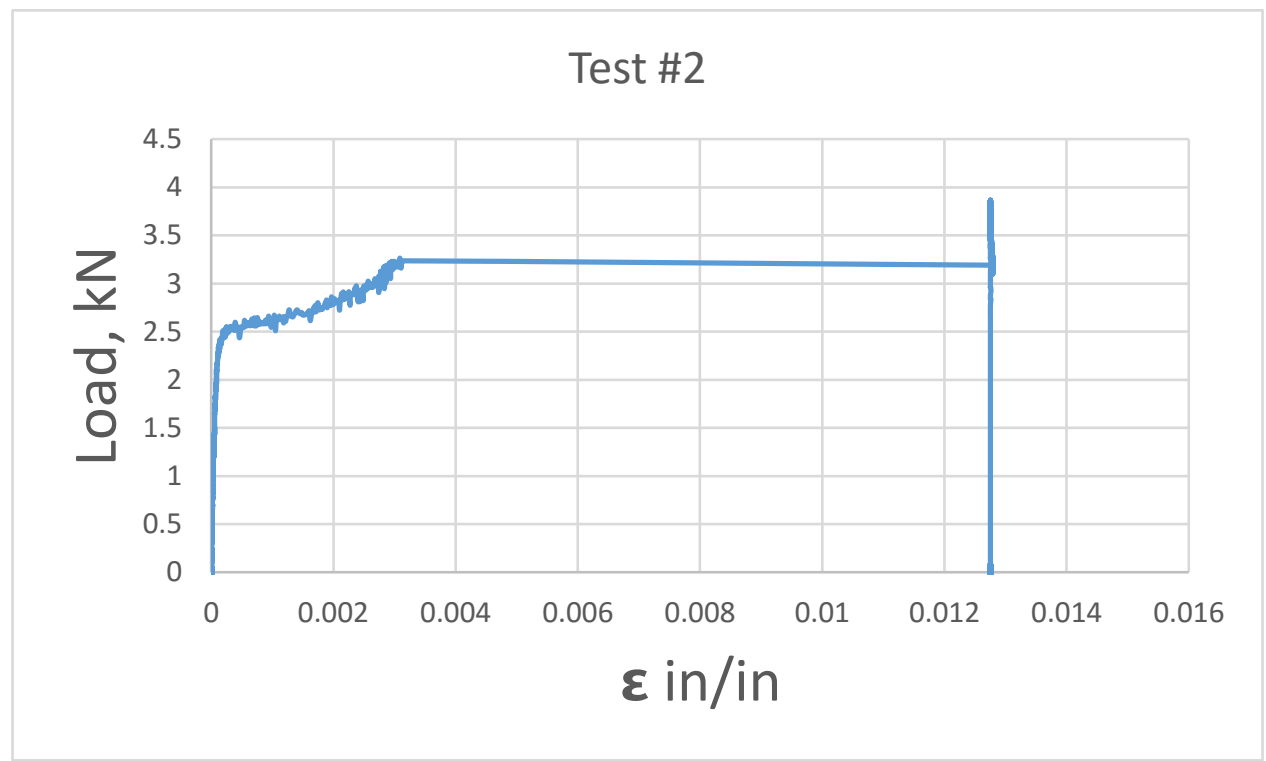

